\author{
Universidade de São Paulo \\ Escola de Comunicação e Artes \\ Programa de pós-graduação em Ciência da Informação
}

\title{
Análise de redes sociais de colaboração científica no ambiente de uma federação de bibliotecas digitais
}

Aluno: Dalton Lopes Martins
Orientadora: Profa. Dra. Sueli Mara Soares Pinto Ferreira

São Paulo

2012 
Dalton Lopes Martins

\section{Análise de redes sociais de colaboração científica no ambiente de uma federação de bibliotecas digitais}

Tese apresentada ao Programa de Pós-graduação em Ciência da Informação, Área de Concentração: Cultura e Informação, Linha de Pesquisa: Acesso à informação, da Escola de Comunicação e Artes da Universidade de São Paulo, como exigência parcial para a obtenção do Título de Doutor em Ciência da Informação.

Orientadora: Profa. Dra. Sueli Mara Soares Pinto Ferreira

São Paulo

2012 


\section{FICHA CATALOGRÁFICA}

\section{MARTINS, Dalton Lopes.}

Análise de redes sociais de colaboração científica no ambiente de uma federação de bibliotecas digitais / Dalton Lopes Martins.

São Paulo: [s.n.], 2012.

$256 \mathrm{f}$.

Tese (Doutorado) - Escola de Comunicação e Artes/USP, 2012.

Orientadora: Profa. Dra. Sueli Mara Soares Pinto Ferreira.

1. Análise de redes sociais. 2. Ciências da comunicação - política científica.

3. Bibliotecas digitais federadas. I. Ferreira, Sueli Mara Soares Pinto. II.Título. 


\section{Análise de redes sociais de colaboração científica no ambiente de uma federação de bibliotecas digitais}

Tese defendida e apresentada ao Programa de Pós-graduação em Ciência da Informação, Área de Concentração: Cultura e Informação, Linha de Pesquisa: Acesso à informação, da Escola de Comunicação e Artes da Universidade de São Paulo, como exigência parcial para a obtenção do Título de Doutor em Ciência da Informação, sob a orientação da Profa. Dra. Sueli Mara Soares Pinto Ferreira.

Aprovada em __ de de de 2012.

Banca Examinadora

Orientadora: Profa. Dra. Sueli Mara Soares Pinto Ferreira.

Prof Dr

Prof Dr

Prof Dr

Prof Dr 
Dedicatória

Aos meus pais, Edgard e Ivone, que me inspiraram $e$ sempre incentivaram a busca pelo conhecimento, mesmo quando era apenas no silêncio que ele se encontrava.

A minha companheira de vida, de jornadas $e$ de sonhos, Paula, que com amor e sinceridade me faz sorrir até dos meus próprios medos. 


\section{Agradecimentos}

À minha família, Edgard, Ivone e André, por serem os companheiros dos primeiros anos de estudo e terem sempre estimulado a curiosidade e a vontade de querer saber mais.

Aos meus companheiros de trabalho e amizade Isis Lima Soares, Mariana Manfredi, Gustavo Valentim, Natalia Noguchi e Mariana Moura, pela paciência nos momentos em que estive ausente, pela amizade em momentos singulares e, sobretudo, pelas discussões, muitas vezes calorosas e intensas, e que foram e são fundamentais no entendimento prático que hoje tenho dos modos de funcionamento dos grupos humanos, das redes e de seus processos de formação. O sentido do que se apresenta aqui foi gerado em muitas de nossas conversas.

Ao amigo Felipe Fonseca por ter me mostrado os primeiros textos e imagens que falavam de redes sociais, abrindo a porta a imaginários que me trouxeram até aqui.

Ao prof. Dr. Ivan Ricarte, meu orientador de mestrado na Faculdade de Engenharia Elétrica e Computação da Unicamp, por ter me dito que aquilo que eu ainda queria fazer em termos de novas pesquisas e discussões não cabia mais no repertório conceitual que a engenharia poderia me apoiar, abrindo questionamentos e reflexões que me trouxeram até a Ciência da Informação.

À minha orientadora, profa. Dra. Sueli Mara Soares Pinto Ferreira, que me acolheu e apresentou a área da Ciência da Informação, tornando nosso espaço de conversa e orientação num espaço de reflexão sobre que questões de fato valeriam a pena serem abordadas e como trabalhar com o repertório conceitual da área, que era até então tão novo para mim.

Aos professores Rogério da Costa e Rogério Mugnaini, membros da banca de qualificação deste trabalho, que em 3 horas de conversa ampliaram a minha capacidade de olhar para meu próprio trabalho, colocando questões e ponderações que foram fundamentais para que conseguisse chegar nos resultados e análises aqui apresentadas.

À minha companheira Paula, pela paciência, incentivo e apoio ao desenvolvimento deste trabalho. 
Epígrafe

Fora de cogitação, entretanto, está o fato de se poder circunscrever, sem limites, todas as relações que possam assim aparecer. É preciso, numa primeira aproximação, aceitar um recorte provisório: uma região inicial que a análise revolucionará $e$ reorganizará se houver necessidade. Mas, como circunscrever essa região? Por um lado, é preciso, empiricamente, escolher um domínio em que as relações corram o risco de ser numerosas, densas $e$ relativamente fáceis de descrever: e em que outra região os acontecimentos discursivos parecem estar mais ligados uns aos outros, e segundo relações mais decifráveis, senão nesta que se designa, em geral, pelo termo ciência?

Michel Foucault 


\section{Resumo}

MARTINS, Dalton Lopes. Análise de redes sociais de colaboração científica no ambiente de uma federação de bibliotecas digitais. 2012. 256 f. Tese (Doutorado em Ciência da Informação) Escola de Comunicação e Artes, Universidade de São Paulo, São Paulo, 2012.

A produção científica de uma área do conhecimento aparece em diferentes formatos e é disponibilizada de forma essencialmente distribuída por entre revistas, anais, teses, dissertações e outros formatos característicos utilizados pela comunidade científica para a sistematização de seu discurso. Uma federação de bibliotecas digitais oferece uma arquitetura da informação que tem por finalidade facilitar a agregação de diferentes tipos de documentos disponibilizados, facilitando termos acesso a esses documentos, bem como a seus metadados descritores, formando, desse modo, verdadeiras estruturas de apoio ao desenvolvimento de pesquisas e análises científicas dos documentos que por ali circulam. Já a análise de redes sociais vem se mostrando um importante objeto de pesquisa da área da Ciência da Informação nas últimas décadas, tendo sido apropriada ainda de forma preliminar pela comunidade científica brasileira. Como forma de ampliar o conhecimento e experimentações com o uso da análise de redes sociais e identificar seu potencial analítico em relação ao que poderíamos coletar de informações de uma federação de bibliotecas digitais, tivemos por objetivo neste trabalho utilizar a análise de rede para mapear os padrões, tendências e estratégias de conectividade de dois planos de relacionamento entre pesquisadores: a coautoria em documentos oriundos de revistas científicas e a participação em bancas de defesas de teses e dissertações. Além disso, buscamos mapear as causas sociais e políticas dos padrões de rede identificados, colocando em evidência um uso crítico e contextualizado dos indicadores estruturais e dinâmicos de redes utilizados neste trabalho. Utilizamos como caso a biblioteca digital federada Univerciencia.org, uma biblioteca especializada na área de Ciências da Comunicação, tendo fornecido como fonte de dados 49 revistas científicas da área com 9864 documentos e 12 bibliotecas digitais de teses e dissertações com 1961 documentos. Os resultados apontam que os movimentos geradores e constituintes das redes sociais em nossos dois planos de análise são fortemente determinados por uma racionalidade característica da política científica do campo da Comunicação e da ciência de modo geral.

Palavras-chave: análise de redes sociais, federação de bibliotecas digitais, Univerciencia.org, Ciências da Comunicação. 


\begin{abstract}
MARTINS, Dalton Lopes. Social network analysis of scientific collaboration in the environment of a digital libraries federation. 2012. $256 \mathrm{f}$. Tese (Doutorado em Ciência da Informação) - Escola de Comunicação e Artes, Universidade de São Paulo, São Paulo, 2012.
\end{abstract}

The scientific production of an area of knowledge appears in different formats and is available in a distributed mainly through journals, proceedings, theses, dissertations and other typical formats used by the scientific community for the systematization of his speech. A federation of digital libraries offers an information architecture that aims to facilitate the aggregation of different types of documents available, facilitating access to those documents and their metadata descriptors, forming thus real structures to support the development of research and analysis of scientific documents that circulate through there. The analysis of social networks has proven an important subject of research in the area of Information Science and in recent decades have been appropriate even in a preliminary way by the Brazilian scientific community. As a way to increase knowledge and experimentation with the use of social network analysis and identify his potential analytical, the objective of this work was use network analysis to map the patterns, trends and connectivity strategies between two planes of relation between researchers: co-authoring of documents from scientific journals and participation in defenses of theses and dissertations. Furthermore, we seek to map the social and political causes of network patterns identified, highlighting a critical use of structural and dynamic indicators. We use as case Univerciencia.org federated digital library, a library specialized in the field of Communication Sciences and provided as a source of data collected 49 scientific journals in the area with 9864 documents and 12 digital libraries of theses and dissertations with 1961 documents. The results show that the generative movements and constituents of social networks in our two levels of analysis are strongly determined by a characteristic rationality of science policy in the field of communication and science in general.

Keywords: social network analysis, federated digital library, Univerciencia.org, Communication Sciences. 


\section{Lista de ilustrações}

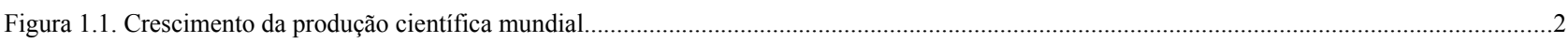

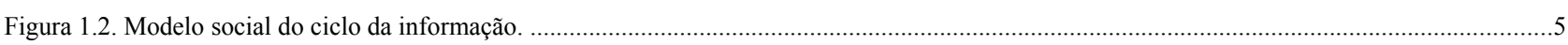

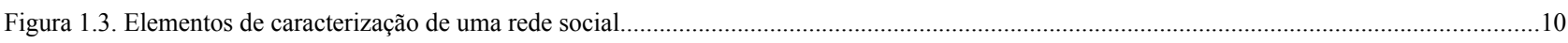

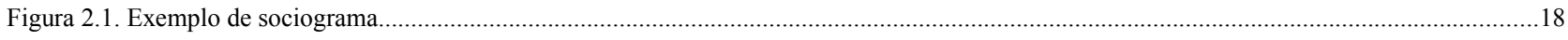

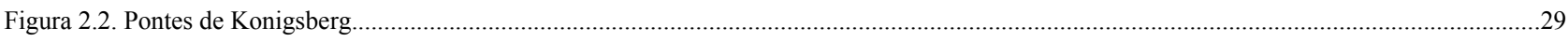

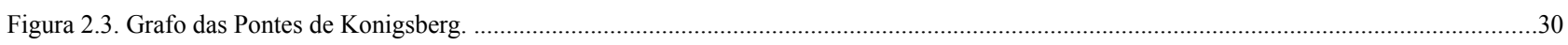

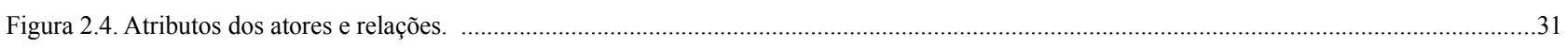

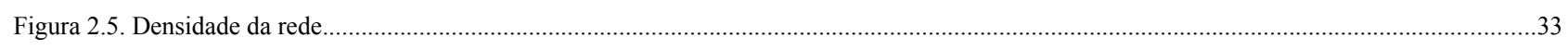

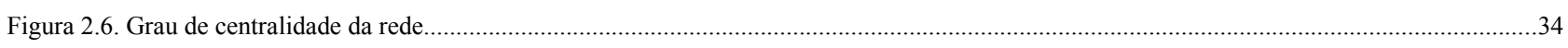

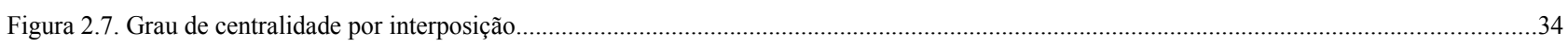

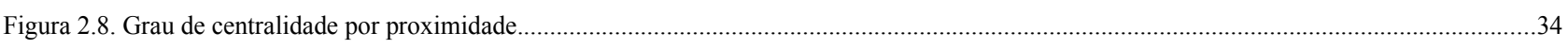

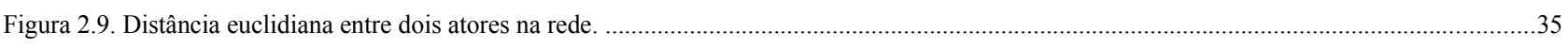

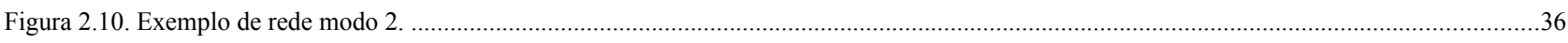

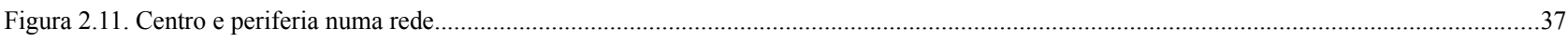

Figura 2.12. Componentes de uma rede

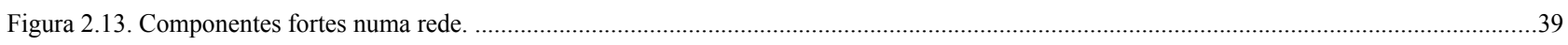

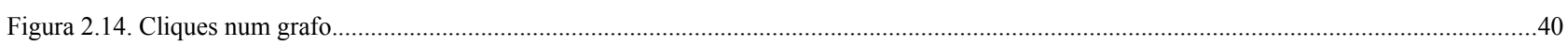

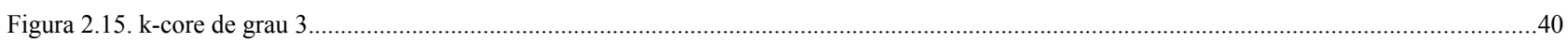

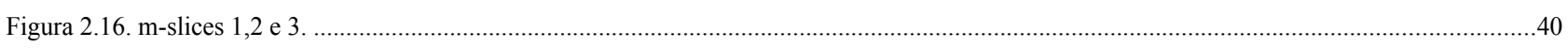

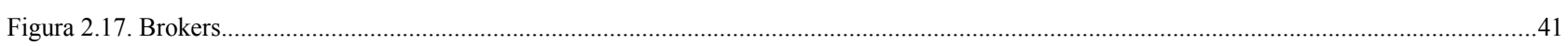

Figura 2.18. Redes de afiliação e papéis estruturais de brokers em diferentes contextos. ………………............................................................. 41

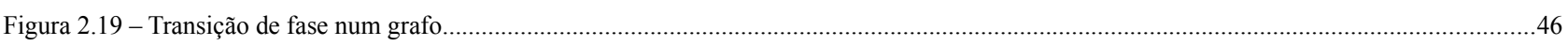

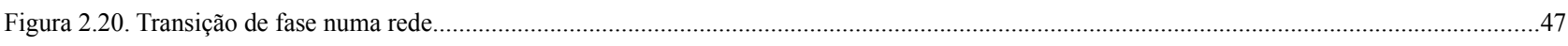

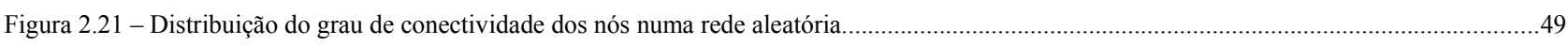

Figura 2.22 - Coeficiente de clusterização

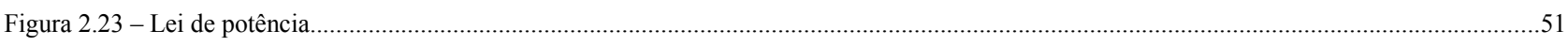

Figura. 2.24. Contrastes entre rede de distribuição de grau aleatória e rede de livre escala. .................................................................................52

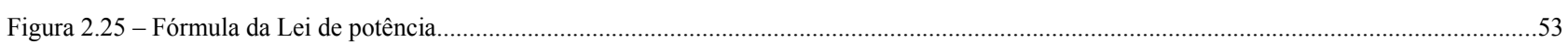

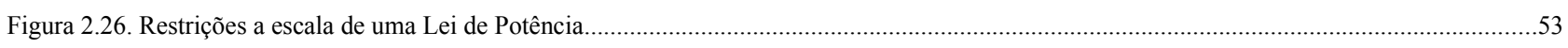

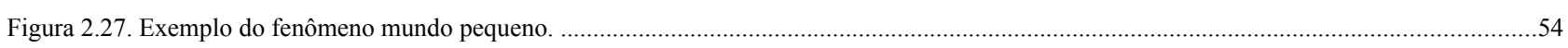

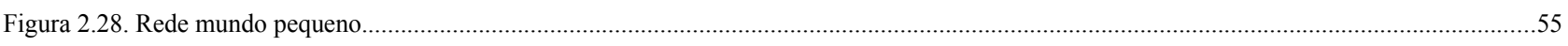

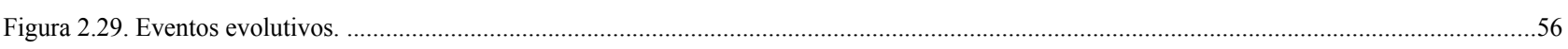

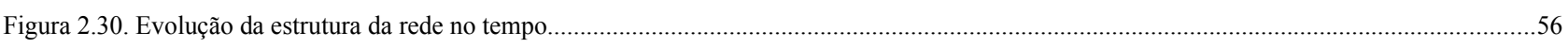

Figura. 2.31.Evolução do uso da análise de redes sociais nos campos da Sociologia, Medicina e Psicologia ............................................................58

Figura 2.32. Distribuição do número de artigos por indicadores de análise de redes sociais utilizados pela produção científica da CI no Brasil...........63

Figura 2.33. Distribuição de defesas de Teses e Dissertações no tempo descritores - redes sociais e informação.....................................................65

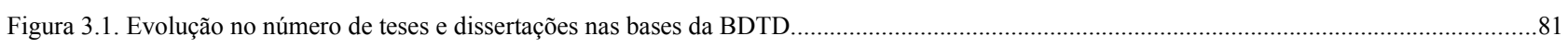

Figura 3.2. Crescimento da colaboração científica nas áreas da Ciência e Engenharia, Ciências Sociais, Artes e Humanidades e Patentes...................83

Figura 4.1. Redes de citação entre Psicologia Social, Comunicações e Ciências Políticas. ....................................................................................97

Figura 4.2. Evolução no número de programas de pós-graduação na área das Ciências da Comunicação.................................................................97

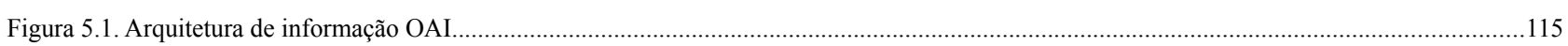

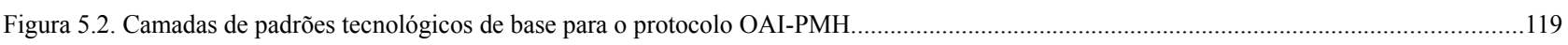

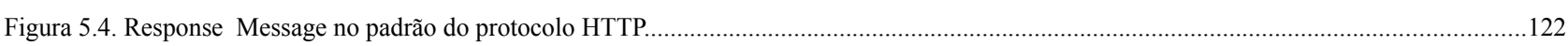

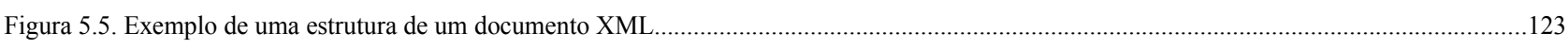

Figura 6.1. Distribuição da frequência do número de registros coletados por fonte de informação das bibliotecas digitais. ........................................145

Figura 6.2. Distribuição da frequência do número de registros coletados por fonte de informação das revistas científicas. .....................................146

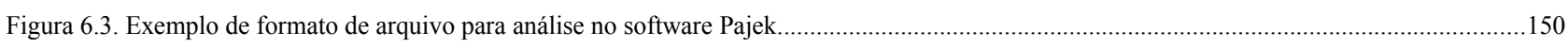


Figura 7.1. Distribuição temporal dos documentos na base de revistas científicas.

Figura 7.2. Distribuição temporal de revistas ativas na base Univerciencia.org..................................................................................................153

Figura 7.3. Distribuição temporal de novas revistas na base Univerciencia.org..................................................................................................153

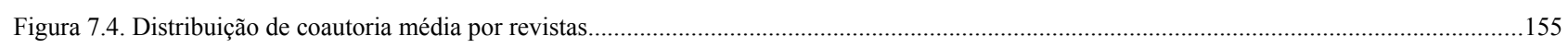

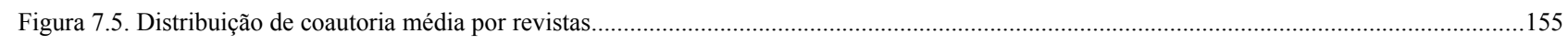

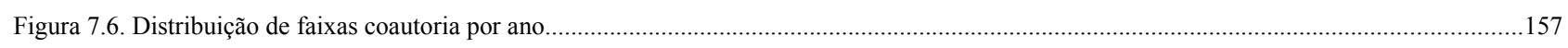

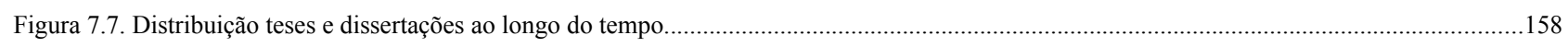

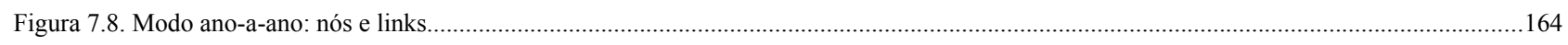

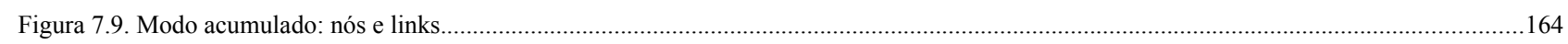

Figura 7.10. Sociograma da rede de coautoria no ano de 2006 - Modo ano-a-ano - Revistas Científicas...............................................................165

Figura 7.11. Sociograma da rede de coautoria no ano de 2007 - Modo ano-a-ano - Revistas Científicas...............................................................165

Figura 7.12. Curvas de densidade média e grau de centralização - Modo ano-a-ano - Revistas Científicas...........................................................167

Figura 7.13. Curvas de densidade média e grau de centralização - Modo acumulado - Revistas Científicas...........................................................167

Figura 7.14. Sociograma da rede de coautoria no ano de 2003 - Modo ano-a-ano - Revistas Científicas.............................................................168

Figura 7.15. Sociograma da rede de coautoria no ano de 2004 - Modo ano-a-ano - Revistas Científicas................................................................168

Figura 7.16. Sociograma da rede de coautoria no ano de 2005 - Modo ano-a-ano - Revistas Científicas...............................................................169

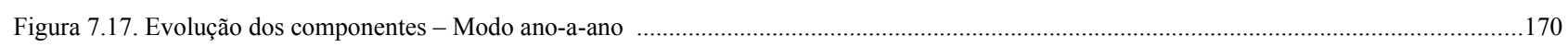

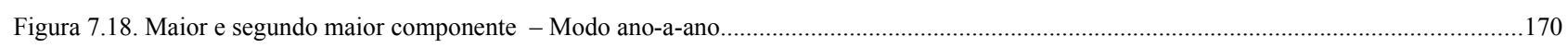

Figura 7.19. Evolução dos componentes, maior e segundo maior componente - Modo acumulado......................................................................170

Figura 7.20. Relação entre componentes, revistas e programas de pós-graduação.................................................................................................171

Figura 7.21. Componentes - modo acumulado - Rede de revistas científicas....................................................................................................172

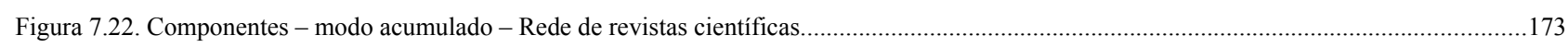

Figura 7.23. Percentual de nós no maior componente - modo ano-a-ano - Rede de revistas científicas............................................................174

Figura 7.24. Percentual de nós no maior componente - modo acumulado - Rede de revistas científicas...............................................................174

Figura 7.25. Grau de conectividade médio - modo ano-a-ano - Rede de revistas científicas............................................................................175

Figura 7.26. Grau de conectividade médio - modo acumulado - Rede de revistas científicas.........................................................................175

Figura 7.27. Maior grau de conectividade - modo ano-a-ano - Rede de revistas científicas.................................................................................176

Figura 7.28. Maior grau de conectividade - modo acumulado - Rede de revistas científicas............................................................................176

Figura 7.29. Distância geodésica - modo ano-a-ano - Rede de revistas científicas..............................................................................................177

Figura 7.30. Distância geodésica - modo acumulado - Rede de revistas científicas...........................................................................................178

Figura 7.31. Coeficiente de clusterização - modo ano-a-ano - Rede de revistas científicas....................................................................................179

Figura 7.32. Coeficiente de clusterização - modo acumulado - Rede de revistas científicas.................................................................................179

Figura 7.33. Coeficiente de potência - modo acumulado - Rede de revistas científicas....................................................................................181

Figura 7.34. Animação gráfica da evolução temporal da rede de coautoria - modo ano-a-ano - Revistas científicas. ............................................182

Figura 7.35. Rede dos 93 nós mais centrais no ano de 2011 - modo acumulado - Rede de revistas científicas.......................................................183

Figura 7.36. Agrupamento por instituição da rede dos 93 nós mais centrais no ano de 2011 - modo acumulado - Rede de revistas científicas..........184

Figura 7.37. Nós e links - modo ano-a-ano - Bibliotecas Digitais de Teses e Dissertações......................................................................................188

Figura 7.38. Nós e links - modo ano-a-ano - Bibliotecas Digitais de Teses e Dissertações...................................................................................188

Figura 7.39. Rede de relações em bancas de defesas no ano de 2004 - modo ano-a-ano - Bibliotecas Digitais de Teses e Dissertações......................189

Figura 7.40. Rede de relações em bancas de defesas no ano de 2005 - modo ano-a-ano - Bibliotecas Digitais de Teses e Dissertações.......................190

Figura 7.41. Densidade média e grau de centralização - modo ano-a-ano - Bibliotecas Digitais de Teses e Dissertações..........................................191

Figura 7.42. Densidade média e grau de centralização - modo acumulado - Bibliotecas Digitais de Teses e Dissertações........................................191

Figura 7.43. Rede de relações em bancas de defesas no ano de 1991 - modo ano-a-ano - Bibliotecas Digitais de Teses e Dissertações......................192

Figura 7.44. Rede de relações em bancas de defesas no ano de 1992 - modo ano-a-ano - Bibliotecas Digitais de Teses e Dissertações.....................192

Figura 7.45. Rede de relações em bancas de defesas no ano de 1996 - modo ano-a-ano - Bibliotecas Digitais de Teses e Dissertações.......................193

Figura 7.46. Rede de relações em bancas de defesas no ano de 1997 - modo ano-a-ano - Bibliotecas Digitais de Teses e Dissertações......................194

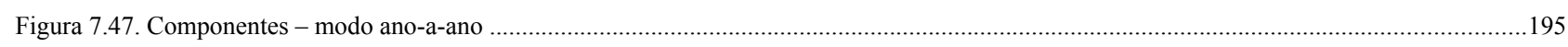

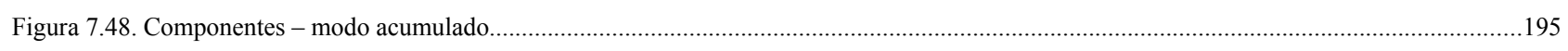

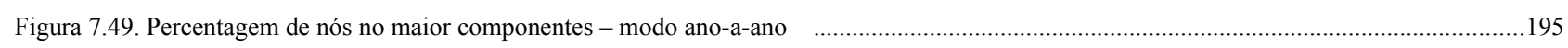

Figura 7.50. Percentagem de nós no maior componentes - modo acumulado - Bibliotecas Digitais de Teses e Dissertações.......................................195

Figura 7.51. Maior e segundo maior componentes - modo ano-a-ano 
Figura 7.52. Maior e segundo maior componentes - modo acumulado.

Figura 7.53. Rede de relações em bancas de defesas no ano de 2006 - modo ano-a-ano - Bibliotecas Digitais de Teses e Dissertações.....................197

Figura 7.54. Rede de relações em bancas de defesas no ano de 2007 - modo ano-a-ano - Bibliotecas Digitais de Teses e Dissertações....................198

Figura 7.55. Rede de relações em bancas de defesas no ano de 2011 - modo acumulado - Bibliotecas Digitais de Teses e Dissertações....................199

Figura 7.56. Rede de relações em bancas de defesas no ano de 2011 - modo acumulado - Bibliotecas Digitais de Teses e Dissertações...................199

Figura 7.57. Grau de conectividade médio - modo ano-a-ano - Bibliotecas Digitais de Teses e Dissertações.........................................................200

Figura 7.58. Grau de conectividade médio - modo acumulado - Bibliotecas Digitais de Teses e Dissertações........................................................200

Figura 7.59. Maior grau de conectividade - modo ano-a-ano - Bibliotecas Digitais de Teses e Dissertações.......................................................201

Figura 7.60. Maior grau de conectividade - modo acumulado - Bibliotecas Digitais de Teses e Dissertações..........................................................201

Figura 7.61. Distância geodésica - modo ano-a-ano - Bibliotecas Digitais de Teses e Dissertações.......................................................................203

Figura 7.62. Distância geodésica - modo acumulado- Bibliotecas Digitais de Teses e Dissertações.......................................................................203

Figura 7.63. Coeficiente de clusterização - modo ano-a-ano - Bibliotecas Digitais de Teses e Dissertações......................................................204

Figura 7.64. Coeficiente de clusterização - modo acumulado - Bibliotecas Digitais de Teses e Dissertações...........................................................204

Figura 7.65. Rede de relações em bancas de defesas no ano de 2000 - modo ano-a-ano - Bibliotecas Digitais de Teses e Dissertações....................205

Figura 7.66. Rede de relações em bancas de defesas no ano de 2001 - modo ano-a-ano - Bibliotecas Digitais de Teses e Dissertações....................205

Figura 7.67. Coeficiente de potência - modo acumulado - Bibliotecas Digitais de Teses e Dissertações..........................................................207

Figura 7.68. Animação gráfica da evolução temporal da rede de coautoria - modo ano-a-ano - Bibliotecas Digitais de Teses e Dissertações. 208

Figura 7.69. Rede dos 97 nós mais centrais de relações em bancas de defesas no ano de 2011 - modo acumulado - Bibliotecas Digitais de Teses e

Dissertações.

Figura 7.70. Agrupamento por instituição da rede dos 97 nós mais centrais de relações em bancas de defesas no ano de 2011 - modo acumulado -

Bibliotecas Digitais de Teses e Dissertações. 


\section{Lista de Tabelas}

Tabela 2.1. Exemplo de matriz de relações e atributos.

Tabela 2.2. Questões de pesquisa em CI e sua relação com a Análise de Redes Sociais. .....................................................................................60

Tabela 2.3. Periódicos em Ciência da Informação: artigos relacionados pelos descritores - informação e redes sociais, 2001 a 2009 . .........................61

Tabela 2.4. Categorização temática dos artigos relacionados pelos descritores - informação e redes sociais, 2001 a 2009........................................61

Tabela 2.5. Indicadores de análise de redes sociais utilizados pela produção científica da CI no Brasil..................................................................62

Tabela 2.6. Distribuição de defesas de Teses e Dissertações por instituição pelos descritores - redes sociais e informação........................................64

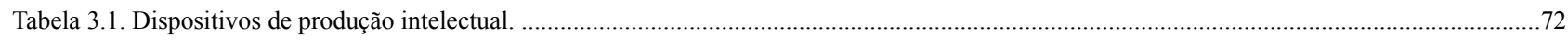

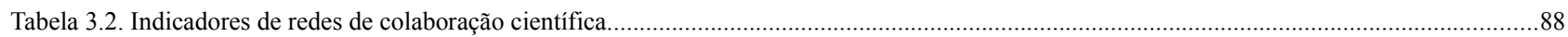

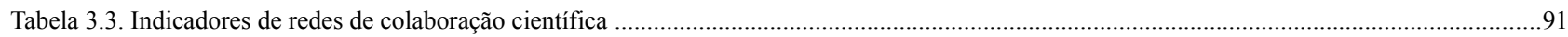

Tabela 4.1 - Distribuição temática dos artigos de 7 fascículos de revistas na área da Ciência da Comunicação. .....................................................104

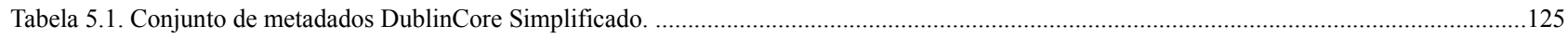

Tabela 5.2. Procedimentos internos de tratamento dos metadados pós-coleta............................................................................................128

Tabela 5.3. Variação no uso de dois elementos Dublin Core por tipos de instituição. ...........................................................................................128

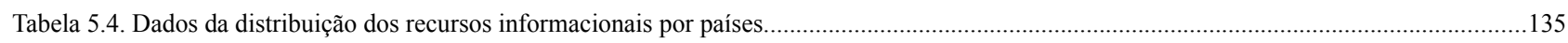

Tabela 5.5. Dados da distribuição dos recursos informacionais por tipos de recursos............................................................................................135

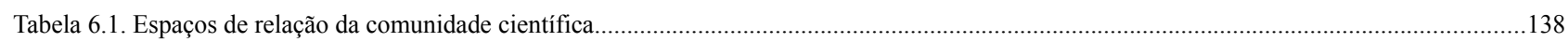

Tabela 6.2. Principais características do paradigma de pesquisa das redes sociais............................................................................................139

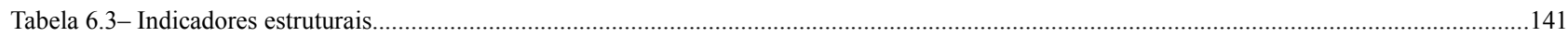

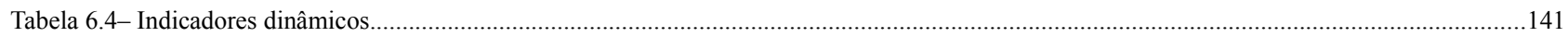

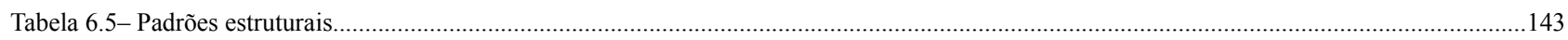

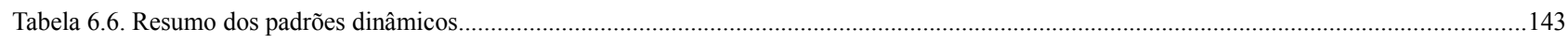

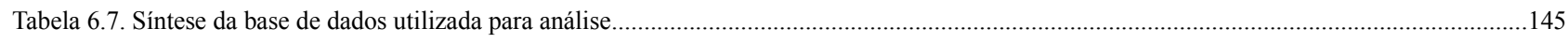

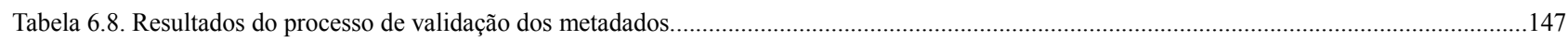

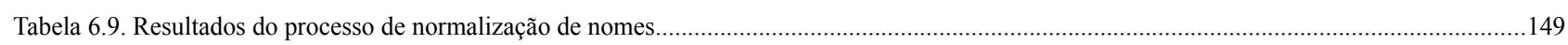

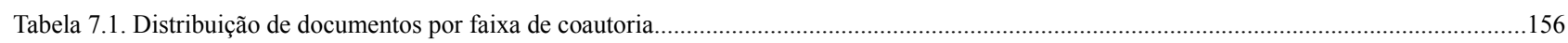

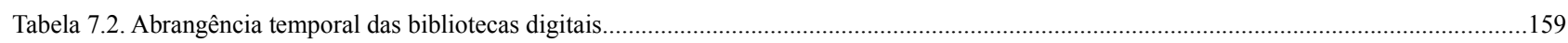

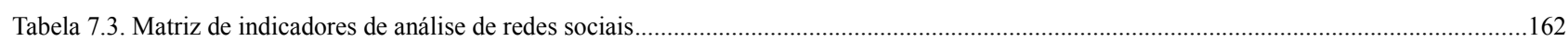

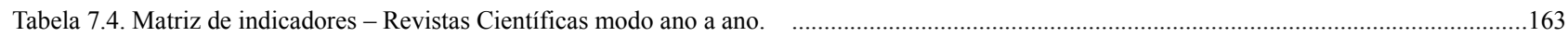

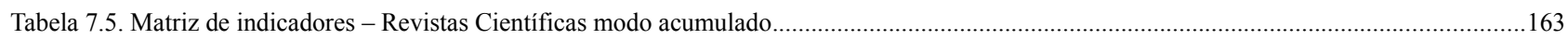

Tabela 7.6. Distribuição de nós por faixa de componentes - 2009, 2010 e 2011 - rede modo ano-a-ano - Revistas científicas................................180

Tabela 7.7. Distribuição de frequência dos nós mais centrais por instituição - Revistas científicas..................................................................185

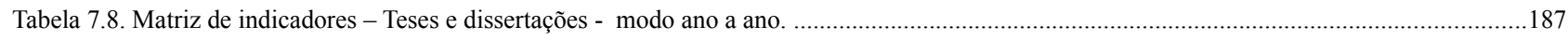

Tabela 7.9. Matriz de indicadores - Teses e dissertações- modo acumulado.....................................................................................................187

Tabela 7.10. Distribuição de frequência dos nós mais centrais por instituição - Bibliotecas Digitais de Teses e Dissertações....................................211

Tabela 7.11. Comparação entre indicadores de redes de diferentes áreas do conhecimento...................................................................................213

Tabela 8.1 - Características da área da Comunicação e resultados da análise de redes sociais.............................................................................219 


\section{Apresentação}

Estudar e investigar assuntos dos quais eu pouco conhecia e tinha muita curiosidade em entender sempre foi um dos vetores centrais que orientaram minhas escolhas ao longo de minha vida. No momento de escolher um curso, na época chamado de colegial, segui um desejo de entender melhor como funcionavam os computadores e, sobretudo, o fascínio de um dia conseguir programá-los. Eram os anos 90, a informática começava a se popularizar no Brasil e a Internet ainda era um nome que mal ouvíamos falar. Estudei na Escola Técnica Estadual (ETE) Lauro Gomes de anos de 1993 a 1995, tendo cursado Processamento de Dados e me formado como Técnico em Processamento de Dados.

Querendo entender melhor como as coisas funcionavam por dentro dos computadores, decidi aprofundar esses estudos e fui em busca de cursar Engenharia Elétrica, estudando com foco na micro e na optoeletrônica. Cursei a Faculdade de Engenharia Elétrica e de Computação (FEEC) da Universidade de Campinas dos anos de 1997 a 2002. Lá, utilizei a Internet pela primeira vez e comecei a tomar contato com o universo das redes, mas ainda pelo olhar técnico. Viajei para a França pela programa Graduação Sanduíche da CAPES no ano de 2000, cursando um ano de engenharia na Supelec e tendo tomado contato com um universo bastante diferente de pensamento, filosofia e espaços de reflexão.

Voltando para o Brasil, já vinha decidido a encontrar um espaço menos técnico por dentro da engenharia e que fizesse sentido com um desejo de contextualizar os efeitos sociais e políticos daquilo que eu mesmo fazia. Encontrei uma área dentro do Mestrado da Engenharia de Computação na Unicamp que trabalhava com ambientes colaborativos de aprendizagem. Foi por ali que iniciei uma nova trajetória. Tomando contato, ainda por dentro da engenharia, com pensadores que buscavam entender as novas tecnologias, a Internet, a cultura digital e seus desdobramentos em novos processos de aprendizagem fui me aproximando do que veio a ser meu objeto de pesquisa, militância e atuação profissional: as redes sociais. Desenvolvi minha dissertação no tema Suporte a Colaboração em Redes P2P dos anos de 2002 a 2004, já buscando mapear os efeitos e usos dessas redes em novos modos de organização social. Foi nessa época que também vim a tomar contato com várias comunidades, listas de discussão e projetos que utilizam a Internet como espaço de interação, reflexão e colaboração. Ali, me engajei em ações ligadas a inclusão e cultura digital. 
Mudanças políticas no país levaram a um novo cenário no governo federal. Gilberto Gil havia se tornado Ministro da Cultura e começado um programa de desenvolvimento de Pontos de Cultura Digital por todo o Brasil. Passei a fazer parte de ações do que chamávamos de Articuladores de Cultura Digital, viajando para diversas regiões do Brasil e do exterior realizando oficinas para centros culturais, bibliotecas, escolas e comunidades de várias origens. Trabalhei em outros programas de inclusão e cultura digital (Rede Humaniza SUS, Acessa SP, Acessa Escola, Casa Brasil, Telecentros.BR) dos anos de 2005 a 2011, sobretudo atuando na construção e ativação de redes sociais de interação entre os usuários e frequentadores de Telecentros públicos. A perspectiva da produção de novos modos de organização e circulação da informação mostravam enormes potenciais em termos de novos serviços que poderiam ser produzidos no âmbito desses programas, favorecendo o acesso a informação e novos meios de empoderamento comunitário.

A experiência na produção e implementação de políticas públicas me trouxe reflexões fundamentais para o que seriam os próximos passos de meu caminho. Quais eram os efeitos desses programas? Como avaliar o que estava sendo produzido? Como analisar os discurso produzido por essas ações e o que de fato é experimentado pelas pessoas que o utilizam? Como criar condições de melhorar esses sistemas de informação, não só do ponto de vista tecnológico, mas sobretudo, dos modos e meios de apropriação, das formas de mediação, suporte e produção de um sentido coletivo que determinasse como e quando essas ações teriam mais sentido de ocorrer. Questões fundamentais e que me levaram a desejar novamente me aproximar da academia para explorar esse espaço de análise, buscando respostas a essas inquietações.

Em 2008, encontrei a área da Ciência da Informação, buscando entender o que definia esse espaço das ciências sociais aplicadas. Entendendo ser uma área que permitiria aproveitar os conhecimentos técnicos que já havia desenvolvido nos percursos anteriores pela engenharia e processamento de dados, sobretudo no encontro com a Bibliometria, Cientometria, Infometria e Webometria, descobri que os desejos de questionamento, reflexão e, sobretudo, contextualização social, política e filosófica poderiam potencializar os trabalhos anteriores que já havia realizado. Daí, a continuar trabalhando com redes sociais como objeto de pesquisa foi um processo natural, se desdobrando no que vem a ser hoje a presente tese.

Já no Doutorado e como forma de conhecer melhor a área da Ciência da Informação, tenho participado de diversos eventos da área como forma de divulgar os trabalhos de pesquisa que tenho realizado, entrando em contato com novos pesquisadores e seus respectivos trabalhos: $4^{\circ}$ SECIN, X 
CINFORM, XII ENANCIB, $3^{\circ}$ EBBC, $3^{\circ}$ SBCC, CONTECSI, entre outros. Além disso, venho publicando os primeiros trabalhos de pesquisa, já resultados desta tese, em revistas como LIINC em revista,Em Questão, Encontros Bibli e Alexandri@.

Entendendo serem as redes sociais, sobretudo em tempos onde dados de relacionamento entre pessoas se tornam cada vez mais centrais nas estratégias políticas modernas, um objeto articulador e multidisciplinar de um universo extremamente amplo de pesquisa, tenho a expectativa de continuar me aprofundando nos estudos e pesquisas na área, tanto do ponto de vista informacional quanto do ponto de vista político, além de continuar produzindo pesquisas que busquem apontar para novas formas de leitura dos movimentos de rede, bem como para melhores modos de organização da informação em espaços de produção coletiva. 


\section{Sumário}

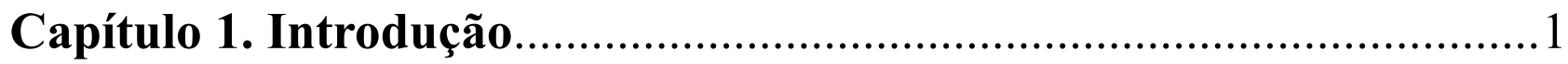

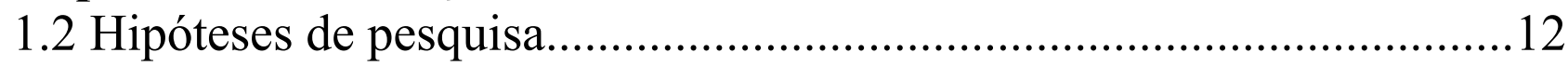

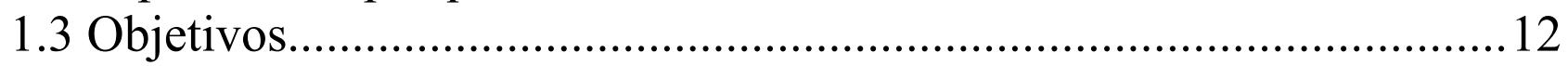

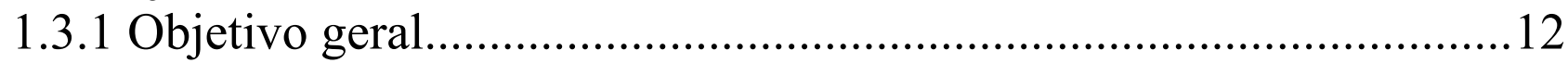

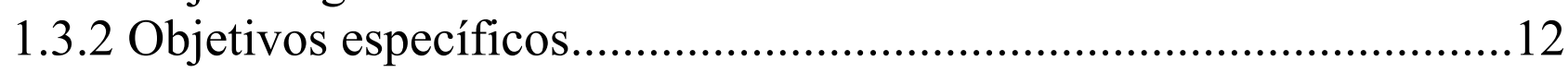

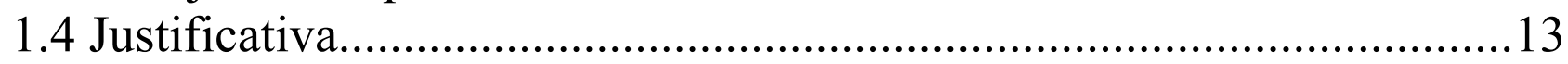

Capítulo 2. Redes Sociais: origens, modos de pensar e analisar..........14

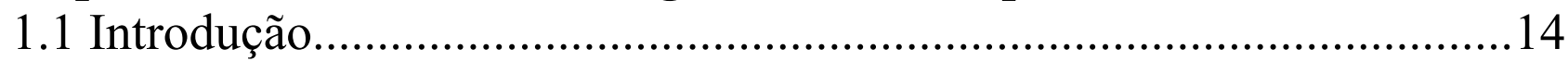

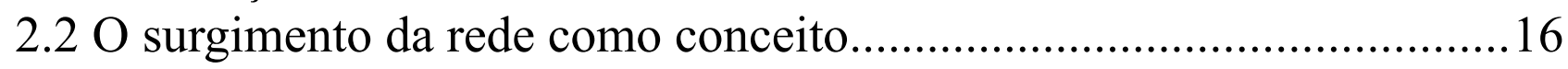

2.3 A estrutura e a dinâmica das redes.....................................................19

2.4 Paradigma de estudo das redes sociais: princípios gerais......................24

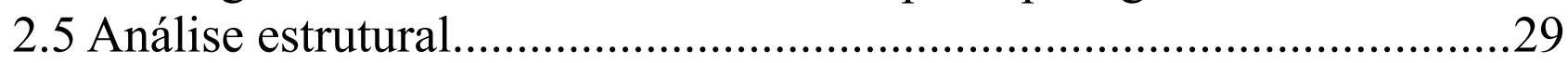

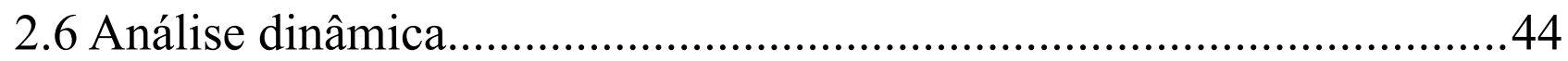

2.7 Análise de redes sociais e a Ciência da Informação no Brasil .............57

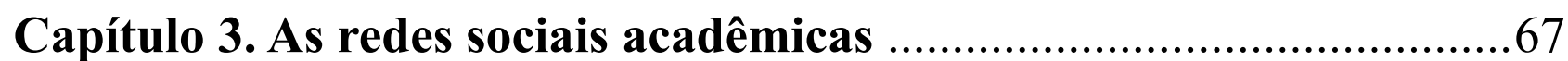

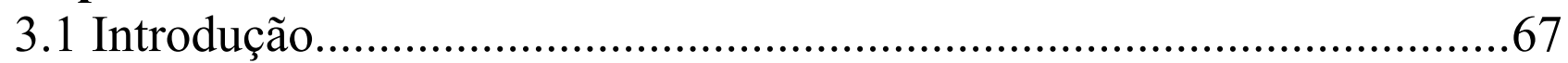

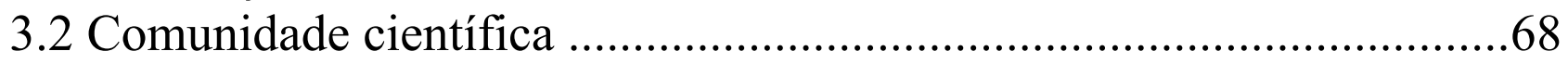

3.3 Dispositivos de sistematização da informação da comunidade

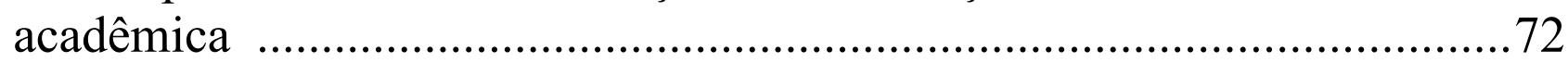

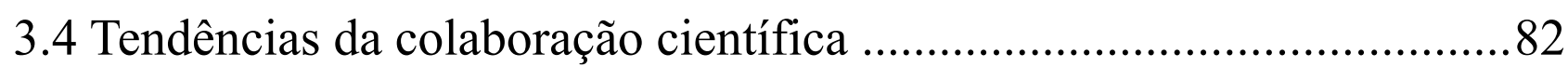

3.5 Efeitos da colaboração na produtividade e no impacto...........................85

3.6 Comunidade científica como sistema complexo auto-organizado........86

3.7 Estudos das redes sociais de co-autores em comunidades científicas .87

Capítulo 4. As redes sociais e a área das Ciências da Comunicação....93

4.1 Introdução ................................................................................93

4.2 A estruturação da Ciências da Comunicação no Brasil.........................97

4.3 Tendências na produção científica.......................................................103

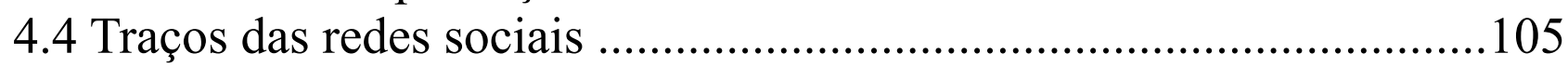

Capítulo 5. Movimento OAI e Sistemas Federados de Informação: fundamentos do portal da produção científica em Ciências da

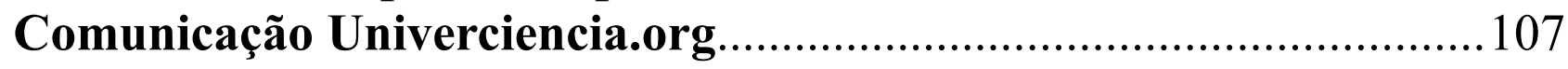

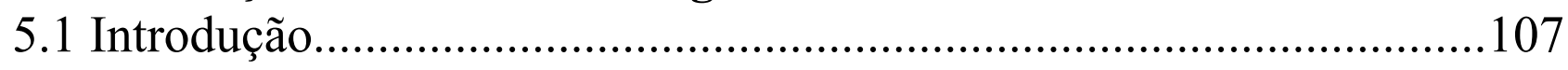


5.2 Contexto e história do movimento Open Archives Initiative (OAI). .108

5.3 OAI: interoperabilidade e modelo de comunicação........................113

5.4 Sistemas federados de informação............................................... 114

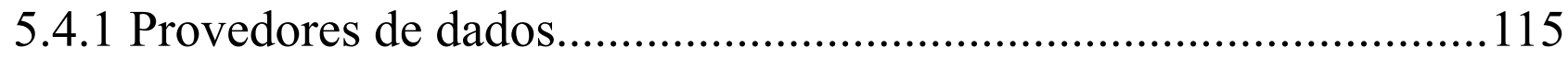

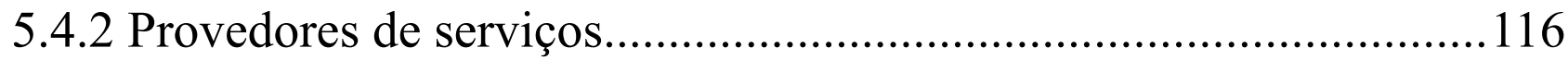

5.5 Federação de Bibliotecas Digitais...................................................117

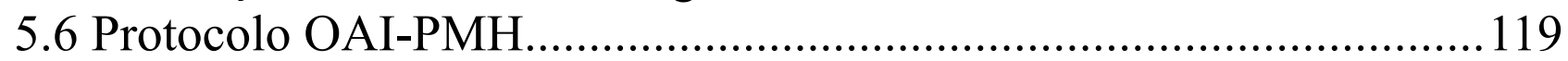

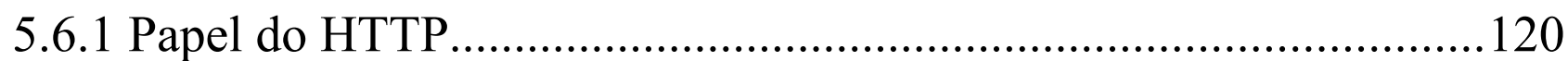

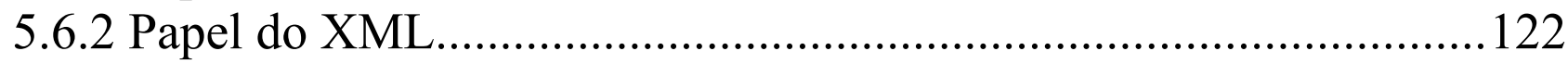

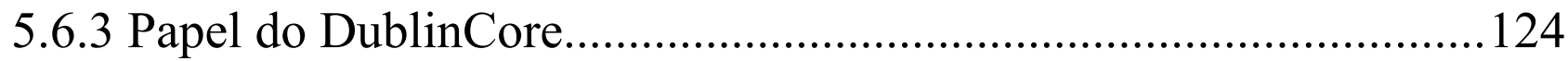

5.7 Metadados e normalização.........................................................126

5.7.1 Agregação de Metadados...........................................................127

5.7.2 Qualidade dos Metadados....................................................... 129

Capítulo 6. Procedimentos metodológicos......................................137

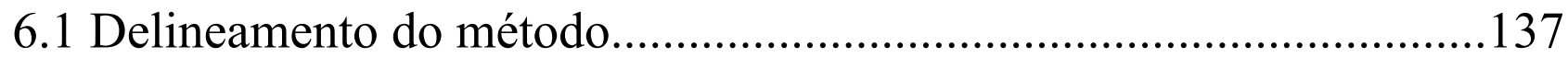

6.2 Tratamento dos dados................................................................ 140

6.3 Indicadores da análise estrutural e dinâmica...................................140

6.4 Análise e interpretação dos dados................................................ 142

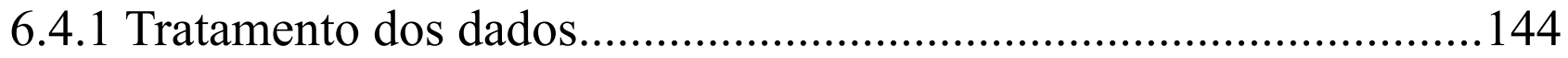

Revisão das fontes de informação............................................. 144

Extração do banco de dados........................................................146

Junção dos arquivos de saída..................................................... 148

Normalização dos nomes............................................................ 148

Produção do arquivo para análise de redes.................................. 149

Capítulo 7. Resultados.................................................................. 151

7.1 Descrição das bases de dados de análise........................................ 151

7.1.1 Base de revistas científicas.....................................................151

7.1.2 Base de bibliotecas digitais de teses e dissertações.......................157

7.2 Resultados da análise de redes sociais......................................... 160

7.2.1 Análise da rede social de relações de coautoria entre pesquisadores

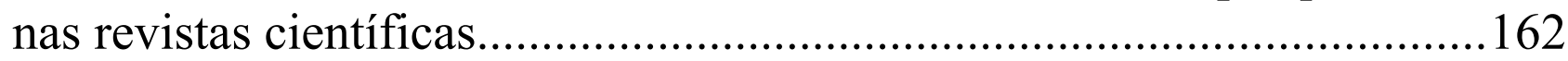

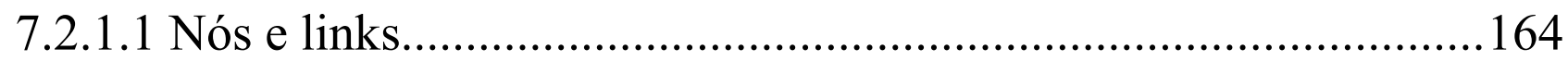

7.2.1.2 Densidade média e grau de centralização...................................167

7.2.1.3 Componentes.....................................................................169

7.2.1.4 Grau de conectividade médio................................................. 175

7.2.1.5 Maior e menor grau de conectividade....................................... 176 


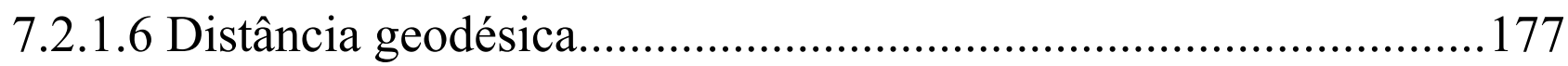

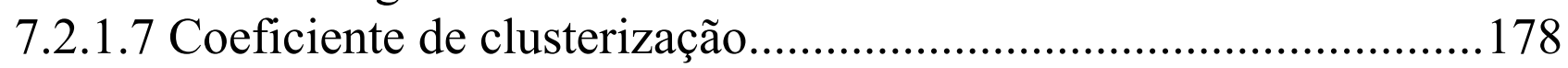

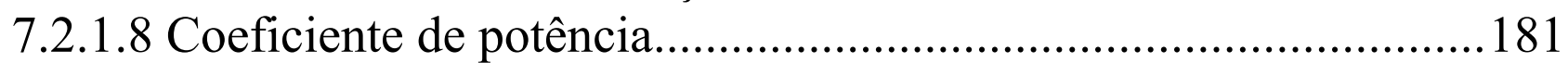

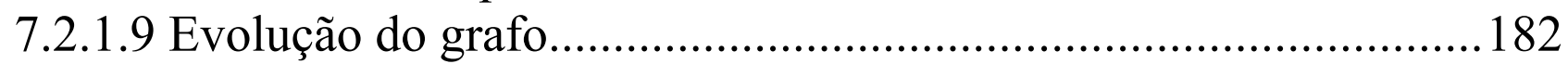

7.2.1.10 Comunidades: principais agrupamentos.....................................182

7.3.1 Análise da rede social de relações em bancas de defesa de teses e

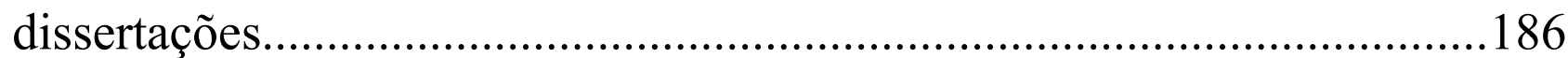

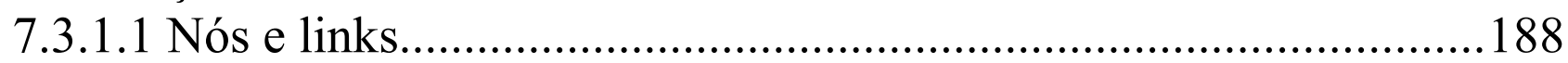

7.3.1.2 Densidade média e grau de centralização.......................................190

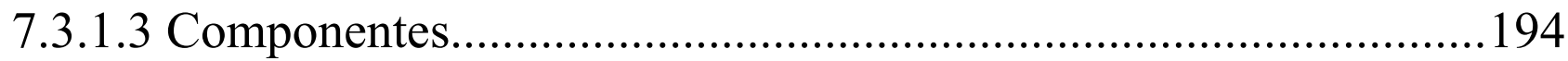

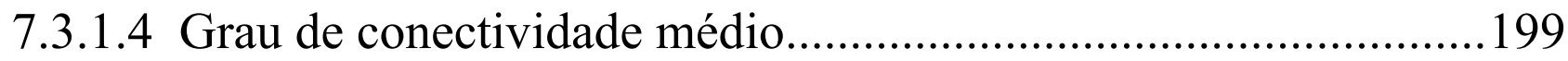

7.3.1.5 Maior e menor grau de conectividade..........................................201

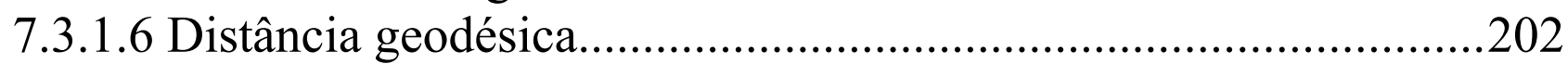

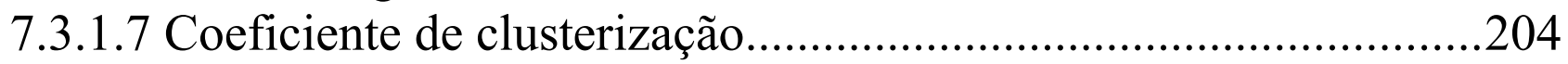

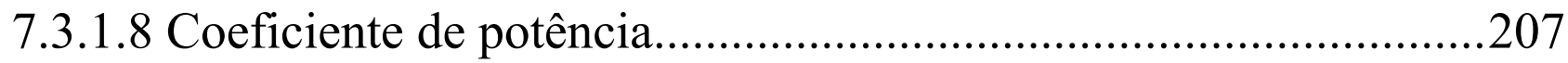

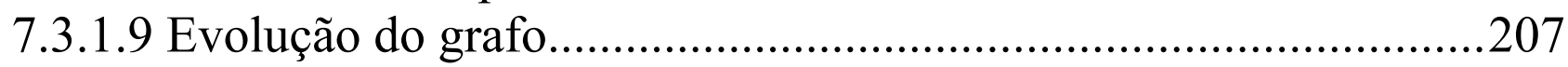

7.3.1.10 Comunidades: principais agrupamentos...................................208

7.4 Comparando padrões e estudos de referência ..................................212

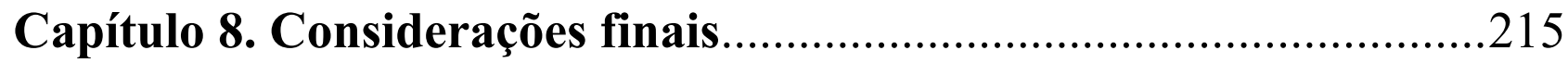

8.1 Considerações sobre a análise de redes sociais.................................217

8.2 Considerações sobre o campo das Ciências da Comunicação...........218

8.3 Considerações sobre a Ciência da Informação ...................................220

8.4 Recomendações de pesquisas futuras.................................................222

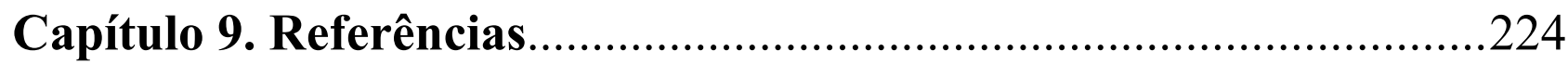




\title{
Capítulo 1 \\ Introdução
}

\begin{abstract}
"Mais uma vez, caímos no mesmo problema: criamos o objeto.
Nessa ordem de ideias, o mundo é literalmente constituído por objetos.

É como objetos que tratamos as outras pessoas e, por fim, tratamos a nós mesmos dessa forma quando dizemos: "Devo me encaixar aqui; devo fazer isso e aquilo; devo me tornar melhor", e assim por diante. Mas a sociedade não é uma realidade objetiva e ponto final. É uma realidade criada por todos seus componentes por meio de suas consciências."
\end{abstract}

David Bohm

As redes sociais invadem nosso imaginário cotidianamente quando nos deparamos com as últimas notícias sobre produtos de tecnologia, serviços disponíveis em nossos telefones móveis, estratégias de políticas públicas nas áreas de educação, saúde e ciência, novos modos e movimentos de ativismo social, marketing, publicidade e formas de relação profissional. Empresas expressivas no cenário mundial, como Google, Facebook, Twitter, Yahoo, Apple, e muitas outras baseiam suas estratégias nas redes sociais como elemento de articulação de seus produtos e serviços. Ao que parece, as redes estão em evidência em muitas áreas e se tornando objetos fundamentais quando o objetivo é entender como essas áreas funcionam, seus modos de operação e desenvolvimento.

Ao mesmo tempo, vivenciamos uma época onde sistemas de informação organizados em rede sintetizam e representam a visão dominante quando pensamos a respeito de processos de comunicação e produção de conhecimento. Visão que orienta e organiza o foco da atenção sobre a distribuição de recursos e esforços da pesquisa científica nas áreas da bibliometria, cienciometria, infometria e webometria interessadas em compreender e produzir seus próprios processos de comunicação e produção. A rede digital abre novas possibilidades e inspira novos modos de organização de grupos de pesquisa, que movidos pelo desejo de ampliar suas estratégias do saber e fazer científico, projetam novos meios de interação.

É por meio desses novos meios de interação, a partir de seus bancos de dados e circulação em rede, que a explosão quantitativa da informação produzida pela ciência se expressa e ganha materialidade. Um fenômeno que atrai interesse de várias áreas, inspiradas nas práticas das redes de produção de conhecimento científico, que podem se beneficiar em suas práticas sociais das melhores formas de organização e sistematização da informação. Um fenômeno que também gera, como seu produto direto, o conjunto mais vasto de bases de dados de interações humanas de 
produção científica nunca antes disponível na história da humanidade. Segundo o portal SCImago ${ }^{1}$, que fornece indicadores de produção científica de mais de 18.000 periódicos indexados com revisão pelos pares, de 1996 até 2009, a produção científica da América Latina cresceu em torno de 345\%, da América do Norte 134\% e da Europa Ocidental 174\%, ampliando sua taxa de crescimento na última década, conforme gráfico apresentado na figura 1.1, a seguir. Vale frisar que esses resultados não indicam apenas crescimento da produção, mas também evidenciam a maior visibilidade da produção já existente que passa a se tornar acessível a partir do uso de novos sistemas de informação.

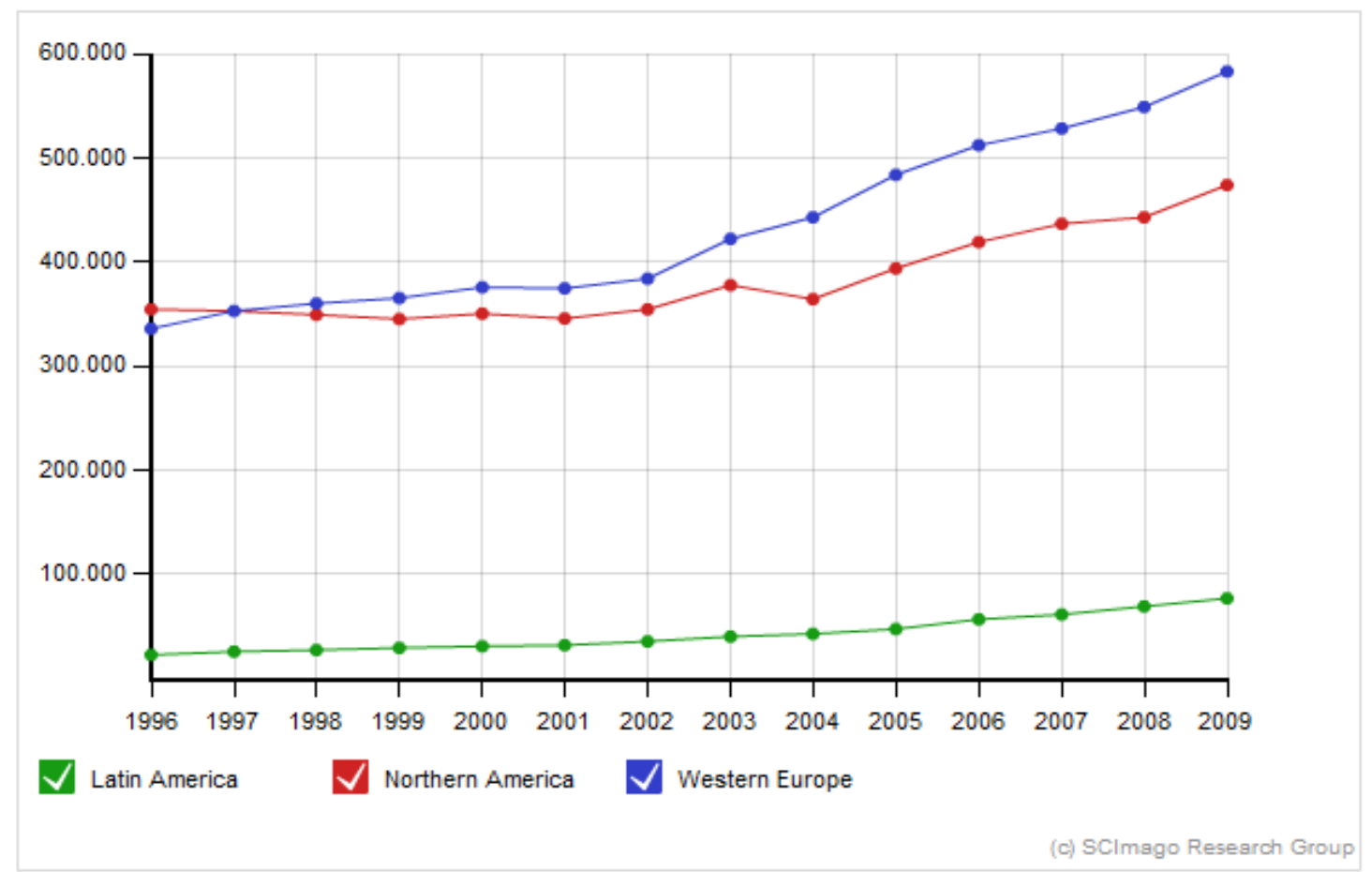

Figura 1.1. Crescimento da produção científica mundial. Fonte: http://www.scimagojr.com

O próprio resultado dessa explosão quantitativa de informação tem se tornado objeto de interesse de investigação em busca de respostas que ampliem o conhecimento existente sobre como funciona a própria comunidade científica, se é que ainda se trata de considerarmos a existência de uma comunidade científica como categoria válida ou nos darmos conta de que talvez estejamos diante de outros modos de organização, investigando seus padrões, suas regularidades, suas tendências, assim como as influências políticas que porventura estejam impulsionando esse tipo de resposta por parte dos pesquisadores como meio de criar critérios de acesso a recursos financeiros para pesquisa. São novamente os próprios pesquisadores que têm facilitado o estudo dessas bases de dados ao promover importantes iniciativas que apoiam o acesso aberto a sua produção, como o

1 http://www.scimagojr.com 
movimento $\mathrm{OA}^{2}$ e a iniciativa $\mathrm{OAI}^{3}$, incentivando novos modelos de negócios e a criação de sistemas de informação em rede que permitem a publicação de trabalhos e a coleta pública dos dados e metadados que armazenam em seus repositórios.

O resultado desse cenário é que o uso conjunto das redes digitais, a maior acessibilidade a bancos de dados que disponibilizem produção científica e a explosão informacional de nossos tempos cria condições favoráveis à investigação das relações sociais mediadas dentro dos limites do que pode ser analisado em termos de produção científica entre pesquisadores, instituições e seus modos de produzir ciência. Aqui, é importante darmos destaque a esse limite de mediação, dado que sabemos que muitos outros planos de relações sociais (encontros, redes sociais abertas, amizade, projetos, relações com empresas, etc.) entre pesquisadores atravessam, pautam e modificam seu modo de interação, influenciando seu fazer científico, que, no entanto, não são facilmente identificáveis ou mesmo possíveis de serem coletados de modo abrangente e representativo, o que não é o caso do plano de relações em torno de suas produções científicas. No entanto, não só temos a disposição novas questões que podem ser estudadas e bases de dados a serem exploradas, como a necessidade de utilização de novas técnicas de análise que possam lidar com toda essa complexidade informacional. Várias questões se colocam a partir desse ponto, envolvendo desde que metodologias de análise podem ser utilizadas, formas de coleta e tratamento dos dados, métricas, indicadores e referências comparativas que auxiliem na categorização dos padrões de colaboração de uma área da ciência em relação a outras.

Mapear uma área do conhecimento a partir da análise de suas redes sociais passa a se tornar tarefa viável devido a quantidade de dados hoje disponíveis e que podem ser coletados de forma automática. Mapeamento múltiplo que pode fornecer dados relevantes sobre várias camadas em que essas relações ocorrem: estratégias de conectividade utilizadas, políticas de relação, ações recorrentes denotando padrões em potencial, linguagem e expressões características, objetos de pesquisa preferenciais, modos de relação entre instituições, departamentos, grupos de pesquisa, pesquisadores, professores e alunos. A rede vira objeto de estudo, artefato de pesquisa e espaço de intervenção por onde se materializa e se atua nos fluxos de comunicação, nas estruturas e dinâmicas de conversação, nos modos de articulação e gestão. No entanto, mais uma vez precisamos aqui ressaltar que a análise da produção científica é apenas um modo de estudo, apesar de um modo de fundamental importância estratégica, pela qual podemos observar como os pesquisadores interagem. Esse modo cria um campo de importantes discussões, disputas e interesse em análise, dado que é por meio desse plano de relações que muitas políticas científicas definem seus critérios

2 Open Access

3 Open Archives Initiative 
de avaliação, levando a que os pesquisadores o utilizem como também um meio preferencial de responderem as exigências e critérios dessas políticas. A análise desse tipo de relação social nos permitiria, portanto, compreender as estratégias de organização dos pesquisadores colocando essas estratégias em perspectiva em relação aos critérios e meios utilizados pela política científica de avaliar, distribuir recursos e estruturar áreas do conhecimento.

É fundamental, portanto, partirmos de uma compreensão de como opera a área científica, suas distintas estruturas de relação e poder e a maneira específica em que ocorre as múltiplas interações sociais em seu meio, considerando as diversas características das áreas de conhecimento, como base conceitual de referência para o estudo do que esses bancos de dados podem nos revelar. É fundamental, antes do início de uma análise de dados, que tenhamos clareza sobre qual o contexto social desses dados, bem como os tipos de relações e modelagem que escolheremos estabelecer. Os dados não são neutros e simplesmente estão a nossa disposição para que possamos utilizá-los da forma que entendermos melhor. Eles são estruturados a partir de determinadas categorias dos sistemas de informação de onde são gerados, que, em geral, refletem categorias de uma política científica que visa organizar as áreas do conhecimento e suas produções. Entender o contexto e as dinâmicas sociais atuando por dentro desses sistemas é uma etapa importante a ser considerada quando da análise de seus bancos de dados. Os dados coletados, dessa maneira, tornam-se reflexos da pergunta que for feita.

A ciência, vista como campo social, fundamenta sua forma de operar nas estratégias, relações de força e interação produzidas pela multiplicidade de interesses em contínua negociação entre os agentes sociais que compõem as redes de produção de conhecimento científico de forma geral. Ora do ponto vista científico, ora do ponto de vista político, ora de ambos entrelaçados, as estratégias de interação no campo social da ciência enfocam, sobretudo, a visibilidade e o reconhecimento, como destaca Pierre Bourdieu (1983, p. 05):

"Não há "escolha" científica - de campo, da pesquisa, dos métodos
empregados, do lugar de publicação; ou, ainda, escolha entre uma publicação
imediata de resultados parcialmente verificados e uma publicação tardia de
resultados plenamente controlados - que não seja uma estratégia política de
investimento objetivamente orientada para a maximização do lucro
propriamente científico, isto é, a obtenção do reconhecimento dos pares-
concorrentes."

A visibilidade da produção científica e daquele que a produziu, portanto, parece ser uma 
premissa estratégica da maneira como a comunidade científica se organiza. Vale destacarmos aqui a ênfase que Bourdieu dá a maximização do lucro propriamente científico, dado que este não se expressa apenas no reconhecimento dos pares e concorrentes, mas, muitas das vezes, nas disputas e buscas por novos recursos financeiros das agências de promoção a pesquisa, os prêmios e titulações, que são diretamente produtos de modos específico de pensar e promover uma política científica. Os efeitos dessas ações estratégias como resposta a esses modos de organização da ciência podem ser percebidas na maneira como os pesquisadores constroem, comunicam e utilizam a informação no desenvolvimento de suas atividades, configurando um modelo social do seu ciclo de informação (LeCoadic, 1994, p. 10), como podemos ver na figura 1.2.

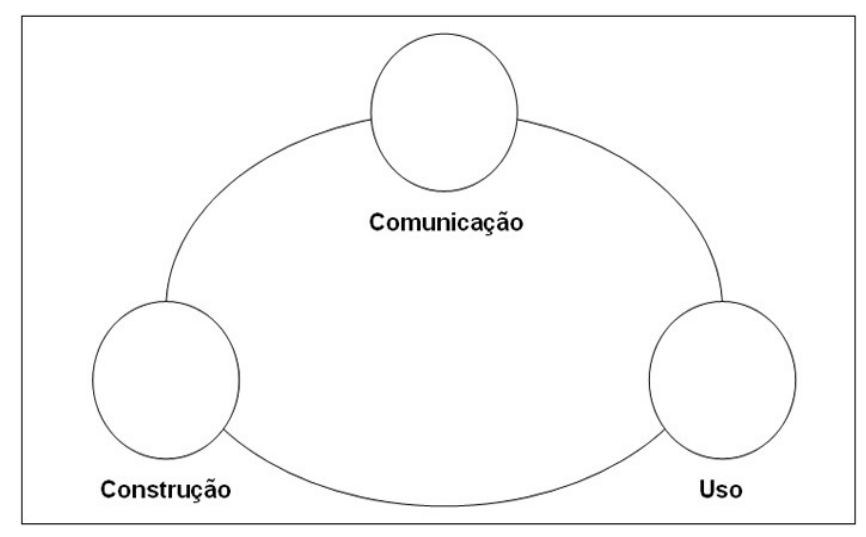

Figura 1.2. Modelo social do ciclo da informação. Fonte: LeCoadic (1994)

É importante destacar a continua inter-relação entre os processos de comunicação, construção e uso da informação. Ao produzir um trabalho e escolher uma forma específica de comunicá-lo, os pesquisadores favorecem determinadas condições de uso da informação, seja por fatores técnicos relacionados aos sistemas de informação que dão acesso aos trabalhos, seja por fatores políticos/sociais, como direitos autorais, por exemplo. O fato é que esses fatores terminam por estarem entrelaçados influenciando a dinâmica de como ocorre o modelo social do ciclo da informação.

O ciclo da informação presume o uso de estratégias articuladas de interação entre pesquisadores quando usam informação que consideram revelante para a construção de novas pesquisas e escolhem meios específicos de comunicação dos seus resultados, de forma a garantir o máximo de relevância para um determinado trabalho. É quando a interação começa a se tornar recorrente entre um grupo de pessoas que conseguimos caracterizar o surgimento de uma comunidade. É a interação recorrente dos membros da comunidade científica a partir desse ciclo da informação que configura a ciência como um sistema social, o que nos permite distingui-la como uma rede formada por grupos com características e estratégias particulares, como define Humberto 
Maturana (1985, p. 199):

"Cada vez que os membros de um conjunto de seres vivos constituem com sua conduta, uma rede de interações que opera para eles como um meio no qual eles se realizam como seres vivos, e no qual eles, portanto, conservam sua organização e adaptação, e existem em uma co-deriva contingente com sua participação em tal rede de interações, temos um sistema social. "

Desse modo, ao criar estratégias de construção, comunicação e uso da informação que levem a uma recorrência de interações entre pesquisadores e, ao mesmo tempo, ao interagir de forma recorrente criando essas estratégias, formando redes na coordenação de suas condutas, as redes de produção de conhecimento científico se constituem como um sistema social. No entanto, é fundamental pontuarmos aqui que essas estratégias de construção, comunicação e uso da informação não surgem de modo aleatório ou espontâneo. Em geral, são modeladas e terminam por modelar modos de se fazer políticas científicas específicas, como por exemplo, no Brasil há o sistema Qualis da CAPES de avaliação de periódicos científicos que influem de modo decisivo na escolha de um pesquisador em relação a qual revista científica ele deve encaminhar seu trabalho. Dependendo de sua escolha, terá mais ou menos pontos nas avaliações trienais. Logo, é a manutenção da relação em torno de estratégias consensuais que produz uma configuração característica de uma multiplicidade de grupos, sob influência direta das políticas científicas em vigor. Surge como campo onde atuam as forças sociais, produzindo uma agenda de demandas, pressões, compartilhamento de recursos, instituições, regras e normas de condutas que terminam por orientar todo seu processo de produção científica. A existência da recorrência de interações evidencia alguma forma de cooperação entre os membros de um sistema social, que conservam e jogam entre si as mesmas regras de um jogo, ora se submetendo a essas regras, ora disputando e visando modificar seus critérios para que novos modos de jogar sejam possíveis.

O estudo da recorrência das interações é, portanto, uma maneira de descrever a estrutura e a dinâmica que caracterizam um determinado sistema social e de observarmos os efeitos que essas políticas causam, permitindo inclusive diferenciá-lo de outros sistemas devido a uma potencial diferença de características entre eles. $\mathrm{O}$ estudo das interações permite produzirmos parâmetros de referência na ampliação do repertório de análise dos movimentos interativos. Para isso, entendemos que uma interação pode ser configurada a partir de 4 fatores, segundo a visão de Edgar Morin (2008, p. 72):

\footnotetext{
- $\quad$ "supõem elementos, seres, objetos materiais que podem se encontrar;
} 
- $\quad$ supõem condições de encontro, quer dizer, agitação, turbulência, fluxo contrário, etc.;

- $\quad$ obedecem a determinações/imposições ligadas a natureza dos elementos, objetos ou seres que se encontram;

- tornam-se, em certas condições, inter-relações (associações, ligações, combinações, comunicações, etc.), ou seja, dão origem a fenômenos de organização."

Logo, caracterizar uma rede a partir da análise das interações entre seus participantes passa por considerar esses quatro fatores acima. Determinar um conjunto de interações para o estudo das recorrências, ou seja, das estratégias de coordenação de condutas, que produzem um sistema social passa por reconhecer quais são os elementos que estão em interação. Esses elementos não interagem de forma aleatória, pois atuam a partir de um contexto, de condições específicas, de encontro singulares de um determinado tipo de interação. A natureza dos elementos determina o tipo de interação que pode ocorrer, seja do ponto de vista estrutural ou mesmo cultural, no caso de seres humanos, que podem estar ou não à disposição de um tipo específico de interatividade. As inter-relações acabam por dar origem a fenômenos de organização, ou seja, estratégias específicas que terminam por configurar como um sistema social organiza seus processos interativos, criando encontros, espaços, títulos, posições produzindo sistemas que refletem suas escolhas.

Podemos dizer que a explosão quantitativa de informações da produção científica, como vimos acima, é produto das estratégias escolhidas pelos pesquisadores no sistema social da ciência como reflexo da própria política científica que lhes serve de orientação e meio de relação, seja mobilizando ou sendo mobilizados por recursos financeiros, políticos ou filosóficos. O aumento de informações indica também um mesmo aumento no número de pesquisadores participantes e/ou nas interações entre pesquisadores nas fases de construção, comunicação e uso da informação no desenvolvimento de suas atividades. O sistema vai gradativamente se tornando mais complexo, exigindo, em contrapartida que tenhamos melhores e mais abrangentes recursos para que possamos analisar e caracterizar seus elementos constituintes. Vale notar aqui que essa visão de complexidade não se refere necessariamente a diversidade de temas e áreas de estudo, mas sim ao fato de termos mais pessoas interagindo, atuando nas disputas por recursos, por espaços de publicação, por modos de distribuição da produção científica, criando múltiplos mecanismos que são atravessados pela circulação da informação relativa a interação entre múltiplos grupos de pesquisadores em suas redes de produção de conhecimento.

$\mathrm{O}$ aumento de interações num sistema leva a um aumento de complexidade em seu funcionamento, podendo mesmo levar o sistema a reconfigurar suas estratégias de organização. $\mathrm{O}$ 
aumento de interações atua como o fogo burilando uma chapa de metal, aquecendo o material que mantém suas características estruturais até um determinado ponto, a partir do qual assume outra forma, outra maneira de expressar sua configuração estrutural, mudando do estado sólido para líquido. A partir de um determinado ponto, um sistema não apenas reproduz mais do mesmo, mas sim muda de estado de maneira muitas vezes imprevisível segundo sua forma tradicional de funcionamento. É um indício que estamos tratando não mais de um sistema linear, mas sim de um sistema complexo não-linear, entendendo por sistema uma inter-relação de elementos constituindo uma entidade ou unidade global (Morin, 2008, p. 131).

Logo, é a partir desse contexto exposto acima que partimos para começar a delinear o problema que pretendemos tratar nesta tese. Segue aqui algumas questões que orientam nosso modo de olhar para esta pesquisa, suscitando e provocando nossa reflexão. Seria o sistema social da ciência mediado pela perspectiva da produção científica um sistema complexo não-linear que poderia ser investigado a partir de grandes bancos de dados representando esse aumento explosivo de interatividade entre os cientistas? Poderia a comunidade científica ser descrita como uma rede complexa auto-organizada, onde os padrões de conexão entre os nós são definidos a partir dos próprios movimentos de interação e não por fatores externos a rede, e, a partir dessa descrição, investigarmos a estrutura e a dinâmica das interações sociais entre pesquisadores de uma área do conhecimento? Ou seria essa rede encontrada fortemente influenciada pelas questões da política científica vigente, estando os fenômenos de auto-organização sujeitos apenas a efeitos locais? Que efeitos têm causado esse aumento expressivo da produção científica no sistema social da ciência? Poderíamos caracterizar as estratégias de conectividade, os padrões de formação e desenvolvimento das redes sociais de uma área do conhecimento analisando as interações em torno de sua produção científica, mesmo sabendo que ali estamos analisando apenas um de seus planos de comunicação? Que recursos técnicos e metodológicos precisaríamos para isso? Como esses elementos estão manifestos numa área específica do conhecimento? Que condições informacionais precisaríamos ter sistematizadas para estudarmos e compararmos padrões de constituição de redes em diferentes áreas do conhecimento?

O ponto em que chegamos reflete um aumento gradativo na complexidade de organização da ciência. É com essa complexidade que nos vemos envolvidos quando nos lançamos numa pesquisa que tenha por objetivo estudar como surgem e se desenvolvem as redes de interação entre pesquisadores determinados como um sistema social mediados pela perspectiva específica da produção científica. Ao que tudo indica, precisaremos de métodos de pesquisa que possam nos auxiliar a lidar com essa complexidade, o que deve ser considerado desde a coleta, processamento e análise de amostras de dados expressivas que permitam caracterizar de forma mais abrangente 
possível essas redes sociais de uma área do conhecimento. Entendemos ser a junção de dispositivos de análise oriundos das ciências sociais, tais como a produção de categorias de análise, ordenação e sistematização de massas de dados nessas categorias, análise do discurso, bibliometria, cienciometria, infometria, webometria, e da dinâmica não-linear de sistemas, tradicionalmente uma área voltada para a caracterização de sistemas físicos, químicos e biológicos, que parece fornecer pistas importantes nos auxiliando a descrever os sistemas que estamos estudando, conforme define Fritojf Capra, ao mencionar os elementos necessários para a compreensão das estruturas das redes sociais (Capra, 1993, p. 94):

“As redes sociais são antes de mais nada redes de comunicação que
envolvem linguagem simbólica, os limites culturais, as relações de poder e
assim por diante. Para compreender as estruturas dessas redes, temos de
lançar mão de ideias tiradas da teoria social, da filosofia, da ciência da
cognição, da antropologia e de outras disciplinas. Uma teoria sistêmica
unificada para a compreensão dos fenômenos biológicos e sociais só surgirá
quando os conceitos da dinâmica não-linear forem associados a ideias
provindas desses outros campos de estudo."

Ao observar o cenário atual das redes de produção de conhecimento científico, percebemos três aspectos inter-relacionados das estratégias de relação dessas redes: mudança nos fluxos de comunicação e produção de sistemas de informação como resultado dos movimentos de acesso aberto a produção científica, crescimento expressivo e/ou maior visibilidade na interatividade entre pesquisadores e a maior complexidade organizacional no sistema social da ciência. Entendemos que são as redes sociais objetos de pesquisa que, por serem produzidas a partir das interações entre pessoas que se relacionam e interagem a partir de seu fazer científico, podem dar visibilidade a como esse cenário tem se manifestado em diferentes áreas do conhecimento.

É com esse cenário em mente que três condições devemos determinar quando nos propomos a estudar as redes sociais de uma área: que conjunto de interações analisar, que metodologia de análise utilizar e que conjunto de dados coletar. Criamos e apresentamos na figura 1.3 um diagrama que permite visualizar a conexão entre essas três perguntas e que nos orientam na organização desta tese e proposta de pesquisa. 


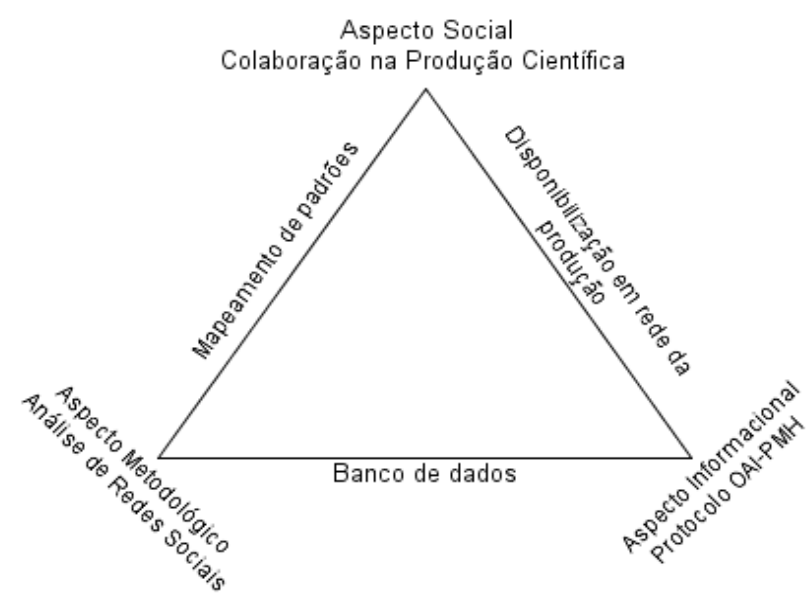

Figura 1.3. Elementos de caracterização de uma rede social.

O que buscamos caracterizar ao propor o esquema da figura 1.3 são as estruturas informacionais em seus diferentes aspectos que devem ser contempladas para a produção do estudo que aqui desenvolvemos. Consideramos, sem dúvida, que outros aspectos sociais poderiam ser levados em consideração, tais como a adesão de pesquisadores a um determinado tipo de evento científico ou mesmo grupo de estudos, assim como outros aspectos protocolos poderiam ser utilizados como modo de obtenção desses dados e mesmo outras metodologias de análise. Nossa escolha específica está centrada no desejo de analisar o que é possível obtermos de colaboração científica na estrutura de uma federação de bibliotecas digitais.

O aspecto metodológico é o responsável pelo procedimento que utilizaremos para mapear os padrões que possam surgir do conjunto de interações que estamos analisando, facilitando, dessa forma, que possamos caracterizar e comparar uma rede a outras . Para o estudo das redes sociais utilizaremos a análise estrutural e dinâmica de redes. Apresentamos no capítulo 2 um breve histórico do conceito de rede, como se formam, como se desenvolvem e uma revisão sobre a forma como tem sido utilizado pelo campo das Ciências da Informação como estratégia de pesquisa e fundamentação teórica.

O aspecto social é o responsável pelo conjunto de interações que iremos analisar e que daremos evidencia num determinado estudo. É a partir de onde iremos denominar quais são os elementos que compõem a rede, suas condições de encontro e seus fenômenos de organização. No nosso caso, estamos interessado em como se formam as redes sociais no contexto científico, mais especificamente em como isso se dá no âmbito de uma área específica do conhecimento, quais estratégias de conexão entre as pessoas, seus jogos de interesses, de poder, articulação e questões específicas do campo do conhecimento que irão pautar a formação de suas redes sociais. 
Apresentamos no capítulo 3 uma revisão teórica sobre a aplicação da análise das redes sociais no contexto da comunidade científica e no capítulo 4, as principais características que devemos levar em consideração na caracterização das redes sociais da área da Ciências da Comunicação. Vale frisar que nosso estudo de campo será realizado no âmbito das Ciências da Comunicação, onde iremos investigar as redes sociais a partir do portal da produção científica em Ciências da Comunicação - Univerciencia.org ${ }^{4}$, nossa base informacional empírica de estudos e que tem por objetivo concentrar a produção científica dessa área do conhecimento em âmbito nacional. A existência do Univerciencia é, portanto, um aspecto fundamental de nosso estudo, pois cria as condições de agregação da informação dos metadados da produção científica da área da Comunicação, bem como permite acesso a organização desses metadados com suas tipologias características.

O aspecto informacional é o responsável pela estrutura da informação que disponibiliza e permite a coleta dos dados que iremos utilizar em nosso estudo. É ele o resultado da publicação da produção científica em rede e que fornece o banco de dados que permitirá a aplicação da metodologia de análise de redes. No nosso caso, estamos interessados nas federações de bibliotecas digitais para agregação da produção científica de uma ou várias áreas do conhecimento. Apresentamos no capítulo 5 o conceito de sistemas federados de informação, bem como de federação de bibliotecas digitais, um breve histórico do movimento OAI que levou a construção do protocolo OAI-PMH no qual está baseado o portal Univerciencia.org, que utilizaremos em nossa análise.

Entendemos que é essa articulação entre os aspectos social, metodológico e informacional uma condição de possibilidade fundamental que viabiliza o estudo das redes sociais a partir de sistemas de informação digitais.

No capítulo 6, apresentamos nossa proposta metodológica de organização desta tese. No capítulo 7, apresentados uma análise detalhada dos dados obtidos e processamentos realizados. No capítulo 8, apresentamos uma discussão sobre os resultados e as conclusões geradas em nossa pesquisa.

Vale também destacar que não encontramos estudos científicos como referência que se propuseram a analisar redes sociais de colaboração em produção científica a partir de bibliotecas digitais federadas.

4 www.univerciencia.org 


\subsection{Hipóteses de pesquisa}

A análise de redes sociais fornece condições metodológicas para o mapeamento de planos de relações sociais, facilitando perceber os efeitos das políticas que regulam essas relações e se propõe a operar como estratégias de atuação em suas características estruturais e dinâmicas.

A produção científica de uma área do conhecimento, em nosso caso a área da Ciências da Comunicação, constitui um plano de comunicação singular a partir do qual podemos analisar suas relações sociais mediadas pela necessidade de produção científica, além dos efeitos, impactos e influências que são geradas pelas políticas científicas que regulam o funcionamento da área.

$\mathrm{O}$ ambiente federado de bibliotecas digitais constitui um sistema de informação que permite ampla agregação da produção científica em formato aberto disponibilizada por diversas instituições, tais como revistas e bibliotecas digitais de teses e dissertações, se tornando um ambiente favorável para o estudo das redes sociais mediadas pela necessidade de produção científica de uma ou mais áreas do conhecimento.

\subsection{Objetivos}

\subsubsection{Objetivo geral}

Demonstrar que um ambiente federado de bibliotecas digitais fornece as condições necessárias para a agregação dos metadados da produção científica de uma área do conhecimento, viabilizando o mapeamento dos padrões de constituição de suas redes sociais, evidenciando as estratégias de formação de importantes planos de relação sociais dos pesquisadores participantes dessa área, bem como os efeitos nesses planos das políticas de regulação da área.

\subsubsection{Objetivos específicos}

- Demonstrar as principais estratégias de conectividade, formação e padrões das redes sociais do que pode ser visto e tem sido registrado nos metadados de coautoria na produção científica para revistas e na participação de bancas de defesas de teses e dissertações de uma área do conhecimento agregados em uma biblioteca digital federada, aplicando como caso a área das Ciências da Comunicação no Brasil, considerando sua produção científica agregada em uma federação de bibliotecas digitais, a Univerciencia.org;

- Estabelecer um conjunto de indicadores de referência para a análise de redes sociais de uma área do conhecimento;

- Mapear o estado da arte da pesquisa em análise de redes sociais; 
- Estudar as possibilidades de análise de redes sociais que possam ser derivadas dos bancos de dados de uma federação de bibliotecas digitais baseada no padrão OAI-PMH;

- Fornecer um esquema de referência para análise de redes sociais a partir de uma federação de bibliotecas digitais;

- Identificar a existência ou não de correlações entre as redes de pesquisadores coautores e participantes de bancas de defesa de teses e dissertações;

- Identificar aplicações e modos de uso da análise de redes sociais na área da Ciência da Informação, como contribuição metodológica para a área;

- Estudar o padrão de qualidade dos metadados, a forma como têm sido gerados em uma federação de bibliotecas digitais e os impactos que isso acarreta para um estudo de análise de redes sociais.

\subsection{Justificativa}

A análise e a caracterização das redes sociais mediadas pela produção científica de uma área do conhecimento pode facilitar uma melhor compreensão de seu funcionamento, seus modos de operação e as estratégias que são construídas pelos membros participantes dessas redes, bem como influenciar em políticas de pesquisa, distribuição de recursos e articulação dos pesquisadores. A ausência de estudos abrangentes que caracterizem as redes sociais de produção científica de uma área do conhecimento a partir do uso de bibliotecas digitais federadas no Brasil aponta para uma questão ainda em aberto para a pesquisa acadêmica.

Além disso, o crescimento da produção científica nas últimas décadas e o uso de novos sistemas de informação que disponibilizam essa produção em acesso aberto tem gerado grandes bases de dados que possibilitam a aplicação de novas técnicas e metodologias para sua caracterização. A sistematização dessas metodologias, indicadores e a produção de sistemas de referência para comparação entre estudos permite o amadurecimento da pesquisa científica na área da Ciência da Informação, sendo os seus resultados de interesse para profíssionais e pesquisadores interessados no estudo e análise de outras áreas do conhecimento e tipos de redes sociais. 


\section{Capítulo 2 \\ Redes Sociais: origens, modos de pensar e analisar}

"O mundo aparece, portanto, como um complicado tecido
de eventos, no qual conexões de diferentes espécies
se alternam, sobrepõem ou combinam, e
dessa forma determinam a textura do todo"
Wiener Heisenberg

\subsection{Introdução}

Estudar, experimentar e vivenciar as redes tem sido uma forte tendência de tempos em que a Internet e o fluxo da produção, organização e circulação da informação em rede desempenham papéis fundamentais na comunicação, na economia, na filosofia, na biologia e em praticamente todos os campos do conhecimento humano onde a metáfora de rede surge como princípio e conceito organizador do pensamento. As redes tornaram-se, antes de tudo, um modo de pensar, de ler e de agir no mundo (Duarte e Frey, 2008, p. 157).

Ao mesmo tempo causa e efeito, a ideia de rede impressiona, seduz e desafia compreensões tradicionais apoiadas num conjunto consolidado de conceitos que utilizamos no cotidiano: equações lineares de previsão do movimento, taxas de crescimento, indicadores de acesso e consumo, o entendimento das partes para compreender o todo, foco no ser e não nas relações. A maneira como concebemos e nos organizamos em grupos de trabalho, os princípios de sistematização da informação, vocabulários controlados, taxonomias pré-determinadas, disponibilização de documentos, a noção de autoria, enfim, diversas dinâmicas que consolidaram modos de fazer e de viver podem ser questionados, revisitados pelas novas possibilidades que o pensar em rede em suas novas metáforas possibilita.

A aparente sensação de incompreensão e necessidade de se encontrar novas ferramentas de análise surge quando modelos teóricos não dão mais conta de ofertar possibilidades de entendimento, previsão e síntese de processos. A capacidade de produzir sentido e encontrar ordem é abalada. Novas metáforas são necessárias, novas condições de possibilidade que se propõem a tratar a complexidade das relações em rede podem ser ensaiadas, analisadas e estudadas quando dispomos de duas características marcantes de nosso tempo: ampla disponibilidade de dados oriundos das múltiplas relações entre pessoas que se constituem nos ambientes digitais (bibliotecas digitais, listas de email, blogs, fóruns, mídias sociais, etc) e alto poder de processamento dessa informação, possibilitando diferentes formas de análise, proposição e testes de novos modelos, visualizações e novos indicadores. 
A questão que se coloca é como tratar essas massas de dados que refletem movimentos, tendências de uso e apropriação registradas pelos sistemas de informação de onde são originadas. O surgimento da Internet e o desenvolvimento da Web produziram uma explosão informacional nunca antes vista na história da humanidade. A capacidade de lidar com tamanho aumento na informação a disposição exige a concepção contínua de novas técnicas de filtragem, navegação e visualização de dados que certamente podem favorecer a percepção da significação emergente que surge do uso desses ambientes de informação (Levy, 2010, p. 62). A capacidade de perceber o que emerge das massas de dados produzidas pelas interações das redes sociais torna-se um elemento central de motivação para pesquisa em várias áreas do conhecimento, não somente como ferramenta de controle e monitoramento, mas também como espaço estratégico de intervenção e deslocamento em movimentos sociais.

Diversos avanços importantes na história de muitos campos da ciência apoiam o surgimento de novas metáforas que se propõem a estudar e analisar as redes. Sem dúvida, o desenvolvimento das Ciências da Informação e seus desdobramentos na informetria, webmetria e cienciometria, influenciados pelo aumento exponencial de nossa capacidade computacional, começou a fornecer os meios não só para se colocar a questão "de que é feita a complexidade?", como para tentar respondê-la (Atlan, 2006). Questões relacionadas a como tratar, organizar e correlacionar a informação para o estudo das relações em rede são questões fundamentais no momento em que buscamos novos métodos de análise. Um forte estímulo para a pesquisa e desenvolvimento desses novos métodos está na ideia de que a inteligência de uma rede recai sobre os padrões de relacionamento entre seus membros (Souza e Quandt, 2008, p. 52). Encontrar esses padrões significa ter acesso, explicitar o tipo de inteligência e suas estratégias em atuação.

Ao se deparar com diferentes situações tais como o metabolismo das células, referências de links entre páginas na Internet, atores que trabalharam juntos em filmes de Hollywood, dinâmica das reações dos gases, os cientistas foram se dando conta de que as interações nos sistemas complexos formavam redes, onde cada nó interagia apenas com uma pequena quantidade de outros nós e cujos efeitos e a presença podiam ser sentidos muitos nós adiante. O mais interessante é que descobriram que as redes complexas possuíam uma estrutura comum orientada por princípios universais (Barabasi, 2003).

A descoberta da estrutura, da dinâmica e de seus princípios universais ocorre na dimensão do comum entre os problemas estudados que seriam, em tese, completamente diferentes, até mesmo oriundos de áreas que se ocupam de objetos de pesquisa muito distintos. A dimensão do comum se torna evidente quando utilizamos a mesma maneira de classificação e organização da informação, ou seja, quando os princípios de coleta, processamento e análise dos dados são semelhantes. Da 
semelhança a abstração da metáfora, surge o comum dos princípios, dinâmicas e estruturas concentrando num conceito-objeto compartilhado: a rede.

\subsection{O surgimento da rede como conceito}

Os primeiros registros que se têm do relato do uso da palavra rede, é o seu aparecimento (réseau) na língua francesa no século XII, vindo do latim retiolus, designando redes de caça, de pesca e malhas que cobriam o corpo (Musso, 2004). Surge como conceito que expressa uma ordem, descreve a maneira como os fios e seus enlaces eram organizados na produção dos tecidos e objetos de caça. Manifesta uma distinção, uma visualização que identifica a manifestação de um reconhecido padrão organizacional.

A apropriação do conceito rede permanece no domínio dos tecelões até meados do século XVII, quando passa a ser utilizado por médicos para designar e desenhar o aparelho sanguíneo e as fibras que compõem o corpo humano. No fim do século XVIII, a medicina e a cristalografia observam efeitos de rede nas formas da natureza. No início do século XIX, a rede deixa de ser apenas observada fora ou dentro do corpo e ganha a possibilidade de ser construída como objeto pensado na relação com o espaço pela engenharia. Passa a servir como artefato técnico e de gestão sobre o espaço e o tempo, que permite distribuir linhas imaginárias sobre o espaço, organizando fluxos logísticos de transporte, comunicação e distribuição de recursos em geral (Musso, 2004).

É interessante notar que a primeira proposta da construção de uma ciência das redes surge já no séc. XVIII, na proposição de uma ciência generalizada das formas e das redes. A rede vai se firmando como um conceito operatório-metodológico que auxilia e estimula a produção e organização do pensamento em suas metáforas. A rede vira ontologia, vira operador para a ação, vira estrutura relacional em diversas formas de sistematização do pensamento, que ora se propõem ao controle dos fluxos e ora a fazer circular os mesmos fluxos (Musso, 2004). Paradoxo de gênese que vai se revelar orientador da busca por métodos que ora possam servir para o controle, da gestão do espaço e do tempo, ora possam servir de fomento a circulação e espalhamento de fluxos.

Ainda no século XIX, no surgimento da sociologia, Comte foi o primeiro a propor um olhar para a sociedade em termos da interconexão entre atores sociais em busca das leis de ação e reação das diferentes partes do sistema social (Freeman, 2004). Surgem os primeiros passos que fundamentam a apropriação do conceito rede como uma maneira de estudo e intervenção na sociedade, o modelo de gestão do espaço e do tempo da engenharia passa a ser utilizado como distinção de análise da estrutura e da dinâmica de interação entre as pessoas.

Criadas as bases de pensamento que construíram a possibilidade de estudo das relações humanas a partir da interconexão entre atores, a questão que se colocava então era que tipo de 
informação coletar e como organizar essa informação de forma a permitir o estudo das interconexões. A questão se tratava, portanto, em como mudar de um foco de análise do indivíduo e seus atributos (idade, sexo, preferências, opiniões, etc.), que exigia um ferramental analítico linear, por meio do uso de questionários estruturados e análises estatísticas, para um foco de análise nas relações, onde o ferramental analítico ainda não era evidente. Focar no estudo das relações representou um avanço na tradicional pesquisa social e comportamental, que era até então focada nos atributos de uma determinada unidade social (Wasserman e Faust, 1994).

Em busca de uma ferramenta analítica e de uma forma de pensar nas relações entre grupos de pessoas, Jacob Moreno, médico romeno que emigrou para os Estados Unidos em 1925 e foi um dos criadores do teatro terapêutico e do psicodrama, cria a sociometria no início dos anos 30 (Freeman, 2004), com a premissa de que a sociedade não é um agregado de indivíduos e a soma de suas características individuais, como os estatísticos assumiam até então, mas sim uma estrutura composta de relacionamentos entre as pessoas. O átomo social, visão da época, era composto por um indivíduo e suas características pessoais. Esse átomo operava conexões com outras pessoas formando grupos sociais. No limite, a sociedade era composta pelo relacionamento entre esses grupos (Nooy, Mrvar, Batagelj, 2005, p. 3).

“O sociograma seria a representação gráfica dessas redes de preferência e rejeição, revelando hierarquias e sistemas de poder. Era uma técnica de mudança social e seu objetivo era pensar/intervir no sistema de grupos, na comunidade como um todo" (Barros, 2007).

"A intervenção sociométrica nos grupos e nas instituições é, portanto, análoga à do psicodrama: trata-se sempre de liberar a espontaneidade e a criatividade, a capacidade de inventar uma história pessoal ou uma história coletiva. Trata-se, portanto, de conhecer os grupos, não com uma finalidade exclusiva de pesquisa, mas, ao contrário, para facilitar as mudanças" (Lapassade,1997 apud Barros ,2007).

A sociometria surge, portanto, não apenas como uma ferramenta analítica de pesquisa e controle da informação sobre os padrões de conexão formados pelas relações entre as pessoas. A sociometria buscava se tornar uma técnica de mudança social, de intervenção em coletivos trazendo à tona mais informações sobre como um grupo de pessoas se relacionava, estruturas hierárquicas e de poder que se constituíam evidenciando padrões de relação até então de difícil explicitação. Ao 
tornar visível esses padrões, para os próprios participantes algo ocorre como intervenção na rede, ampliando seu repertório de conversa e análise de seus modos de relação. A sociometria buscava ser mais que um método, uma ferramenta analítica, mas uma maneira de se pensar e atuar nas redes. Além disso, um dos pontos cruciais para os analistas estruturais de rede era se contrapor de algum modo as grandes categorias estáticas da sociologia clássica, considerando que seria papel da análise de redes explicar como poderiam surgir essas categorias a partir da densidade de relações entre pessoas e seus múltiplos grupos em potencial. A ideia era primeiro avaliar a densidade de laços entre pessoas para depois, então, propor categorias de agrupamento.

É a partir dessa visão que a sociometria surge com o principal objetivo de detectar e interpretar padrões de relacionamentos sociais entre os atores de uma rede. Quanto mais informações sobre essas relações pudessem ser coletadas, processadas e analisadas de forma integrada, maiores possibilidades de análise estariam disponíveis, novas possibilidades de intervenção poderiam ser pensadas. Dessa forma, um dos primeiros recursos de pesquisa desenvolvidos pela sociometria e otimizado matematicamente pelo uso da Teoria dos Grafos foi o sociograma, apresentado na figura 2.1 .

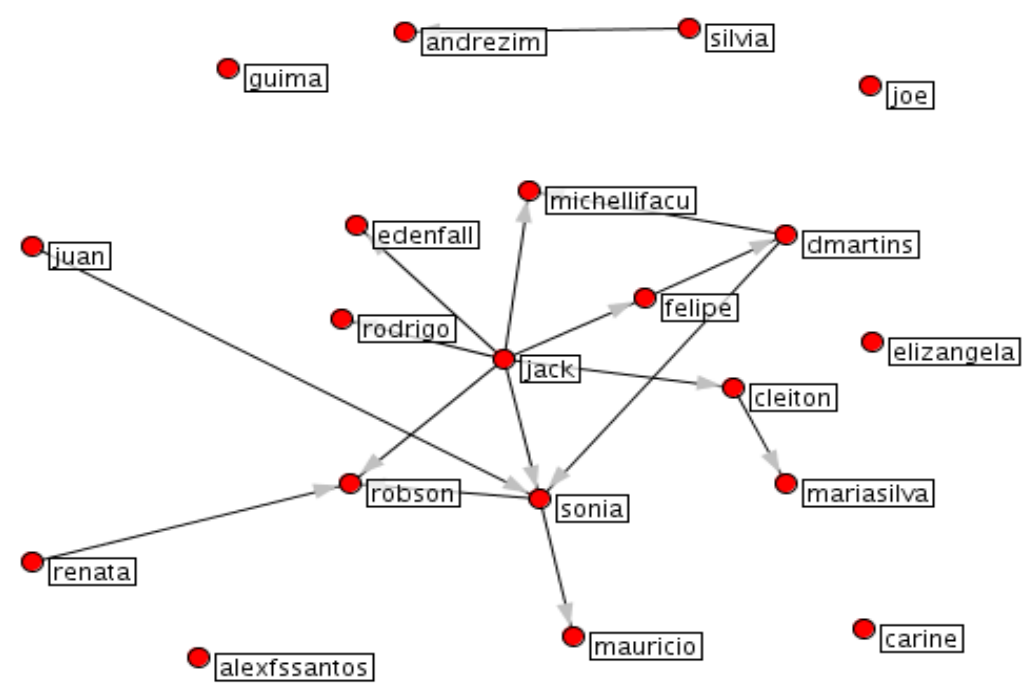

Figura 2.1. Exemplo de sociograma

Um sociograma é uma imagem que revela visualmente a estrutura de conexão de um grupo de atores. Os pontos vermelhos da imagem representam os atores da rede, as linhas representam as conexões entre os atores, sendo que a ponta das setas indica o sentido da conexão, ou seja, que ator iniciou a conexão. O sociograma tornou-se uma importante ferramenta analítica na pesquisa de redes sociais, auxiliando a revelar diversas características estruturais de um grupo social, que 
apenas observando dados estatísticos seriam difíceis de perceber (Nooy, Mrvar, Batagelj, 2005, p. $5)$.

O surgimento da análise de redes sociais se dá, portanto, num encontro propício entre a teoria social e suas aplicações com o formalismo matemático, estatístico e metodologia computacional (Wasserman e Faust, 1994). Também culminam para a produção da teoria de análise das redes elementos da Psicologia Social, da Antropologia e da Gestalt, que considerava que o todo é maior que a soma das partes (Miranda, 2009). Parte fundamental deste singular encontro foi a possibilidade de utilização da teoria dos grafos como o formalismo matemático para o estudo das interconexões. É interessante notar que a teoria dos grafos, publicada em 1736 por Leonhard Euler, se constituiu como um ramo da matemática que estuda as relações entre objetos de um determinado conjunto e surgiu do propósito de resolver o problema de como atravessar todas as pontes que conectavam duas ilhas sem repetir nenhuma, um típico problema de otimização na engenharia.

A aplicação de conceitos da Dinâmica e da Complexidade de Sistemas, sobretudo a partir do final da década de 90, revolucionaram a maneira como os estudos de rede vinham sendo orientados, quando começam a considerar os efeitos do tempo: as redes antes eram vistas como pura estrutura, sendo que suas propriedades eram entendidas como fixas no tempo (Watts, 2003). Um novo olhar permitiu compreender as redes como algo dinâmico, como sendo composta de elementos vivos que atuam modificando a estrutura da rede a partir do padrão de suas interações. As redes evoluem e mudam com o tempo, podendo ser compreendidas como sistemas dinâmicos. No contexto das redes sociais, as comunicações puderam ser estudadas como ciclos múltiplos de retroalimentação (feedback) produzindo um sistema compartilhado de crenças, explicações e valores (Capra, 2008, p. 23). Compreensão fundamental, pois permitiu a introdução de vários novos dispositivos e possibilidades de análise para o estudo das redes sociais.

A rede, vista como estrutura e dinâmica formada pelas relações existentes entre seus objetos constituintes, agora encontra o formalismo matemático que permite criar novas metáforas de organização e análise da informação, favorecendo sua utilização como um operador metodológico a ser utilizado em diversos estudos de interesse da pesquisa científica.

\subsection{A estrutura e a dinâmica das redes}

O surgimento do estudo formal da análise de redes sociais esteve ligado com a teoria social e com formalismos matemáticos que embasavam a pesquisa da relação entre objetos de um determinado conjunto, como vimos no item 2.2 deste capítulo. Esse formalismo inicial esteve influenciado conceitualmente por uma visão estruturalista da sociedade (Waaserman e Faust, 1994, 
p. 5), que buscava explicar a sociedade não apenas a partir de seus elementos, mas sim a partir da estrutura formada pelas relações entre esses elementos.

O estruturalismo se manteve como o enfoque principal da análise de redes até final dos 90 e começo dos anos 2000, quando a chegada de novos métodos oriundos da dinâmica e complexidade de sistemas começaram a ser utilizados, trazendo novos resultados e alargando os horizontes da pesquisa em análise de redes. Vale a pena ressaltar que a chegada de novos métodos de análise se deve, principalmente, ao fato de que grandes bases de dados relacionais estavam disponíveis e que os métodos tradicionais de análise de redes não davam conta de tratar problemas complexos dessa ordem. As primeiras bases de dados utilizadas para o estudo de aspectos dinâmicos das redes foram as tabelas de roteamento entre servidores na Internet e os padrões de links entre páginas Web (Barabasi, 2003). Sem dúvida, nunca antes na história da ciência, bancos de dados relacionais contendo conexões da ordem de milhões estiveram disponíveis, como estiveram a partir do final dos anos 90. Apesar disso, a visão estruturalista não deixou de ter importância e continua sendo uma linha utilizada pelos pesquisadores, dependendo do contexto do problema que desejam estudar.

A questão chave da pesquisa estruturalista é que ela enfocava as redes como sendo formadas de pura estrutura com propriedades que não se modificam ao longo do tempo (Watts, 2003). As questões da pesquisa estruturalista tinham por objetivo investigar qual era a estrutura formada por uma determinada rede e classificar seus atores conforme as diferentes posições que poderiam ocupar dentro dessa estrutura, utilizando para isso diversos modelos matemáticos. Essa classificação de posições permitiria identificar diferentes níveis de influência dos atores na estrutura, basicamente determinando atores centrais, intermediários, periféricos, laços fortes e fracos entre eles, além da possibilidade de identificação de sub-grupos constituindo zonas de articulação dentro da rede.

A identificação de sub-grupos se tornou um tema de grande interesse pois dispõe de métodos para investigar grupos dentro de uma rede que apresentam um padrão de interatividade entre si que difere de como se relacionam com o restante da rede. A crença na investigação dos sub-grupos, dentro da visão estruturalista, é de que interação social é a base para solidariedade, compartilhamento de normas e comportamento coletivo. Espera-se encontrar maiores semelhanças entre pessoas que interagem mais entre si do que com outras dentro do contexto de uma rede (Noor, Mrvar e Batagelj, 2005, p. 61). Outra questão de interesse relacionada a identificação de subgrupos, é a capacidade de identificação de atores que servem como pontes entre sub-grupos. São os chamados conectores. Acredita-se que eles têm alta capacidade de influência, pois podem servir de elementos que transmitem informação de um grupo para o outro dentro de uma rede. 
A visão estruturalista da análise de redes sociais teve grande repercussão na ciência, influenciando a pesquisa em diversas áreas (Wasserman e Faust, 1994, p. 5), tais como:

- mobilidade ocupacional;

- impacto da urbanização no bem-estar individual;

- o sistema político e econômico mundial;

- tomada de decisão por comunidades;

- apoio social;

- comunidades;

- resolução de problemas em grupo;

- difusão e adoção de inovações;

- articulação corporativa;

- percepção cognitiva e social;

- mercados;

- sociologia da ciência, bibliometria;

- poder e influência;

- consenso e influência social

- formação de coalizões.

Um estudo fundamental sobre a perspectiva das estruturas sociais foi realizado por Barry Wellman (1983). Em busca de realizar uma síntese dos principais desenvolvimentos da análise estrutural das redes sociais, distinguindo suas características e princípios analíticos, Wellman posiciona a análise como um modo de pensar sobre redes mais do que apenas um conjunto de métodos.

"Os analistas de redes tratam os sistemas sociais como redes de relações de dependência de recursos escassos localizados nos nós e a estrutura de alocação desses recursos nas conexões. Alguns analisam múltiplos tipos de conexão entre indivíduos de forma a estudar as formas complexas nas quais essas conexões conectam membros específicos do sistema social. Outros analisam poucos tipos de conexão em busca de estudar o padrão geral de um sistema social" (Wellman, 1983). 
A maneira de descrever os recursos alocados nos nós e a forma como a distribuição das conexões influencia a estrutura geral da rede é descrita por Wellman (1983) a partir de seis princípios analíticos que devem ser considerados na análise estrutural de redes sociais:

- as conexões são assimetricamente recíprocas, diferindo em conteúdo e intensidade: uma conexão de amizade entre uma pessoa não significa que é correspondida pela outra;

- as conexões ligam membros direta e indiretamente, dado que podem ser analisadas em contextos de redes maiores: a análise de uma rede pode sempre ser expandida, dado que podemos ampliar o olhar e observar como as conexões de uma determinada camada se organizam em relação a outras camadas;

- a estrutura das conexões sociais cria redes não-aleatórias, formando grupos, fronteiras e conexões cruzadas com outras redes: as estruturas são determinadas e determinam uma rede, sendo que configuram atributos característicos, permitindo a comparação entre redes;

- conexões cruzadas conectam indivíduos mas também subgrupos: as conexões não são analisadas apenas entre indivíduos numa rede, mas também entre os grupos dos quais os indivíduos fazem parte;

- conexões assimétricas e redes complexas distribuem os escassos recursos de formas particulares: os recursos não fluem de forma aleatória, podendo ser identificados caminhos preferenciais, padrões de conexão e interação;

- redes estruturam ações colaborativas e competitivas na articulação dos recursos escassos: grupos e indivíduos podem competir e/ou colaborar em relação a distribuição dos recursos finitos.

Os princípios de Wellman descrevem as principais características que devem ser levadas em consideração na análise estrutural das redes sociais. Auxiliam aos analistas a levarem em consideração que as redes a serem analisadas não são simples artefatos que evidenciam relações entre pessoas, mas devem incorporar em sua modelagem as tensões, as práticas, as formas e regularidades de organização social. As redes podem revelar e afirmar formas de relação ampliando a percepção da complexidade envolvida no estudo das relações sociais.

A abordagem de Wellman, na realização de seu estudo de síntese, deixa claro que a essência da análise de redes não se encontra nos métodos aplicados, mas no tipo de pergunta e resposta que se procura em termos da estrutura de conectividade de uma rede. Os tipos de conexão que serão analisadas determinam o enfoque do analista, sendo que as respostas que irá encontrar estarão 
dependentes dos dados coletados. A rede tem diversas faces, múltiplos níveis, muitas camadas que se entrelaçam produzindo deslocamentos individuais e coletivos. A análise serve como uma maneira de pensar, um modo de olhar para as camadas em que focamos nossa atenção num determinado momento.

Todos esses temas acima apresentados puderam ser estudados essencialmente a partir da aplicação da Teoria dos Grafos, do conceito de topologia e seus dispositivos de abstração e análise matemática a questões de interesse social (Pinto et al, 2009) (Parente, 2004, p. 100) . No entanto, um problema fundamental ainda não poderia ser tratado apenas dessa forma: faltava considerar o aspecto dinâmico das redes. Ao invés de considerar as redes como entidades que se desenvolvem sob a influência de forças sociais, os analistas estruturalistas tinham a tendência de tratar essas forças como fixas no padrão estrutural apresentado por uma rede. Deste ponto de vista, a estrutura da rede revelada por seus indicadores estruturais fornecia toda a informação social necessária para analisar o comportamento dos atores e suas respectivas relações de força em rede (Watts, 2003, p. $50)$.

A dinâmica de redes considera que os atores são entidades que evoluem ao longo do tempo. Suas propriedades e atributos mudam, assim como a maneira que irão interagir, levando a uma reconfiguração global da estrutura da rede quando analisada no tempo. É essa perspectiva que permite entendermos as redes sociais como sistemas dinâmicos, onde podemos ampliar o escopo de análise, não considerando apenas suas propriedades topológicas/estruturais, mas também suas propriedades dinâmicas. A dinâmica da rede surge como possibilidade de pesquisa quando observamos o processo que ocorre quando as conexões e atores surgem ou desaparecem da rede, indicando a maneira que a estrutura será alterada ao longo do tempo (Newman, Barabasi e Watts, 2006, p. 7).

A compreensão básica que emerge é que a estrutura afeta as conexões que um ator pode fazer e as conexões que um ator pode fazer afetam a estrutura da rede. Como se pode notar, não é um processo linear, com uma relação direta de causa e efeito. Denota um problema complexo, onde parte e todo se afetam mutuamente, gerando ciclos de realimentação que podem aumentar ou subtrair tendências que não poderiam ser previstas inicialmente. É essa a característica emergente das redes sociais, evidenciando a relação e interdependência da parte com o todo e do todo com a parte.

A visão dinâmica das redes tem influenciado importantes temas de pesquisa, onde tem sido aplicada nos últimos anos (Watts, 2004):

- dinâmica humana;

- contágio social e de doenças; 
- modelos de dinâmicas de sistemas;

- algoritmos de buscas de informações;

- sistemas robustos.

O objetivo maior da nova ciência das redes é entender como a estrutura de uma rede opera em nível global dependente de processos dinâmicos que operam em nível local. É uma visão que busca integrar macro e micro análise, considerando e integrando padrões dinâmicos e estruturais, podendo atuar em três níveis distintos de análise: macroestrutura, mapeando o contexto e sua evolução no qual uma rede está inserida, mesoestrutura, mapeando como a estrutura de uma rede é formada e como evolui ao longo do tempo, microestrutura, mapeando as especificidades estruturais e dinâmicas dos atores envolvidos diretamente na rede (Britto, 2008, p. 109) (Raider e Krackhardt, 2001). Questões relacionadas a como um padrão emergente ocorre, com que frequência ocorre e com que consequências, são pontos que podem ser resolvidos pela junção da abordagem estrutural e dinâmica, bem como da relação entre as duas (Newman, Barabasi e Watts, 2006, p. 7).

\subsection{Paradigma de estudo das redes sociais: princípios gerais}

Um paradigma de pesquisa científica pode ser entendido como um critério para a escolha de problemas, que, enquanto o paradigma for aceito, serão considerados como dotados de uma solução possível (Kuhn, 2005, p. 60). Compreender o paradigma de estudo das redes é, portanto, mapear quais são os critérios de pesquisa e como devem ser utilizados, facilitando o entendimento de que tipos de problemas podem ser potencializados pelo uso da metodologia de análise de redes sociais.

As interações humanas, quando recorrentes e conservadas ao longo do tempo, terminam por formar redes de interações, conjuntos compartilhados e reforçados continuamente de regras de conduta, que definem as características daquilo que chamamos de sistemas sociais auto-organizados (Maturana, 1997, p. 199) (Brown e Duguid, 1998). De uma certa forma, para que exista um sistema social as interações devem ser recorrentes, resultando em alguma forma de coordenação de condutas entre os membros participantes do sistema.

A questão imediata que nos colocamos é como identificar um sistema social quando estamos interessados no estudo dos padrões de interação que são produzidos e que produzem esse sistema. A identificação de um sistema passa por perceber quais são as unidades simples que o compõem, ou seja, aquilo que iremos denominar como sendo ora seus membros, seus atores ou mesmo seus nós. Ao identificar as unidades simples, o próximo passo é caracterizar a rede de interações entre essas unidades que produz o contexto do sistema. É o que permite identificá-lo como uma unidade 
composta, ou seja, o próprio sistema.

Segundo Maturana e Yáñez (2009, p. 134), "uma unidade composta existe e opera em dois âmbitos ou domínios de existência disjuntos, a saber, no âmbito ou domínio do operar de seus componentes e no âmbito ou domínio de seu operar como totalidade em interações no meio que a contém”. Logo, um sistema social opera no nível de suas unidades simples, ou seja, os atores que de alguma forma fazem parte do sistema, e no nível de sua unidade composta, ou seja, a totalidade formada pelos atores e suas redes de interações. As unidades simples permitem que identifiquemos comportamentos e características individuais dos membros de um sistema. A unidade composta surge quando passamos a considerar as relações. A distinção da unidade simples, composta e interações é condição fundamental para que possamos chamar algo de um sistema, seja ele social ou não, pois será isto que nos permitirá encontrarmos regularidades estruturais e dinâmicas entre sistemas (Bertalanffy, 1968, p. 33). O que nos permite chamar algo de um sistema social é o fato da interação entre seus membros ocorrem a partir do comportamento humano.

A unidade composta define a organização do sistema, ou seja, a configuração de relações entre seus componentes. Se esta configuração em um dado momento deixa de existir, a unidade composta deixa de existir, desaparecendo portanto aquilo que é caracterizado como um determinado sistema social. O contexto desaparece e as regras de conduta que configuravam o sistema social deixam de existir, podendo as redes de interações entre seus atores se reorganizarem de outra forma, compondo um novo sistema social. A maneira como a configuração de relações entre os componentes do sistema é expressa, ou seja, a manifestação da rede de interações entre as unidades simples que compõem o sistema, forma aquilo que denominamos por sua estrutura. A estrutura em um sistema pode ser variante, dinâmica e mesmo assim conservar em suas diferentes formas de manifestação a organização que caracteriza o sistema (Maturana e Yáñez, 2009, p. 131).

A rede de interações em um sistema social termina por constituir tendências e hábitos de padrões de relacionamentos entre seus atores quando o sistema é conservado ao longo do tempo. Ocorre que a percepção dessas tendências permite criar mecanismos de previsão dos movimentos futuros da rede, o que termina por estimular diferentes interesses dos mais diversos nas técnicas e metodologias de análise. São essas maneiras específicas de interagir que acabam por constituir uma estrutura típica, a forma das relações, e uma dinâmica típica, a maneira como as relações evoluem, características de um determinado sistema social. Investigar, portanto, quais são essas características através da estrutura e da dinâmica da rede de interações do sistema é uma maneira de descrevê-lo, de estudá-lo e compará-lo a outros sistemas em busca de padrões recorrentes ou distintos. 
As redes podem ser entendidas como um conjunto de objetos e suas relações. Os objetos são os componentes ou partes da rede, são as unidades simples que iremos considerar como membros da rede. Os atributos são as propriedades dos objetos. As relações entre os objetos é o que dá coesão a rede como um todo. A arte de descobrir que tipo de relações analisar depende exclusivamente do contexto de um dado conjunto de objetos e como estes se relacionam com o problema em estudo, sendo incluídas as relações importantes ou interessantes e excluídas as relações triviais ou supérfluas (Watzlawick, Beavin e Jackson, 1973, p. 109-110). É o foco de interesse que delimita como a metodologia pode ser utilizada, permitindo que diferentes recortes possam ser experimentados, influenciando que tipos de objetos serão entendidos como estando em relação, que tipos de atributos nos interessam para a categorização desses objetos e quais relações desejamos mapear para estudar a emergência de padrões entre os objetos.

A metodologia é tão flexível quanto o olhar do pesquisador, tornando-se um recurso importante de projeto e modelagem, facilitando o desenho de novos contornos, novas fronteiras que podem expandir o limite daquilo que podemos estudar. A contextualização do objeto ou do problema de estudo torna-se um exercício de ampliação de foco, nos levando a visualizar sistemas mais amplos e relações ainda não imaginadas. Vasconcellos (2009) sugere que as primeiras perguntas que poderiam facilitar essa percepção são: em que condições acontece o fenômeno no qual estou interessado? Como o vejo relacionado com outros elementos do sistema? Dessa forma, conseguimos retirar o foco exclusivo nos objetos, ampliando para que possamos considerar as relações. O centro da rede emerge como consequência do evento que se olha.

O que caracteriza as redes como redes sociais, portanto, é o uso dos objetos, atributos e relações da perspectiva de sistemas sociais, ou seja, formados por características originadas do comportamento humano. A partir dessa definição, alguns conceitos auxiliam na caracterização das redes sociais (Wasserman e Faust, 1994):

- os objetos são vistos como atores dentro da rede, sendo suas ações vistas como interdependentes, ao invés de unidades autônomas;

- as relações entre atores são canais para transferência ou fluxo de recursos, sejam eles materiais ou imateriais;

- modelos de rede evidenciam características individuais dos atores em relação ao ambiente da rede, explicitando oportunidades ou restrições para suas ações;

- modelos matemáticos e computacionais de rede conceitualizam estrutura e dinâmica (social, econômica, política, etc.) como emergentes do padrão de relação entre os atores. 
Os analistas de rede têm trabalhado em três direções no desenvolvimento de métodos para o estudo das estruturas sociais (Wellman, 1983): definindo populações e amostras de dados relacionais ao invés de alocação dos dados em categorias, modificando seus métodos analíticos de categóricos para relacionais e desenvolvendo métodos matemáticos e estatísticos para substituir as técnicas estatísticas individuais para análises relacionais. Vale ressaltar que os modelos matemáticos e computacionais de rede estruturais estão essencialmente baseados no uso da Teoria dos Grafos $^{5}$ e os modelos dinâmicos baseados no uso da Física Estatística ${ }^{6}$ e Processos Estocásticos ${ }^{7}$.

Do ponto de vista da maneira que podemos categorizar os dados que utilizamos para análise de redes sociais, Christakis e Fowler (2010, p. 124) apresentam a distinção entre redes totalmente observadas e redes inferidas. Nas redes inferidas apenas podemos observar as interações realizadas que podem ser registradas de alguma forma, como nas relações de colaboração científica que se materializam numa co-autoria de um artigo científico. Esse tipo de rede nos permite analisar relações parciais, sendo que muitas das relações de colaboração não são registradas em nenhum tipo de sistema de informação. Nas redes totalmente observadas, conhecemos todas as relações existentes, como as relações de amizade num grupo de alunos dentro do âmbito de sua sala de aula, podendo analisar as relações realizadas e as relações em potencial.

Os tipos de dados que podemos observar dependem do tipo de técnicas que temos a disposição para coletá-los. Os dados para análise de redes podem ser coletados utilizando diversas técnicas, que podem ser utilizadas conforme o contexto do problema que desejamos estudar (Wasserman e Faust, 1994):

- questionários: técnica utilizada quando os atores envolvidos são humanos e não há sistemas de informação disponíveis que registrem as interações que desejamos estudar;

- entrevistas: são aplicadas em situações onde o uso de questionários não é viável, como, por exemplo, em casos onde as pessoas estejam distantes fisicamente e não possuam acesso a tecnologias da informação;

- observações: técnica utilizada quando observamos as relações entre os atores para coletar os dados, como, por exemplo, no estudo de padrões de relações entre crianças numa escola;

5 Teoria dos Grafos: ramo da matemática que estuda as relações entre os objetos de um determinado conjunto. Fonte: Wikipedia.

6 Física estatística: é o ramo da física que faz uso extensivo da estatística para analisar sistemas físicos de alta complexidade, via de regra devido a um elevado número de entes constituintes, o que dificulta ou mesmo impossibilita a análise acurada e detalhada de todos os aspectos do sistema. Fonte: Wikipedia.

7 Processos estocásticos: é uma família de variáveis aleatórias indexadas por elementos t pertencentes a determinado intervalo temporal. Fonte: Wikipedia 
- bancos de dados: técnica utilizada quando dispomos de sistemas de informação que registram o tipo de interação que desejamos estudar;

- outras técnicas e experimentos: estudos experimentais nos quais os dados são coletados sob situações controladas, estudos que levem em consideração a percepção de um ator sobre sua rede, entre outros.

A escolha do contexto sob o qual iremos proceder uma análise de rede é seguida pela forma como iremos categorizar e coletar os dados das relações entre os atores da rede. Uma das maiores dificuldades apontadas por diversos estudos (Brandes, Kenis e Raab, 2005), (Smeaton et al., 2003), (Newman, 2001a), (Newman, 2001a) e (Newman, 2004) é a obtenção de bases de dados que expressem amostras significativas das relações que pretendemos analisar.

Os principais obstáculos para uma análise de redes sociais são (Britto, 2008, p. 139):

- incompletude: dificilmente teremos sistemas de informação que registrem todas as relações sociais de interesse sobre um determinado contexto;

- limites imprecisos: a dificuldade de decidir quem deve ser incluído e quem não deve ser;

- dinâmica: essas redes não são estáticas, estando em contante mudança. Conseguir dados que registrem as séries históricas dessas mudanças torna-se um desafio a mais.

Dessa forma, a importância de atuarmos a partir de estruturas de coleta de informação que reflitam da forma mais abrangente possível o contexto e as relações sociais estabelecidas é fundamental para o bom desenvolvimento de uma pesquisa sobre redes sociais.

A ciência das redes está fortemente baseada na arte de descobrir que tipo de relações analisar, que tipos de dados observar e como podemos inferir informações úteis a partir dessas relações. É importante destacar, a partir deste ponto, que o elemento que une tantas áreas diferentes do conhecimento interessadas nos recursos da análise de redes sociais é o fato de que a identificação de padrões de relações formadas pelos objetos interagindo em rede é independente do tipo de conteúdo que flui por essas relações. Sejam elas constituídas por conversas entre pessoas, co-autoria em documentos, enzimas trocadas em um processo químico dentro de uma célula, conexões aéreas entre aeroportos ou as relações entre neurônios no cérebro quando estimulados por pensamentos específicos, o padrão que surge das relações pode indicar pistas de como operam em grupo e de como afetam os objetos individuais que constituem a rede em análise. 
O desenvolvimento contínuo de aplicações e experiências por parte das diversas áreas interessadas começam a evidenciar, quando integradas, um paradigma de pesquisa, que pode auxiliar a definir os critérios para escolhas de problemas (Freeman, 2004):

- análise de redes sociais é motivada por uma intuição de que as relações entre atores formam padrões emergentes que podem ser estudados;

- a pesquisa está fundamentada na sistematização de dados empíricos;

- a pesquisa utiliza intensamente recursos de visualização de imagens das redes;

- a pesquisa depende do uso de modelos matemáticos e computacionais.

Vejamos agora como os métodos estruturais e dinâmicos podem ser caracterizados para o uso em pesquisas relacionadas as redes sociais.

\subsection{Análise estrutural}

A análise estrutural é baseada na premissa de que o padrão de conexão formada por uma estrutura de relacionamentos humanos transmite comportamentos, atitudes, informações e bens, sejam materiais ou imateriais. Como maneira de viabilizar o estudo das estruturas, os primeiros cientistas que desenvolveram esse paradigma se deram conta do formalismo matemático fornecido pela Teoria dos Grafos, que poderia ser facilmente adaptado às relações humanas, fundando aquilo que veio a ser chamado de sociometria e, seu principal instrumento de pesquisa, o sociograma.

A teoria dos grafos data de 1736, quando Leonard Euler publica seu artigo sobre o problema das pontes de Konigsberg. O problema consistia em encontrar uma forma de como atravessar sete pontes que interligavam uma ilha com o continente (ver figura 2.2) de maneira a atravessar as pontes apenas uma única vez. Essencialmente um problema de topologia, da forma como visto por Euler, que consistia em encontrar uma forma possível de organizar o movimento no território.

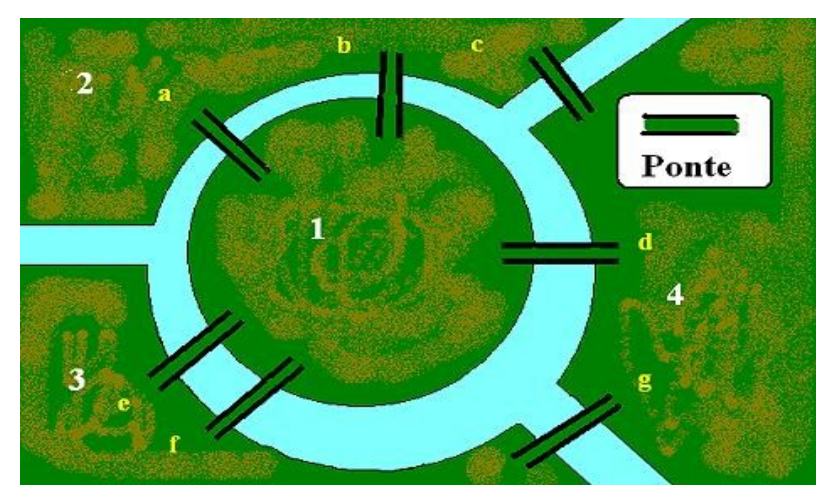

Figura 2.2. Pontes de Konigsberg. Fonte: Wikipedia 
A inovação na solução proposta por Euler, que acabou dando origem a Teoria dos Grafos, foi a maneira como ele imaginou modelar o problema para buscar uma solução. Sua modelagem transformou os caminhos em linhas e as pontes em vértices, como apresentado na figura 2.3.

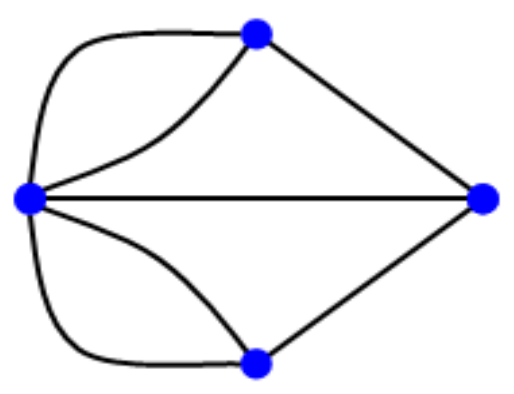

Figura 2.3. Grafo das Pontes de Konigsberg. Fonte: Wikipedia

A partir dessa forma de modelar o problema, criando um grafo para representá-lo, Euler pôde criar novas definições que pudessem descrever essa estrutura, utilizando-as para a produção de novos algoritmos matemáticos que permitissem caracterizar e resolver questões relacionadas ao padrão estrutural de um grafo.

Um grafo pode ser descrito como um conjunto de vértices e um conjunto de linhas que conectam esses vértices. Uma rede pode ser descrita, portanto, como sendo um grafo com informação adicional sobre os atributos dos vértices e das linhas que formam suas relações. Os vértices, do ponto de vista da análise de redes sociais, podem ser pessoas, sendo seus atributos características individuais como idade, sexo, profissão, instituição de origem, país, entre tantos outros que considerarmos relevantes para a pesquisa que desejamos realizar. A mesma flexibilidade vale para as relações, pois seus atributos podem definir qualquer característica que permita estabelecer alguma forma de vínculo entre duas pessoas, tais como a publicação de um artigo em co-autoria, a troca de emails, uma relação de amizade, intercâmbios comerciais, entre outros.

Dessa forma, vemos que a teoria dos grafos é útil para a análise de redes sociais nos seguintes aspectos (Wasserman e Faust, 1994, p. 93):

- fornece um vocabulário que pode ser utilizado para nomear muitas propriedades das estruturas sociais;

- fornece um conjunto de operações matemáticas e ideias sobre como essas propriedades podem ser quantificadas e mensuradas;

- fornece o rigor matemático necessário para a produção de teoremas e simulações relacionadas a padrões que representem estruturas sociais. 
Os grafos podem ter como propriedades valores que permitam caracterizar tanto os atores quanto as relações envolvidas.

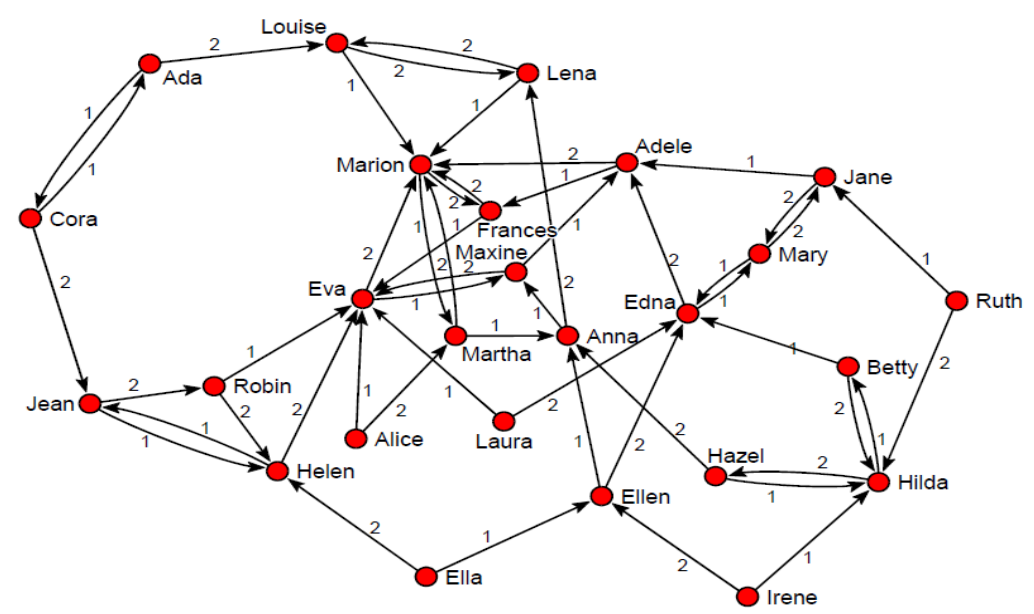

Figura 2.4. Atributos dos atores e relações. Fonte: Nooy, Mrvar, Batagelj (2005).

$\mathrm{Na}$ figura 2.4, os atributos dos atores são representados por seus nomes ao lado de cada vértice do grafo e os atributos das relações são apresentados como números em cima da linha de conexão.

Os vértices receberam como parâmetro o nome dos atores da rede, podendo receber qualquer tipo de parâmetro que for necessário para caracterizá-los. É importante destacar que os atributos de um vértice podem ser múltiplos, como nome, idade, sexo, organização, país de origem, entre outros, permitindo que possamos investigar múltiplas características entre atributos que o padrão estrutural de uma rede pode apresentar.

O significado do atributo das linhas, neste caso, indica a quantidade de vezes que um ator entrou em contato com o outro, indicando o sinal da seta quem originou a conexão com quem. No entanto, poderia representar outro aspecto relacional qualquer, como o número de vezes que trabalharam juntos em um projeto, por exemplo. Os atributos das linhas de um grafo também podem ser múltiplos, muitas das vezes modificando todo o padrão estrutural de uma rede quando observamos outras características de relações entre os atores, como, por exemplo, a diferença que poderia surgir entre o padrão de amizade e de relacionamento profissional entre moradores de uma comunidade.

As linhas que representam as relações nem sempre precisam indicar a direção da relação, apontando quem a origina e quem a recebe. Redes onde a direção é indicada são chamadas de redes direcionais e, onde não são indicadas, são chamadas de não-direcionais. A disponibilidade da informação de quem origina uma conexão e quem a recebe varia muito conforme o contexto da rede que estamos analisando, podendo fazer ou não sentido esse tipo de direcionamento. Por exemplo, 
numa lista de emails podemos identificar quem envia email para quem, gerando uma rede direcionada. Numa relação de co-autoria, podemos presumir que a relação de colaboração não é direcionada, simplesmente indicando que dois ou mais autores trabalharam juntos.

Em termos formais matemáticos, esse atributos são organizados em forma de matrizes. As colunas da matriz organizam as relações entre atores, bem como os atributos de cada relação estabelecida, como apresentamos na tabela 2.1.

\begin{tabular}{|c|c|c|c|c|c|}
\hline \multicolumn{1}{|c|}{ Pesquisador1 } & Pesquisador2 & FonteAbrev & FonteInstituicao & Relação & TipoDeRecurso \\
\hline CiciliaMKrohlingPeruzzo & JoseBeneditoPinho & AnurioLUSOCOM & LUSUCOM & Co-Autor & Anuário \\
\hline CiciliaMKrohlingPeruzzo & AdilsonOdairCitelli & BDTDPortaldoSaberUSP & USP & MembroBanca & Dissertação/Tese \\
\hline CiciliaMKrohlingPeruzzo & MarialmmacolataVassallodeLopes & BDTDPortaldoSaberUSP & USP & MembroBanca & Dissertação/Tese \\
\hline CiciliaMKrohlingPeruzzo & AdolphoCarlosFrancosoQueiroz & BDTDUMESP & UMESP & MembroBanca & Dissertação/Tese \\
\hline
\end{tabular}

Tabela 2.1. Exemplo de matriz de relações e atributos.

A matriz acima apresenta as relações estabelecidas entre Pesquisador1 e Pesquisador2, caracterizando como atributos desses atores seus nomes, e como atributos dessas relações, a fonte de onde relação foi extraída (FonteAbrev), a instituição de origem de onde a relação foi estabelecida (FonteInstituicao), o tipo de relação que está sendo caracterizada (Relação), bem como o tipo de recurso que foi produto dessa relação (TipoDeRecurso). Para explicitar uma relação de prioridade, por exemplo, a ordem em que aparecem os nomes dos pesquisadores (1 e 2) poderia indicar uma eventual relação de hierarquia, por exemplo, do orientador de uma tese e seu orientando. Essa relação de hierarquia poderia ser modelada na rede, por exemplo, considerando que o pesquisador1 inicia a relação com o pesquisador2.

Como mencionamos no item 2.4 deste capítulo, a arte da ciência das redes se encontra exatamente em determinar que tipos de atores, relações e atributos iremos coletar para a realização de um estudo. Dependendo da escolha, principalmente se as relações e atributos ainda nunca foram estudados com as características que iremos investigar, novos padrões podem emergir, dando pistas de novas maneiras de entender as estruturas formadas pelo complexo relacionamento humano.

Após a coleta e sistematização dos dados em matrizes, a análise estrutural utiliza diversas operações matemáticas para mensurar os padrões da rede em análise. Veremos a seguir os tipos de cálculos estruturais que são utilizados no estudo das redes sociais.

\subsubsection{Cálculos estruturais}

Todos os cálculos estruturais abaixo representados são baseados em operações matemáticas oriundas da Teoria dos Grafos. 
A densidade de uma rede é representada por uma taxa, indicando o número de linhas (conexões) presentes numa rede dividida pelo número máximo de conexões que poderiam ser realizadas se todos os atores estivessem conectados a todos os atores.

A densidade de uma rede é calcula pela fórmula apresentada na figura 2.5, a seguir, onde $\boldsymbol{L}$ representa o número de conexões e $\boldsymbol{g}$ representa o número de vértices presentes no grafo.

$$
D=2 \cdot L / g \cdot(g-1)
$$

Figura 2.5. Densidade da rede.

O valor da densidade da rede pode ser utilizado como um parâmetro de comparação entre diferentes redes, permitindo avaliar a diferença global do padrão de conectividade que apresentam. Em tese, a densidade nos mostra o potencial de conexões realizadas e aquelas que ainda poderiam ser estabelecidas em uma rede.

A distância entre dois nós de uma rede é determinada como sendo o caminho mais curto entre esses nós. O diâmetro de uma rede é representado pelo tamanho do maior caminho existente entre dois nós, denotando a maior distância a ser percorrida dentro de uma rede. O diâmetro é também chamado de distância geodésica. É um indicador que auxilia a mensurar a quantidade máxima de passos necessários para, num cenário ideal, uma informação qualquer percorrer todos os nós de uma rede.

Já partindo para medidas que caracterizam os nós da rede, a forma que permite analisar o número de conexões de cada nó é chamada de centralidade. A medida de centralidade tem por objetivo investigar quais seriam os atores mais importantes que estão presentes em uma rede. A hipótese utilizada para o grau de importância de um ator é de que quanto mais relações e articulação de relações um ator tenha, mais importante ele é para o padrão estrutural que é denotado pela rede (Wasserman e Faust, 1994, p. 169).

Há três medidas que são utilizadas para o cálculo de centralidade dos vértices: grau de centralidade da rede, grau de centralidade por interposição (betweenness) e o grau de centralidade por proximidade (closeness) (Fellman e Wright, 2008, p. 145).

O grau de centralidade da rede representa o número de linhas incidentes em um vértice do grafo, ou seja, o número de conexões diretas que um determinado ator estabelece dentro de sua rede. A fórmula do grau de centralidade é apresentada na figura 2.6, onde $\boldsymbol{d}(\boldsymbol{n i})$ representa a proporção de vértices que estão conectados ao nó que desejamos calcular o grau de centralidade, e $g$ representa o número de vértices totais da rede. 


$$
C_{D}\left(n_{i}\right)=d\left(n_{i}\right) / g-1
$$

Figura 2.6. Grau de centralidade da rede

O grau de centralidade por interposição (betweenness) representa a habilidade de um indivíduo de se conectar aos círculos importantes da rede (Fellman e Wright, 2008, p. 145). A interposição é uma característica "entre", que denota o grau de centralidade que um vértice se encontra em relação as principais rotas por onde os fluxos de uma rede são estabelecidos. A fórmula do grau de centralidade por interposição é apresentada na figura 2.7. É calculada com base na probabilidade de que a comunicação entre o ator $\boldsymbol{j}$ e o ator $\boldsymbol{k}$ tomem o mesmo caminho. O membro $g_{j k}$ representa o número de caminhos mais curtos que existem entre dois atores. Lembrando que podem existir diversos caminhos que conectam dois atores quaisquer numa rede, o caminho mais curto é o menor número de linhas que precisam ser atravessadas para se chegar de um ator ao outro. Pode existir mais de um caminho entre dois atores que sejam os mais curtos entre eles, contendo o menor número de passos cada um. O membro $g_{j k}\left(n_{i}\right)$ representa o número de caminhos mais curtos que interliga dois atores e que passam pelo ator $i$, o qual estamos calculando o grau de centralidade por interposição.

$$
\begin{aligned}
& \qquad C_{B}\left(n_{i}\right)=\sum_{j<k} g_{j k}\left(n_{i}\right) / g_{j k} \\
& \text { Figura 2.7. Grau de centralidade por interposição }
\end{aligned}
$$

O grau de centralidade por proximidade (closeness) representa a habilidade de um indivíduo monitorar o fluxo de informação e enxergar o que está acontecendo na rede (Fellman e Wright, 2008, p. 145). A proximidade é uma característica “com”, que denota o grau de centralidade (o quão próximo), que um vértice se encontra em relação aos principais atores que estabelecem os fluxos de uma rede. A fórmula do grau de centralidade por interposição é apresentada na figura 2.8. O membro $d\left(n_{i}, n_{j}\right)$ representa o número de linhas que existem no menor caminho que conecta o nó $\boldsymbol{i}$ e $\boldsymbol{j}$ dentro da rede.

$$
C_{C}\left(n_{i}\right)=1 /\left[\sum_{j=1}^{g} d\left(n_{i}, n_{j}\right)\right]
$$

Figura 2.8. Grau de centralidade por proximidade

As três medidas de centralidade apresentadas acima, podem ser utilizadas para mensurar o grau de centralidade de cada ator na rede, criando três critérios possíveis para que se possam categorizar e comparar esses atores entre si. Tornam-se os instrumentos de mensuração que são 
utilizados para identificação dos atores mais importantes que compõem uma rede, a partir do critério de importância por centralidade.

O quão semelhantes são os nós de uma rede é algo a ser explorado pela medida de equivalência estrutural, sendo uma aplicação da teoria dos grafos com o objetivo de identificar nós que compartilhem o máximo possível de características estruturais dentro da mesma rede. Essa identificação tem por base mapear atores que possuem papéis muito semelhantes, permitindo inferir intercâmbio de responsabilidade e de papéis compostos pela atuação desses atores.

Há dois aspectos importantes que precisam ser levados em consideração quando da aplicação da equivalência estrutural na análise de redes. Podemos identificar posições sociais como grupos de atores que compartilham significativas semelhanças estruturais e, sobretudo, podemos modelar posições sociais como um sistema de conexões entre atores e entre as posições que estes representam (Wasserman e Faust, 1994, p. 351). A equivalência estrutural pode nos auxiliar a caracterizar diferentes papéis que são exercidos nas redes.

Tecnicamente, dois atores são idênticos numa rede se eles compartilham as mesmas conexões com todos os outros atores da rede. Uma das formas de calcular a equivalência estrutural entre dois atores é medir a Distância Euclidiana entre eles, ou seja, a somatória da distância que possuem em relação a todos os outros atores da rede. A fórmula de cálculo da Distância Euclidiana é apresentada na figura 2.9, onde o fator $x$ representa a distância entre os dois atores.

$$
d_{i j}=\sqrt{\sum_{k=1}^{g}\left(x_{i k}-x_{j k}\right)^{2}-\left(x_{k i}-x_{k j}\right)^{2}}
$$

Figura 2.9. Distância euclidiana entre dois atores na rede.

Vale ressaltar que é fundamental analisar com cuidado várias das características estruturais de uma rede, inclusive comparativamente, antes de se tomar conclusões, que podem se mostrar apressadas e errôneas, a respeito da importância de um determinado ator. O significado do grau de centralidade deve ser analisado sempre em relação ao contexto social da rede.

A participação de pessoas em eventos, organizações, clubes ou frequentando os mesmos lugares é uma importante fonte de conexões sociais, podendo mesmo formar círculos sociais que possuem características específicas (Nooy, Mrvar, Batagelj, 2005, p. 101). A análise estrutural de redes chama essas relações estabelecidas entre pessoas a partir da adesão aos mesmos espaços sociais de afiliação.

A afiliação expressa arranjos organizacionais e institucionais que podem afetar de forma significativa a estrutura social da qual esses arranjos fazem parte. As pessoas tendem a se filiar a 
vários desses arranjos organizacionais ao longo de sua vida, seja nas relações de trabalho, de lazer, de voluntariado ou mesmo no local onde moram. Muitas delas acabam por se tornar pontes que conectam diferentes organizações, possibilitando o intercâmbio entre elas, gerando zonas de influência, articulação e potencial mobilização social.

O conceito de afiliação está diretamente ligado a uma forma de categorização de grafos a partir de modos, também gerando aquilo que é chamado de redes bipartite. Nos grafos modo 1, os vértices são representados por relações diretas entre os atores na mesma rede. Todos os grafos que vimos até agora são modo 1 . Nos grafos modo 2, os vértices são divididos em dois conjuntos, o conjunto das organizações e o conjunto dos atores que se relacionam a essas organizações. Vemos um exemplo de rede modo 2 na figura 2.10, onde os vértices em amarelo representam instituições e os vértices em verde representam nomes de pessoas.

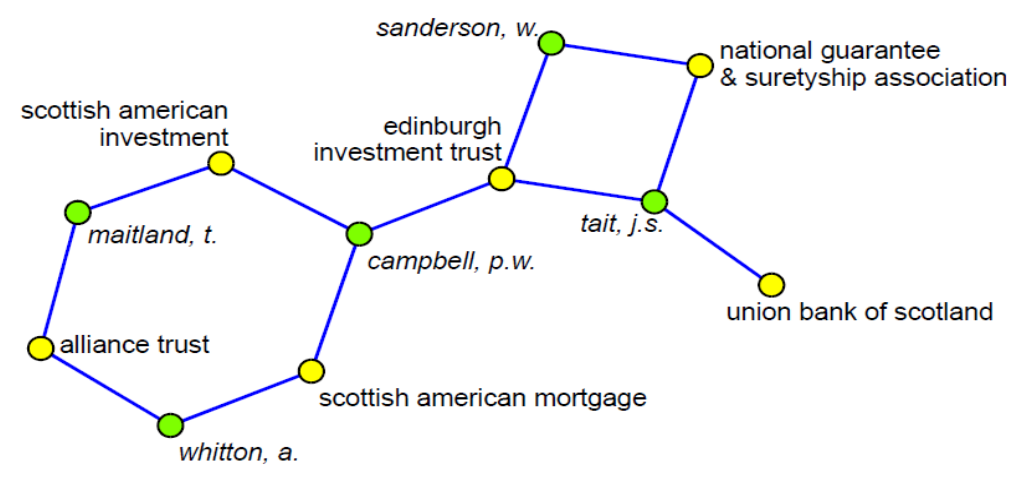

Figura 2.10. Exemplo de rede modo 2. Fonte: Nooy, Mrvar, Batagelj (2005).

Normalmente, os dados de afiliação das pessoas a grupos sociais não são tão difíceis de se obter, pois muitos eventos, clubes e organizações registram a participação de seus afiliados. O conceito de afiliação e a utilização de redes modo-2 é utilizado quando desejamos estudar a relação de um determinado grupo social com os arranjos organizacionais nos quais estão inseridos, ou quando desejamos avaliar como um grupo de organizações impacta e produz uma estrutura de articulação social. Os mesmos cálculos estruturais que vimos até aqui podem ser utilizados para as redes modo-2, havendo apenas ajustes necessários na distinção dos tipos de vértices presentes na rede.

Uma das formas utilizadas para simplificar a análise de redes modo-2 é transformar a rede em modo-1, como sugerem Nooy, Mrvar, Batagelj (2005) e Wasserman e Fauts (1994). A transformação se dá quando mantemos apenas um tipo de vértices na rede, transformando o outro tipo nas linhas que conectam dois vértices. Como exemplo, imagine que na figura 2.10, os vértices verdes serão transformados em linhas. A relação entre a alliance trust e scottish american mortgage 
existe apenas por que o ator (whitton, a) está em conexão com essas duas organizações. Numa transformação para modo-1, o vértice (whitton, a) viraria uma linha que conectaria as duas organizações. No entanto, vale ressaltar, esse tipo de projeção reduz a quantidade de informação disponível para análise, o que deve ser levado em consideração.

\subsubsection{Comunidades e subgrupos}

Um dos usos frequentes da análise de redes sociais é a identificação de comunidades e subgrupos dentro de uma rede. O interesse na investigação de subgrupos está baseado na hipótese de que eles podem revelar características específicas da estrutura social da qual pertencem, evidenciando estruturas de articulação, de tomada de decisão, de identidades e características culturais compartilhadas.

Os cálculos estruturais apresentados acima são utilizados como base na mensuração e caracterização das áreas de uma rede que podem ser distinguidas como formando comunidades dentro da própria rede. Diferentes abordagens de como uma comunidade é formada na estrutura da rede são utilizadas.

As medidas de centralidade podem ser aplicadas para a distinção de duas zonas dentro de uma rede: centro e periferia. $\mathrm{O}$ centro da rede seria representado pelos atores que possuem maior centralidade, logo estabelecendo as principais relações de articulação que são responsáveis pelo padrão estrutural da rede. A periferia da rede seria representada pelos atores que possuem menor centralidade, realizando conexões pontuais, normalmente com elementos que pertencem ao centro da rede. Vejamos um exemplo de como essa distinção pode ser aplicada a um sociograma na figura 2.11 , onde o centro é caracterizado pelos vértices em azul e a periferia em verde.

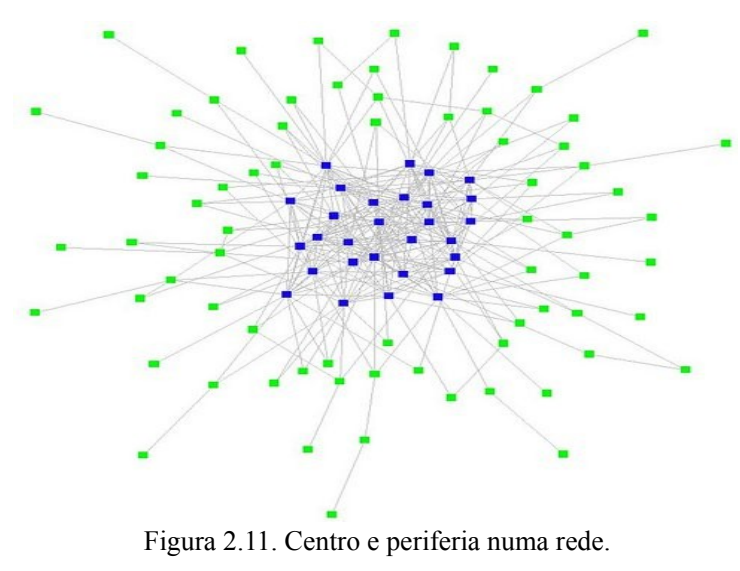

A distinção centro e periferia pode ser utilizada em estudos onde pretendemos identificar grupos de atores que são mais importantes e grupos que são periféricos a um determinado contexto de relações. O critério que estabelece quais são os atores que fazem parte do centro e da periferia da 
rede podem ser variáveis, dependendo apenas das características que o pesquisador deseja evidenciar. As três medidas de centralidade podem ser utilizadas para a construção desses critérios, indicando cada uma um tipo diferente de centro e periferia, que pode ser utilizado pelo pesquisador para apresentar diferentes níveis de importância dos atores de uma rede.

Uma outra forma de observar comunidades é através da análise de seus componentes. Os componentes de uma rede são partes da rede que se encontram isoladas de todas as demais. Nem sempre todos os atores da rede estão conectados formando apenas um único componente, podendo apresentar setores que se encontram isolados. Vejamos um exemplo na figura 2.12.

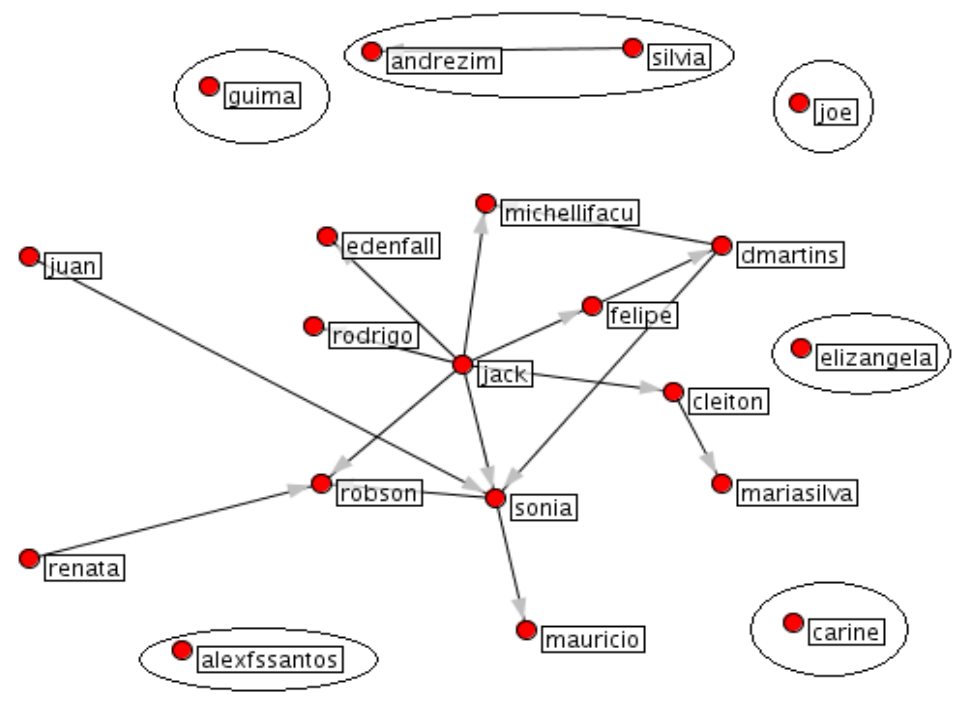

Figura 2.12. Componentes de uma rede.

A rede da figura 2.12 possui sete componentes. Os componentes estão selecionados pelas elipses na figura, além do componente central, que representa a maioria das conexões da rede. Observamos que cinco componentes da rede são atores isolados, não tendo estabelecido nenhuma conexão, um componente mostra a conexão entre dois atores e um componente representa aquilo que poderíamos considerar o núcleo da rede, apresentando um maior nível de integração entre os atores.

Uma rede pode ser classificada também por componentes fortes e fracos. Para entender como essa classificação ocorre, utilizaremos alguns conceitos de base da Teoria dos Grafos.

Uma semicaminhada (semiwalk) de um vértice $u$ a um vértice $v$ é uma sequência de linhas tais que o vértice final de uma linha é o vértice inicial da próxima, terminando apenas quando chegar no vértice $v$. Uma caminhada (walk) é uma semicaminhada considerando a informação adicional do direcionamento (a posição das setas numa conexão, como na figura 2.12) das conexões entre os vértices, ou seja, há uma conexão direta entre os vértices $u$ e $v$, de onde a primeira conexão 
parte de $u$ em direção a $v$ e assim consecutivamente, não havendo nenhuma inversão de direção das conexões. Um semicaminho (semipath) é uma semicaminhada na qual nenhum vértice entre o primeiro e o último vértice ocorrem mais de uma vez. Um caminho (path) é uma caminhada na qual nenhum vértice entre o primeiro e o último vértice ocorrem mais de uma vez.

Podemos considerar que uma rede pode ser chamada de fracamente conectada (weakly connected) quando cada par de vértices é interligado por um semicaminho. Uma rede pode ser chamada de fortemente conectada (strongly connected) quando cada par de vértices é interligado por um caminho.

A partir dessas definições, surge uma nova possibilidade de classificação dos componentes dentro de uma rede. Componente fraco (weak components) é uma subrede fracamente conectada. Componente forte (strong components) é uma subrede fortemente conectada. Vejamos um exemplo de componentes fortes na figura 2.13 .

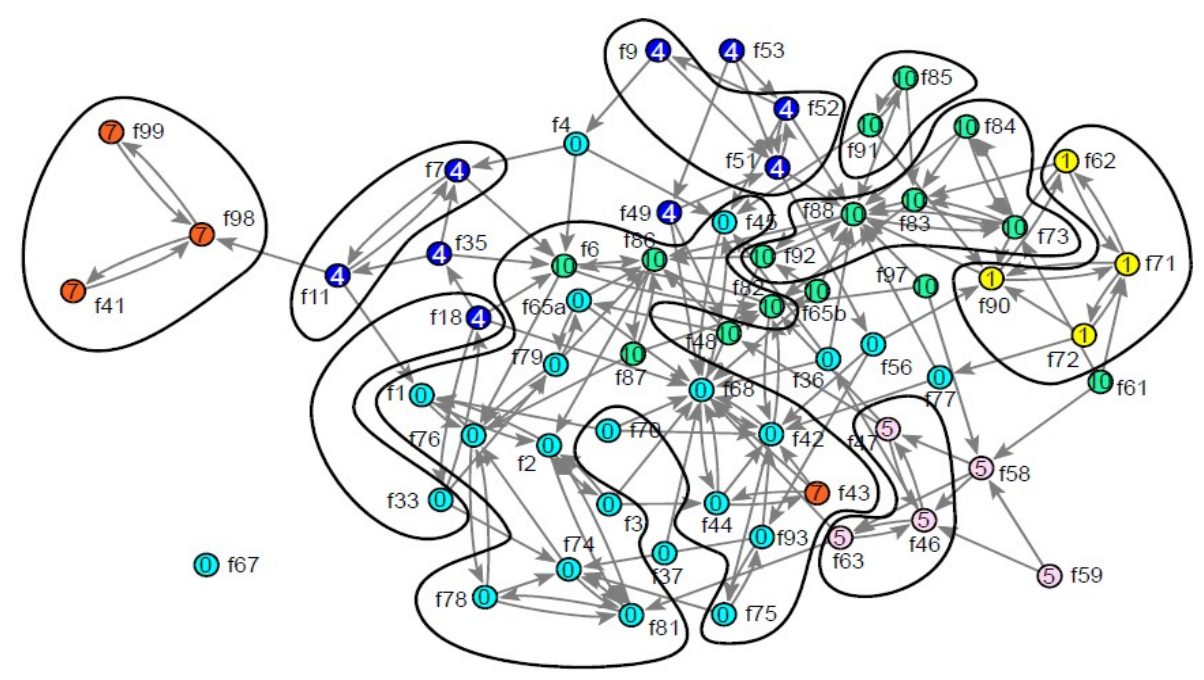

Figura 2.13. Componentes fortes numa rede. Fonte: Nooy, Mrvar, Batagelj (2005)

Os componentes estão selecionados pelo contorno na figura. É interessante notar que a classificação componentes fortes e fracos permite caracterizar regiões da estrutura de uma rede, ampliando o potencial de categorização de componentes de apenas regiões que não estão conectadas entre si. A busca de componentes na rede é feita através de algoritmos que permitem classificar essas diferentes regiões a partir dos conceitos de caminhada, semicaminhada, caminho, semicaminho e redes fraca e fortemente conectadas. Essa capacidade de distinção fornece um importante recurso a ser utilizado na análise estrutural quando queremos distinguir regiões de um grafo.

Uma outra forma utilizada para a identificação de comunidades e subgrupos na análise estrutural é a ideia dos cliques. Um clique é uma subrede completa que contém três ou mais vértices. Por subrede completa, entendemos todos os vértices conectados entre si. Em tese, indica 
uma subrede com máxima densidade de conexão entre os vértices. Vejamos um exemplo na figura 2.14 .

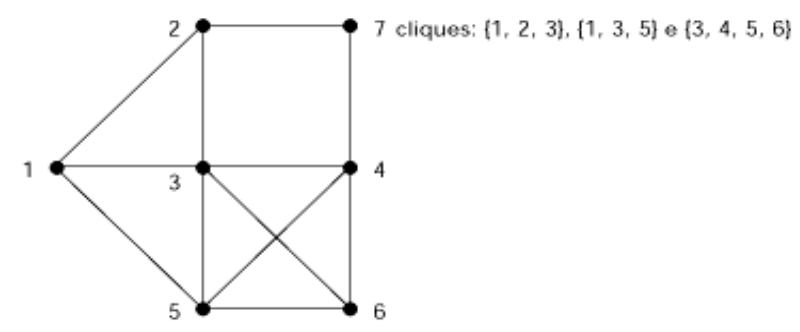

Figura 2.14. Cliques num grafo.

A figura indica a presença de três cliques, apresentando qual a sequência de conexões de vértices que formam esses cliques. É uma técnica que identifica zonas altamente densas dentro de uma rede, apresentando um padrão de interatividade total entre os atores envolvidos.

As técnicas m-slices e k-cores para identificação de subgrupos utilizam o número de conexões e o grau de centralidade dos vértices de uma rede.

Um k-core é um subgrafo onde cada vértice estabelece relação com um número mínimo $k$ de outros vértices dentro do subgrafo, ou seja, vértices que se relacionam possuindo o mesmo grau de centralidade. Vejamos um exemplo na figura 2.15, onde as linhas vermelhas denotam um subgrafo, onde os vértices possuem o mesmo grau três de centralidade.

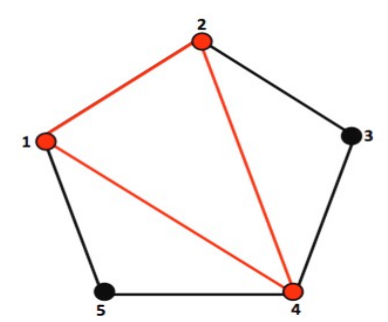

Figura 2.15. k-core de grau 3.

Um m-slice é um subgrafo contendo um número mínimo de linhas $m$ e os vértices que são relacionados por essas linhas. Vejamos um exemplo na figura 2.16, que apresenta um m-slice de nível três, onde observamos que o subgrafo contém três conexões entre os vértices representados.

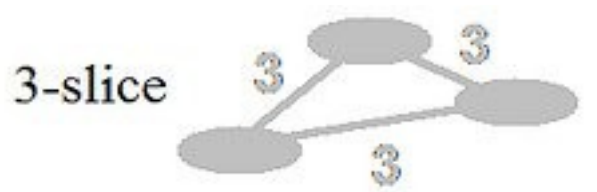

Figura 2.16. m-slices 1,2 e 3 . 
A diferença entre os dois é que k-core foca no grau de centralidade e m-slices no número de relações, apresentando duas formas diferentes de ressaltar padrões de interconectividade em rede. A hipótese é que grupos coesos em rede devem possuir um padrão de conectividade semelhante, que pode ser investigado ora pelo grau de centralidade, ora pelo número mútuo de conexões.

As técnicas de identificação de comunidades terminam por estarem relacionadas com técnicas de identificação de papéis de atores na rede. Vejamos como isso pode ser analisado. O broker, também chamado na literatura de $h u b$, é um papel estrutural que identifica algum tipo de relação de intermediação entre dois ou mais atores que um determinado ator desempenha na rede. Vejamos um exemplo na figura 2.17, onde podemos notar o papel de intermediação exercido por Jenny, Jack e John, como sendo os conectores entre as três subredes presentes no grafo.

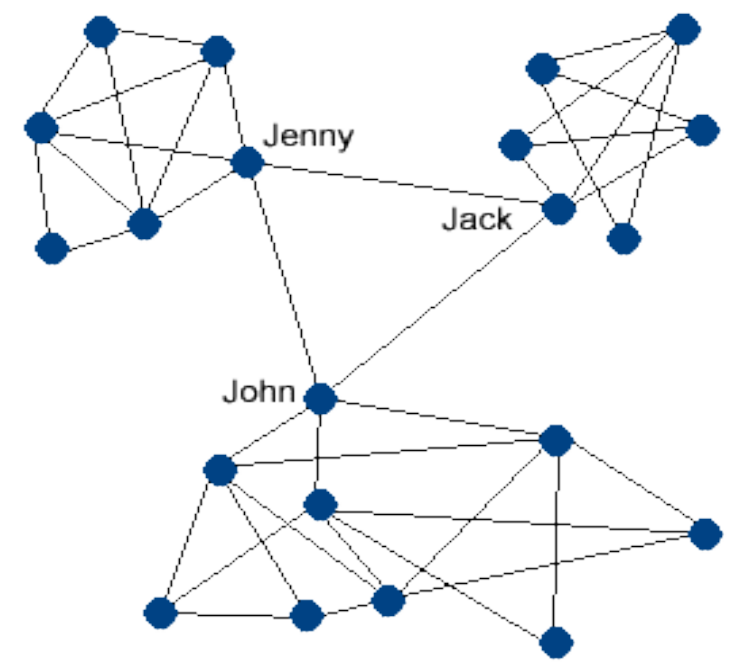

Figura 2.17. Brokers.

Uma outra forma de utilizar o conceito de brokers/hubs é no caso de considerarmos situações de afiliação. Nas redes de afiliação, consideramos que os vértices presentes numa rede podem fazer parte de diferentes organizações. Esse aspecto pode levar a diferentes papéis estruturais de intermediação entre atores numa rede. A variação depende do contexto em que os atores se encontram. Vejamos um exemplo na figura 2.18.
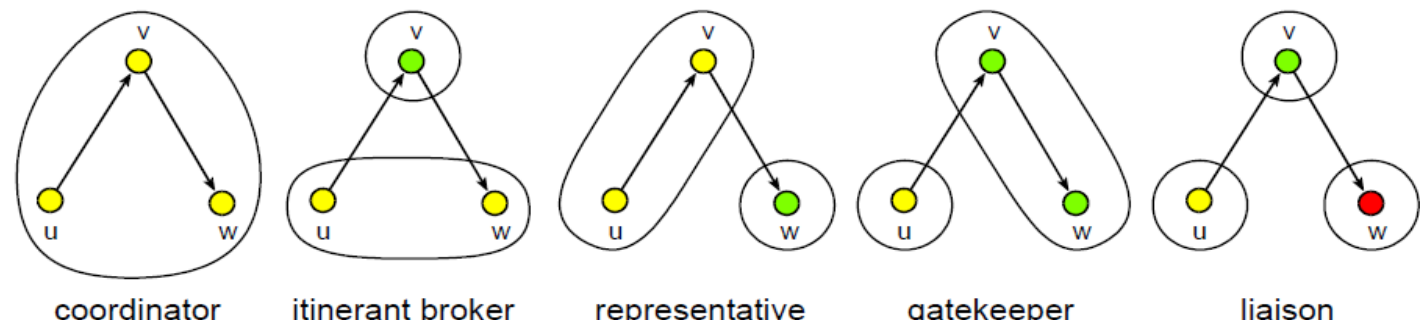

itinerant broker

representative

gatekeeper

liaison

Figura 2.18. Redes de afiliação e papéis estruturais de brokers em diferentes contextos. Fonte: Nooy, Mrvar, Batagelj (2005) 
$\mathrm{Na}$ figura 2.18, as cores indicam que os vértices fazem parte de organizações diferentes, sendo amarelo, verde e vermelho uma respectiva organização. Todas as posições são descritas a seguir em relação ao vértice V. No caso dos vértices serem membros da mesma organização, o papel de intermediação pode configurar uma relação de coordenação, onde um nó acessa o papel do coordenador para articular uma determinada interação. No caso dos vértices de um mesmo grupo utilizarem um broker de outro grupo, pode-se inferir uma relação de mediação, onde um ator externo articula dois atores internos. No caso onde dois membros de um grupo articulam um externo, ele pode atuar como um representante de seu grupo, enviando a informação a ser repassada. No caso onde é articulado por membros de um outro grupo, ele controla de alguma forma como a informação será repassada, operando essa relação de intermediação de seu grupo para fora. No caso onde articula dois grupos diferentes, ele passa a ter um papel de conexão entre esses grupos. Como podemos notar, o mesmo tipo de conexão pode representar papéis totalmente diferentes, apenas mudando o contexto de análise em que estamos operando quando mudam as organizações sob a qual cada nó atua.

Um ator ser um $h u b$ ou não depende fortemente do contexto das relações em rede que estamos investigando. Algoritmos podem indicar posições em potencial, a partir de uma análise de formação de subgrupos e que atores atuariam numa potencial articulação desses grupos. No entanto, o uso das técnicas de visualização de redes através da geração de sociogramas tornam-se fundamentais para que possamos avaliar qualitativamente se as conexões em potencial de fato indicam relações que deveriam ser investigadas mais a fundo, para confirmarem ou não papéis importantes de intermediação a serem considerados. Vale ressaltar que a pesquisa utilizando essas técnicas deve investigar de forma qualitativa o contexto de uma rede social, através de questionários e entrevistas, de forma a validar suas premissas encontradas na análise estrutural.

\subsubsection{Padrões estruturais}

A distinção entre espécies diferentes de estruturas de redes são devidas as diferenças nas distribuições dos atores e suas relações na qual eles tipicamente se engajam (Faust e Skovoretz, 2002). Essas distribuições acabam por representar tipos específicos de estruturas que se tornam recorrentes quando comparados diversos conjuntos de dados que representam redes sociais. Ao longo do tempo, analistas de redes sociais foram mapeando tipos de distribuições e criando denominações que se tornaram úteis na identificação de padrões e critérios de comparação entre diferentes tipos de redes, atores e relações. 
A variação no número de conexões que um nó recebe e gera numa rede direcionada pode gerar diferentes papéis estruturais para esse nós. Vejamos quais seriam (Wasserman e Faust, 1994, p. 128):

- isolado: se um nó não recebeu e não gerou nenhuma conexão;

- transmissor: se o nó apenas gerou conexões, não recebendo nenhuma;

- receptor: se o nó apenas recebeu conexões, não gerando nenhuma;

- ordinário: se o nó possui algumas conexões que gerou e outras que recebeu.

Já propriedades gerais de um grafo, foram exploradas no famoso experimento de Stanley Milgram (Milgram, 1967) realizado nos anos 60, através do envio de cartas para que pessoas enviassem diretamente ao destinatário, caso o conhecessem, ou as enviassem para alguém que consideravam que poderia conhecer sugeriu evidências de que o grau de distância médio entre duas pessoas na sociedade era algo em torno a 6 . A hipótese era que entre quaisquer duas pessoas haveriam apenas 6 outras entre elas, sugerindo pela primeira vez a expressão "mundos pequenos" para a caracterização das redes.

O experimento de Milgram foi refeito por Duncan Watts, Peter Dodds e Roby Muhamad (2003) em 2002 com 98 mil voluntários. Watts utilizou desta vez a Internet e substituiu o envio de cartas pelo envio de emails pelos voluntários, enviando a cada voluntário 18 possíveis alvos em 13 países diferentes. Os resultados da pesquisa confirmaram os dados de Milgram, mostrando que foram necessários em média 6 passos para que um email chegasse a outra pessoa. A distância de conexão máxima em uma rede social, sua distância geodésica, a partir dessas pesquisas, vem se confirmando como um padrão que gira em torno do número 6.

Christakis e Fowler (2010, p. 22) demonstraram que nosso potencial de influencia numa rede tem o poder de se disseminar por três graus de conexão a partir da posição em que um ator se encontra. Ou seja, um ator tem o potencial de contágio que pode ser percebido influenciando seus amigos, os amigos de seus amigos e os amigos dos amigos de nossos amigos. Quanto maior o número de caminhos que o conectam a outras pessoas numa rede, mais suscetível um ator se encontra à aquilo que flui pela rede.

Já a coesão estrutural de uma rede pode ser entendida como o número mínimo dos atores que, caso fosse removido, desconectaria o grupo (Britto, 2008, p. 151). A partir dessa definição, dois padrões estruturais são destacados:

- redes fortemente coesas: são redes que apresentam um nível de coesão que suplanta qualquer membro individual do grupo, não se tornando dependentes de um ou dois 
atores centrais. Em geral são redes mais robustas, pois para romper sua estrutura, separando os membros em vários componentes independentes, é preciso considerar que muitas conexões sejam rompidas.

- redes fracamente coesas: são redes que apresentam baixo nível de coesão, sendo fortemente dependentes de poucos membros centrais. Em geral são redes mais frágeis, pois podem romper em vários componentes independentes com a saída de poucos atores.

A pesquisa sobre padrões estruturais é uma área em contínuo desenvolvimento, sendo que podemos esperar novos padrões sendo descobertos, categorias e formas de classificação das redes como resultados futuros das pesquisas atuais.

\subsection{Análise dinâmica}

O paradigma de pesquisa da análise de redes sociais desenvolveu o estudo das regularidades estruturais ao longo de mais de 80 anos de pesquisas, desde a fundamentação da sociometria como um campo das ciências sociais a partir do início dos anos 30. A análise estrutural evidenciou importantes fenômenos ao estudar essas regularidades estruturais formadas pelas relações sociais. No entanto, o estudo das estruturas não nos informa sobre como surgiram, nem sobre a forma de organização de seus elementos, apresentando apenas um plano estático, uma espécie de retrato que mostra o estado atual da organização de uma rede (Levy, 2010, p. 173).

Em paralelo, a partir de outras áreas da pesquisa científica, a ciência aprimorava outros métodos que tinham por objetivo buscar sinais de ordem e auto-organização de elementos em relação numa rede. A Teoria Cinética dos Gases, desenvolvida no final do século 19, mostrava como as propriedades dos gases, da pressão a temperatura, poderiam ser reduzidas ao estudo do movimento aleatório dos átomos e moléculas. Nos anos 40 e 50, o desenvolvimento da cibernética e da Teoria Geral de Sistemas, trouxe o estudo dos padrões regulares em diferentes tipos de sistemas, apresentando conceitos como ciclos de retroalimentação, redes neurais e inteligência artificial, fundamentando a pesquisa que viria a produzir as bases conceituais dos modernos computadores e sistemas robóticos. Nos anos 60 e 70, pesquisadores desenvolveram importantes recursos para descrição e quantificação da transição de estados de desordem para estados de ordem de sistemas materiais, tais como a física dos fluídos. Nos anos 80, a Teoria do Caos demonstrou como comportamentos imprevisíveis poderiam surgir de interações não-lineares de poucos componentes num sistema. Nos anos 90, o estudo dos fractais demonstrou como padrões geométricos emergiam de sistemas auto-organizados, tais como folhas e flocos de neve (Barabasi, 2007). 
A ciência desenvolvia os princípios do estudo da dinâmica e da complexidade de sistemas. Inicialmente, voltada para a resolução de problemas essencialmente relacionados a Física, Matemática e Química, a dinâmica de sistemas começou a ser utilizada para o estudo de padrões dinâmicos em bases de dados que continham informações sobre relacionamentos sociais. Sendo uma área acostumada a tratar grandes massas de dados coletadas das pesquisas científicas, o surgimento da Internet e o desenvolvimento da Web, no final dos 90 e começo dos anos 2000, forneciam bases de dados ideais para a aplicação de novos métodos nos estudos das interações sociais. $\mathrm{O}$ fato é que os matemáticos e físicos possuíam nessa época bons recursos computacionais e métodos de pesquisa que não faziam parte do cenário habitual dos cientistas sociais até então, que normalmente trabalhavam em projetos com bases de dados menores e métodos analíticos mais simples (Watts, 2003, p. 28)(Barabasi et al., 2002).

Vale destacar que a disponibilização dessas bases de dados de interações sociais não foi um fato trivial. A web representa um dos maiores bancos de dados de interações sociais já existentes na história da humanidade, com documentos e conexões da ordem de bilhões, criando mais de trilhões de links de diferentes tipos de conexões.

A percepção que estabeleceu essa conexão entre diferentes áreas da ciência, levando a novos resultados e possibilidades promissoras de pesquisa retrata que as interações nos sistemas complexos formam redes, onde cada nó interage com um pequeno número de parceiros, sendo o efeito e a presença dessa interação sentido por vários nós distantes na rede (Barabasi, 2007). Aplicar essa abordagem a problemas sociais parecia natural.

O início da aplicação da dinâmica de sistemas ao estudo das redes sociais se deu quando os cientistas se deram conta de que assim como estudavam as transições de fase em sistemas físicos, como da água em seu estado líquido para a água em seu estado sólido, poderiam estudar movimentos, transições de fase entre os estados desconectado e conectado de um grafo (Watts, 2003, p. 65). Aqui surge um conceito fundamental sobre análise dinâmica que precisamos nos ater com mais cuidado para entender seus efeitos na análise de redes sociais. Para isso, vamos utilizar a figura 2.19, apresentada a seguir. 


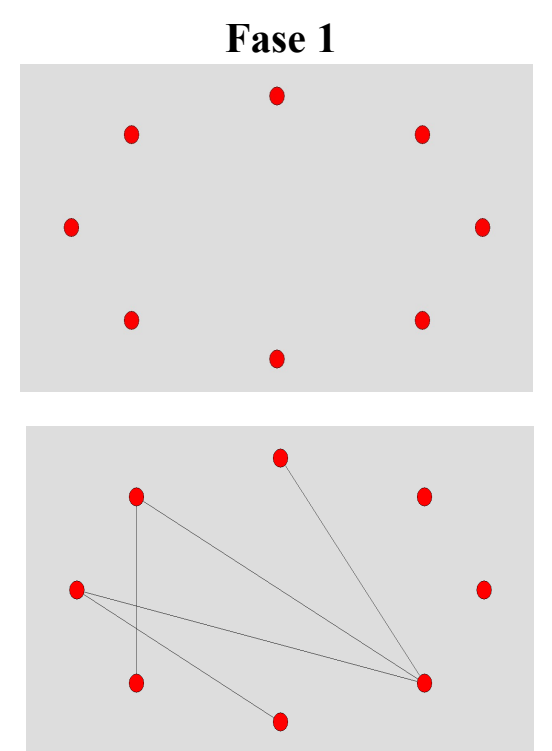

Fase 3
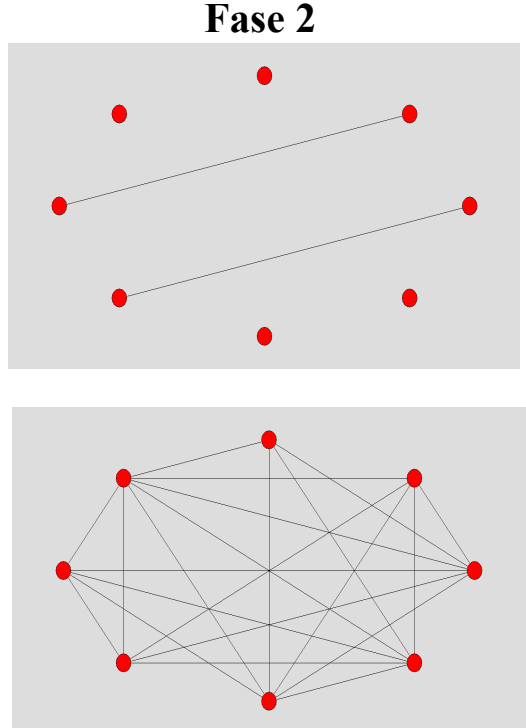

Fase 4

Figura 2.19 - Transição de fase num grafo

A figura 2.19 é divida em 4 partes, que chamaremos de 4 fases de formação do grafo. Para simplificar, estamos analisando apenas a dinâmica de formação de novas relações entre os 8 vértices do grafo, não considerando aqui a chegada de novos vértices na rede. $\mathrm{O}$ grafo de uma rede inicia na fase 0 , sem nenhuma conexão. $O$ processo dinâmico inicia na fase 1 , quando ao longo do tempo novas conexões vão sendo estabelecidas. Da fase 1 até a fase 3, o grafo ainda é formado de vários componentes independentes, apenas formando um único componente, onde todos os vértices estão conectados, na fase 4. Do ponto de vista dos cientistas físicos, o que emerge ao longo desse processo é uma transição de fases do sistema, indo da fase desconectado até conectado. Representa a formação de um componente que unifica todos os vértices da rede, criando caminhos que permitam um vértice trocar e receber informações de outros vértices, bem como influenciar e ser influenciado pelo padrão de conectividade global do qual passa a fazer parte. Vale dizer que a mesma dinâmica pode ser aplicada quando estudamos o efeito de chegada de novos vértices na rede.

As pesquisas apontam (Watts, 2003) que há um ponto crítico no número médio de links por nó que, quando atingido, ocorre a transição de fase do estado desconectado para conectado, conforme vemos na figura 2.20. Quando o número médio de links por nó atinge o grau 1, a rede rapidamente começa a se conectar, o início da subida da curva no gráfico, levando a transição de estados, passando por suas fases intermediárias. É fundamental entendermos que a transição de estados num grafo só pode ser estudada quando consideramos que o grau de conectividade dos nós evolui com o tempo, o que pode ocorrer de formas muito diferentes na história de cada rede social. Dessa maneira, resgatar a história de formação do grafo de uma rede demarcando efeitos dos 
principais fatos promotores de conectividade traz à tona a própria história de como as relações se constituíram. Sem dúvida, um campo de pesquisa ainda a ser muito explorado como potencial de análise.

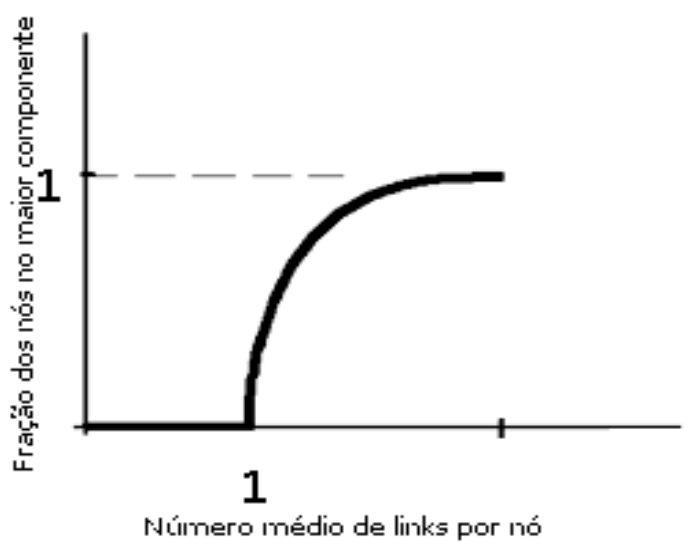

Figura 2.20. Transição de fase numa rede.

Ilya Prigogine descrevendo as semelhanças entre as colisões de moléculas químicas e o fluxo de comunicação entre humanos, explicita o efeito do tempo nas interações em rede:

"As colisões entre as moléculas têm dois efeitos: elas tornam a distribuição das velocidades mais simétrica e criam correlações entre essas moléculas. Mas uma partícula correlata com uma outra encontrará em seguida uma terceira. As correlações binárias transformam-se, pois, em correlações ternárias etc. Temos, a partir daí, um fluxo de correlações ordenado no tempo. A analogia mais próxima de um tal fluxo seria a comunicação entre humanos. Quando duas pessoas se encontram, elas se comunicam. Depois de se separarem, elas se lembram de seu encontro, e encontros ulteriores levam à disseminação de seus efeitos. Podemos falar de fluxo de comunicação numa sociedade, exatamente como há um fluxo de correlações na matéria." (Prigogine, 1996, p. 83).

A perspectiva de Prigogine traz um avanço fundamental para a ciência das redes, pois todos os métodos matemáticos e estatísticos disponíveis para o estudo da dinâmica de transição de fases em sistemas complexos tornava-se disponível para o estudo das redes sociais. A natureza da transição de fases entre sistemas físicos e sociais era a mesma do ponto de vista dos grafos (Watts, 
2003, p. 65), levando a ciência a mais uma vez conseguir dar um passo atrás e perceber elementos abstratos que poderiam conectar diferentes fenômenos sob o mesmo tipo de padrão emergente, trazendo definitivamente a dimensão do tempo para o estudo e a modelagem das redes sociais.

O próximo passo, a partir dessa compreensão, foi a classificação dos métodos oriundos da dinâmica de sistemas complexos que poderiam ser utilizados para a análise de redes sociais. Ao aplicar esses métodos em diversos conjuntos de dados, cientistas começaram a identificar novos padrões dinâmicos recorrentes que se repetiam em diferentes tipos de redes. Vejamos quais são os métodos utilizados e os padrões encontrados.

\subsubsection{Cálculos dinâmicos}

Os cálculos dinâmicos utilizados para a análise de redes lidam basicamente com aquilo que podemos chamar de variável aleatória. Uma variável aleatória é uma variável que representa o resultado de um evento não-determinístico, ou seja, de um evento que pode produzir a cada ocorrência um valor diferente. Logo, os cálculo dinâmicos são voltados para facilitar a identificação de padrões que podem ser observados a partir da análise de grandes quantidades de dados de eventos aleatórios.

Do ponto de vista do comportamento das variáveis aleatórias que representam um sistema complexo, o sistema parece ocupar uma posição intermediária entre ordem e caos. As interações no sistema não geram simplesmente desvios das condições iniciais que tenderiam a uma situação de desordem, levando o sistema ao caos. A evolução do sistema é bem menos imprevisível, ocorrendo por uma lei de potência ${ }^{8}$, que tende a levar o sistema a um estado crítico auto-organizado. Esse estado formaria uma fronteira entre ordem e caos (Nussenzveig, 2006).

No caso das redes sociais, esse eventos aleatórios representam o processo dinâmico da rede, ou seja, como se dá a chegada ou saída de nós na rede, além da forma como as conexões são estabelecidas ou desfeitas ao longo do tempo.

A distribuição de probabilidade é um recurso estatístico fundamental para a análise de como os dados coletados de eventos aleatórios são distribuídos. É um recurso utilizado para o estudo de grandes massas de dados na investigação de regularidades entre os dados, onde a análise individual dos elementos que constituem um sistema torna-se inviável devido a alta complexidade.

Ilya Prigogine, ao descrever o uso da distribuição de probabilidades ao invés da análise individual da trajetória de uma partícula num sistema dinâmico instável, define a importância da distribuição na descrição dinâmica:

8 Leis de potência: leis onde uma variável é proporcional a potência de outra. 
"Mas há algo mais: a distribuição de probabilidades permite-nos incorporar no quadro da descrição dinâmica a micro-estrutura complexa do espaço das fases. Ela contém, portanto, uma informação adicional, que se perde na descrição das trajetórias individuais. Este é um ponto fundamental: a descrição probabilística é mais rica que a descrição individual, que, no entanto, sempre foi considerada a descrição fundamental. Esta é a razão pela qual obteremos no nível das distribuições de probabilidades P uma descrição dinâmica que permite predizer a evolução do conjunto.(...) Evidentemente, quando consideramos sistemas estáveis, a descrição estatística reduz-se à descrição usual." (Prigogine, 1996, p. 39)

Os primeiros estudos que utilizaram a distribuição de probabilidades na caracterização de redes datam do final dos 50, com o clássico trabalho de Paul Erdos e Alfréd Rényi (Erdos e Rényi, 1959) aplicado a como se distribuía o grau de centralidade, o número de conexões que um nó possui na rede, concluindo que o grau de conectividade dos nós apresentavam uma distribuição de probabilidade aleatória (Newman, Barabasi e Watts, 2006, p. 38), também conhecida como distribuição de Poisson, apresentada na figura 2.21. Uma predição direta dessa conclusão é que a maioria dos nós de uma rede possuem aproximadamente o mesmo número de conexões, o que pode ser compreendido pelo seu agrupamento majoritário ao redor do valor médio da distribuição na figura 2.21 .

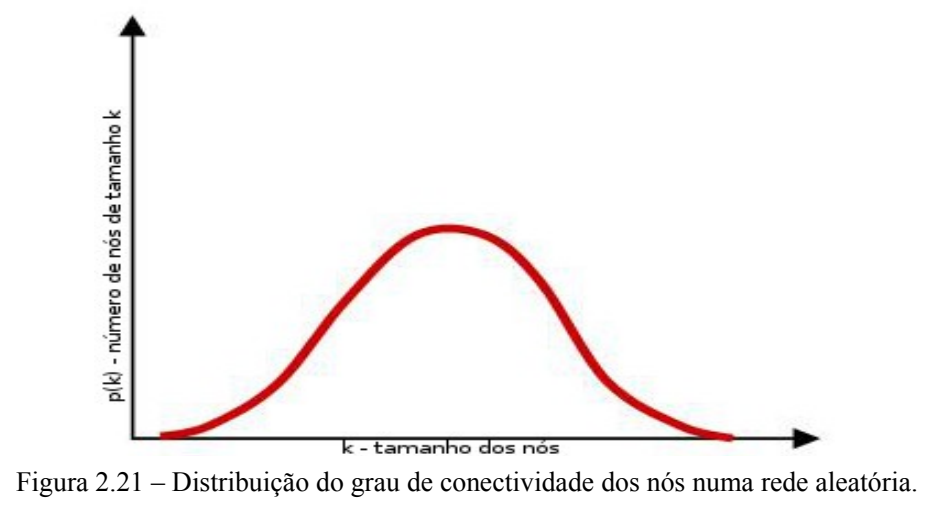

Não há nada mais aleatório do que a distribuição de Poisson, que representa nada mais do que uma sequência de eventos aleatórios, como os resultados de um jogo de dados, a distribuição da idade da população e renda mensal onde o agrupamento maior de resultados se dá em torno do valor médio. Todavia, um conjunto de dados que apresente uma distribuição diferente de Poisson pode ser tomado como uma evidência de que exista alguma ordem oculta, uma lei ou padrão a ser descoberto (Barabasi, 2010, p. 86). 
Dessa forma, a análise dinâmica de redes utiliza a distribuição de probabilidade do grau de conectividade dos nós como um recurso de investigação da formação de padrões ao longo do tempo. Nada impede que um conjunto de dados que descreva as relações estabelecidas numa rede possa apresentar uma distribuição diferente de Poisson, indicando algum tipo de estratégia diferente da formação aleatória que poderia ser investigada, oferecendo pistas de como um determinado comportamento individual pode afetar o comportamento coletivo. Logo, estudos da análise dinâmica de redes sociais tem a tendência de analisar a distribuição de probabilidades do grau de conectividade de seus conjuntos de dados, observando se apresentam ou não as mesmas regularidades de outros tipos de redes. Tornou-se um critério de comparação para a pesquisa na área.

Outra medida que adquiriu importância no estudo dinâmico das redes é o seu coeficiente de de clusterização, que é uma medida utilizada para avaliar o grau de influência que uma relação entre dois atores numa rede pode causar num terceiro. É uma forma de avaliar transitividade entre atores. Considerando que exista uma relação entre os atores A e B e uma relação entre os atores B e C, a transitividade ocorre quando a partir disso surge uma relação entre A e C. A análise da evolução desse indicador se tornou uma maneira de perceber como a rede se clusteriza, ou seja, como os seus atores vão se tornando ou não mais interconectados entre si.

A fórmula de cálculo do coeficiente é apresentado na figura 2.22, onde uma tripla de vértices consiste de um ator conectado a mais dois outros e triângulo consiste de uma relação transitiva entre três atores.

$$
C=\frac{3 \cdot \text { número de triângulos do grafo }}{\text { número de triplas de vértices }}
$$

Figura 2.22 - Coeficiente de clusterização

Também buscando perceber efeitos de coesão e espalhamento de uma rede, a variação no tempo da distância geodésica - a maior distância entre dois nós - passou a ser considerada um indicador dinâmico. Em tese, se a distância aumenta a rede está num processo de expansão com mais intermediários a serem atravessados para se chegar a um ponto, sendo o contrário válido quando seu valor diminui.

\subsubsection{Padrões dinâmicos}

Os padrões dinâmicos são identificados quando a análise da evolução da estrutura da rede revela que ocorre algo diferente de um evento puramente aleatório. Essa não-aleatoriedade indica 
algum tipo de ordem, alguma tendência específica pela qual a rede opera o seu desenvolvimento no tempo, como vimos anteriormente.

É interessante notar, no caso das redes sociais, que essa não-aleatoriedade pode indicar a tendência de sermos influenciados em nossas escolhas pelas pessoas a nossa volta, formando padrões coletivos. As redes sociais em que estamos envolvidos podem ampliar o que se inicia como sendo uma variação aparentemente aleatória. São essas pequenas variações que podem resultar em eventuais grandes transformações na rede, transformando-se em tendências majoritárias que influenciam grande parte das atores envolvidos (Christakis e Fowler, 2010, p. 132). Descobrir essas tendências antes que se tornem majoritárias, inclusive podendo prever alguns de seus movimentos, passa a ser uma área estratégica de grande interesse do pesquisadores de análise de redes sociais.

Em busca dessas tendências, as grandes massas de dados (Newman, 2001a), (Newman, 2001b), (Barabasi et al., 2002) que foram utilizadas pelos precursores da análise dinâmica de redes permitiram a identificação de alguns desses padrões, que serão apresentados a seguir.

As redes sociais raramente possuem uma distribuição de grau de centralidade aleatória. Em geral, apresentam uma distribuição que é chamada de lei de potência ${ }^{9}$. A lei de potência denota um padrão estrutural formado por poucos nós que com um alto grau de centralidade, chamados de hubs, e muitos nós com baixo grau de centralidade, conforme podemos visualizar na figura 2.23. Teoricamente, não há limites de escala para o tamanho dos nós de uma rede, fator que dá o nome a esse tipo de rede: redes de livre escala.

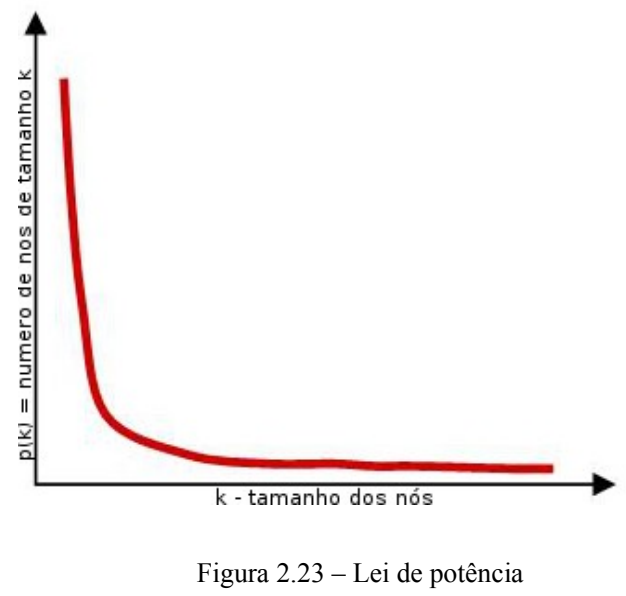

Considerando a distribuição aleatória que vimos anteriormente, na figura 2.21, a distribuição das redes de livre escala demonstram um padrão bastante diferente na figura 2.23. O grau de

\footnotetext{
9 É interessante notar que a lei de potência também é utilizada para caracterizar a distribuição de frequência das palavras utilizadas num texto, numa distribuição conhecida como Lei de Zipf, além da Lei de Lotka, como vimos no capítulo 2 e da lei de Bradford, que indica como os pesquisadores acessam as revistas e publicações científicas., determinando o núcleo e áreas de dispersão de um assunto pelas produções.
} 
centralidade dos nós não mais se distribui em torno de seu ponto médio, apresenta uma tendência que pode ser entendida como muitos com poucas conexões e poucos com muitas conexões. Em termos práticos, podemos visualizar esse contrastes entre as duas distribuições na figura 2.24, a seguir, onde percebemos com maior clareza o efeito que esse papel concentrador produz na estrutura das duas redes.

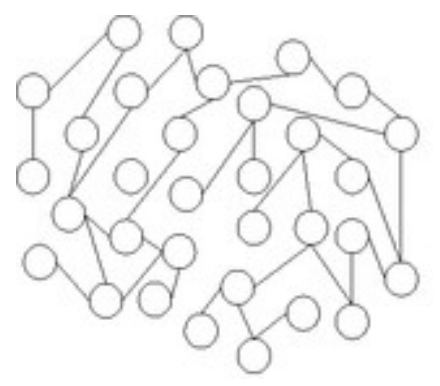

Rede Aleatória

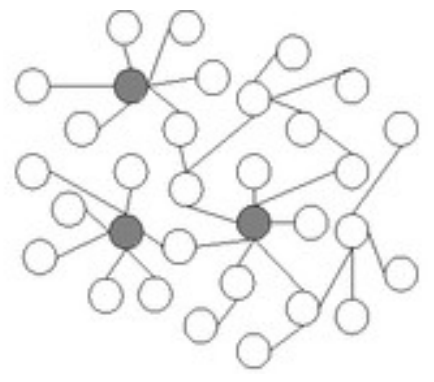

Rede Livre escala

Figura. 2.24. Contrastes entre rede de distribuição de grau aleatória e rede de livre escala.

Os hubs, os nós cinzas na rede de livre escala na figura 2.24, podem ser considerados os principais elementos da rede responsáveis por suas características estruturais, dado que são eles que, de uma certa forma, agenciam a conectividade dos nós de baixo grau de centralidade. Sem eles a rede praticamente se despedaçaria em vários componentes independentes. É interessante notar que uma percepção mais precisa dessa forma de organização das redes apenas se deu quando grandes bancos de dados de relações tornaram-se disponíveis para análise. Pequenas amostras não revelam esse padrão de forma clara. Certamente, quanto maior a amostra, mais precisa será a forma que uma distribuição irá tomar.

Analisando quais seriam as causas que levariam a uma distribuição de grau de centralidade por uma Lei de Potência, a partir de dados empíricos e simulações numéricas de efeitos nãolineares, (Barabasi et al., 2002) chegaram a conclusão que três leis dinâmicas regem o processo de evolução da rede:

- novos nós chegam na rede a uma taxa constante;

- novos nós se conectam aos nós presentes na rede seguindo uma tendência de conexão preferencial;

- nós que estavam presentes na rede formam novas conexões também seguindo uma tendência de conexão preferencial. 
Essa tendência de conexão preferencial dos novos nós e a formação de novas conexões na rede entre os nós já existentes tem relação direta com o grau de centralidade dos nós na rede. Em tese, significa que a conexão de novos nós e novas conexões entre os nós já existentes na rede tem maior probabilidade de ocorrer a nós mais centrais. Os hubs, seguindo essas leis dinâmicas, funcionariam como verdadeiros atratores de conectividade dentro de uma rede, reforçando a ideia de que os maiores tem a tendência de continuar maiores.

A distribuição de graus de centralidade numa rede social seria regida pela lei de potência apresentada na figura 2.25 .

$$
P(k)=k^{(-y)}
$$

Figura 2.25 - Fórmula da Lei de potência

A variação do fator $y$ na fórmula da figura 2.25 depende do tipo de rede social que está sendo estudada, normalmente variando entre 2 e 3 . O cálculo desse fator tornou-se, portanto, uma forma de descrever a dinâmica de uma rede, pois pesquisas indicam que o fator da lei de potência não varia de maneira aleatória, indicando sua variação importantes diferenças nos mecanismos que regem a sua dinâmica (Barabasi, 2010, p. 138). A variação do fator $y$ pode indicar diferentes níveis de centralidade na rede, mostrando o quão distantes ou próximos os hubs se encontram dos nós periféricos.

No entanto, existem restrições às 3 leis dinâmicas que regem o processo evolutivo das redes que podem ser percebidas na distribuição de graus de centralidade. Na prática, as redes sociais apresentam limites de escala, fazendo com que o grau de centralidade de seus nós não cresça a partir de certos limites. Na figura 2.26, em escala logarítmica, a reta vermelha demonstra uma Lei de Potência ideal. Os pontos abaixo da reta, representando dados reais, seguem a mesma tendência até um determinado ponto, começando a decair até seu ponto limite, que representa o maior grau de centralidade encontrado em uma determinada rede.

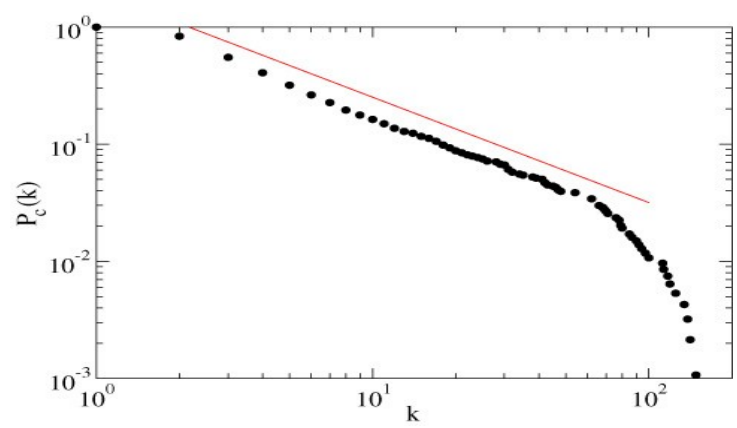

Figura 2.26. Restrições a escala de uma Lei de Potência 
As restrições denotam características sociais como, por exemplo, um profissional que se aposenta e deixa de estabelecer relações com seus antigos colegas de trabalho, um laboratório que pode encerrar seu funcionamento, parando de gerar novas conexões, autores que pararam de colaborar em torno de suas pesquisas, entre tantos outros. Essas restrições ajudam a compreender o processo pelo qual novos nós chegam e podem se tornar centrais, constituindo novos hubs, e hubs mais antigos podem sair de cena, se tornando nós periféricos ou mesmo desaparecendo da rede. $\mathrm{O}$ grau de centralidade dos nós é limitado pelo custo de manutenção dos conexões ou mesmo por questões temporais, levando um nó a se retirar eventualmente quando não compartilhando da dinâmica de relações estabelecidas (Newman, Barabasi e Watts, 2006, p. 174).

Outro padrão dinâmico, também descoberto no final dos anos 1990, de forte influência na análise de redes sociais é o que é conhecido como efeito "mundo pequeno". O modelo que descreve o padrão dinâmico das redes mundo pequeno é caracterizado por duas propriedades, observadas a partir da análise de dados de redes reais (Newman, Barabasi e Watts, 2006, p. 286):

- o efeito mundo pequeno significa que dois nós são conectados entre si por um caminho pequeno dentro da rede, normalmente não maior que 6 passos entre eles. Significa, em termos matemáticos, que a distância entre dois nós cresce a uma taxa logarítmica com o número total de nós na rede;

- alto coeficiente de clusterização ou transitividade na rede, indicando que há uma alta probabilidade de que dois nós serão conectados se um dos dois possui um vizinho em comum.

Para entender o impacto dessas duas propriedades numa rede social, utilizaremos um exemplo na figura 2.27 .
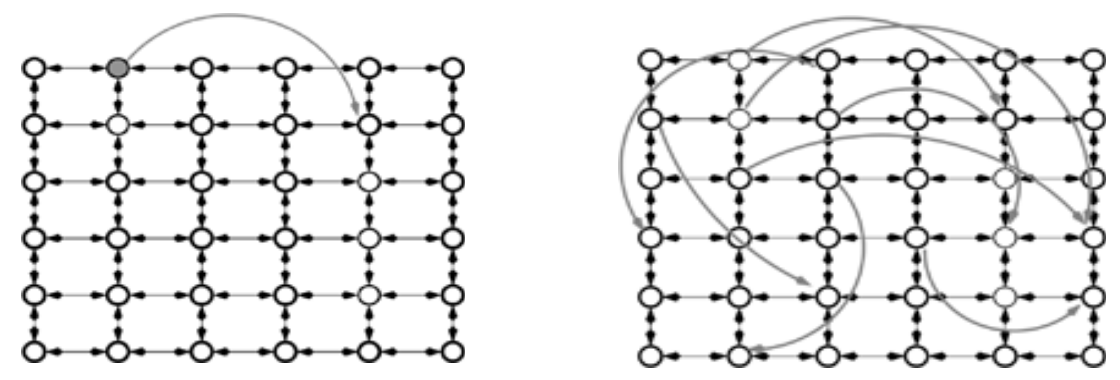

Figura 2.27. Exemplo do fenômeno mundo pequeno.

Fonte: http://mathaware.org/mam/04/essays/smallworld.html (acessado em 10/02/2011).

A primeira parte da figura 2.27, lado esquerdo, apresenta um padrão de conexão entre os nós onde todos os vizinhos possuem relação direta com todos os seus vizinhos. No entanto, existem 
poucos caminhos intermediários na rede, ou seja, se um nó precisar entrar em contato com outro que esteja no seu extremo oposto da imagem, ele terá de passar por vários nós, tornando alto o caminho de conexão entre os dois. Já na segunda parte da figura, lado direito, observamos que há vários nós que estabelecem conexões pontuais com outras áreas do grafo que não apenas seus vizinhos. São essas conexões que tornam o "mundo pequeno", pois permite que de uma determinada região do grafo se possa saltar para outra extremidade com apenas poucos contatos.

Nas redes sociais, isso significa que temos forte tendência a nos conectarmos com nossos vizinhos, sejam de profissão, de bairro, de escola, das organizações sociais que atuamos. No entanto, como estabelecemos conexões pontuais com outros grupos, acabamos nos tornando conectores entre diferentes áreas de múltiplas redes. Colocando isso em perspectiva e analisando o fenômeno em escala, o alto coeficiente de clusterização somado a alguns nós que estabelecem conexões pontuais com outros grupos gera uma distância pequena entre dois nós quaisquer dentro de uma rede. Mesmo que um nó específico não possua um caminho direto a uma determinada região da rede, ele provavelmente estará conectado com um outro nó em sua vizinhança que possui um acesso com um caminho menor a sua região de interesse. As redes acabam por ter a forma apresentada na figura 2.28 .

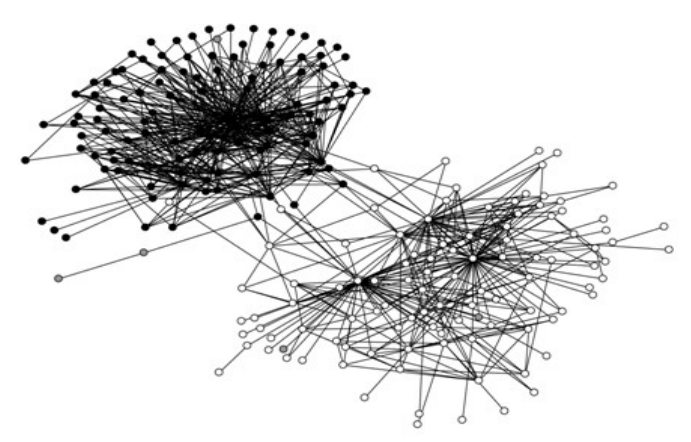

Figura 2.28. Rede mundo pequeno

O estudo das redes de livre escala e mundo pequeno levaram a percepção de que existem determinados eventos ao longo do tempo que determinam como uma rede evolui, tanto em termos de crescimento quando de redução, influenciando em seu padrão estrutural. O mapeamento desses movimentos levou a identificação dos padrões apresentados na figura 2.29 e 2.30 (Palla, Barabasi e Vicsek, 2007). 

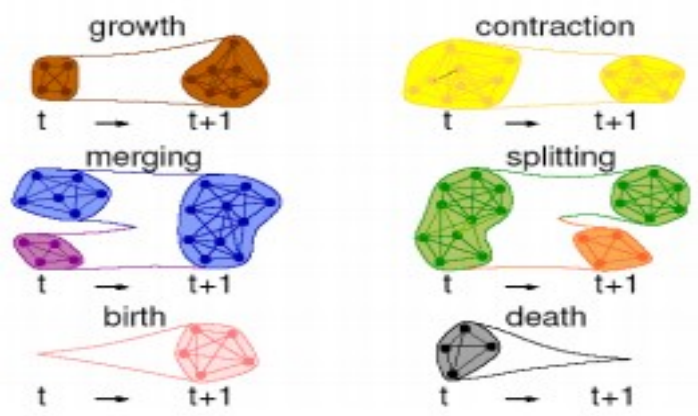

Figura 2.29. Eventos evolutivos. Fonte: Palla, Barabasi e Vicsek (2007).

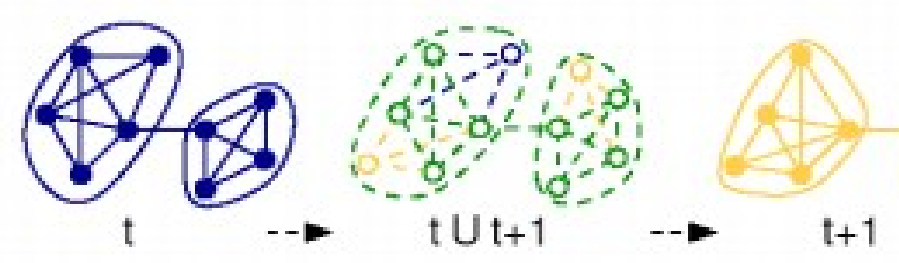

Figura 2.30. Evolução da estrutura da rede no tempo. Fonte: Palla, Barabasi e Vicsek (2007).

Os eventos evolutivos podem ser descritos a partir de seu padrão dinâmico:

- crescimento: a chegada de novos nós e de novas conexões entre os nós já existentes promove o crescimento da rede;

- junção: duas ou mais redes podem ser conectadas quando ao menos um dos nós de uma rede estabelece conexão com outro de outra rede;

- nascimento: duas ou mais conexões entre atores, num determinado contexto, podem dar nascimento a uma rede;

- contração: a saída de nós ou a desconexão entre nós pode levar a redução da estrutura da rede;

- divisão: uma rede pode ser subdividida em duas ou mais partes se os nós que estabeleciam essas partes unidas se desconectarem;

- morte: uma rede pode deixar de existir quando os nós que a compõem, dentro do contexto que designava a rede, deixarem de se conectar.

É importante destacar a questão do contexto de uma rede. Todos os eventos evolutivos apresentados acima dependem do contexto em que estamos analisando uma rede. É dentro de um determinado contexto de colaboração que uma rede nasce e morre, quando esse contexto deixa de existir. O fundamental a se analisar é a persistência do contexto ao longo do tempo e, a partir daí, analisar os eventos evolutivos que possam vir a ocorrer por dentro desse contexto. Como já 
frisamos anteriormente, a arte da ciência das redes está na escolha desse contexto, a partir de onde iremos focar nosso olhar como pesquisadores, investigando seus padrões estruturais e dinâmicos de relacionamento. São essas regularidades diferentes dos eventos aleatórios que levam a padrões dinâmicos que acabam por formar atualmente os seis princípios de organização das redes complexas (Barabasi, 2010):

- redes de livre escala: muitos pequenos nós são agrupados e articulados por poucos grandes hubs;

- redes mundo-pequeno: caminhos de conexão pequenos entre dois nós quaisquer;

- evolução: os hubs emergem por crescimento da rede e conexões preferenciais;

- competição: nós com alto desempenho na articulação da rede se tornam hubs;

- robustez: a rede é resistente a ataques, pois há muitos caminhos que mantém a rede conectada se poucos nós desaparecem;

- comunidades: grupos terminam por formar estruturas hierárquicas.

A contextualização das redes sociais a partir desses princípios de organização cria um campo de análise que permite que diferentes redes possam ser analisadas e comparadas a partir dos mesmos princípios. Parte importante do trabalho do analista é identificar como e se esses princípios se manifestam a partir de seus conjuntos de dados, criando condições para inferir quais são as estratégias de conectividade da rede analisada que leva a esses modos preferenciais de organização. A análise de como essas regularidades se manifestam numa rede específica torna-se um campo de possibilidades de compreensão e intervenção no modo como as redes operam: a estrutura e a dinâmica da rede passam a incorporar o repertório de análise estratégica dos movimentos sociais, sejam eles de que caráter for, podendo ser apropriados para fins de gestão, de intervenção, reflexão e tantas outras possibilidades que podem ser imaginadas. Descobrir variações, recursividades, o surgimento de novas estratégias e formas específicas de conexão define o campo de base da análise das redes sociais do ponto vista informacional: a informação enquanto relação social define e é definida por seus movimentos de apropriação e circulação.

\subsection{Análise de redes sociais e a Ciência da Informação no Brasil}

O uso da análise de redes sociais como objeto de estudo e pesquisa pela Ciência da Informação não é uma novidade. No entanto, ao rever a literatura da área para a construção da fundamentação teórica desta tese, nos deparamos com uma subutilização de seu potencial analítico, evidenciando a necessidade de avanços na área. Dessa forma, como modo de encerrar este capítulo, 
fizemos uma revisão de como o objeto é utilizado, buscando identificar quais pontos poderiam ser melhor explorados, facilitando inclusive prever possíveis contribuições deste trabalho.

O conceito de redes sociais possui uma íntima ligação com as áreas da Antropologia, Psicologia Social e, sobretudo, das Ciências Sociais (Freeman, 2004) (Marteleto, 2010). A razão que ajuda a explicar essa ligação tem origem na intuição de que o padrão de conexões constituído pelos atores de uma rede tem importantes consequências para esses atores (Marteleto, 2010). A investigação do padrão de relações torna-se, portanto, um elemento de conexão entre as áreas, promovendo maior colaboração em torno da pesquisa de metodologias que pudessem lhes servir de apoio.

O interesse pelo uso da análise de redes sociais vem aumentando de forma significativa nos últimos 30 anos, sobretudo pelo fato de nesse período aumentar significativamente a disponibilidade de dados que pudessem ser utilizados como elementos de pesquisa, ampliar a capacidade de computação e softwares disponíveis para análise de redes, além de mais áreas compartilharem do interesse pela investigação de padrões de relações de seus objetos de interesse (Matheus e Silva, 2006). O aumento no uso de sistemas de informação e seu potencial de organização foram tomando a forma de uma rede mediante o uso de tecnologias de arquivamento, que puderam então fornecer uma estrutura concreta e palpável ao estudo dessas formas de organização (Marteleto, 2007).

Otte e Rousseau (2002), apresentam um estudo (ver fig. 2.31) que vai do período de 1974 a 1999 mapeando o uso da análise de redes sociais como estratégia de pesquisa das Ciências Sociais, Medicina e Psicologia, nos bancos de dados CSA Sociological Abstracts Database, Medline Advanced e PsycINFO.

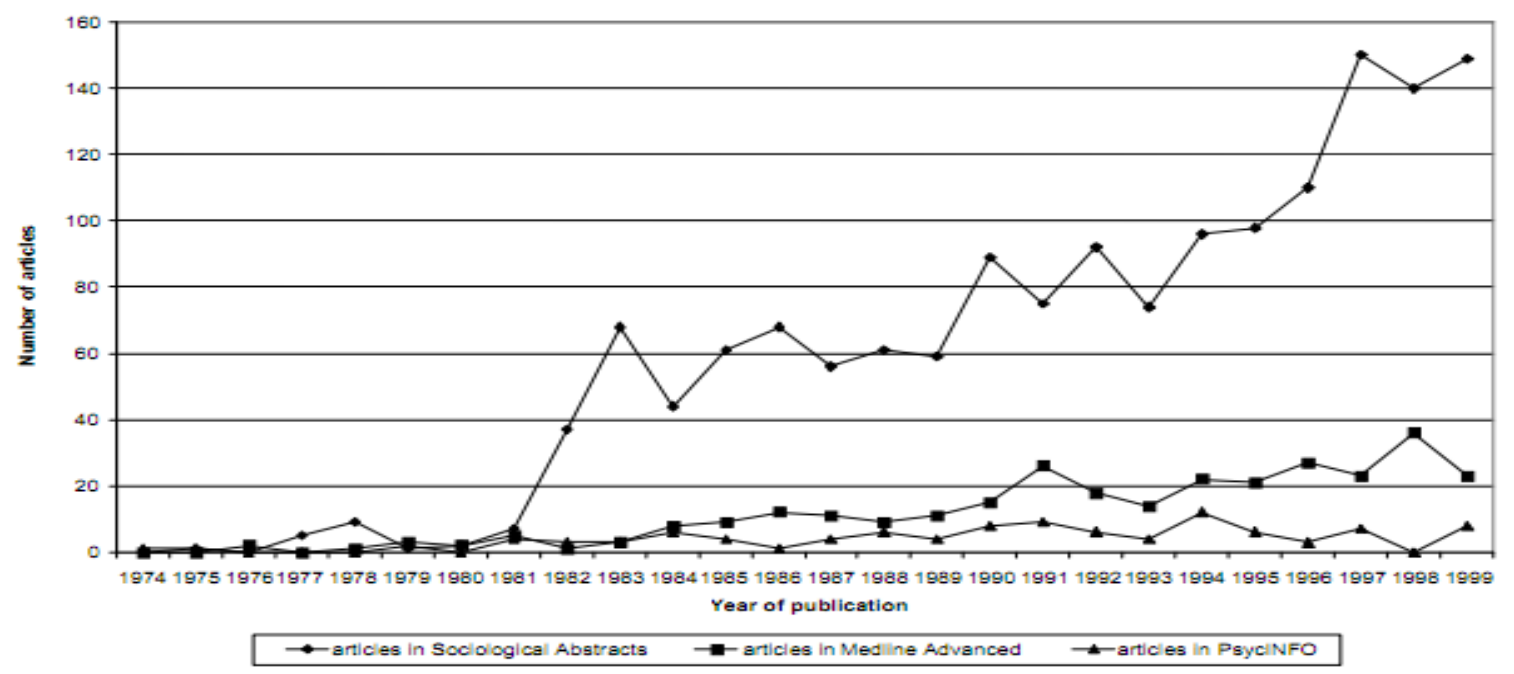

Figura. 2.31 - Evolução do uso da análise de redes sociais nos campos da Sociologia, Medicina e Psicologia - Fonte: Otte e Rousseau (2002) 
O estudo confirma esse aumento expressivo, sobretudo no campo das Ciências Sociais a partir de 1981, apontando um padrão linear de crescimento ao longo do período. É a partir dessa constatação que encontramos os primeiros traços de conexão do uso da análise de redes sociais com a Ciência da Informação, considerando que a CI situa-se no campo das ciências sociais aplicadas, preocupada com a investigação da questão social da informação e daquele ser social que procura a informação (Le Coadic, 2004, p. 19). Sem muito risco, podemos inferir que esse aumento expressivo de pesquisas utilizando análise de redes sociais a partir dos anos 80 possui relação direta em relação a como esses estudos passaram a utilizar uma nova metodologia para processar informações de interesse, de onde podemos concluir que parte desses estudos tem relação direta com temas relevantes para a área da CI.

Os cientistas da informação estudam redes sob diversos aspectos, sobretudo relacionadas a citação, co-citação, co-autoria, estruturas de colaboração e outras formas de interação social (Otte e Rousseau, 2002). A análise de redes sociais empresta um ferramental metodológico que permite grande flexibilidade na proposição de atores e relações na rede, complementando os recursos disponíveis pelas análise bibliométricas (Silva et al., 2006). É uma abordagem que pode auxiliar e favorecer novos mecanismos analíticos na modelagem de redes que interessam a CI. Como exemplo, o estudo de padrões de citação entre pesquisadores tem como unidade de observação a citação, mas como um artigo pode ter mais de uma citação, o ator pode ser modelado como sendo o artigo que contém a citação, o jornal que contém o artigo, ou mesmo os atores dos artigos citados (Wasserman e Faust, 1994). A partir de uma mesma metodologia, três enfoques diferentes podem ser abordados, eventualmente levando a conclusões importantes em cada enfoque, considerando um mesmo conjunto de dados.

Mapeando as principais questões de interesse da CI que poderiam ser favorecidas pela pesquisa utilizando a análise de redes sociais, Matheus e Silva (2006) produziram uma síntese, como vemos na tabela 2.2 .

\begin{tabular}{|l|l|}
\hline \multicolumn{1}{|c|}{ Problema da Ciência da Informação } & \multicolumn{1}{|c|}{ Contexto da Análise de Redes Sociais } \\
\hline Acesso a informação e tipos de usuário da informação & $\begin{array}{l}\text { A importância do tipo e da posição que um ator se } \\
\text { encontra dentro da rede determina tipos de usuários } \\
\text { da informação. }\end{array}$ \\
\hline Difusão da inovação e de novas ideias & $\begin{array}{l}\text { As diferentes posições que atores podem ocupar } \\
\text { numa rede tem efeito direto de como ocorre a difusão } \\
\text { da informação, permitindo a identificação de } \\
\text { diferentes perfis de atuação. }\end{array}$ \\
\hline Acesso à informação como vantagem social & $\begin{array}{l}\text { Os atores capazes de intermediar informação para } \\
\text { fora e para dentro do contexto de seus grupos sociais } \\
\text { apresentam correlações com padrões de vantagem }\end{array}$ \\
\hline
\end{tabular}


social.

Acesso a informação e novos canais de informação, Redes de contatos humanos através de novos canais, redes de computadores bem como novas formas de armazenar, trocar e buscar informação. O comportamento das redes sociais formadas através do uso de computadores.

Análise de co-autoria, de citações e de co-citação em Análise de redes de co-autoria, citações e de coartigos científicos, colaboração científica citação em artigos científicos. Identificação de colégios invisíveis, redes de colaboração científica, dos autores e pesquisadores mais proeminentes em uma área de pesquisa.

Fluxos de informação dentro das organizações, Redes de contatos humanos como canais de Gestão do conhecimento, tomada de decisão informação versus as redes formais previstas no organograma. Informação e cultura organizacional.

Tabela 2.2. Questões de pesquisa em CI e sua relação com a Análise de Redes Sociais. Fonte Matheus e Silva (2006), adaptada.

Observamos que as questões da CI que podem receber contribuições da análise de redes sociais tem relação direta a padrões de circulação da informação. Como as estruturas são formadas da relação de atores envolvidos nesse processo de circulação e como essas estruturas mudam no tempo, influenciando múltiplas formas de organização do processo de circulação da informação, representam um mesmo tema e interesse entre os problemas mapeados. A conclusão da análise dos diferentes problemas de interesse da CI é que as contribuições do uso da análise de redes sociais, também apresentado por Matheus e Silva (2006), são:

- método comum para o estudo de redes em geral, sejam elas redes de pessoas, organizações, documentos ou redes eletrônicas;

- fundamentação teórica e matemática para estudos e pesquisas conduzidas na área.

O uso da análise de redes sociais em pesquisas no campo da Ciência da Informação não é uma novidade no Brasil. Os estudos sobre redes sociais no campo da CI iniciaram a partir do final dos anos 90 e começo dos anos 2000, no entanto os estudos e aplicações desenvolvidas no país ainda podem ser considerados raros, não chegando a formar um tema e uma comunidade abrangente de pesquisa. Com o objetivo de mapear como a análise de redes sociais vem se desenvolvendo no Brasil na área da CI, Marteleto (2010) fez um levantamento nas revistas de Ciências da Informação classificadas nas categorias A e B na lista Qualis da Coordenação de Aperfeiçoamento de Pessoal de Nível Superior (CAPES), pesquisando os temas - informação e redes sociais - sem restrição de data.

No total, foram encontrados 41 artigos a partir de 2001 até 2009, conforme apresentado na tabela 2.3. 


\begin{tabular}{|l|c|}
\hline \multicolumn{1}{|c|}{ Título } & Número de Artigos \\
\hline Brazilian Journal of Information Science & 1 \\
\hline Ciência da Informação & 6 \\
\hline Datagramazero & 4 \\
\hline $\begin{array}{l}\text { Encontros Bibli: Revista Eletrônica de } \\
\text { Biblioteconomia e Ciência da Informação }\end{array}$ & 4 \\
\hline Informação \& Informação & 9 \\
\hline Informação \& Sociedade: estudos & 3 \\
\hline Perspectivas em Ciências da Informação & 5 \\
\hline Transinformação & 2 \\
\hline Liinc em Revista & 4 \\
\hline $\begin{array}{l}\text { Em Questão: Revista da Faculdade de } \\
\text { Biblioteconomia e Comunicação da UFRGS }\end{array}$ & 1 \\
\hline $\begin{array}{l}\text { Revista Eletrônica de Informação, Inovação e } \\
\text { Comunicação em Saúde }\end{array}$ & 2 \\
\hline TOTAL & 41 \\
\hline
\end{tabular}

Tabela 2.3. Periódicos em Ciência da Informação: artigos relacionados pelos descritores - informação e redes sociais, 2001 a 2009. Fonte: Marteleto (2010).

Realizando uma classificação desses 41 artigos por título, resumo e palavra-chave, Marteleto (2010) produziu uma estratificação temática, que apresentamos na tabela 2.4.

\begin{tabular}{|l|c|}
\hline \multicolumn{1}{|c|}{ Temática } & Número de Artigos \\
\hline Redes científicas, colaboração e co-autoria & 11 \\
\hline Desenvolvimento socioeconômico, inovação & 6 \\
\hline $\begin{array}{l}\text { Informação, mobilização, movimentos sociais, ações } \\
\text { sociopolíticas }\end{array}$ & 5 \\
\hline Folksonomias, thesaurus, ontologias, hipertexto & 3 \\
\hline Metodologia de Análise de Redes Sociais & 3 \\
\hline Teoria e fundamentos de redes e redes sociais & 3 \\
\hline Estudos das organizações & 3 \\
\hline Interação e contatos na Web & 41 \\
\hline \multicolumn{1}{|c|}{ TOTAL } & \\
\hline
\end{tabular}

Tabela 2.4. Categorização temática dos artigos relacionados pelos descritores - informação e redes sociais, 2001 a 2009. Fonte: Marteleto (2010)

Apenas 14,6\% dos artigos são voltados para discutir o uso metodológico e conceitual da análise de redes sociais, sendo todo o restante dos artigos encontrados direcionados ao estudo direto de problemas relevantes para a área da CI. Em torno de $27 \%$ dos artigos dizem respeito ao estudo de redes científicas, colaboração e co-autoria, representando a área de maior utilização da metodologia como recurso de pesquisa. Supomos que uma das razões é, dentre os temas 
apresentados, o estudo de co-autoria e das redes científicas é uma questão da CI que apresenta uma relação mais simples de estabelecer com o uso da análise de redes sociais, facilitando sua apropriação e experimentação como metodologia de pesquisa. Vale ressaltar, conforme a listagem fornecida no apêndice de Marteleto (2010), que nenhum dos artigos apresentou o termo biblioteca digital em seu título ou definição da temática.

Dos 41 artigos, apenas 11 (26,8\%) utilizaram algum tipo de indicador e análise de padrão, sendo que a maioria dos textos tinha por objetivo discutir assuntos de característica conceitual, não trabalhando diretamente com amostras de dados. Dos 11 artigos que utilizaram amostras de dados para suas pesquisas, apenas $3(7,3 \%$ do total) incluíram em sua discussão algum aspecto dinâmico das redes sociais, do ponto de vista dos indicadores e padrões apresentados anteriormente. Analisamos os artigos mapeados por Marteleto em busca de identificar que tipos de indicadores estruturais e dinâmicos foram utilizados pelos pesquisadores da Ciência da Informação no Brasil, considerando os indicadores que apresentamos ao longo deste capítulo. Apresentamos na tabela 2.5, a seguir, o resultado dessa análise.

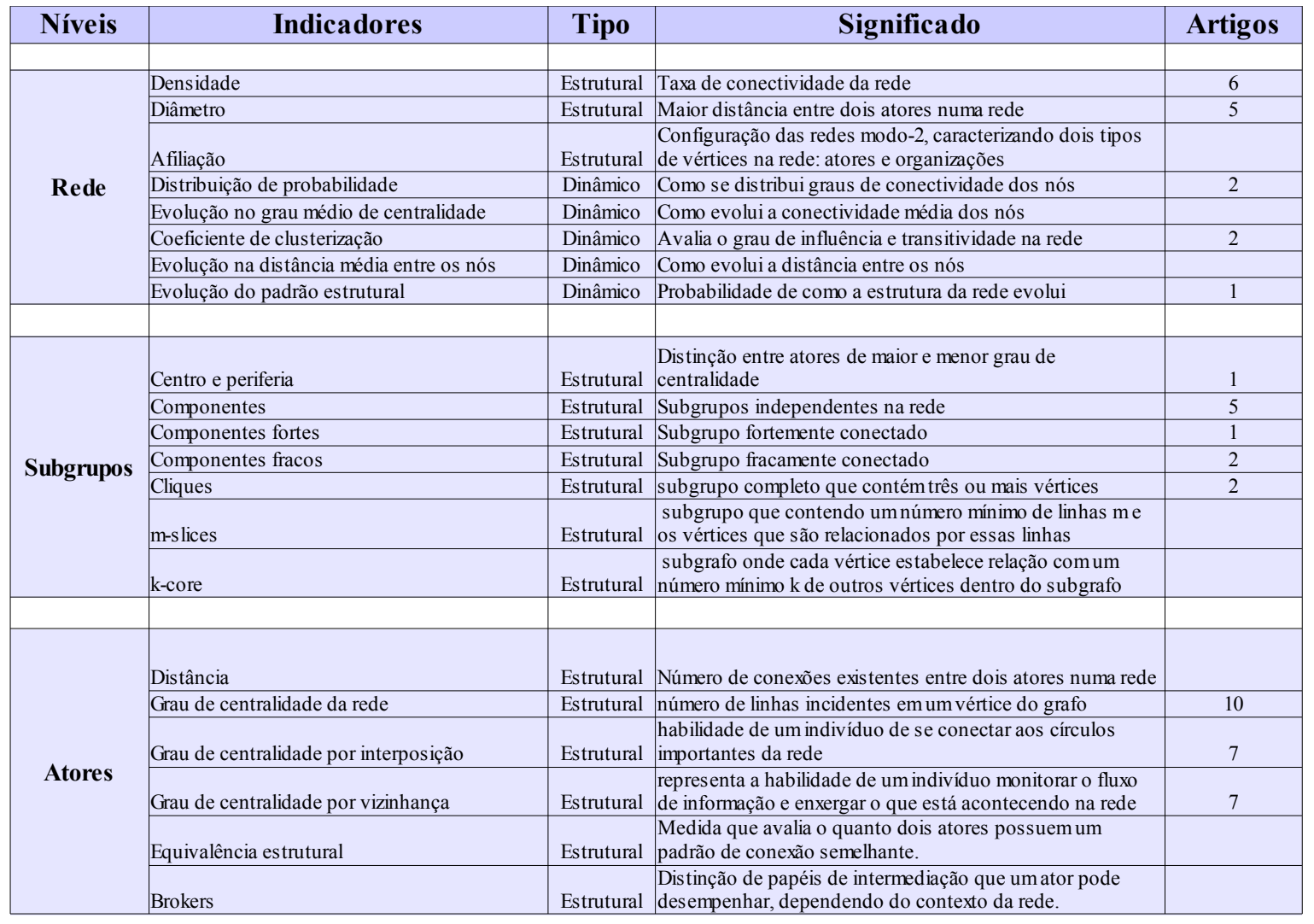

Tabela 2.5. Indicadores de análise de redes sociais utilizados pela produção científica da CI no Brasil

Vejamos um gráfico, na figura 2.32, que auxilia a compreender as principais tendência de uso desses indicadores. 


\section{Indicadores de Análise de Redes Sociais}

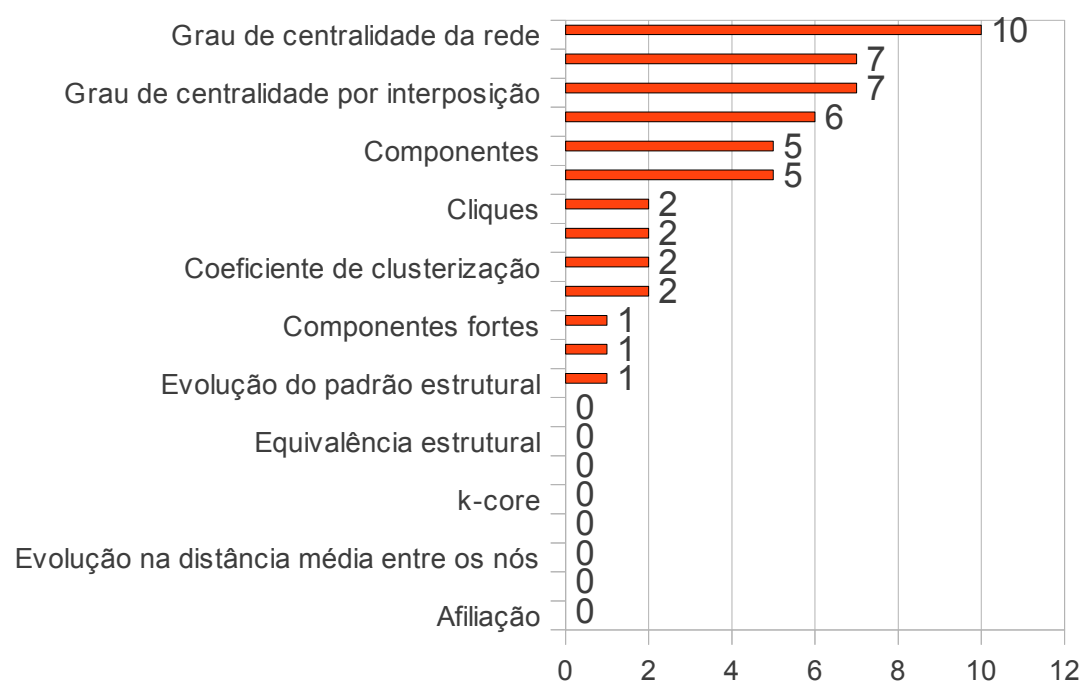

Figura 2.32. Distribuição do número de artigos por indicadores de análise de redes sociais utilizados pela produção científica da CI no Brasil

A maior parte da produção científica utiliza apenas a análise estrutural de redes, sendo que dos 11 artigos que utilizaram amostras de dados, 10 utilizaram os indicadores de grau de centralidade como base de sua argumentação. Os estudos, em geral, utilizaram amostras de dados pequenas, sendo que a maior base de dados utilizadas era composta de 1812 artigos para análise das redes de co-autoria (Brandão, Parreiras e Silva, 2007), o que justifica em parte a baixa utilização da análise dinâmica, que faz sentido quando temos grandes massas de dados para análise dos padrões evolutivos.

Acreditamos que um dos fatores que ajuda a explicar a falta de aprofundamento metodológico e o investimento parcial no uso da análise de redes tem relação com os tipos de dados ou falta deles que os pesquisadores de CI utilizam no Brasil. A revisão dos artigos nos leva a concluir que não são muitas as bases de dados disponíveis e de fácil acesso a manipulação pelos pesquisadores e, quando o são, não possuem grande abrangência e nem séries históricas significativas dos dados representados, sendo uma das dificuldades mapeadas no item 2.4 deste capítulo. Um outro fator diz respeito ao treinamento no uso das metodologias de análise. Muitos pesquisadores utilizam os recursos básicos da análise estrutural de redes, não incorporando ainda em seu repertório de pesquisa novos métodos de análise e caracterização de padrões dinâmicos.

Os resultados apresentados acima nos levam a duas questões que podem ser apontadas como lacunas ainda a serem preenchidas no uso da análise de redes sociais no estudos da CI no Brasil: pouco aprofundamento teórico e metodológico, e baixo nível de investimento no uso da análise de 
redes no estudo das redes de informação, levando a um uso ainda muito simplista e inicial de potencial ainda a ser explorado pela área. Essa visão também é compartilhada por Brandão, Parreiras e Silva (2007) e Marteleto (2010), que além disto, mencionam que as pesquisas no Brasil normalmente utilizam a análise de redes sociais de maneira estática, não considerando os aspectos de evolução da rede ao longo do tempo.

Com o objetivo de checar como a produção da pesquisa na área de redes sociais tem se desenvolvido em termos de teses e dissertações, não apenas no campo da Ciências da Informação e incluindo na pesquisa todas as áreas disponíveis, realizamos a mesma consulta dos termos - redes sociais e informação - na base da Biblioteca Digital Brasileira de Teses e Dissertações ${ }^{10}$ (BDTD), em janeiro de 2010, coletando todos os resultados retornados até então. Obtivemos como resultado 69 documentos, distribuídos em 47 dissertações de mestrado e 22 teses de doutorado. Vejamos na tabela 2.6 a distribuição desses documentos por instituição onde foram defendidos.

\begin{tabular}{|c|c|}
\hline Instituição de Defesa & Teses e Dissertações \\
\hline Universidade Federal de Minas Gerais & 11 \\
\hline Universidade de Brasília & 10 \\
\hline Pontifícia Universidade Católica de São Paulo & 8 \\
\hline Universidade Federal do Rio Grande do Sul & 8 \\
\hline Universidade de São Paulo & 5 \\
\hline Universidade Católica de Brasília & 4 \\
\hline Pontifícia Universidade Católica do Paraná & 3 \\
\hline Universidade Federal da Bahia & 3 \\
\hline Universidade Estadual de Campinas & 2 \\
\hline UNIVERSIDADE FEDERAL DE SANTA CATARINA & 2 \\
\hline Universidade Salvador & 2 \\
\hline Fundação João Pinheiro & 1 \\
\hline PONTIFÍCIA UNIVERSIDADE CATÓLICA DO RIO DE JANEIRO & 1 \\
\hline Pontifícia Universidade Católica do Rio Grande do Sul & 1 \\
\hline Universidade Catolica de Pelotas & 1 \\
\hline Universidade Católica de Santos & 1 \\
\hline UNIVERSIDADE DE CAXIAS DO SUL & 1 \\
\hline Universidade do Vale do Itajaí & 1 \\
\hline Universidade Federal de São Carlos & 1 \\
\hline Universidade Federal de Viçosa & 1 \\
\hline Universidade Federal do Rio de Janeiro & 1 \\
\hline Universidade Presbiteriana Mackenzie & 1 \\
\hline \begin{tabular}{|r|} 
Total \\
\end{tabular} & 69 \\
\hline
\end{tabular}

Tabela 2.6. Distribuição de defesas de Teses e Dissertações por instituição pelos descritores - redes sociais e informação.

Vejamos na figura 2.33 a distribuição ao longo do tempo das 69 teses encontradas.

10 http://bdtd.ibict.br/ 


\section{Evolução de Teses e Dissertações}

\section{Descritores: redes sociais e informação}

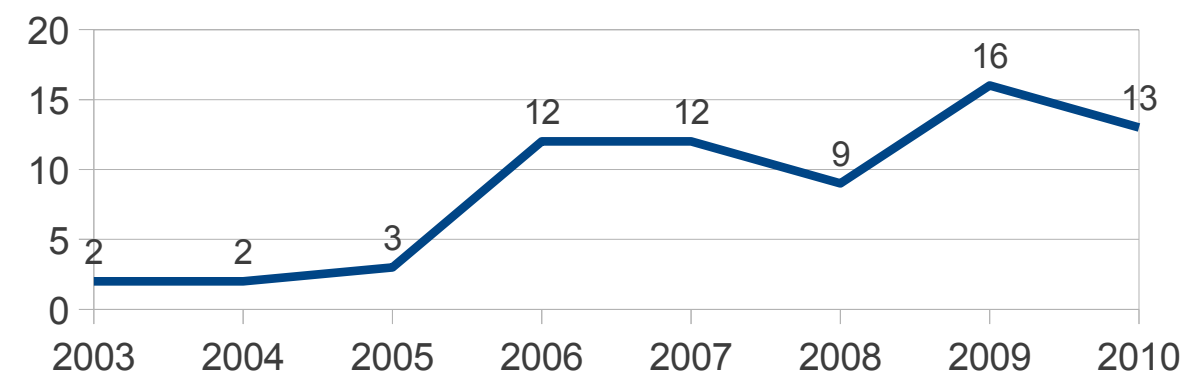

Figura 2.33. Distribuição de defesas de Teses e Dissertações no tempo descritores - redes sociais e informação.

Confirmando a análise de artigos publicados apresentada anteriormente, o início do desenvolvimento de pesquisas no formato de teses e dissertações no Brasil se dá a partir do começo dos anos 2000, apontando um crescimento significativo a partir de 2006. Pode-se notar que os dados evidenciam uma área em formação, sendo que aproximadamente $90 \%$ da pesquisa formal foi realizada nos últimos 5 anos, demonstrando um processo ainda em amadurecimento na formalização de métodos de pesquisa, na estrutura de apresentação de resultados, bem como da utilização de estudos paralelos para efeito comparativo.

É interessante notar, a partir da distribuição da tabela 2.6, que dentro das 5 principais instituições que fomentam pesquisa nos temas selecionados, representando aproximadamente $61 \%$ da produção, estão localizados reconhecidos departamentos e grupos de pesquisa na área da Ciência da Informação.

Os dados apresentados confirmam a visão de uma área ainda em processo de estruturação no Brasil. No entanto, o potencial de temas da CI que podem ser beneficiadas pelo uso da análise de redes sociais e o quanto esse tema ainda tem para ser experimentado o projetam como um foco de desenvolvimento da pesquisa científica a ser explorado pelos próximos anos. Outro ponto a destacar, é o fato de ampliarmos o espaço dentro do campo da CI para discussões de enfoque conceitual, teórico e metodológico a respeito da análise de redes sociais, dado que a maioria dos trabalhos publicados na área consistem de aplicações de análise e pouca reflexão sobre seus fundamentos.

A ampliação da pesquisa pode favorecer a melhor sistematização de novas formas de uso da metodologia, considerando aspectos dinâmicos da evolução, bem como ampliar o escopo dos estudos, utilizando novas possibilidades metodológicas de caracterização das redes, ampliando o investimento no uso das possibilidades ofertadas pela análise de redes. Acreditamos que esse 
enfoque facilitaria a melhor percepção dos potenciais da metodologia, facilitando a sensibilização e absorção por pesquisadores da área. 


\section{Capítulo 3 \\ As redes sociais acadêmicas}

\begin{abstract}
"As frequentes designações "estrutura da linguagem", "taxionomia", "cultura", "paradigma" e "sociedade" podem ser usadas para definir-se reciprocamente: essas são algumas das palavras usadas para resumir o conjunto de elementos que aparecem ligados a uma alegação em debate"
\end{abstract}

Bruno Latour

\subsection{Introdução}

As redes sociais se configuram pelas características de seus nós, da forma como estabelecem conexões e como as relações vão se desenvolvendo ao longo tempo, compondo um entrelaçamento entre padrões estruturais e dinâmicos que podem ser característicos de um conjunto de nós atuando em um contexto específico. A rede torna-se uma escolha, um modo de observar e participar em fluxos de relações sociais com os quais interagimos.

As redes produzem e surgem a partir de contextos específicos pelos quais as pessoas se relacionam: moradores de uma mesma comunidade, funcionários de uma empresa, de um mesmo ramo de negócios, alunos de uma escola, participantes de um movimento social, relações comerciais entre empresas, colaboração de pesquisadores em projetos em comum, co-autores de um artigo científico, pesquisadores de um mesmo campo do conhecimento, entre tantos outros.

Não é difícil supormos que o contexto deve influenciar diretamente nas características que irão descrever os modos de operação de uma rede. A dificuldade de obter dados sistematizados que permitam comparar uma grande variedade de redes que operam a partir de contextos diferentes é um dos pontos limitantes na pesquisa científica sobre as redes sociais e por onde podemos esperar avanços significativos nas próximas décadas com o aumento de bases de dados disponíveis e pesquisadores atuantes na área. É a partir da análise do contexto que iremos definir quem fará parte da rede e quem não fará, que conjunto de dados iremos coletar e quais não iremos, que métodos, perguntas e respostas estaremos procurando.

Um dos objetivos desta tese é identificar as potencialidades da análise de redes no contexto de uma federação de bibliotecas digitais, no caso específico de aplicação no campo das Ciências da Comunicação. Para isso, é fundamental compreendermos qual o contexto social em que surge uma comunidade acadêmica e, mais especificamente, a comunidade acadêmica formada pelos pesquisadores da Ciências da Comunicação. Comecemos por descrever quais são as principais linhas de força, os planos de referência em que podemos nos basear para compreender como a ciência opera para, no próximo capítulo, analisarmos em detalhes como essas forças se manifestam 
no caso da Ciências da Comunicação.

\subsection{Comunidade científica}

A comunidade científica forma uma rede de interações característica que nos permite distinguir como ela se organiza, fornecendo critérios específicos que possibilitam dizer quais são as fronteiras da comunidade, que grupos fazem ou não parte dela, considerando que isso está em constante disputa e redefinição por diferentes interesses. A rede de interações, neste caso, representa o conjunto de ações e das regras de conduta que os cientistas conservam em sua prática e objetivo principal: fazer ciência.

Mas, podemos agora nos perguntar, o que significa fazer ciência e o como isso impacta na formação de redes sociais características de uma comunidade científica? A ciência opera como uma prática social onde se tem por objetivo sistematizar informações, produzir novos conhecimentos, sendo a maior expressão de força e relevância social de um cientista quando ele produz um novo objeto de conhecimento, seja uma definição, um conceito, um parâmetro que passa a ser utilizado como referência por sua comunidade (Latour, 1998, pg. 150). É a partir dessa definição de ciência como uma prática social de produção de novos objetos que começamos a nos dar conta da relação que ela passa a ter com as redes sociais: a construção de fatos, dos objetos da ciência é uma prática que só possui sentido enquanto um processo coletivo (Latour, 1998, pg. 171).

O cientista só produz conhecimento novo, logo ciência reconhecida como relevante, quando esse conhecimento é reconhecido por sua comunidade. Para que isso ocorra redes de conversação precisam ser ativadas, desde a concepção de uma ideia enquanto plano abstrato da modelagem de um novo objeto científico à produção e desenvolvimento sistematizado de um projeto de pesquisa. Fazer ciência, a partir dessa perspectiva, é continuamente mobilizar redes de pessoas e instituições em torno de objetivos comuns. Latour (1998) descreve esse processo com a imagem da construção de uma poderosa rede de alianças onde, quanto mais sistematizado, estruturado e intermediado por várias redes de apoio, maior e mais expressiva será a força que um novo objeto do conhecimento terá enquanto apropriação social.

"Tome uma caixa-preta qualquer e congele a cena: você pode então considerar o sistema de alianças que ela une de duas formas diferentes. Em primeiro lugar, observando quem ela tem por finalidade alistar. Em segundo, considerando a que ela está ligada, a fim de tornar o alistamento inelutável. Por um lado, podemos traçar seu sociograma; por outro, o seu tecnograma. Para cada informação obtida num sistema há também uma informação no 
outro." (Latour, 1998, pag. 229)

Os cientistas operam, portanto, desenvolvendo, alargando e construindo estratégias de pesquisa que envolvem a produção de sociogramas e tecnogramas quando envolvem outras pessoas, seja por forma de apoio direto em sua pesquisa por meio de grupos de colaboradores, avaliadores, leitores e usuários, seja por forma de citação a trabalhos anteriores, metodologias de referência ou instrumentos de pesquisa como apoio aos seus argumentos. A ciência opera como uma contínua rede de conversações onde os objetos conceituais são construídos como produtos das conversações sistematizadas. Dessa forma, os cientistas tendem a produzir uma dinâmica de relações onde os mais bem-sucedidos, segundo um critério de produtividade, são aqueles que conseguem mobilizar suas relações em direção aos seus objetos de interesse, criando campos expressivos de influência a partir de suas ideias. Sendo assim, grupos e zonas de influência podem ser observados, bem como suas áreas de concentração, espalhamento e dissolvência quando do surgimento de novos objetos mais interessantes e atratores de relevância social.

"Se a tecnociência pode ser descrita como algo tão poderoso apesar de tão pequeno, tão concentrado e tão diluído, significa que tem as características de uma rede. A palavra rede indica que os recursos estão concentrados em poucos locais - nas laçadas e nos nós - interligados - fios e malhas. Essas conexões transformam os recursos esparsos numa teia que parece se estender por toda a parte.” (Latour, 1998, pag. 294)

A tentativa mais influente de mapear as regras de conduta, ou seja, as normas sociais que pautam os cientistas e permite distingui-los como membros de uma comunidade propõe a existência de quatro normas básicas: universalismo, sentido de comunidade, desprendimento e ceticismo organizado (Meadows, 1999, p. 49). O universalismo representa a prática científica de avaliar qualquer resultado com critérios impessoais, apenas com interesse no rigor e na metodologia utilizada para se chegar a qualquer resultado, independente de outras características pessoais de quem produziu uma pesquisa. O sentido de comunidade representa a prática de que o conhecimento científico deve ser propriedade comum, permitindo que qualquer grupo possa utilizar os resultados de outro no avanço de suas pesquisas. $\mathrm{O}$ desprendimento é a prática que orienta o pesquisador a focar no progresso do conhecimento, mais do que em outros fatores. O ceticismo organizado representa a prática de submeter qualquer trabalho científico a análise crítica para avaliação pelos pares. 
Com base nas regras de conduta apresentadas acima, mesmo sabendo que representam um ideal e uma utopia a ser seguido, entendemos que é fundamental para a rede de interações que configura a comunidade científica tornar públicos os resultados de uma pesquisa científica. É um meio de ser reconhecido e se fazer parte da comunidade. Um cientista é reconhecido e constrói sua reputação quando publica trabalhos relevantes, recebe positivas avaliações de seus pares. Um novo cientista será reconhecido como atuando numa área específica quando publicar trabalhos em revistas importantes de sua área, que são lidas e avaliadas continuamente por outros pesquisadores que têm interesse no desenvolvimento do conhecimento dessa região da ciência. Tornar públicos os resultados é um recurso básico de interação entre pesquisadores, possibilitando que se alimentem de novas ideias, novas maneiras de enxergar os problemas que estudam, viabilizando dessa maneira processos de inovação e alargamento das fronteiras do conhecimento humano. Logo, a interação entre cientistas permeia todo o processo de produção científica, que vai desde o surgimento de uma ideia até a publicação dos resultados da pesquisa (Weitzel, 2006, p. 97). Essa visão é também compartilhada por Katz e Martin (1997), que contextualiza a ciência como uma instituição social, onde o avanço depende crucialmente das interações entre os cientistas. A ciência, vista como manifestação cultural e social, funciona em rede por meio dos recursos de relações que a constituem, tais como a comunicação direta, verbal e gestual, a comunicação escrita e virtual (Pisciotta, 2006, p. 133).

Entendemos, dessa maneira, que a colaboração científica ocorre quando os cientistas, através de suas ações, conservam a rede de interações que permite caracterizá-los como uma comunidade científica. Vejamos como essa rede de interações é descrita por Lara e Lima (2009) quando define a expressão colaboração científica:

“Processo social intrínseco às formas de interação humana para efetivar a comunicação e o compartilhamento de competências e recursos. A colaboração científica é um meio para otimizar recursos, dividir o trabalho, aliviar o isolamento próprio da atividade acadêmica, criar sinergia entre os membros da equipe na conclusão de projetos etc. O processo de colaboração científica é permeado por fatores como: a alteração no padrão e níveis de financiamento; os anseios por parte dos pesquisadores em aumentar a popularidade, visibilidade e reconhecimento científico; a demanda gradual pela racionalização do poder científico; a necessidade de mais instrumentos, em maior escala e cada vez mais complexos, o aumento na especialização na ciência; o avanço das disciplinas nas quais o pesquisador necessita cada 
vez mais de conhecimento de outros pesquisadores; a profissionalização crescente da ciência; a necessidade de adquirir experiência e treinar novos pesquisadores; o desejo de trabalhar interdisciplinarmente entre as áreas; a necessidade de trabalhar em estreita proximidade física com outros pesquisadores para beneficiar-se das habilidades e conhecimentos implícitos. A negociação e a troca na colaboração científica exigem, também, investimentos de ordem sócio-emocional para manter relacionamentos colaborativos. A colaboração científica pode ser medida a partir da interação entre os pesquisadores."

Os fatores que permeiam a colaboração científica são basicamente fatores ligados aos jogos de interação sociais e seus diversos interesses entre os pesquisadores quando atuam em parcerias, grupos e equipes de trabalho com objetivos científicos e, sobretudo, políticos em comum. Entendendo que a unidade básica fundamental da colaboração é o contato direto entre duas pessoas (Vanz e Stumpf, 2010), portanto, que a colaboração científica pode ser medida a partir da interação entre os pesquisadores, a questão que surge é quais são os dispositivos utilizados pela comunidade científica que registram essa interação e que podem servir de base para o estudo de padrões de colaboração e articulação.

É novamente Latour que nos auxilia quando descreve a importância dos textos científicos como um dispositivo fundamental não só de sistematização do conhecimento, mas, sobretudo, como um dispositivo de aquecimento da conversação entre pesquisadores a partir de suas disputas de sentido, de suas colaborações e da busca por produção de relevância em uma área do conhecimento.

\footnotetext{
"Os textos científicos ou técnicos - usarei os dois termos indiferentemente não são escritos de modo diverso por diferentes castas de escritores. Entrar em contato com eles não significa deixar a retórica e entrar no reino mais tranquilo da razão pura. Significa que a retórica se aqueceu tanto ou ainda estão tão ativa que é preciso buscar mais reforços para manter a chama dos debates. Explico o que acabo de dizer por meio do exame da anatomia do mais importante e menos estudado dos veículos retóricos: o artigo científico." (Latour, 1998, pag. 55)
}

Os cientistas conversam e aquecem sua retórica a partir de seus dispositivos de sistematização da informação, quando e onde desenvolvem o maior nível possível de estruturação 
de seus argumentos, visando mobilizar o maior número de pessoas em torno de seu objeto de conhecimento, ampliando sua relevância e capacidade de influenciar o pensamento de sua comunidade.

Vejamos a seguir como esses dispositivos operam e como são articulados pelas redes sociais da ciência.

\subsection{Dispositivos de sistematização da informação da comunidade acadêmica}

Os cientistas utilizam diversos dispositivos para sistematizar informações em seu fazer científico. Como vimos acima, esses dispositivos acabam por funcionar como modos de conversação da comunidade acadêmica, sendo canais por onde as opiniões, os embates e as colaborações terminam por se expressar devido ao alto nível de sistematização que a comunidade exige para considerar objetos do conhecimento como relevantes.

A CAPES (Coordenação de Aperfeiçoamento de Pessoal de Nível Superior) é um dos mais altos órgãos federais do governo brasileiro que tem por objetivo produzir critérios de avaliação e avaliar como se desenvolvem instituições de pequisas, grupos, pesquisadores e suas diferentes áreas do conhecimento. A CAPES (2009) indica em seus critérios de avaliação quais são os dispositivos de sistematização da informação que devem ser acompanhados quando da análise da produção intelectual de pesquisadores, divididos em três grandes categorias, produção bibliográfica, produção técnica e produção artística.

Mencionamos na tabela 3.1, a seguir, e utilizaremos como referência para nossa pesquisa os dispositivos apontados pela CAPES (2009) para a área das Ciências Sociais Aplicadas, onde se encontra a área da Ciências da Comunicação.

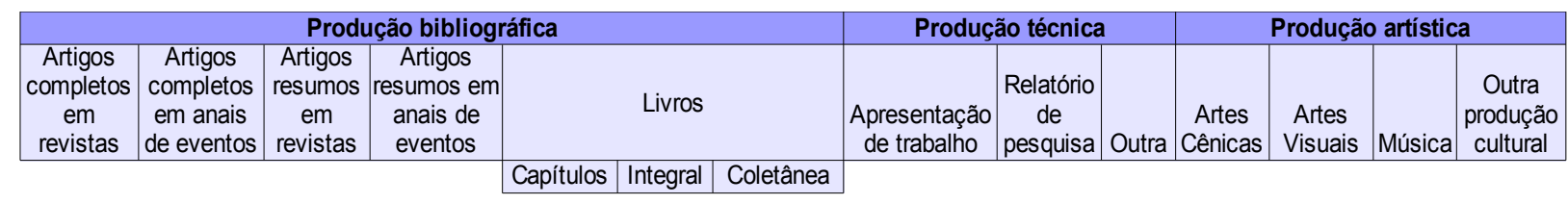

Tabela 3.1. Dispositivos de produção intelectual. Fonte: CAPES, 2009.

A questão imediata que nos colocamos diz respeito aos critérios de avaliação desses dispositivos e que princípios de base são utilizados como orientação em sua produção. Sugerimos aqui que a CAPES define seus critérios com base em parâmetros que explicitam o nível de estruturação e articulação necessários para se conseguir publicar um determinado trabalho. No 
fundo, é esse nível de articulação que funciona como um operador de distribuição de recursos financeiros, cargos e posições sociais. Vejamos como isso opera tomando por referência a própria definição da CAPES (2009) dos critérios utilizados para definir seus diferentes níveis de qualis para os artigos em periódicos:

\section{- Estrato C}

- Periódicos impróprios, considerados não científicos não receberão pontuação.

- Estrato B5

- Periódicos que atendam aos critérios mínimos, sem cumprir quaisquer das exigências adicionais descritas nos estratos subsequentes.

- Estrato B4

- Publicar pelo menos $20 \%$ de artigos cujos autores sejam vinculados a pelo menos 3 instituições diferentes daquela que edita o periódico, por volume;

- Publicar pelo menos 20\% de autores doutores;

- Manutenção da periodicidade.

- Estrato B3

- Ser publicado por instituição com Pós-Graduação stricto sensu, ou Sociedade Científica de âmbito nacional reconhecida pela Coordenação de Área, ou por Instituição Profissional de âmbito nacional, ou Instituição de Pesquisa, ou ser publicada com apoio da CAPES, CNPq ou financiamento estatal;

- Publicar pelo menos 30\% de artigos cujos autores sejam vinculados a pelo menos 3 instituições diferentes daquela que edita o periódico, por volume;

- Publicar pelo menos $40 \%$ de autores doutores;

- Manutenção da periodicidade.

- Estrato B2

- Ser publicado por instituição com Pós-Graduação stricto sensu, ou Sociedade Científica de âmbito nacional ou internacional reconhecida pela Coordenação de Área, ou por Instituição Profissional de âmbito nacional, ou Instituição de Pesquisa, ou ser publicada com apoio da CAPES, CNPq ou financiamento estatal;

- Publicar pelo menos 50\% de artigos cujos autores sejam vinculados a pelo menos 3 instituições diferentes daquela que edita o periódico, por volume;

- Presença em duas das seguintes bases de dados ou indexadores do tipo: LATINDEX 
(Sistema Regional de Información em Línea para Revistas Científicas de América Latina, el Caribe, España e Portugal); REDALYC (Red de Revistas Científicas de América Latina, el Caribe, España y Portugal); Directory of Open Access Journals (DOAJ) - (para periódicos eletrônicos); CLACSO , CLASE - Citas Latinoamericanas En Ciencias Sociales Y Humanidades e Ciência da Informação e Museologia: Paschal Thema: Science de L'Information, Documentation; INFOBILA (Base de Dados de Información y Bibliotecologia Latinoamericana) ; Library Literature \& Information Science, Library and Information Science Abstracts (LISA); Scopus, ISI (Web of Science); ou similar; Comunicação: Communication \& Mass Media CompleteTM (CMMC),Scopus, , Index to Journals in Communication Studies (Índice impresso), LATIN AMERICAN PERIODICALS TABLES OF CONTENTS (LAPTOC, Communication Abstracts; Scopus; ISI (Web of Science) ou similar;

- Publicar pelo menos $60 \%$ de autores doutores;

- Manutenção da periodicidade.

- Estrato B1

- Ser publicado por instituição com Pós-Graduação stricto sensu, ou Sociedade Científica de âmbito nacional ou internacional reconhecida pela Coordenação de Área, ou por Instituição Profissional de âmbito nacional, ou Instituição de Pesquisa, ou ser publicada com apoio da CAPES, CNPq ou financiamento estatal;

- Manutenção da periodicidade;

- Presença em três das seguintes bases de dados ou indexadores do tipo: LATINDEX (Sistema Regional de Información em Línea para Revistas Científicas de América Latina, el Caribe, España e Portugal); REDALYC (Red de Revistas Científicas de América Latina, el Caribe, España y Portugal); Directory of Open Access Journals (DOAJ) - (para periódicos eletrônicos) e Ciência da Informação e Museologia: Paschal Thema: Science de L'Information, Documentation; INFOBILA (Base de Dados de Información y Bibliotecologia Latinoamericana) ; Library Literature \& Information Science, Library and Information Science Abstracts (LISA); Scopus, ISI (Web of Science); Scielo; ou similar; Comunicação: Communication \& Mass Media CompleteTM (CMMC) , Scopus, ComAbstracts, Index to Journals in Communication Studies (Índice impresso), LATIN AMERICAN PERIODICALS TABLES OF CONTENTS (LAPTOC), Communication Abstracts; Scielo; Scopus; 
ISI (Web of Science) ou similar;

- Publicar pelo menos $60 \%$ de artigos cujos autores sejam vinculados a pelo menos 4 instituições diferentes daquela que edita o periódico, por volume;

- Publicar pelo menos $10 \%$ de artigos, por volume, com autores ou co-autores filiados a instituições estrangeiras;

- Publicar pelo menos 70\% de autores doutores.

- Estrato A2

- Ser publicado por instituição com Pós-Graduação stricto sensu, ou Sociedade Científica de âmbito nacional ou internacional reconhecida pela Coordenação de Área, ou por Instituição Profisssional de âmbito nacional, ou Instituição de Pesquisa, ou ser publicada com apoio da CAPES, CNPq ou financiamento estatal;

- Manutenção da periodicidade;

- Presença em quatro das seguintes bases de dados ou indexadores do tipo: LATINDEX (Sistema Regional de Información em Línea para Revistas Científicas de América Latina, el Caribe, España e Portugal); REDALYC (Red de Revistas Científicas de América Latina, el Caribe, España y Portugal); Directory of Open Access Journals (DOAJ) - (para periódicos eletrônicos) e Ciência da Informação e Museologia: Paschal Thema: Science de L'Information, Documentation; INFOBILA (Base de Dados de Información y Bibliotecologia Latinoamericana) ; Library Literature \& Information Science, Library and Information Science Abstracts (LISA); Scopus, ISI (Web of Science); Scielo ou simila ; Comunicação: Communication \& Mass Media CompleteTM (CMMC), Scopus, ComAbstracts, Index to Journals in Communication Studies (Índice impresso), LATIN AMERICAN PERIODICALS TABLES OF CONTENTS (LAPTOC), Communication Abstracts; Scielo; Scopus; ISI (Web of Science) ou similar ;

- Publicar pelo menos 70\% de artigos cujos autores sejam vinculados a pelo menos 4 instituições diferentes daquela que edita o periódico por volume;

- Publicar pelo menos $20 \%$ de artigos, por volume, com autores ou co-autores filiados a instituições estrangeiras;

- Publicar pelo menos $80 \%$ de autores doutores.

- Estrato A1

- Periódicos de destacada qualidade, devidamente demonstrada em relatório pelos avaliadores e necessariamente superiores a todas as exigências estabelecidas para o 


\section{Estrato 6;}

- Títulos do JCR de 2008.

Ao mapearmos a produção de critérios de avaliação da produção científica acadêmica, nos deparamos também com o modo como os programas de pós-graduação organizam em suas Comissões de Pós-graduação e Pesquisa critérios para a composição de bancas de mestrado e doutorado, também influenciados pelas políticas de avaliação regulamentadas pela CAPES. Vejamos aqui um exemplo, extraído da Universidade Federal do Rio de Janeiro na unidade Coppe Instituto Alberto Luiz Coimbra de Pós-Graduação e Pesquisa de Engenharia ${ }^{11}$, sobre os critérios de formação das bancas de mestrado e doutorado (o que é entendido por pesquisa tipo I e tipo II é definido logo a seguir):

\section{Mestrado}

- Pelo menos 1 (um) membro da banca externo ao Programa deverá ter produção científica independente do(s) orientador(es) da dissertação equivalente a, no mínimo, 8 (oito) pontos de pesquisa avançada (Tipo I) ou 16 (dezesseis) pontos de pesquisa total (Tipos I ou II). Pelo menos 4 pontos de pesquisa avançada (Tipo I)* ou 6 pontos de pesquisa Tipo II* deverão ter sido publicados nos últimos 3 anos;

- Os demais membros da banca deverão possuir produção científica mínima equivalente a 10 (dez) pontos de pesquisa total (Tipos I ou II).

\section{Doutorado}

- Pelo menos 2 (dois) membros da banca deverão apresentar produção científica independente do(s) orientador(es) da tese de, no mínimo, 8 (oito) pontos de pesquisa avançada (Tipo I). Pelo menos metade dessa produção deverá ter sido publicada nos últimos 3 anos.

- Deverá ser incluído na banca pelo menos 1 (um) membro externo à UFRJ que seja pesquisador sênior com produção científica majoritária independente do(s) orientador(es) da tese e equivalente a 30 (trinta) pontos de pesquisa avançada (Tipo I), sendo que parte (a critério da CPGP) dessa produção deve ser dos últimos 3 anos.

- Os demais membros da banca deverão possuir uma produção científica mínima equivalente a 8 (oito) pontos de pesquisa avançada (Tipo I).

\section{Pesquisa Tipo I:}

11 www.coppe.ufrj.br/ensino/arquivo_cpgp/diretrizesbancas.pdf. Acessado em 25/08/2012. 
a. Periódicos de circulação internacional indexados (JCR) - 4 pontos.

b. Livros de circulação internacional - 10 pontos.

c. Capítulos de Livros (stricto sensu) de circulação internacional - 4 pontos.

\section{Pesquisa Tipo II:}

a. Periódicos de circulação internacional não indexados -4 pontos.

b. Periódicos de circulação nacional - 3 pontos.

c. Livros de circulação nacional - 10 pontos.

d. Trabalhos completos publicados em anais de congressos internacionais -2 pontos.

e. Trabalhos completos publicados em anais de congressos nacionais -1 ponto.

Ao observar os tipos principais de critérios mencionados nas descrições acima, propomos ao menos três recorrências que se repetem ao longo dos critérios:

- variação dos vínculos institucionais dos autores, incluindo vínculos com instituições do exterior;

- categorias e porcentagem de titulações dos autores exigidas;

- participação em bases de dados de alta relevância;

- os critérios de avaliação de periódicos não incluem exigências de relacionamento entre pesquisadores, o que ocorre nos critérios para formação de bancas, quando é exigido a participação de pesquisadores externos ao programa (Mestrado) e a própria universidade (Doutorado).

São critérios, do nosso ponto de vista, que têm por objetivo gradativamente ampliar a variedade, abrangência e nível formal de titulação das instituições e dos autores que publicam seus trabalhos sob esses critérios. Estamos falando aqui de critérios que promovem, movimentam e agenciam redes de pesquisadores quando buscam ampliar o potencial e a relevância de sua produção científica como estratégia de melhor nível de avaliação. Desse ponto de vista, estamos diante de camadas de redes que terminam por ser interdependentes, dado que os pesquisadores podem se movimentar por todos esses critérios através do uso de diferentes estratégias de articulação de suas conexões em rede. Os critérios ajudam a delimitar diferentes níveis de exigência para tipos específicos de redes de conversação. São critérios que instauram uma política de produção científica e um modo de governança da comunidade científica.

A relevância dessas informações fica visível quando entendemos que a avaliação da CAPES está atrelada diretamente a relatórios que vão impactar, em última instância, na distribuição de 
recursos financeiros para os pesquisadores, as instituições e seus programas de pesquisa. Logo, podemos inferir, que esses critérios passam a fazer parte do cotidiano da comunidade científica, que os utiliza como referência na produção de suas estratégias de pesquisa, buscando alcançar a maior relevância possível. A articulação das redes sociais da comunidade acadêmica não só se preocupa na produção de textos científicos, mas de tipos específicos de textos que trarão como retorno imediato maior ou menor projeção segundo os critérios de avaliação sob os quais estão submetidos. Esses critérios, sem dúvida, devem ser levados em consideração quando da modelagem de redes sociais de uma área do conhecimento, pois evidenciam valores que vão influenciar a estrutura e a dinâmica de como uma rede irá operar.

Os dispositivos são as formas que a comunidade científica utiliza para registrar sua produção, são os mecanismos que permitem tornar pública uma pesquisa, bem como o registro das relações de colaboração entre pesquisadores que permitiram gerar os resultados apresentados numa dada publicação.

A colaboração científica é muitas vezes relacionada na literatura científica à co-autoria (Maia e Caregnato, 2008) (Vanz e Stumpf, 2010) (Bufrem, 2010) (Bufrem, Gabriel e Gonçavelz, 2010). Essa correlação direta é feita com base numa das regras centrais de funcionamento da comunidade científica, que é a necessidade de publicar um trabalho para que ele se torne reconhecido como produção científica de uma área do conhecimento. A premissa é que há diversas interações formais e informais entre os cientistas, mas que essas interações em torno da produção irão se materializar de alguma forma em uma publicação.

O produto da produção científica, com seus artigos, relatórios, teses e dissertações, em suas diferentes formas de publicação, acabam constituindo pontos de conexão que permitem sua caracterização como verdadeiras redes sociais, de informação, de comunicação e de conhecimento (Miranda, 2009, p. 109). Os níveis formal e informal de colaboração científica tem relação direta com a forma como ocorre a comunicação científica entre os pesquisadores na atualidade, podendo ser classificada em três categorias básicas: formal, informal e eletrônica (Pisciotta, 2006, p. 125). A formal diz respeito a todo dispositivo de comunicação escrita, como artigos, revistas, livros, anais de congresso, teses, dissertações etc. A informal diz respeito ao que ocorre nos contatos interpessoais, como encontros em reuniões, palestras, congressos, seminários, etc. A comunicação eletrônica auxilia na manutenção da comunicação informal, criando registro e constituindo, muitas vezes, bases de dados que podem ser utilizadas como mais um plano de relações de como se relaciona a comunidade científica.

Os pontos de conexão ficam explícitos quando os nomes dos pesquisadores que auxiliaram de alguma forma nos resultados apresentados são registrados, bem como das instituições e grupos 
de pesquisa que representam em sua atuação científica. A relação de colaboração surge como resultado da participação de um pesquisador em algum momento da pesquisa, seja opinando no desenvolvimento de um trabalho, sejam fornecendo ideias significativas, seja questionando os métodos adotados ou fornecendo novos dados que devem ser considerados para análise.

No entanto, nem todas as relações de colaboração científica terminam por ser registradas em algum tipo de publicação. É preciso considerar relações entre pesquisadores que são informais demais, apesar de não menos importantes na influência sobre um determinado trabalho científico, para serem registradas em algum tipo de publicação. É como se o nível ou intensidade de colaboração precisasse alcançar um determinado grau para ser reconhecido como tal e ser registrado formalmente (Katz e Martin, 1997). Abaixo desse grau, a relação termina por ser considerada informal, não merecendo registro explícito.

Muitas das relações inicialmente informais podem terminar por serem recorrentes e se transformarem ao longo do tempo em relações formais. A dinâmica que rege essa passagem de relação formal e informal é complexa e carece de maiores estudos, sobretudo, devido a falta de dados para análise de como ocorre a colaboração informal.

As relações de colaboração informais entre os pesquisadores dificilmente são registradas de alguma forma em sistemas de informação. Dificilmente podem ser recuperadas, a não ser por pesquisas qualitativas onde cientistas podem ser entrevistados para apontarem quais foram e como se deram essas relações. No entanto, os processos formais deixam registro, normalmente em sistemas de informação que têm por objetivo facilitar o acesso as produções científicas. Katz e Martin (1997) argumentam que as relações formais não são perfeitas para a caracterização da colaboração científica, mas possuem três importantes vantagens em relação ao estudo das relações informais. Elas dão acesso a amostras de dados que facilitam com que outros pesquisadores possam reproduzir os resultados, seu estudo é relativamente barato oferecendo métodos práticos para quantificação da colaboração e o tamanho das amostras que são passíveis de análise usando esses métodos podem ser muito grandes, resultando em estudos com validade estatística mais significante do que estudos de caso específicos.

Logo, o estudo desses sistemas e dos tipos de relações que podem disponibilizar em seus dados se torna um elemento fundamental para o estudo da estrutura e da dinâmica das redes de interação. Vale lembrar que essas redes são formadas pelos padrões de colaboração, que se materializam pela produção científica quando disponibilizada nos sistemas de informação. Quanto mais abrangentes forem as bases de dados desses sistemas, mais representativas serão as redes de interação da real dinâmica de colaboração científica.

Os dispositivos nos quais se dá a colaboração são diversos e ocorrem através de diferentes 
estratégias que mobilizam a comunidade científica, criando espaços de interação que facilitam e promovem compartilhamento de informações, análise crítica e mapeamento de novas tendências por parte dos pesquisadores. Ora formais, ora informais, são eles as estratégias utilizadas pela comunidade científica para conservar sua rede de interações, suas regras e normas de conduta, caracterizando, dessa maneira, seu sistema social.

Um dispositivo importante que tem influência quando buscamos analisar as redes sociais acadêmicas são as teses e dissertações. A defesa de uma tese ou dissertação é uma das etapas da divulgação dos resultados de uma pesquisa que poderá também ser comunicada em outros formatos, como artigos, capítulo de livro, congresso, entre outros. As dissertações e teses acabam por configurar um acervo científico importante, pois o trabalho é julgado por pares no momento da pesquisa onde o estado do conhecimento é mais atualizado, sendo base para estudos que buscam determinar as tendências de um campo de estudo (Lopes e Romancini, 2006, p. 143). Epstein (2009, p. 50) analisando um artigo que estudou as redes sociais formadas pelos grupos de pesquisa em Ciência da Informação chama a atenção para as teses e dissertações, questionando se não seria o caso de pesquisas futuras investigarem esse ponto.

A realização da defesa de uma tese ou dissertação, considerando a presença da banca de pesquisadores, pode ser considerado como um espaço importante onde, na dinâmica da comunidade científica, relações de colaboração podem ocorrer. Essas relações podem se dar de maneira formal, onde a banca colabora com suas críticas e sugestões ao trabalho que está sendo avaliado, e de maneira informal, considerando o espaço de conversação entre os pesquisadores e participantes, que podem aproveitar as oportunidades para se conhecerem melhor, informar novidades de seu campo, apontar tendências ou estabelecer parcerias. As participações em bancas, teses e atividades de orientação podem tanto revelar cooperações não declaradas em publicações conjuntas, quanto estabelecer fontes de contatos entre interessados (Balancieri et al, 2005).

A ideia por trás dessas cooperações é de que elas não ocorrem apenas entre aqueles que assinam uma obra, mas sim entre todos aqueles que produzem a chance de constituição de outros textos (Targino, 2010), a partir de seus comentários, críticas e opiniões. E não seriam essas as funções de uma banca? Ao ler os trabalhos, ao perceber pontos que precisam ser melhorados, analisados sobre diferentes visões, ressaltando qualidades e deficiências de um trabalho, a banca fornece subsídios para que outras narrativas sejam possíveis, para que outras teses e dissertações possam surgir, seja da melhora do trabalho atual, seja no estabelecimento de novas conexões e insights que podem surgir das conversas ali estabelecidas. É mais uma estratégia de reforço às redes de interação da comunidade científica.

O que tomamos como princípio é que as bancas de defesas de teses e dissertações podem ser 
entendidas como dispositivos de promoção da colaboração científica. O ponto-chave é que esses dispositivos vêm ganhando importantes espaços de sistematização da informação, através do uso de sistemas de informação, como as Bibliotecas Digitais de Teses e Dissertações, que tornam públicos os dados da tese, bem como dos participantes das bancas de defesa. Vejamos como o número de teses e dissertações vem crescendo, por ano de defesa, nas bases de dados da BDTD ${ }^{12}$ :

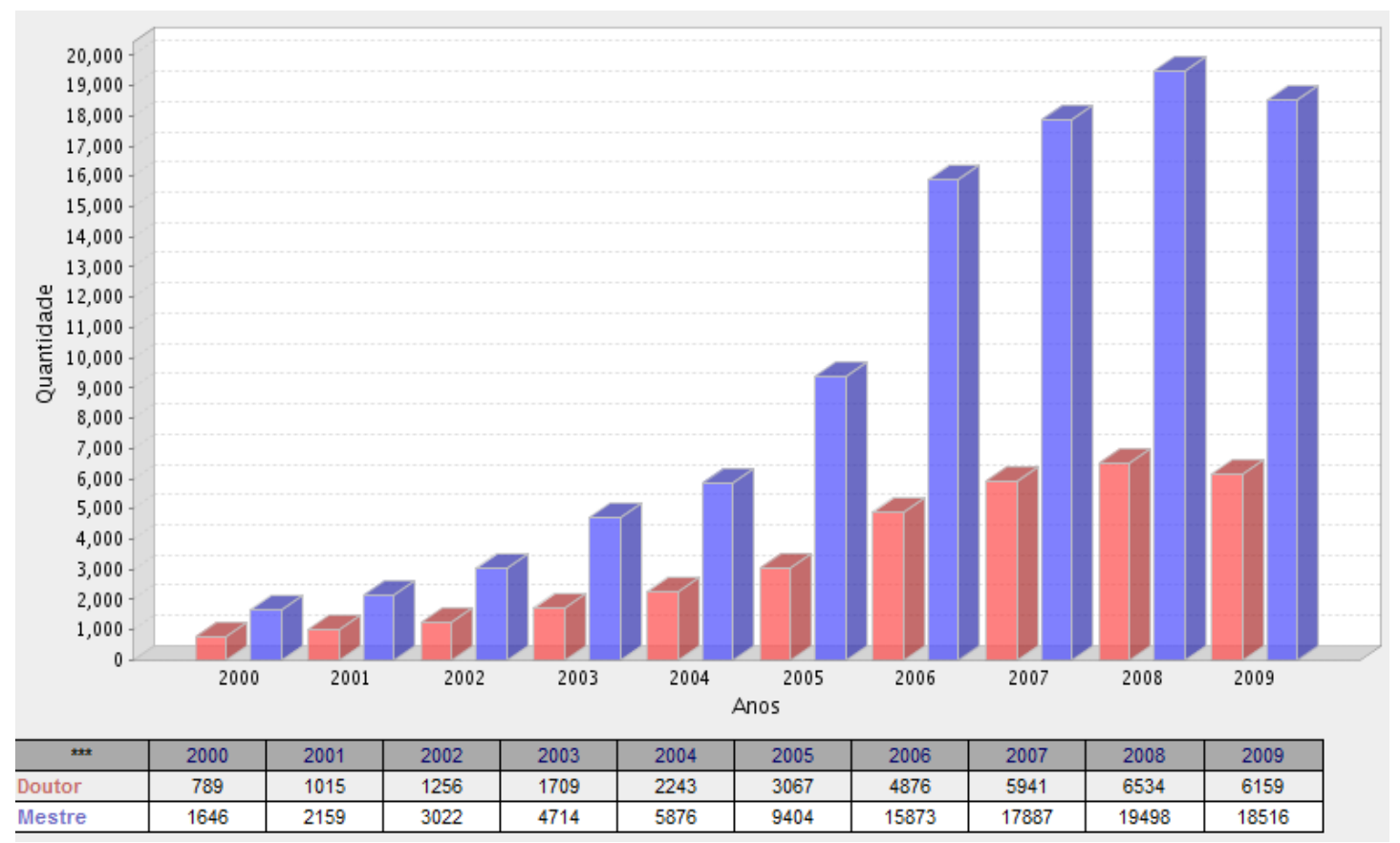

Figura 3.1. Evolução no número de teses e dissertações nas bases da BDTD. Fonte: http://bdtd.ibict.br

Os dados mostram crescimento expressivo desde o início dos anos 2000. É importante dizer que esse aumento não se deve apenas ao aumento do número de estudantes em nível de pósgraduação, mas sim, também, ao aumento no número de bibliotecas digitais em instituições de pesquisa que passaram a fornecer dados para o sistema da BDTD. Esses dados reforçam a relevância da utilização das relações formadas nas bancas de defesa como espaço de investigação de relações de colaboração.

Estudar se existem correlações entre as redes das bancas de defesa e as redes de co-autoria pode ampliar a visão e indicar novas tendências de como a comunidade científica se regula e se organiza. Vale frisar que não encontramos na bibliografia pesquisada nenhum estudo científico que tenha utilizado as bases de dados de bibliotecas digitais de teses e dissertações para o estudo das redes de interação entre os pesquisadores participantes das bancas de defesa.

12 http://bdtd.ibict.br/pt/indicadores.html 


\subsection{Tendências da colaboração científica}

A colaboração na área da ciência vem modificando a forma de organizar e produzir ciência nas últimas décadas, a começar pelo trabalho em equipe na produção científica. A organização de equipes de pesquisa científica é um fenômeno que se desenvolveu na primeira metade do século $\mathrm{XX}$, com o surgimento dos primeiros grupos científicos constituídos por assistentes de pesquisa, estudantes de pós-graduação, técnicos, professores, todos orientados por um pesquisador sênior em sua área (Meadows, 1999, p. 108).

A organização do trabalho em equipe reflete um maior nível de investimentos em novas instituições, novos laboratórios e, sobretudo, novas subdivisões e campos do conhecimento científico (Wuchty, Jones e Uzzi, 2007). Esse crescimento da ciência também se refletiu no número de publicações científicas, que vem crescendo de forma exponencial nos últimos 60 anos, gerando uma verdadeira explosão informacional que afeta os pesquisadores de muitas maneiras. Esse fenômeno tem levado os pesquisadores a restringirem sua atenção a partes específicas da pesquisa científica, mantendo, de certa maneira, a quantidade de informações que precisam lidar em sua área num nível ainda aceitável (Gardin, 2001) (Meadows, 1999, p. 19).

Podemos dizer que a colaboração é uma tendência crescente de forma geral em todas as áreas da ciência (Meadows, 1999, p. 110). Num estudo publicado em 2007 com 19.9 milhões de artigos científicos e 2.1 milhões de patentes de todas as áreas da ciência da base de dados Web of Science do Institute for Scientific Information (ISI), Wuchty, Jones e Uzzi (2007) demonstraram que a colaboração científica, refletida no aumento do número de artigos e de pesquisadores que realizam trabalhos em co-autoria, vem crescendo de maneira expressiva na ciência em geral. Seus resultados indicam que trabalhos assinados por mais de um autor produzem pesquisas que são mais citadas, sendo essa uma tendência que vem se ampliando com o tempo. Considerando o campo das Ciências Sociais em geral, em 1955 os cientistas escreveram apenas 17,5\% dos artigos em coautoria, já no ano 2000, esse número passou para 51,5\% dos artigos, sendo a média de 2 de autores por artigo na área. Mais especificamente, na área de Ciências da Informação a média cresceu de 1,07 para 1,69 nas últimas décadas, representando um aumento de $58 \%$ no crescimento da coautoria. Já na área de Ciências da Comunicação a média cresceu de 1,16 para 1,75, representando um aumento de $51 \%$. Vejamos na figura 3.2 as curvas de crescimento das quatro principais áreas do estudo citado. 


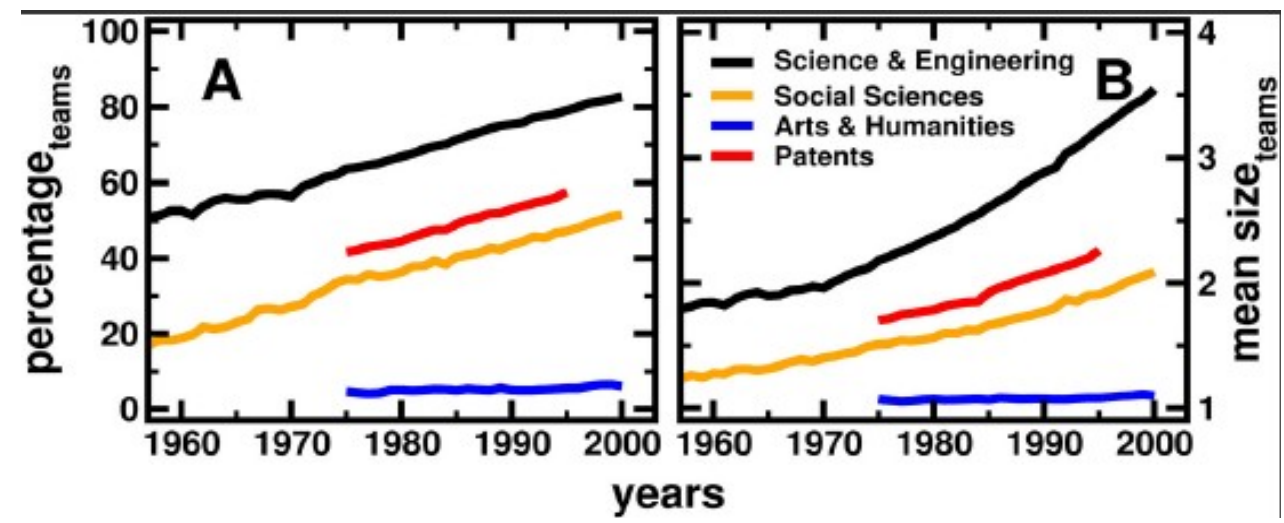

Figura 3.2. Crescimento da colaboração científica nas áreas da Ciência e Engenharia, Ciências Sociais, Artes e Humanidades e Patentes. Fonte:

Wuchty, Jones e Uzzi (2007).

Ao observar a figura 3.2, percebemos que apesar do aumento das Ciências Sociais em geral ser menor que nas Ciências e Engenharia, é uma tendência com crescimento linear e que vem se mantendo ao longo das décadas desde final dos anos 50 até começo dos anos 2000, chegando a média de 2 autores por publicação.

Um outro estudo importante no Brasil, dessa vez focado nos grupos de pesquisa em Comunicação cadastrados no Diretório do CNPq (Lopes e Romancini, 2009), parece também reforçar a mesma tendência para as Ciências da Comunicação. Os dados coletados foram do censo de 2004, tendo sido encontrados 270 grupos de pesquisa na área. No período de 1993 a 2004, houve um crescimento de 33 para 270 grupos, passando a representar de $0,5 \%$ a $1,4 \%$ do total dos grupos de pesquisa cadastrados na plataforma. A maioria dos grupos de pesquisa, cerca de $58,1 \%$, possuem entre 1 a 4 anos de existência, apontando para um fenômeno recente de expansão nos últimos anos dos dados coletados do estudo. O estudo também apontou que o número médio de participantes por grupo de trabalho era de 9,7 pessoas, distribuídos entre líderes, pesquisadores, estudantes e técnicos de apoio. Considerando o tamanho dos grupos, o aumento significativo no número de grupos e, tomando como hipótese que mais grupos de pesquisa impulsionam mais trabalhos de co-autoria pelas relações de colaboração entre os pesquisadores do grupo a partir do interesse de temas em comum, o estudo reforça a tendência no aumento da colaboração também na área de Comunicação no Brasil.

Sem dúvida, os dados apresentados indicam maior interação entres pesquisadores, apontando uma tendência crescente no aumento da colaboração científica de forma geral. Há diversos motivos que têm influenciado e são influenciados pelas práticas sociais promovidas pela comunidade científica que ajudam a explicar essa tendência de crescimento da colaboração na ciência em geral (Katz e Martin, 1997):

- mudanças nos padrões e níveis de financiamento, que acabam por privilegiar pesquisas 
realizadas por grupos de cientistas do que financiar pesquisadores individuais;

- o desejo dos pesquisadores de aumentar sua popularidade científica, visibilidade e reconhecimento;

- aumento nas demandas por racionalização dos recursos científicos;

- aumento na complexidade da instrumentação científica;

- aumento na especialização na ciência;

- avanço nas disciplinas científicas, significando que os pesquisadores precisam ter mais conhecimentos específicos para realizar progressos significativos. Essa é uma demanda que promoveria maior interação entre especialistas;

- crescimento da profissionalização científica;

- necessidade de treinamento e experiência da maneira mais efetiva possível;

- ampliação no desejo de interconectar disciplinas;

- maior necessidade de trabalhar fisicamente próximo a outros pesquisadores, de maneira a se beneficiar de seus conhecimentos tácitos.

O que esses motivos têm em comum é que eles surgem como iniciativa de reforçar as redes de interação entre os pesquisadores, a partir da constante negociação de suas normas e regras de conduta, como vimos acima. Esses critérios demonstram o grau de racionalismo na produção científica que tem levado a novas estratégias de colaboração entre pesquisadores, se mantendo em evidência e em condições de disputarem a partir dos critérios de distribuição de recursos e posições.

É essa pressão pelos indicadores e resultados que é colocada aos acadêmicos que parece também influenciar a maneira como as relações de co-autoria vem se modificando nas últimas décadas. Targino (2010) aponta que os pesquisadores acabam sendo pressionados a atuarem como uma verdadeira indústria de produção de artigos, levando a autores de artigos acrescentarem coautores por coação, amizade, conveniência, falta de esclarecimento, intenção de facilitar a ascensão profissional do colega etc. Aponta também mais dois fatores agravantes dessa situação, a maior exigência dos órgãos de fomento de privilegiar projetos integrados de pesquisa e o fato de revistas e eventos renomados privilegiarem textos produzidos por autores com titulações mais elevadas.

Os motivos acima ajudam a entender como diversas forças que atuam no campo social da ciência vêm influenciando mudanças nos padrões de colaboração científica nas últimas décadas. Sejam fatores que tem por objetivo aumentar o ciclo virtuoso da produção científica ou estratégias de sobrevivência e ascensão social criadas pelos pesquisadores em resposta às circunstâncias institucionais em que vivem, esses fatores criam efeitos dinâmicos que podem ser percebidos nas 
mudanças de padrões das redes de interação entre cientistas, gerando ondas de influência que percorrem todo o sistema social da ciência. Beaver (2001) aponta que essas mudanças de padrões de colaboração criam efeitos exponenciais na produtividade e no impacto da produção científica.

\subsection{Efeitos da colaboração na produtividade e no impacto}

A lei de Lotka é uma conhecida distribuição que avalia o grau de produtividade dos pesquisadores medindo a assimetria da produção entre eles. Segundo essa lei, o número de autores que publicam cai na proporção do inverso do quadrado do número de artigos publicados. Ou seja, um pequeno grupo de pesquisadores será responsável pela maioria da publicação científica de um campo. Se um campo possuir 100 autores, é possível que 10 deles sejam responsáveis pela metade da produção científica de sua área (Meadows, 1999, p. 87).

A questão que se coloca é se existe algum tipo de correlação entre os pesquisadores que fazem parte desse grupo mais produtivo e seus padrões de colaboração. Katz e Martin (1997) mapearam 10 estudos que parecem confirmar que os pesquisadores de maior produtividade são os que possuem maior nível de colaboração. Alguns dos estudos também apontam que há correlação entre o impacto das pesquisas e o nível de colaboração em sua produção, fornecendo evidências de que o número de citações de uma publicação aumenta na proporção em que cresce o número de autores. Essa visão também é reforçada em evidências por Meadows (1999), Maia e Caregnato (2008) e Wuchty, Jones e Uzzi (2007).

No entanto, existem padrões específicos de relação entre produtividade e colaboração para diferentes campos científicos. A colaboração promove aumento na produtividade até um certo limite, a partir do qual o nível de correlação começa a se tornar negativo (Maia e Caregnato, 2008). Em áreas como matemática esse limite está entre 1-2 autores, 3-4 em química e 5-6 autores nas áreas da biomédicas. Esse limite na correlação entre colaboração e produtividade na pesquisa parece fornecer pistas sobre como a dinâmica de relação entre os pesquisadores ocorre em suas redes de interação. Tamanhos de grupos preferenciais podem ser vistos como estratégias de organização das comunidades de pesquisadores, maneiras que entendem facilitar suas relações de colaboração como forma de melhor desenvolver seus trabalhos de pesquisa. Os padrões revelam a dinâmica humana no processo de atuação da produção científica.

A lei de Lotka é também conhecida como uma lei de potência, onde uma variável é proporcional a potência da outra. As leis de potência são evidências de que um determinado sistema parece se comportar como um sistema complexo adaptativo, como vimos no capítulo anterior.

Os sistemas complexos, portanto, são sistemas onde a interação entre seus elementos, suas 
unidades, formam padrões que produzem essa situação intermediária entre ordem e caos que pode ser percebida como um indício de ordem através das leis de potência, ordem essa que é reflexo dos arranjos sociais e políticos sobre como um sistema se organiza. As leis de potência parecem regular a maneira como as unidades do sistema se relacionam, fornecendo evidências de padrões semelhantes de articulação aos indicados pela lei de Lotka no caso da produção científica. Alguns avanços importantes na pesquisa sobre colaboração e co-autoria parecem concordar com a ideia de que as redes de interações humanas podem ser estudadas pelo olhar dos sistemas complexos (Newman, 2001a), (Newman, 2001b), (Newman, 2004), (Barabasi et al, 2002), (Barabasi, 2007), (Wagner e Leydesdorff, 2003), (Wagner e Leydesdorff, 2005).

\subsection{Comunidade científica como sistema complexo auto-organizado}

No nível mais básico, são as pessoas que colaboram e não suas instituições. A co-operação entre dois ou mais pesquisadores é a unidade fundamental da colaboração (Katz e Martin, 1997). O fato de podermos identificar padrões coerentes de organização que se formam a partir dessa unidade fundamental da colaboração, para além do nível individual, é uma forte evidência da formação de sistemas auto-organizados (Brown e Duguid, 1998). A seleção dos parceiros e a localização da pesquisa dependem das escolhas dos pesquisadores, pautadas pelos critérios das políticas científicas vigentes, reverberando suas ações de colaboração nas redes onde atuam.

As relações de co-autoria podem ser entendidas como formando redes complexas, ou sistemas complexos, que são pautados em sua dinâmica por relações de colaboração e competição (Wagner e Leydesdorff, 2005) (Vegeneroles, Murad e Vicente, 2009). A dinâmica que rege como essas relações ocorrem foi estudada por Newman (2001a), Newman (2001b), Newman (2004) e Barabasi et al (2002) que demonstram que os padrões dinâmicos que regulam as relações de colaboração são baseadas nas seguintes regras:

- novos autores chegam na rede a uma taxa constante;

- novos autores se conectam aos autores presentes na rede seguindo uma tendência de conexão preferencial;

- autores que estavam presentes na rede formam novas conexões também seguindo uma tendência de conexão preferencial.

Vejamos como cada uma dessas três regras é produto de interações estratégicas que formam os padrões de organização da comunidade científica. Antes de mais nada, entendemos por interações estratégicas o fato de que cada ação de um membro da comunidade científica afeta os 
demais, produzindo padrões de comportamentos estratégicos, onde cada membro, ao tomar decisões, também leva em consideração que os outros membros da comunidade interagem entre si (Fiani, 2009).

Novos autores chegam a uma taxa constante a rede de interações, indicando que a comunidade continuamente se renova como produto de sua maneira de formar novos pesquisadores, a partir de cursos de pós-graduação nos níveis mestrado e doutorado, além do contínuo incentivo a publicação dos resultados das pesquisas. Esse incentivo se dá na forma de reconhecimento acadêmico e profissional, permitindo pesquisadores com melhores índices de publicação a concorrer a melhores posições e cargos na estrutura acadêmica. Os novos autores não se conectam na comunidade científica de forma aleatória, revelando em sua estratégia de conexão um padrão específico. Esse padrão revela uma escolha de conexão preferencial, significando que a conexão de novos autores com os autores já existentes na rede se dá preferencialmente com aqueles que possuem maior produtividade. A conexão preferencial demonstra uma interação estratégica, onde novos pesquisadores levam em consideração os resultados das interações anteriores entre pesquisadores. A conexão preferencial também ocorre entre os pesquisadores já presentes na rede, revelando o mesmo padrão de interação estratégica, onde os mais produtivos acabam recebendo a maioria das novas conexões entre pesquisadores.

Quando um novo pesquisador entra numa área, segundo essa visão, sua estratégia básica é procurar se conectar a um pesquisador já central nessa área. Esse nível de centralidade é medido com base na produtividade de um pesquisador. Se, como vimos acima, os pesquisadores que mais produzem são os que mais colaboram, essa estratégia diz respeito a escolha de um novo pesquisador se conectar preferencialmente com pesquisadores mais articulados na rede de interações de sua área.

Essa estratégia revela uma certa forma de equilíbrio na dinâmica da comunidade científica. Novos pesquisadores procuram pesquisadores mais articulados e mais produtivos para se conectarem, pesquisadores mais produtivos aceitam novos pesquisadores como um meio de ampliar seus grupos de trabalho e dar continuidade a sua produção científica. Um equilíbrio regulado por relações onde, aparentemente, os autores e grupos mais centrais terminam por concentrar ainda mais as novas conexões e recursos.

\subsection{Estudos das redes sociais de co-autores em comunidades científicas}

A maior sistematização e disponibilização em bases de dados de informações relacionadas a produção científica, tais como relações de co-autoria, citação e co-citação entre artigos científicos, foi um dos elementos que tem impulsionado, desde o início dos anos 2000, a pesquisa sobre análise de redes sociais. Disciplinas como a cienciometria, bibliometria e informetria, preocupadas com a 
sistematização de dados para seus estudos de interesse, terminaram por fornecer aquilo que faltava: grandes amostras de dados para testes e avaliação de novos métodos, experimentação de novos indicadores e, sobretudo, dados de referência para fomentar estudos comparativos.

Estudos pioneiros relacionando estrutura, dinâmica e propondo conjuntos de indicadores de referência para o estudo de redes formadas pela co-autoria de pesquisadores em suas áreas do conhecimento foram publicados por Newman (2001,2001a, 2001b, 2004) e Barabasi et al. (2002). Tendo a sua disposição bases de dados de mais de 2 milhões de artigos, esses pesquisadores originados das áreas da matemática e da física encontraram um campo amostral ainda inexplorado para aplicação e identificação de muitos dos padrões que revisamos no capítulo 2 .

As bases de dados analisadas são de áreas como a biomedicina, física e ciência da computação. O interessante para nosso objeto de estudo é que sistematizaram um conjunto de indicadores que podem nos servir como parâmetro de comparação, mesmo considerando que a área da Ciência da Comunicação deve apresentar resultados que lhe são particulares, sobretudo por se tratar de uma área que apresenta uma dinâmica bastante diferente das Ciências Exatas, como veremos no capítulo 4.

Newman (2001) utilizou os indicadores apresentados na tabela 3.2 como referência para a comparação entre as bases de dados de publicações científicas da Medline (biomedicina), biblioteca da pre-prints de Los Alamos (física teórica), SPIRES (física de alta energia) e NCSTRL (ciências da computação).

\begin{tabular}{|l|c|c|c|c|c|c|c|}
\hline \multirow{2}{*}{ Indicadores } & \multicolumn{3}{c|}{ Arquivo de e-prints - Los Alamos } & & \\
\cline { 2 - 9 } & MEDLINE & Complete & astro-ph & cond-mat & hep-th & SPIRES & NCSTRL \\
\hline Total de artigos & 2.163 .923 & 98.502 & 22.029 & 22.016 & 19.085 & 66.652 & 13.169 \\
\hline Total de autores & 1.520 .251 & 52.909 & 16.706 & 16.726 & 8.361 & 56.627 & 11.994 \\
\hline \multicolumn{1}{|c|}{ Somente a primeira inicial } & 1.090 .584 & 45.685 & 14.303 & 15.451 & 7.676 & 47.445 & 10.998 \\
\hline Média de artigos por autor & $6,4(6)$ & $5,1(2)$ & $4,8(2)$ & $3,65(7)$ & $4,8(1)$ & $11,6(5)$ & $2,55(5)$ \\
\hline Média de autores por artigos & $3,754(2)$ & $2,53(7)$ & $3,35(2)$ & $2,66(1)$ & $1,99(1)$ & $8,96(18)$ & $2,22(1)$ \\
\hline Média de colaboradores por autor & $18,1(1,3)$ & $9,7(2)$ & $15,1(3)$ & $5,86(9)$ & $3,87(5)$ & $173(6)$ & $3,59(5)$ \\
\hline Corte da curva exponencial & $5.800(1.800)$ & $52,9(4,7)$ & $49,0(4,3)$ & $15,7(2,4)$ & $9,4(1,3)$ & $1.200(300)$ & $10,7(1,6)$ \\
\hline Expoente Y & $2,5(1)$ & $1,3(1)$ & $0,91(10)$ & $1,1(2)$ & $1,1(2)$ & $1,03(7)$ & $1,3(2)$ \\
\hline Tamanho do maior componente & 1.395 .693 & 44.337 & 14.845 & 13.861 & 5.835 & 49.002 & 6.396 \\
\hline \multicolumn{1}{|c|}{ Somente a primeira inicial } & 1.019 .418 & 39.709 & 12.874 & 13.324 & 5.593 & 43.089 & 6.706 \\
\hline & $92,6(4) \%$ & $85,4(8) \%$ & $89,4(3) \%$ & $84,6(8) \%$ & $71,4(8) \%$ & $88,7(1,1) \%$ & $57,2(1,9) \%$ \\
\hline Tamanho do segundo maior componente & 49 & 18 & 19 & 16 & 24 & 69 & 42 \\
\hline Distância média entre os nós & $4,6(2)$ & $5,9(2)$ & $4,66(7)$ & $6,4(1)$ & $6,91(6)$ & $4(1)$ & $9,7(4)$ \\
\hline Distância geodésica & 24 & 20 & 14 & 18 & 19 & 19 & 31 \\
\hline Coeficiente de clusterização & $0,066(7)$ & $0,43(1)$ & $0,414(6)$ & $0,348(6)$ & $0,327(2)$ & $0,726(8)$ & $0,496(6)$ \\
\hline
\end{tabular}

Tabela 3.2. Indicadores de redes de colaboração científica. Fonte: Newman (2001). Os dados entre parênteses são as medidas de erro padrão.

É interessante observar que Newman utiliza um conjunto de indicadores bibliométricos para caracterizar as bases de dados, tais como o total de artigos, total de autores, média de artigos por 
autores, média de autores por artigo e média de colaboradores por autor. A partir disso, apresenta os indicadores de corte da curva exponencial, que mostra o ponto em que as redes deixam de se comportar como de livre escala (como vimos nos capítulo 2, item 2.6), o expoente $\mathrm{Y}$ da curva de distribuição de graus de centralidade dos nós, o que permite caracterizar que tipo de rede de livre escala se trata, o tamanho do maior componente da rede (a maior estrutura de nós totalmente conectada, ou seja, existindo ao menos um caminho de conexão entre todos eles), o tamanho do segundo maior componente (a segunda maior estrutura de nós totalmente conectada), a distância média entre os nós (o quão próximo ou distantes se encontram em média), a distância geodésica (a maior distância entre dois nós) e o coeficiente de clusterização (indicando o nível de coesão da estrutura geral da rede).

Vale observar que para as medidas de total de autores e tamanho do maior componente, Newman chama a atenção de que os autores podem se identificar de forma diferente em diferentes artigos, ora utilizando a primeira inicial, ora outras iniciais de seu nome e ora seu nome completo, o que pode gerar uma taxa de erros entre o número total de nós que serão identificados como autores na rede. Outro ponto que destaca é o fato de autores poderem compartilhar o mesmo nome, o que também pode impactar no total de participantes a serem considerados. Como forma de considerar esse efeito, Newman calcula esses indicadores considerando duas abordagens. Na primeira, os nomes têm forma absoluta, ou seja, os autores são diferentes quando apresentarem qualquer parte do nome diferentes, já a outra, considera apenas o sobrenome e a primeira inicial do seu nome. Observamos que quando apenas a primeira inicial é considerada o número de autores é reduzido, estimando que os mesmos autores apresentados com iniciais diferentes terminam por ser agrupados dessa maneira. Essa é uma observação que devemos levar com consideração em nossos procedimentos metodológicos, que serão apresentados no capítulo 6 .

Os dados da tabela 3.2 apresentam os macro indicadores utilizados como referência para o estudo de redes sociais baseadas em dados de colaboração na produção científica. Os dados mostram diferentes padrões de comportamento entre as áreas, mostrando efeitos desses padrões em seus indicadores bibliométricos e características estruturais de como suas redes são constituídas, fornecendo evidências que diferentes estratégias de produção científica e características específicas de suas áreas do conhecimento podem ser avaliadas a partir desses dados. Por exemplo, numa primeira instância, Newman avalia que áreas com maior enfoque experimental, como a biomedicina (base Medline) e física de alta energia (base Spires) tendem a apresentar maiores médias de coautoria na publicação de trabalhos, o que acaba por impactar em maiores taxas de participação dos atores no componente principal da rede e menores distâncias médias entre os nós. Vejamos em maiores detalhes a interpretação que é construída por Newman (2001) para alguns desses 
indicadores que marcaram padrões importantes em seu trabalho:

- média de artigos por autor: um dos fatores para a base SPIRE apresentar um valor acima da média das outras bases é justificado pelo fato dos pesquisadores atuarem em pesquisas experimentais, alem de teóricas, na área da física de alta energia;

- média de colaboradores por autor: a mesma tendência é reforçada no número de colaboradores por autor, onde a base SPIRE também apresenta um valor muito acima das outras médias, denotando um padrão de colaboração bastante diferente;

- corte da curva exponencial: observando a tabela 3.2, percebemos que esse valor é em torno de 10 para a área da Ciência da Computação (NCSTRL), física da matéria condensada (cond-mat) e teoria de física de alta energia (hep-th), indicando que os pesquisadores mudam pouco o número de colaboradores ao longo do tempo. Já no caso da base SPIRES esse valor é muito maior, novamente indicando que a física experimental amplia muito o número de colaboradores no tempo. Na base MEDLINE, esse número é muito maior, porém o número de colaboradores por autor é bem menor que a base SPIRES. É apontado no estudo que uma dos fatores que pode explicar isso é um tipo de prática de pesquisa na área da biomedicina onde diretores de laboratórios acabam assinando os estudos que são realizados em seus espaços de atuação, levando as redes a apresentarem poucos autores com alto nível de colaboradores.

- expoente Y: é interessante notarmos o comportamento desse indicador. O número 2 é considerado como um divisor entre dois comportamentos diferentes na estrutura das redes. Para expoentes menores do que 2, a rede é dominada por poucos indivíduos que possuem um número muito grande de colaboradores. Para expoentes maiores do que 2 , a rede é dominada por muitos grupos com poucos colaboradores. O que nos ajuda a entender o comportamento desse indicador é observarmos o comportamento da curva exponencial, onde para valores maiores do que 2 a curva tem uma queda mais rápida, mostrando que a maioria da distribuição estará concentrada em autores com poucos colaboradores, já para valores menor que 2 a curva tem uma queda mais lenta, mostrando que há muito mais autores que possuem mais colaboradores.

- tamanho dos componentes: em redes com poucas conexões entre os atores, eles acabam ficando isolados em ilhas de conectividade ao longo da rede, o que pode ser observado pelo total de componentes e pela porcentagem de atores que fazem parte do principal componente. Quanto maior a taxa de participação nesse componente, mais os atores possuem caminhos para estabelecer vínculos com outros atores, facilitando a circulação 
da informação, das relações e das intermediações que possam ser feitas.

- distância entre os nós: podemos perceber que em comunidades mais conectadas em seus componentes principais, a distância entre os nós é em média menor, indicando novamente sua maior possibilidade de conectividade.

- coeficiente de clusterização: o coeficiente permite avaliar o nível de formação de comunidades dentro de uma rede. Em tese, a MEDLINE apresenta uma diferença significativa entre a SPIRES, quando podemos inferir que a formação de comunidades de pesquisadores é muito menor na MEDLINE, indicando tipos de práticas de pesquisa que podem estar relacionadas a políticas institucionais mais restritivas do que no caso da SPIRES.

O uso desses indicadores na caracterização de comunidades científicas ainda é um instrumento novo da ciência, logo uma série de experimentos precisam ser feitos e avaliados em contraste com as políticas, estratégias e características sociais de cada área. No entanto, já podemos notar como possibilitam leituras de diferentes comportamentos que ampliam nosso potencial de compreensão de como as redes se formam, como evoluem e quais são suas principais tendências.

Vale também citarmos o trabalho de Martins et al. (2010), que realizaram uma revisão das principais publicações que utilizaram alguns dos indicadores de referência apresentados por Newman na tabela 3.2, incluindo nesse estudo dados sobre áreas como administração e sociologia. Apresentamos os dados na tabela 3.3.

\begin{tabular}{|c|c|c|c|c|c|c|c|}
\hline & \multicolumn{2}{|c|}{ BRASIL } & \multicolumn{5}{|c|}{ INTERNACIONAL } \\
\hline & $\begin{array}{l}\text { GESTÃO DE } \\
\text { OPERAÇŌES }^{1}\end{array}$ & $\begin{array}{c}\text { ESTRATÉGIA } \\
\text { E ESTUDOS } \\
\text { ORGANIZACIONAIS }^{2} \\
\end{array}$ & $\begin{array}{l}\text { ADMINIS- } \\
\text { TRAÇÃ̄O }\end{array}$ & MEDICINA $^{4}$ & FísICA $^{5}$ & $\begin{array}{l}\text { MATEMÁ- } \\
\text { TICA }^{5}\end{array}$ & SOCIOLOGIA \\
\hline Período & $1997-2009$ & $1997-2005$ & $1980-2002$ & $\begin{array}{l}1995- \\
1999\end{array}$ & $\begin{array}{l}1995- \\
1999\end{array}$ & 1995-1999 & 1963-1999 \\
\hline $\begin{array}{l}\text { Total de } \\
\text { pesquisadores }\end{array}$ & 3.148 & 2.072 & 10.176 & 1.520 .251 & 52.909 & 253.339 & 197.976 \\
\hline $\begin{array}{l}\text { Média de laços por } \\
\text { autor }\end{array}$ & 2,52 & 2,25 & 2,86 & 16,93 & 9,27 & 3,90 & 1,88 \\
\hline $\begin{array}{l}\text { \% pesquisadores no } \\
\text { componente principal }\end{array}$ & $48,5 \%$ & $37,9 \%$ & $45,4 \%$ & $92,6 \%$ & $85,4 \%$ & $82,0 \%$ & $34,5 \%$ \\
\hline
\end{tabular}

Tabela 3.3. Indicadores de redes de colaboração científica 2 - Fonte: Martins et al. (2010).

É interessante notarmos a diferença na participação de pesquisadores no componente principal e na média de laços por autor, também fornecendo evidências de padrões de comportamento no nível da co-autoria nessas áreas que são refletidos na estrutura de suas redes sociais, tornando a rede mais ou menos distribuída entre seus componentes. Esses indicadores nos chamam a atenção, pois denotam no caso da sociologia e das áreas ligadas a administração redes mais dispersas, compostas por ilhas mais isoladas de relacionamento entre os pesquisadores. 
Outros estudos utilizaram esses mesmos indicadores de referência, porém analisaram como os mesmos evoluíram, permitindo analisar mudanças de tendências e padrões nas áreas em intervalos de tempo específicos. Podemos citar como referência os trabalhos de Grossman (2002), estudando a evolução do grafo de colaboração de pesquisadores da área de Matemática, Moody (2004), estudando a evolução das redes de colaboração científica da área da sociologia, Lee et al. (2010), estudando a evolução da redes na área da física e Martins et al. (2010), estudando a área de gestão de operações no Brasil. O estudo da evolução das redes cria uma espécie de genealogia de sua constituição estrutural e dinâmica, permitindo apontar e demarcar eventos importantes, fatos que eventualmente modificam os rumos e pautam a formação dos padrões característicos de cada rede.

Uma vez que vimos o que caracteriza redes sociais acadêmicas, como têm sido estudadas e quais são suas tendências de evolução nas últimas décadas, veremos agora quais são as características mais específicas da área de Ciências da Comunicação, foco da pesquisa de campo desta tese. 


\title{
Capítulo 4 As redes sociais e a área das Ciências da Comunicação
}

\subsection{Introdução}

\author{
"Arriscando um julgamento, talvez seja o caso de pensar se a comunicação, \\ conforme entendida espontaneamente, não é um sumidouro ou buraco negro \\ que traga todos os objetos hoje em dia; se não é esse espaço onde hoje está \\ a se desfazer a referência moderna ao objeto de conhecimento." \\ Francisco Rüdiger
}

O desenvolvimento da pesquisa de campo desta tese se dará no âmbito das Ciências da Comunicação, onde investigaremos as redes sociais formadas pelos pesquisadores a partir do Portal da Produção Científica em Ciências da Comunicação ${ }^{13}$. Dessa forma, buscamos aqui caracterizar como é constituído esse campo, quais áreas abrange, suas tendências na produção científica, quais são seus principais objetos de pesquisa e como a área tem se organizado como uma comunidade acadêmica.

A produção científica de uma determinada área do conhecimento pode ser entendida como o conjunto de estratégias que a comunidade científica utiliza para a divulgação de suas pesquisas, criando e alimentando os ciclos e as redes de interatividade que promovem a construção, comunicação e uso da informação por parte dos pesquisadores. Vejamos como Witter (1997) define produção científica:

"Produção científica é a forma pela qual a universidade ou instituição de pesquisa se faz presente no saber-fazer-poder ciência; é a base para o desenvolvimento e a superação de dependência entre países e entre regiões de um mesmo país; é o veículo para a melhoria da qualidade de vida dos habitantes de um país; é a forma de se fazer presente não só hoje, mas também amanhã. (...) Este rol pode ir longe, mas, seja qual for o ângulo que se tome por referência, é inegável o papel da ciência na vida das pessoas, das instituições e dos países. Pode-se afirmar que alguma produção científica está ligada à maioria, quase totalidade das coisas, dos eventos, dos lugares com que as pessoas se envolvem no cotidiano. “

A colaboração em torno da produção científica se configura, portanto, a partir das estratégias que são construídas pelos pesquisadores para esse saber-fazer-poder da ciência. No entanto,

13 www.univerciencia.org 
podemos presumir que diferentes estratégias podem ser utilizadas pelas várias áreas do conhecimento, explicitando suas singularidades e maneiras próprias de articular suas redes em torno de seus interesses políticos no seu fazer ciência. São essas diferentes estratégias, o compartilhamento, a disputa e a colaboração em torno de um objeto, mesmo que múltiplo e difuso, de pesquisa que pode nos servir como indício da formação de uma comunidade específica.

Uma das ideias que fundamenta uma comunidade e um determinado campo científico está ligado ao tipo de prática que um conjunto de pesquisadores realiza. Ao desenvolverem práticas semelhantes e divergentes com foco em temas semelhantes terminam por configurar uma comunidade, que colabora e disputa discursos do que é verdade a respeito desse objeto de interesse, produzindo redes de interação para divulgação de seus trabalhos e construção de reputação em grupo, reforçando o tipo de interatividade que alimenta o jogo do desenvolvimento científico. Segundo Thomas Kuhn (2005, pag. 222) "uma comunidade é formada pelos praticantes de uma especialidade científica. Estes foram submetidos a uma iniciação profissional e a uma educação similares, numa extensão sem paralelos na maioria das outras disciplinas."

Mas, mais do que isso, a ideia de um campo está ligado, de alguma forma, a ideia de redes de conversação que conservam condutas, práticas, discursos e domínios consensuais do que faz ou não parte de seus objetos de estudos.

“... a construção da própria existência de um campo passa, sim, por sua forma de poder, mas se vê permeada por várias outras formas de poderes de racionalidades de "regimes de verdades" de dispositivos etc, que se entrecruzam, se co-determinam, guardando ainda, certas possibilidades de autonomia" (Neto, 2002).

Aquilo que é conservado nas conversações de determinadas redes pautam e explicitam as grandes linhas que movimentam, tensionam, definem e são definidas como o que chamamos de um campo, uma área do conhecimento. Vejamos com qual foco e como ocorrem essas conversações no campo da Ciências da Comunicação.

O campo da comunicação, de modo geral, se compreende como um campo em construção buscando definir se há ou não uma existência explícita de seus objetos de pesquisa, seus métodos e critérios de produção científica. É uma área que se articula com outros campos do conhecimento, sendo definida pelos seus teóricos como um verdadeira zona de articulação de conhecimentos, na forma de um campo específico, mediante dispositivos estratégicos dotados de singularidades (Neto, 2002) enfatizando as perspectivas interacionais como substância principal das pesquisas na área 
(Weber, Bentz e Hohlfeldt, 2002).

“Os objetivos do campo procedem de diferentes quadrantes como também o discurso da Comunicação. Este, com frequência é elaborado a partir do repertório filosófico, sociológico, linguístico, semiótico ou semiológico, entre outros. A essas terminologias devemos acrescentar ainda as dos profissionais que aportam o jargão do cotidiano jornalístico, publicitário, cinematográfico, mercadológico e, recentemente, o novo dialeto do escrever/pensar pontocom" (Issler, 2002).

O quanto essa articulação de conhecimentos produz unicidade ou fragmentação em termos de práticas e modos de pesquisar o objeto da comunicação é uma questão em aberto, pertencendo a um importante debate em andamento pela própria comunidade de seus pesquisadores. Maria Immacolata retoma essa questão, argumentando que a área ainda se encontra, assim como desde sua origem, operando a partir de uma visão fragmentada e tecnicista de olhar para a comunicação:

"Podemos dizer que os estudos da Comunicação foram marcados desde os seus começos, entre os anos (19)20 e os (19)30, pelo paradigma de Lasswell, responsável por uma visão fragmentada e parcelar do processo de comunicação que se mantém até hoje: estudos do emissor, do canal, da mensagem e do receptor. Em cada um desses fragmentos como que houve uma "especialização" em determinados aportes disciplinares. Assim, os estudos do canal na análise tecnológica; os da mensagem na linguística e os do receptor na sociologia ou na psicologia e, mais recentemente, na antropologia" (Vassalo de Lopes, 2006).

O que nos interessa dessa visão é observamos que efeitos dessa fragmentação podem ser percebidos nos padrões estruturais e dinâmicos das redes sociais da área que analisamos nesta tese.

Logo, é a partir dessa fragmentação que a área da Comunicação articula seu repertório teórico dialogando diretamente com outras áreas, como a filosofia e a sociologia, criando espaços de análise e aplicação técnica de suas questões naquilo que considera como sendo suas áreas profissionais, como o jornalismo, a publicidade e o rádio. O que a caracteriza, mais do que seus princípios e conceitos teóricos, é, como vimos acima, um direcionamento de enfoque, uma continua busca pelas perspectivas interacionais como espaço de articulação de diferentes saberes. 
"A transdisciplinaridade de modo algum significa a dissolução dos problemas-objeto do campo da comunicação nos de outras disciplinas sociais, mas a construção de articulações - intertextualidades - que fazem possível pensar os meios e as demais indústrias culturais como matrizes de desorganização e reorganização da experiência social e da nova trama de atores e estratégias de poder” (Vassalo Lopes, 2006 apud Martín-Barbero, 1996, p.62).

A área da Comunicação surge como essa intertextualidade, como um espaço de interação, como uma rede de conversação de pesquisadores oriundos de diferentes áreas do conhecimento com interesses em desenvolver suas pesquisas com esse enfoque nas perspectivas interacionais, sejam elas apropriadas de maneiras distintas, até mesmo antagônicas a partir das múltiplas visões que vão definindo a área. É a articulação dessa rede em sua contínua conservação de seu espaço relacional que faz surgir o campo como uma zona de articulação conhecimentos. Toda a dinâmica de uma rede social acadêmica, como vimos no capítulo 3, é acionada a partir do interesse de grupos de pesquisadores de sistematizarem suas pesquisas, disputarem recursos, verdades sobre seus objetos, criando redes de conversação que utilizam como espaço de relação os dispositivos de sistematização da informação produzidos pela comunidade acadêmica, produzindo artigos em revistas, participando em congressos, seminários, produzindo livros, produção técnica e artística.

As Ciências da Comunicação acabam por utilizar vocabulários e referências de outras áreas que possuem forte conexão com seus temas de interesse, como se a área ocupasse um espaço "entre", indicando o processo ainda em construção de seu campo científico. É a essa conclusão que chegam Leydesdorff e Probst (2009), ao analisarem as redes de citação (ver figura 4.1) entre revistas das áreas de Comunicação, Psicologia Social e Ciência Política, demonstrando como a área de comunicação ocupa um espaço "entre" as duas outras, tomando emprestado recursos metodológicos, conceitos e teorias de referência. Na figura 4.1, a seguir, as revistas da área de comunicação estão circuladas pelos pontilhados em vermelho. 


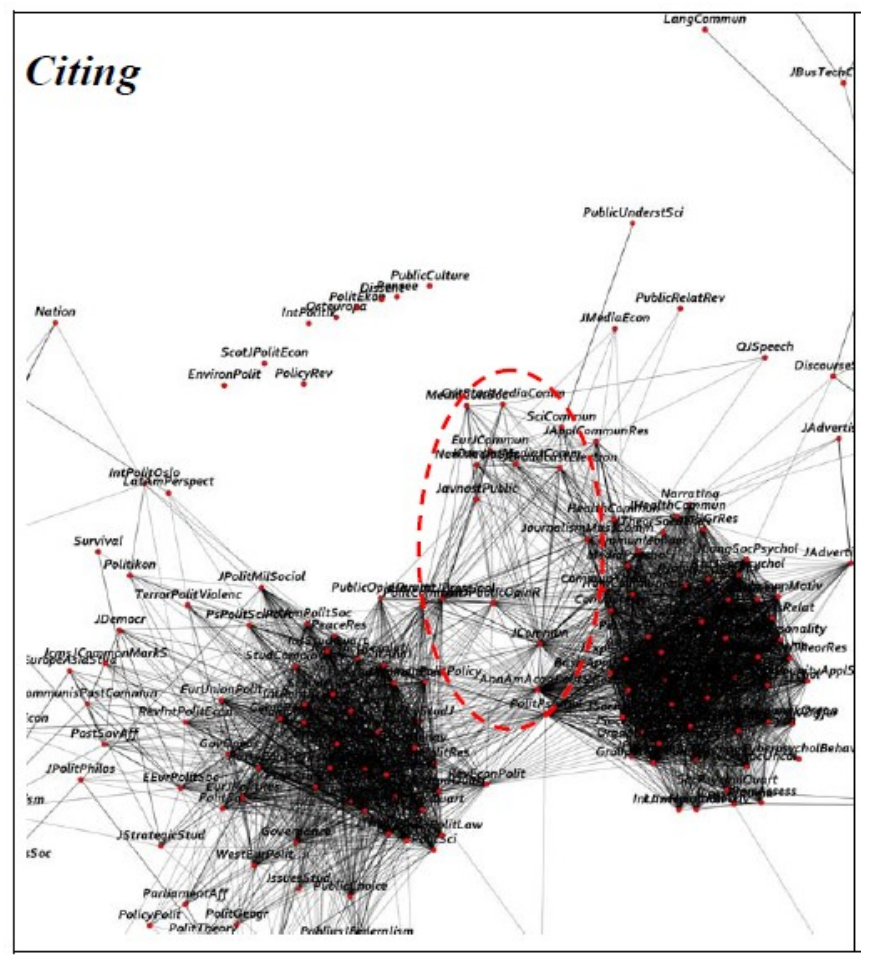

Figura 4.1. Redes de citação entre Psicologia Social, Comunicações e Ciências Políticas. Fonte Leydesdorff e Probst (2009)

Vejamos como essa área é estruturada e delimitada no Brasil.

\subsection{A estruturação da Ciências da Comunicação no Brasil}

As atividades de pesquisa na área da Ciências da Comunicação iniciam no Brasil a partir dos anos 1970 com a criação do primeiro programa de Mestrado na PUC/SP, sendo dois anos depois seguido pelos cursos de mestrado na UFRJ e na USP (Neto, 1996). Segundo os dados do relatório trienal da CAPES (2009), no ano 2000 havia 14 programas de pós-graduação em Comunicação no país, passando esse número para 39, sendo destes 15 programas incluindo Doutorados no último relatório publicado em 2009. Vejamos na figura 4.2 como o número de programas se desenvolveu, onde temos um crescimento linear de 1996 até 2009, se acentuando a partir de 2006.

Evolução nos programas de Pós-graduação

Área da Ciências da Comunicação

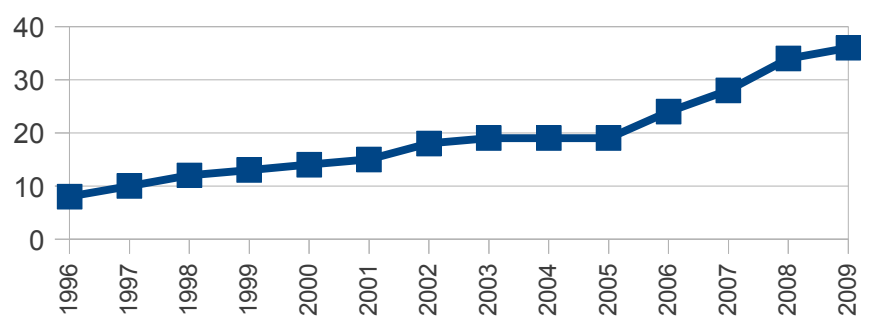

Figura 4.2. Evolução no número de programas de pós-graduação na área das Ciências da Comunicação. Fonte: CAPES (2009). 
Deve ser ressaltado, também, o desequilíbrio na distribuição dos programas por região do país. Com efeito, dos 39 Programas existentes atualmente no Campo da Comunicação, 21 estão localizados na região Sudeste (53,8\%), sendo que, destes, 14 (35,8\%) no Estado de São Paulo; 8 (20,5\%), na região Sul; 5 (12,8\%), na região Nordeste; 3 (7,6\%), na região Centro-Oeste e 2 (5,12\%), na região Norte (CAPES, 2009).

Toffoli e Ferreira (2011) ao realizarem um mapeamento da produção científica de pesquisadores brasileiros de Ciências da Comunicação no período de 2000 a 2009 trazem alguns dados que nos permitem entender melhor como a área se organiza:

- o estado de São Paulo concentra o maior número de programas: 14, no total;

- há um total bruto de 519 docentes atuando nos programas de pós-graduação, sendo 498 efetivos, 3 convidados e 14 docentes colaboradores. Há 16 docentes que figuram em mais de um programa, levando o total real de docentes para 503;

- o maior número de docentes encontra-se no PPGCOM da USP (46), seguido da UFRJ (27), UnB (25) e UFF (20), sendo os quatro do setor público e três deles situados na região Sudeste;

- do mapeamento da produção científica realizada, se obteve 6520 documentos categorizados como "artigos", 1772 como "livros" e 4635 "capítulos de livros";

- dos 6520 artigos identificados, 766 (12\%) foram publicados em revistas científicas internacionais, 1659 (25\%) foram publicados em revistas brasileiras de programas de pós-graduação. O restante, 4095 (62,8\%) documentos, foi publicados em outras revistas da área que não coordenados por programas de pós-graduação, publicados em revistas de outras áreas e publicados como outros tipos de documentos (resenhas, entrevistas, trabalhos apresentados em eventos, catálogo, documentos em site, etc.);

- os anos de 2007 e 2008 foram os mais produtivos para os pesquisadores.

Os dados acima nos permitem dizer que a área ainda apresenta uma concentração regional considerável, sobretudo na região Sudeste. Além disso, o perfil da área em termos de tipos de produção científica parece bastante equilibrado em termos quantitativos entre artigos (6520) e livros/capítulos de livros (6407), afirmando como tendência da área a produção tanto em artigos quanto em livros.

A área de Ciências da Comunicação é vista no Brasil como Ciências Sociais Aplicadas. Vejamos como os pesquisadores da área a configuram: 
"No que se refere à sua área de atuação, de acordo com o CNPq e demais agências de financiamento do país, as Ciências da Comunicação estão inscritas na grande área classificada como "Ciências Sociais Aplicadas", subdividindo-se em outras subáreas tais como: comunicação visual, jornalismo e editoração, rádio e televisão, relações públicas e propaganda. Porém, tal classificação de áreas e subáreas não é ponto pacífico entre seus especialistas" (Ferreira et al., 2009).

"Partimos da hipótese de que os estudos comunicacionais e informacionais consistem em um campo de conhecimento em construção. A base de nossa esquema cognitivo é a de estudar os fenômenos da comunicação humana, associados à produção, estocagem e difusão da informação. (...) A tradição brasileira recente vem compreendendo essa área de estudo sob a rubrica das chamadas "ciências sociais aplicadas", usando-se a nomenclatura das agências de financiamento. Segundo esta, estamos longe das "ciências humanas", tais como a filosofia, a história, a sociologia e a psicologia. Curiosamente, estamos próximos, ou metidos na mesma gamela, da economia doméstica, do serviço social e do turismo. A ciência política, em outro exemplo, é vista, pelos mesmo órgãos, como parte da nobre área de humanas. Nós, assim como a economia e a arquitetura, somos parte das "ciências aplicadas" (Lopes, 2000).

É interessante notarmos na colocação de Ferreira et al. como as subáreas que configuram as Ciências da Comunicação refletem questões de fundo técnico, relacionando uma subárea diretamente a um tipo de mídia que vincula formatos específicos de comunicação. Essa especialização e, de certa forma, como já vimos acima, fragmentação na organização da área é um dos elementos que devemos considerar nos padrões de relacionamento entre os pesquisadores em torno de suas estratégias de produção científica.

Realizamos uma consulta a Tabela de Áreas do Conhecimento ${ }^{14}$ mantida pela CAPES para verificar a última versão das áreas que compõem as Ciências da Comunicação. Atualmente, fazem partes desta classificação Teoria da Comunicação, Jornalismo e Editoração, Teoria e Ética do Jornalismo, Organização Editorial de Jornais, Organização Comercial de Jornais, Jornalismo Especializado (Comunitário, Rural, Emp. Cientif.), Rádio e Televisão, Radiofusão, Videodifusão,

14 http://www.capes.gov.br/images/stories/download/avaliacao/TabelaAreasConhecimento_042009.pdf 
Relações Públicas e Propagando, Comunicação Visual, Programação Visual e Desenho de Produto. No entanto, como mencionado acima, a classificação da área e suas subáreas não é ponto pacífico entre as instituições e mesmo entre as publicações científicas da áreas.

Pela listagem de subáreas que vimos acima, podemos entender que o campo da Ciências da Comunicação é uma área ainda em construção, sendo constituída por temas com poucas décadas de existência ainda em processo de amadurecimento de metodologias, técnicas de pesquisa, vocabulários em comum, entre outros recursos que são fundamentais para constituição de uma comunidade científica. Segundo Ferreira et al. (2009):

"A maturação e o entendimento que atingiram as chamadas ciências duras (Saúde e Tecnologia, por exemplo), quanto à necessidade de representar bem o conhecimento para recuperar eficazmente sua própria produção científica, não é equivalente em todas as áreas. Os campos das Ciências Sociais e Humanidades, dentre as quais as Ciências da Comunicação, destituídas tanto de instrumentos (vocabulários controlados e/ou tesauros) quanto de sistemas de informação específicos, vivenciam uma situação problemática frente à falta de fontes de referência terminológica para o uso de seus pesquisadores."

A falta desses importantes instrumentos de pesquisa, sem dúvida, causa impactos que podem ser observados e devem ser considerados quando do estudo da produção científica das Ciências da Comunicação. As redes de interação são formadas e fortalecidas pelo compartilhamento do que há de comum entre os pesquisadores, ou seja, pela sua possibilidade de entender o comum no trabalho do outro que pode disparar interações de colaboração com objetivo de avanço científico. Novamente, esse é um fator que devemos considerar na avaliação dos padrões de formação das redes sociais que analisamos nesta tese. Esse comum, muitas vezes, é refletido pela terminologia e referências compartilhadas. As ciências duras, como citado acima, por serem mais antigas e já terem melhor consolidados seus recursos e metodologias de pesquisa, representam melhor seu corpo de conhecimento.

Uma das sociedades científicas mais importantes e relevantes na área da Comunicação no Brasil é a Intercom. Segundo a definição de seu próprio portal na Internet ${ }^{15}$ :

15 http://www.portalintercom.org.br/index.php?option=com_content\&view=article\&id=263\&Itemid=85 Acessado em $25 / 06 / 2011$. 
"A Intercom - Sociedade Brasileira de Estudos Interdisciplinares da Comunicação - é uma instituição sem fins lucrativos, destinada ao fomento e à troca de conhecimento entre pesquisadores e profissionais atuantes no mercado. A entidade estimula o desenvolvimento de produção científica não apenas entre mestres e doutores, como também entre alunos e recémgraduados em Comunicação, oferecendo prêmios como forma de reconhecimento aos que se destacam nos eventos promovidos pela entidade. Fundada no dia 12 de dezembro de 1977 em São Paulo, a Intercom preocupase com o compartilhamento de pesquisas e informações de forma interdisciplinar. Além de encontros periódicos e simpósios, a instituição promove um Congresso Nacional - evento de maior prestígio na área de pesquisa em Comunicação, que recebe média de 3.500 pessoas anualmente, entre pesquisadores e estudantes do Brasil e do exterior. O evento, sediado em cidade escolhida pelos sócios no ano anterior, é precedido de cinco Congressos Regionais."

Como uma forma de criar parâmetros em comum para o desenvolvimento de pesquisas na área de Comunicação, a Intercom propõe um conjunto de oito divisões temáticas (DTs) que são utilizadas para orientar a divisão dos trabalhos produzidos por seus grupos de pesquisa ${ }^{16}$ : Jornalismo; Publicidade e Propaganda; Relações Públicas e Comunicação Organizacional; Comunicação Audiovisual; Comunicação Multimídia; Interfaces Comunicacionais; Comunicação, Espaço e Cidadania; e Estudos Interdisciplinares da Comunicação.

Outra sociedade importante da área da Comunicação é a $\operatorname{COMPOS}^{17}$ (Associação Nacional dos Programas de Pós-graduação em Comunicação). A COMPOS já apresenta uma organização da área em 15 grupos de trabalho (GTs) que se reúnem pela ocasião de seu encontro anual, reunindo, desse modo, os pesquisadores pela publicação e adesão de seus trabalhos enviados para comunicação oral e posters nestes GTs: Comunicação e Cibercultura , Comunicação e Cidadania , Comunicação e Cultura , Comunicação e Experiência Estética , Comunicação e Política , Comunicação e Sociabilidade, Comunicação em Contextos Organizacionais, Cultura das Mídias , Estudos de Cinema, Fotografia e Audiovisual, Estudos de Jornalismo, Estudos de Televisão , Epistemologias da Comunicação, Imagem e Imaginários Midiáticos, Práticas Interacionais e Linguagens na Comunicação, Recepção: processos de interpretação, uso e consumo mediáticos.

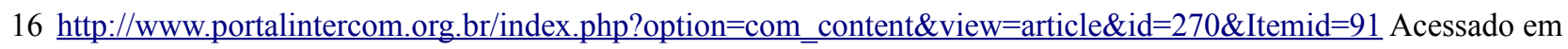
$25 / 06 / 2011$.

17 http://www.compos.org.br/
} 
Analisando os dois modos de organização do INTERCOM e COMPOS, percebemos diferenças significativas, sendo o primeiro mais voltado para os aspectos técnicos da área, refletindo dessa forma as subáreas que organizam a própria comunicação, já o segundo mais voltado para aspectos conceituais que determinam as interfaces e conexões que se operam a partir da comunicação.

Analisando as mais de 85 linhas de pesquisa dos principais programas no Brasil em busca de compreender como essas linhas pautam a produção científica da área, Neto (1996) constata cinco características do campo que, reforçando o que já vimos anteriormente, irão nos auxiliar na análise de como operam suas redes sociais:

- há uma fragmentação do campo da comunicação numa heterogeneidade de problemas, questões e temas;

- temos a eleição de um conjunto temático de referências que fazem emergir, necessariamente, a questão da transdisciplinaridade como um desafio e, ao mesmo tempo, como uma variável essencial na eleição de procedimentos que vão nortear o desenvolvimento da pesquisa;

- também, a verticalização de interesses por temas mais abrangentes que, de uma forma ou de outra, se situariam nas fronteiras teóricas da área;

- há uma excessiva tematização de certas questões de maneira que não ficam claras as fronteiras e delimitações existentes entre elas;

- finalmente, reconhecimento de uma massa de questões a serem trabalhadas sistematicamente no conjunto de atividades dos cursos, cujos desembocadouros se constituem, naturalmente, as teses e dissertações.

A fragmentação do campo na variedade de temas e problemas, bem como a transdisciplinaridade são questões que terão impactos diretos em nossa análise de como surgem e se articulam as redes sociais. A hipótese que temos é que esta fragmentação não se dá apenas nos temas, mas nas associações entre pessoas a partir de interesses fragmentados e de diferentes áreas do conhecimento. Como essas associações se formam, se articulam, que estratégias são construídas e que padrões geraram ao longo do tempo é um ponto que temos de levar em consideração em nossa análise.

A questão da não clareza das fronteiras temáticas é outro ponto que imaginamos ter impacto em nossa pesquisa. Considerando que os pesquisadores se agrupam e formam comunidades a partir de redes de conversação com foco em seus objetivos de interesse. Compreender como essas 
fronteiras impactam nas estratégias de formação das redes é um ponto de interesse a ser explorado. O mesmo vale para as teses e dissertações, sendo espaços de interação de pesquisadores e que nos interessam como elementos que ativam encontros, conversas, influenciando na formação das redes.

É fato que essa análise inicial da área mostra que ela ainda se encontra em fase de construção, apresentando, porém, um crescimento contínuo em termos de pessoas envolvidas, programas de pós-graduação, formas de categorização de seus objetos de pesquisa, bem como organizações que a representam. Ao que tudo indica, observamos aqui um ponto crucial e que é fundamental ressaltarmos nas palavras de Vassalo de Lopes (2006), quando caracteriza algumas das estratégias que estão em jogo nesse momento de consolidação da área das Ciências da Comunicação:

\begin{abstract}
"A competição que se instala num campo é, ao mesmo tempo, científica e econômica. Por um lado, à medida que crescem os recursos científicos acumulados, que se expressam nos avanços da pesquisa, aumenta o grau de homogeneidade entre os concorrentes e isso faz aumentar a competição científica. Por outro lado, o crescimento da competição científica torna mais acirrada a luta pelos recursos econômicos do campo, que já são, por definição, escassos. Identificamos claramente esse percurso percorrido pela pós-graduação no campo Comunicação."
\end{abstract}

Sem dúvida, esse acirramento da competição é um dos elementos centrais desta análise que devemos levar em consideração quando da observação dos padrões estruturais e dinâmicos da formação das redes sociais da área.

\title{
4.3 Tendências na produção científica
}

O desenvolvimento de maior número de publicações em co-autoria e a tendência no aumento de colaboração na área das Comunicações vem sendo percebido por diversas pesquisas, como vimos no capítulo 3. A colaboração, no entanto, é também um processo em construção na área, como aponta Correa et al. (2005) num estudo realizado em sete fascículos das revistas Comunicação \& Sociedade, Contracampo, Eptic On-Line, Revista Fronteiras, Galáxia, Intercom Revista Brasileira de Ciência da Comunicação e Revista FAMECOS. Os resultados do estudo apontaram que mais de $88 \%$ dos artigos foram escritos por um único autor, numa amostra de 114 artigos coletados.

Sobre a temática da produção mapeada, Correa et al. (2005), apresentam a tabela 4.1 a seguir: 


\begin{tabular}{|c|c|c|}
\hline \multicolumn{3}{|l|}{ Temas dos Artigos } \\
\hline Núcleos Temáticos (Intercom) & no & $\%$ \\
\hline Teorias da Comunicação & 24 & 21,05 \\
\hline Tecnologias da Informação e da Comunicação & 18 & 15,75 \\
\hline Jornalismo & 12 & 10,53 \\
\hline Comunicação Audiovisual & 10 & 8,77 \\
\hline $\begin{array}{l}\text { Relações Públicas e Comunicação } \\
\text { Organizacional }\end{array}$ & 7 & 6,14 \\
\hline Políticas e Estratégias de Comunicações & 7 & 6,14 \\
\hline Semiótica da Comunicação & 6 & 5,26 \\
\hline Comunicação para a Cidadania & 5 & 7 \\
\hline Comunicação e Cultura das Minorias & 5 & 4,39 \\
\hline Comunicação e Cultura Urbanas & 5 & 4,39 \\
\hline Folkcomunicação & 4 & 4,39 \\
\hline Ficção Seriada & 3 & 3,51 \\
\hline Produção Editorial & 2 & 2,63 \\
\hline História em Quadrinhos & 2 & 1,75 \\
\hline Fotografia: Comunicação e Cultural & 2 & 1,75 \\
\hline Rádio e Mídia Sonora & 1 & 1,75 \\
\hline Comunicação e Esporte & 1 & 0,88 \\
\hline Publicidade, Propaganda e Marketing & 0 & 0,88 \\
\hline Comunicação Científica e Ambiental & 0 & 0 \\
\hline Comunicação Educativa & 0 & 0 \\
\hline Comunicação, Turismo e Hospitalidade & 0 & 0 \\
\hline \begin{tabular}{|c|} 
Total \\
\end{tabular} & 114 & 100 \\
\hline
\end{tabular}

Tabela 4.1 - Distribuição temática dos artigos de 7 fascículos de revistas na área da Ciência da Comunicação. Fonte: Correa et al. (2005)

Foram utilizados a divisão temática proposta pela Intercom para a distribuição da tabela 4.1.

Primo et al (2008) realizaram um mapeamento das citações nos trabalhos da COMPÓS do encontro anual de 2008, mostrando importantes tendências na produção científica na área da Comunicação que nos auxiliam a entender melhor como o campo se organiza. No estudo, foram analisados 120 artigos do XVII Encontro da Associação Nacional dos Programas de Pós-graduação em Comunicação, tendo sido encontradas 2111 referências nos trabalhos. Apresentamos alguns resultados desse estudo que nos são úteis ao nosso foco de análise:

- os grupos de trabalho (válidos na época do estudo, sendo que atualmente são diferentes, conforme apresentamos acima) que tiveram mais trabalhos publicados foram: Comunicação e Cibercultura (221), Recepção, usos e consumo midiáticos (212), Comunicação e Sociabilidade (198) e Estudos de jornalismo (188);

- dos 120 artigos, $92(76,6 \%)$ foram escritos por apenas um pesquisador, $26(21,6 \%)$ por 2 autores e apenas $2(1,6 \%)$ por 3 autores;

- das referências realizadas, 1321 (62,58\%) foram escritas por autores estrangeiros, 783 $(37,09 \%)$ por autores nacionais e apenas 7 trabalhos combinavam autores nacionais e estrangeiros;

- das citações, 1217 (57,7\%) foram relativas a livros, 275 (13\%) a capítulos de livros, 297 $(14,1 \%)$ a artigos de periódicos e $107(10,2 \%)$ a trabalhos em anais; 
- dos eventos da área referenciados nos trabalhos, $40,6 \%$ se remetiam a COMPOS e $25,7 \%$ a INTERCOM.

Ressaltamos dois pontos que são recorrentes nos estudos apresentados, sendo estes os mais expressivos que encontramos sobre o mapeamento da produção científica da área da Ciências da Comunicação no Brasil: a maioria dos artigos produzidos são feitos de forma individual e a abrangência de temas ou modos de descrever os temas evidencia essa fragmentação do campo na heterogeneidade de problemas que são abordados, além da falta de uma nomenclatura comum que sirva de referência para a área como um todo.

\subsection{Traços das redes sociais}

Realizamos aqui um mapeamento das principais linhas que permitem caracterizar o que é hoje a área da Ciência da Comunicação como campo do conhecimento no Brasil. Desde a percepção da formação da área, a distribuição de seus temas e objetos de interesse, bem como sua articulação conceitual nosso interesse tem sido observar quais são os traços dessa área que influenciam sua caracterização pela análise de suas redes sociais.

Destacamos a seguir os principais pontos que levaremos em consideração, com base em nossa revisão:

- acirramento na disputa de recursos;

- visão tecnicista e fragmentada da área;

- abrangência temática;

- forte relação multidisciplinar;

- área em construção, sem referenciais terminológicos consensuais entre os pesquisadores;

- não há uma fronteira muita clara estabelecida entre as pesquisas desenvolvidas;

- maior parte da produção científica é realizada por autores individuais, sem colaboradores explicitamente reconhecido na autoria dos artigos;

- um crescimento expressivo nos último 10 anos de programas de pós-graduação, sendo que a maior parte dos programas de pós-graduação estão concentrados nas regiões sudeste e sul;

- os estudos encontrados que se propõe a mapear a área possuem uma baixa quantidade de dados amostrais, logo, análises mais expressivas poderiam contradizer os resultados apresentados até então. 
Em nossa análise da Ciências da Comunicação buscaremos analisar se e como cada um desses fatores acima listados influencia na estrutura e na dinâmica de suas redes sociais. Uma de nossas hipóteses de pesquisa na qual nos baseamos para tanto é de que se a produção científica de uma área do conhecimento, em nosso caso a área da Ciências da Comunicação, constitui um plano de comunicação singular a partir do qual podemos analisar suas relações sociais mediadas pela necessidade de produção científica, além dos efeitos, impactos e influências que são geradas pelas políticas científicas que regulam o funcionamento da área.

Entender como a área vem sendo construída no Brasil a partir de suas características institucionais, geográficas e de sua produção científica, dá o panorama geral por onde as redes de conversação dos pesquisadores têm produzido seus traços e seus modos de organização social como uma comunidade acadêmica. Não entendemos aqui que as redes são "influenciadas" por essas características e nem que as redes produzem essa visão macro da área. Entendemos aqui que estamos falando de dimensões entrelaçadas, camadas de rede que podem ser visualizadas a partir de diferentes pontos de vista e perspectivas analíticas, sendo nosso objetivo nesta tese caracterizá-las, demonstrar como operam, como surgem e se desenvolvem ao longo do tempo.

Vejamos agora qual base informacional iremos utilizar para coletar os dados da produção científica da área da Ciências da Comunicação. 


\title{
Capítulo 5
}

\section{Movimento OAI e Sistemas Federados de Informação: fundamentos do portal da produção científica em Ciências da Comunicação Univerciencia.org}

\begin{abstract}
"O ideal sistemista não poderia ser o isolamento do sistema, a hierarquização do sistema.
Ele está na arte aleatória, incerta, mas rica e complexa como toda arte, de conceber as interações, interferências e encadeamentos polissistêmicos. As noções de arte e ciência, que se opõem na ideologia tecnoburocrática dominante, devem aqui, como por todo lugar onde há realmente ciência, se associar."
\end{abstract}

Edgard Morin

\subsection{Introdução}

O movimento Open Archives Initiative ${ }^{18}$ vem se estabelecendo como um modelo de transporte e compartilhamento de metadados ${ }^{19}$ desde a publicação do protocolo OAI-PMH (Open Archives Initiative Protocolo for Metadata Harvesting $)^{20} \mathrm{em}$ janeiro de 2001. Sendo um modelo de arquitetura da informação projetado para ampliar a interoperabilidade entre bibliotecas digitais e facilitar a disseminação da informação de forma mais eficiente (Cole e Foulonneau, 2007, p.3), tem sido utilizado como base no desenvolvimento de novos serviços de dados para essas bibliotecas.

A produção de novos serviços presume a possibilidade de agregação dos dados a partir de normas e convenções básicas compartilhadas entre as bibliotecas digitais que se deseja integrar. Uma vez respeitadas e implementadas essas normas e convenções básicas, é necessário analisar a qualidade semântica dos dados coletados, permitindo avaliarmos as reais possibilidades de agregação e representatividade desses dados. Procedimentos de normalização e tratamento também são elementos fundamentais a serem considerados na melhoria das condições de agregação dos dados. Como veremos, o uso do protocolo OAI-PMH tem incentivado a produção de novos serviços e facilitado esses procedimentos de tratamento e integração da informação.

Há um crescimento expressivo no número de bibliotecas digitais que ofertam metadados de seu conteúdo seguindo os padrões do protocolo OAI-PMH (Cole e Foulonneau, 2007, p.55) que envolve diversas instituições, dentre elas universidades, centros de pesquisa, laboratórios, bibliotecas e serviços especializados na disponibilização de produções científicas ao redor do mundo. No Brasil, o movimento segue a mesma tendência, sendo que em 2009 já tínhamos 227 títulos de revistas em formato eletrônico registradas no Portal Scielo ${ }^{21}, 757$ revistas registradas no

18 Iniciativa dos Arquivos Abertos

19 Metadados: informação estruturada utilizada para descrever um recurso de informação em particular

20 Protocolo para Coleta de Metadados da Iniciativa dos Arquivos Abertos

21 Portal Scielo:http://www.scielo.br/ 
IBICT $^{22}$ e 90 bibliotecas de teses e dissertações usando o protocolo, além de contar com editais públicos para fomento de projetos de digitalização e disponibilização de acervos (Ferreira, 2009, p. $10)$.

É importante notar que a possibilidade de integração dos metadados disponibilizados dessas bibliotecas digitais permite aos pesquisadores acesso a grandes bancos de dados para diversas análises da produção científica. Dependendo da abrangência e da distribuição dessas bibliotecas, podemos ainda considerar a hipótese de analisar toda ou, ao menos, a maioria da produção científica de uma determinada área do conhecimento, considerando que suas principais instituições e pesquisadores disponibilizarem sua produção nas bibliotecas digitais de acesso aberto.

Veremos neste capítulo como o movimento OAI se desenvolveu, seus princípios técnicos, organizacionais e como eles fundamentam um sistema federado de informação, permitindo a criação de ambientes federados, que será usado como base de coleta de dados para esta tese.

\subsection{Contexto e história do movimento Open Archives Initiative (OAI)}

O início do movimento OAI ocorreu num encontro em 1999, em Santa Fe, nos Estados Unidos, conhecido como Convenção de Santa Fe, com o objetivo de discutir como as novas possibilidades de interconectividade da Internet poderiam ser utilizadas para distintas formas de disponibilização de informação acadêmica em rede. O encontro resultou na formação de um grupo de trabalho chamado Open Archives Initiative que tinha por objetivo desenvolver um modelo para facilitar a agregação de provedores de conteúdo na Web (Van de Sompel e Lagoze, 2000).

A Internet e, sobretudo na época, a Web vinha se constituindo como um modelo de comunicação e compartilhamento de conteúdo em rede. O aumento expressivo e a consolidação de padrões como a linguagem $\mathrm{HTML}^{23}$ e o protocolo HTTP $^{24}$ estavam sendo utilizados como base para inovações na área de sistemas de informação e novos modelos de comunicação.

No entanto, não era apenas a disponibilidade de uma base técnica de comunicação mais eficiente, disponível pela Internet e a World Wide Web, que motivou o encontro de Santa Fe e incentivou a criação da OAI. O paradigma de comunicação científica tradicional também passava por um momento de crise e enfrentava diversos desafios, um consenso que motivava o encontro entre os pesquisadores reunidos em Santa Fe (Lagoze e Van de Sompel, 2001):

- o explosivo crescimento da Internet deu aos pesquisadores acesso universal a um meio

22 IBICT - Instituto Brasileiro de Informação em Científica e Tecnológica

23 HTML - HyperText Markup Language

24 HTTP - HyperText Transfer Protocol 
de comunicação que facilita o compartilhamento imediato de resultados;

- a rapidez no avanço em muitas áreas do conhecimento tem tornado o modelo de revisão tradicional um impeditivo para o compartilhamento entre pesquisadores;

- a transferência total dos direitos autorais para as editoras das revistas científicas frequentemente age como um impeditivo para o pesquisador que possui interesse em disseminar da forma mais ampla possível seu trabalho;

- a atual implementação do sistema de revisão por pares - um elemento fundamental da comunicação científica - é muito rígido e muitas vezes age sufocando novas ideias, favorecendo artigos de instituições de mais prestígio, causando atrasos para outras publicações;

- o desequilíbrio entre o aumento gradativo dos preços de assinatura de revistas especializadas e o congelamento dos orçamentos das bibliotecas tem criado uma crise econômica para as bibliotecas de pesquisa.

Logo, um dos principais motivos do encontro era reunir pesquisadores e organizações que tivessem interesse em discutir e ajudar a propor as bases técnicas e organizacionais de um novo mecanismo de comunicação científica que buscasse ser uma alternativa aos desafios acima apresentados.

A experiência dos repositórios de preprints $^{25}$, tendo na iniciativa arXiv.org ${ }^{26}$ do Laboratório Nacional de Los Alamos, Estados Unidos, uma das mais conhecidas e disseminadas com foco na área da Física, Ciência da Computação, Matemática e Ciências Não-Lineares, foi extremamente importante para o encontro. Experiências com preprint existiam desde 1991, iniciando com o arXiv.org, sendo que muitos outros destes sites estavam se tornando veículos para a disseminação preliminar de resultados de pesquisas e literatura cinzenta ${ }^{27}$. Estes sites acabaram se tornando meios essenciais para compartilhar resultados entre pesquisadores de um campo do conhecimento (Lagoze e Van de Sompel, 2001), dando maior agilidade e facilitando o acesso dos pesquisadores a novos resultados, bem como a aqueles que os produziram. Os repositórios de preprints representavam, na época, uma inovação do ponto de vista de como organizar e administrar o conhecimento de organizações, bem como uma nova forma de comunicação acadêmica entre os pesquisadores dessas instituições (Cole e Foulonneau, 2007, p. 47).

25 Repositórios de pre-print: repositórios de publicações científicas com possibilidades de envio e acesso a publicações de forma aberta pela Internet sem intermediários. Pode ter ou não recursos de revisão pelos pares dos conteúdos postados.

26 www.arxiv.org

27 Literatura cinzenta: literatura não convencional, incluindo relatórios, patentes, monografias, teses, dissertações que não foram disponibilizadas por algum meio comercial. 
A questão que se colocava era como aproveitar a experiência dos repositórios de preprint e dar um passo a mais, propondo um modelo de interoperabilidade entre esses repositórios, permitindo que pudessem conversar entre si, compartilhando conteúdos, além da possibilidade de agregação de suas publicações, gerando novos serviços e inovações na área da comunicação científica. Logo, o tema central desse primeiro encontro foi o estabelecimento de recomendações e mecanismos para facilitar o desenvolvimento de serviços entre repositórios de conteúdos. Para que tais recomendações e mecanismos pudessem ser sugeridos, acordos entre os participantes sobre o conceito de interoperabilidade se faziam necessários (Lagoze e Van de Sompel, 2001).

Interoperabilidade tem vários aspectos incluindo uniformização de nomes, formatos de metadados, modelos de documentos, arquitetura de informação, protocolos de acesso, abertura para criação de serviços de terceiros, integração com os mecanismos estabelecidos da comunicação científica, usabilidade entre vários campos do conhecimento, habilidade para contribuir na análise de métricas de uso e citações etc. (Lagoze e Van de Sompel, 2001). Cada um desses aspectos pode ter diferentes interpretações, levando a muitas soluções técnicas possíveis de implementação. $\mathrm{O}$ trabalho inicial da OAI era avaliar sugestões e facilitar as negociações entre os membros e comunidades participantes da iniciativa.

Dependendo da forma como a OAI entendesse a interoperabilidade entre sistemas e conforme desenvolvesse suas sugestões de padrões a serem adotados, haveria um impacto direto na possibilidade de ampla adoção ou não dos padrões pela comunidades de potenciais usuários. Havia clareza entre os participantes dos grupos de trabalho da OAI de que criar padrões muito rígidos e especificações muito detalhadas geraria maior resistência e dificuldade para os usuários. Com essa questão em mente, o comitê técnico da OAI entendeu que as recomendações a respeito de interoperabilidade deveriam se restringir ao nível do transporte e compartilhamento de metadados (Lagoze e Van de Sompel, 2001), influenciando e regulando apenas o que o comitê considerou fundamental para que diferentes sistemas de informação pudessem trocar dados.

Decisão fundamental, pois permitiu que a iniciativa focasse apenas nas questões relacionadas ao movimento dos metadados em rede, permitindo que outras questões relacionadas a padrões de desenvolvimento de sistemas de informação, as funcionalidades dos sistemas, as estruturas de bancos de dados, interface com usuário, entre outras, pudessem ficar a critério de cada comunidade de desenvolvedores. A escolha da OAI permitiu que diversas soluções de sistemas de repositórios de conteúdos e bibliotecas digitais pudessem atuar com enfoques diferentes, para resolverem demandas diferentes, mantendo, entretanto, o mesmo protocolo para transporte e compartilhamento de metadados, o que tornava os sistemas interoperáveis nesse sentido. A partir dessa escolha, várias aplicações surgiram implementando o padrão OAI, sendo as mais conhecidas 
citadas a seguir: ePrints ${ }^{28}$, Dspace $^{29}$, Greenstone $^{30}$, CDS Invenio ${ }^{31}$, FEDORA $^{32}$, ARNO $^{33}$, I-Tor $^{34}$ e $\mathrm{PKP}^{35}$.

Com esse enfoque e a partir da motivação de promover inovações no fluxo de comunicação científica, foi produzida a declaração de missão do movimento OAI, resultado do encontro de Santa $\mathrm{Fe}$, definindo seu escopo e foco de trabalho:

"A OAI desenvolve e promove padrões de interoperabilidade que objetivam facilitar a disseminação eficiente de conteúdo. A OAI tem suas raízes num esforço para estimular o acesso a repositórios preprint como um meio de ampliar a disponibilização da comunicação científica. Contínuo suporte a esse trabalho é a base do programa OAI. Os fundamentos tecnológicos e padrões que são desenvolvidos para suportar esse trabalho são, entretanto, independentes do tipo de conteúdo e dos mecanismos econômicos que regulamentam o conteúdo, se tornando, portanto, promissores na abertura ao acesso de vários outros tipos de objetos digitais, além da comunicação científica. Como resultado, o movimento OAI é uma organização e um esforço explícito na transição e no comprometimento de viabilizar este novo e amplo escopo de aplicações. Conforme ganharmos conhecimento sobre o escopo de aplicação da tecnologia e dos padrões sendo desenvolvidos, e começarmos a compreender a estrutura e a cultura das várias comunidades que irão adotar OAI, nós esperamos realizar contínuas mudanças na missão e na organização da OAI." (Van de Sompel e Lagoze, 2000)

A missão da OAI evidencia importantes aspectos que possuem relação direta com o modelo de comunicação que pode ser construído utilizando suas especificações. O fato de ter se originado e continuar diretamente conectada com a ideia dos repositórios preprints mantém a iniciativa voltada para produzir especificações técnicas e modelos de comunicação que sirvam como alternativas ao modelo tradicional da comunicação científica. A independência do tipo de conteúdo disponibilizado, ou seja, dos padrões e formatos de documentos que podem utilizar essa

\footnotetext{
28 www.eprints.org/software

29 www.dspace.org

30 www.greenstone.org

$31 \mathrm{http} / / /$ cdsware.cern.ch

32 www.fedora.info

33 www.uba.uva.nl/arno

34 www.i-tor.org/en/

35 www.pkp.ubc.ca
} 
especificação, cria uma abertura essencial para que o uso dos padrões OAI possa escalar para novos formatos de arquivos e mídias digitais. A independência do modelo econômico posiciona os esforços da iniciativa com foco nos modelos técnicos de comunicação, permitindo que possam ser utilizados com diferentes enfoques, sejam proprietários ou livres. Decisão importante, pois garante que diferentes instituições e comunidades de pesquisadores possam, mesmo com fins econômicos diferentes, serem interoperáveis no nível dos metadados de suas publicações científicas.

Os aspectos organizacionais e culturais explicitados na missão OAI garantem sua intenção de que, por trás de especificações técnicas, possa ser produzido um trabalho contínuo de articulação entre as comunidades usuárias das especificações, mapeando tendências, dificuldades, limitações e possíveis inovações que possam ser incorporadas a iniciativa. O protocolo OAI-PMH, principal especificação da OAI, se encontra em sua versão 2.0, publicada em 14 de junho de 2002, considerada como versão estável pela comunidade para uso no desenvolvimento de aplicações em ambientes de produção.

Analisando os principais elementos que facilitaram a ampla adoção e sucesso na implementação do protocolo OAI-PMH, Carl Lagoze e Herbert Van de Sompel, presidentes do comitê técnico da OAI, consideram as decisões a seguir tomadas pelo comitê como fundamentais (Cole e Foulonneau, 2007, p. 35):

- o modelo organizacional que equilibra liderança efetiva com participação da comunidade: abertura, desde o início, a participação de vários agentes interessados nas especificações, garantindo que múltiplas visões e demandas fossem contempladas ou, ao menos, negociadas. Além de um modelo com intensa participação comunitária, o equilíbrio da liderança efetiva do comitê facilitava o encaminhamento de decisões e agenciamento de impasses que surgiram ao longo do caminho;

- um foco restrito e bem definido do problema a ser resolvido: apesar de inúmeras demandas e sugestões fossem constantemente feitas para serem incorporadas a OAI, o projeto manteve seu foco restrito no nível do transporte e compartilhamento de metadados, garantindo que tudo que estivesse fora desse escopo poderia ser livremente desenvolvido pelas comunidades que adotassem o padrão;

- um esforço proativo da comunidade: envolvimento intenso e proativo da comunidade, na revisão de especificações, nos testes pilotos e na documentação de problemas;

- um esforço consistente para tomar decisões técnicas transparentes e efetivas através de todo o processo: publicização do modelo de forma aberta e transparente desde o início, garantindo encontros, reuniões, eventos que pudessem definir pontos críticos das 
especificações.

Ao que parece, uma mistura de bons fatores técnicos e organizacionais emprestou equilíbrio e ritmo a iniciativa, facilitando que soluções simples e inovadoras pudessem surgir como respostas as questões que a OAI se propunha a responder.

Vejamos como o contexto do seu desenvolvimento e as especificações da OAI se constituíram num novo modelo de comunicação em rede para a comunidade científica.

\subsection{OAI: interoperabilidade e modelo de comunicação}

A proposta da comunidade OAI, em seu contexto organizacional e tecnológico, representa a maneira como a comunidade científica vem utilizando a tecnologia para produzir, disseminar e usar literatura científica estruturada em rede (Weitzel, 2006, p. 87). Oriunda diretamente de uma demanda de melhores estruturas e fluxos de comunicação entre pesquisadores, seu foco se tornou facilitar a disseminação da informação, a busca e o encontro de informação relevante, bem como incentivar a colaboração científica através de um modelo de comunicação que facilitasse a qualquer pesquisador acompanhar o que outros pesquisadores, instituições e centros de pesquisa tem produzido de relevante em sua área de interesse. É a partir dessa perspectiva que se pode entender os repositórios digitais como ferramentas para a promoção da comunicação científica (Bufrem, Gabriel Jr., Gonçalves, 2010).

O ponto chave desse modelo de comunicação proposto pela OAI é a questão da interoperabilidade entre repositórios de conteúdos digitais. Uma das razões para o lançamento da OAI é a crença de que a interoperabilidade entre repositórios é chave para o aumento do seu impacto e no seu estabelecimento como uma alternativa viável ao modelo existente de comunicação. As vantagens da interoperabilidade podem estimular o uso dos repositórios digitais nos blocos de construção de uma transformação no modelo de comunicação científica (Lagoze e Van de Sompel, 2001).

Um dos objetivos de um modelo de comunicação científica é garantir a mais ampla possibilidade de troca entre os pesquisadores. Considerando que a Internet e a World Wide Web se tornaram um espaço fundamental para a comunicação em rede, essa mais ampla possibilidade de troca entre pesquisadores passa pela capacidade de interoperabilidade entre seus sistemas de informação escolhidos para a publicação do resultado de suas pesquisas.

O modelo OAI foca a questão da interoperabilidade no transporte e no compartilhamento de metadados. Entende-se essa interoperabilidade como a possibilidade de diferentes sistemas de informação publicarem informações sobre suas publicações armazenadas seguindo os mesmos 
princípios, normas e padrões. Sendo assim, torna-se possível agregar essas informações publicadas e, a partir daí, gerar novos serviços e inovações no uso e processamento da informação.

Novos serviços podem incluir diferentes usos da publicação científica agregada, gerando indicadores, mapas, gráficos, análises bibliométricas e relacionais, bem como novos serviços de busca, monitoramento, acompanhamento de áreas, temas e focos de interesse. A interoperabilidade encoraja a construção de novos serviços (Van de Sompel e Lagoze, 2000), além de ser uma condição fundamental para qualquer modelo de comunicação que pretenda agregar diferentes sistemas de informação distribuídos em rede.

O protocolo OAI-PMH atua no ponto central deste modelo, viabilizando tecnicamente a circulação da informação em rede. É esse ponto central que viabiliza inovações, como a adoção uma visão federada de sistemas de informação para comunicação científica.

\subsection{Sistemas federados de informação}

Os sistemas federados de informação surgiram da necessidade de integração de sistemas de informação distribuídos em rede, como uma solução para minimizar dispersão de fontes de dados, reduzir a divergência entre interfaces de busca e ampliar as possibilidades de integração de conteúdos.

Existem várias alternativas de como essa integração pode ocorrer, no entanto, essas alternativas podem ser agrupadas em dois grandes grupos (Marcondes e Sayão, 2001):

- busca distribuída a diferentes servidores: a pergunta de busca é enviada a diferentes servidores, sendo os resultados agrupados e apresentados em uma interface única ao usuário do sistema;

- busca em uma base de metadados centralizada: o sistema realiza um harvesting ${ }^{36}$ periódico nos servidores de dados distribuídos, formando um repositório global de metadados. As pesquisas são realizadas nesse repositório global, sendo os usuários redirecionados ao servidor específico de um determinado recurso quando do acesso ao seu conteúdo.

A busca em diferentes servidores é recomendada em situações onde há poucos integrantes e com grandes coleções de dados, do contrário problemas de escalabilidade poderiam ocorrer. Já a busca em uma base de metadados centralizada é recomendada em situações onde a rede é composta de muitos sistemas e se deseja maior agilidade no acesso aos conteúdos, centralizando o processo de busca. As duas soluções acabam por considerar um uso diferente da infra-estrutura de rede, 36 Harvesting: sistema de coleta de metadados 
permitindo uma maior ou menor centralização de recursos conforme a demanda e características do tipo de integração que se deseja realizar.

O sistema de base de metadados centralizada, operando através do mecanismo de harvesting, ganhou maior ênfase para o movimento OAI, mostrando-se a solução mais viável para a formação de redes envolvendo vários repositórios digitais (Ferreira e Souto, 2006).

A coleta de metadados vem se tornando, com o movimento OAI, um padrão de organização das redes de bibliotecas digitais, tornando-se um paradigma de ambiente federado de informação. A forma como sua arquitetura de informação foi projetada influencia os aspectos técnicos e organizacionais de como essa rede deve ser estruturada. A arquitetura é baseada na existência de provedores de dados e provedores de serviços, como podemos visualizar na figura 5.1.

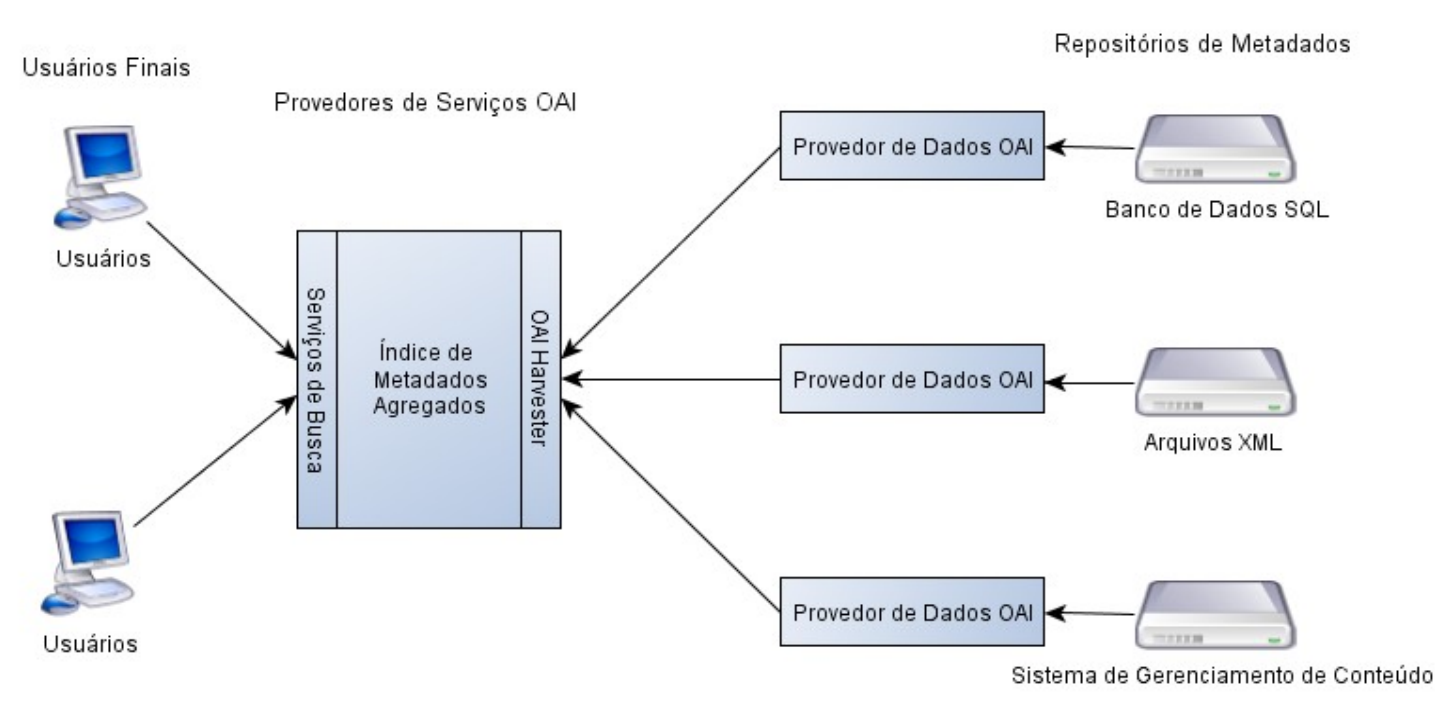

Fig. 5.1 - Arquitetura de informação OAI

Vejamos como a especificação OAI propõe a definição desses provedores.

\subsubsection{Provedores de dados}

O provedor de dados é um site na Internet que disponibiliza os conteúdos a serem compartilhados em rede. A especificação OAI não normatiza um formato específico nos quais os documentos de origem precisam ser construídos. Em tese, organizações que possuam uma rotina de disponibilização de conteúdos na Web e um fluxo de produção de metadados poderiam agregar o protocolo OAI-PMH em suas aplicações, tornando-se compatíveis e interoperáveis numa federação de sistemas de informação.

Ao longo dos anos, as comunidades que adotaram o padrão OAI acabaram por adotar formas específicas de como implementar provedores de dados. Os cenários mais comuns são apresentados 
a seguir (Cole e Foulonneau, 2007, p. 93):

- metadados armazenados como arquivos XML: a arquitetura do repositório assume que os ítens de metadados serão armazenados como arquivos no próprio servidor do sistema de arquivos disponível na Internet. Normalmente, alocam os recursos a serem disponibilizados numa área do servidor e os arquivos de metadados que descrevem esses recursos em outra área;

- metadados armazenados como um banco de dados relacional: é a arquitetura mais utilizada, sendo os metadados armazenados em um banco de dados relacional, normalmente o mesmo banco de dados que armazena os recursos descritos pelos metadados;

- metadados armazenados dentro do recurso que descreve: os próprios arquivos dos recursos a serem disponibilizados incluem uma área alocada para os metadados que descrevem seus recursos

- repositório OAI estático: é representado por um único arquivo XML que contém todos os metadados que são descritos pelo repositório. Normalmente, é utilizado para pequenos repositórios que não são alterados com frequência.

As diferentes formas que podem ser implementadas como um provedor de dados seguindo os padrões OAI dão uma ideia da diversidade e da flexibilidade de soluções que podem ser desenvolvidas. A especificação acaba por atender diferentes necessidades e escalas de repositórios digitais, oferecendo soluções simples e mais complexas, sendo que todas elas podem ser interoperáveis quando agregadas num mesmo provedor de serviços.

\subsubsection{Provedores de serviços}

O provedor de serviços é um site que realiza o processo de harvesting dos metadados dos sistemas integrantes da federação. É nele que ocorre efetivamente o processo de agregação dos metadados, construindo o índice de metadados agregados, conforme apresentado na figura 5.1.

O protocolo OAI-PMH não regula os tipos de serviços que podem ser construídos, ficando a critério das comunidades interessadas a produção de diferentes formas de processar, analisar e ofertar possibilidades de interesse geral de manipulação de seus metadados coletados.

Os provedores de serviços acabam se tornando grandes bases de dados que agregam os metadados disponibilizados por todos os sistemas que compõem uma federação. No entanto, a partir da arquitetura da informação a que servem, tornam-se um ponto único de acesso para buscas e 
análises de todos os repositórios disponíveis nessa rede, verdadeiros pontos de articulação, acesso e disseminação de todo o conteúdo compartilhado em rede. É uma maneira de construir e articular uma rede, não apenas de sistemas de informação, mas de pessoas e organizações que se apropriam desse meio para se comunicarem e compartilharem recursos de interesse.

Logo, esses provedores de serviços tornam-se pontos fundamentais numa federação e espaços privilegiados quando desejamos estudar tendências de como as relações sociais ocorrem entre os membros participantes de uma rede, considerando que esses membros consideram importante ocupar um espaço nessa rede, estar em rede e articular a própria rede em torno de seus objetivos e interesses.

A ideia de utilizar ambientes federados de informação gerou o que a comunidade OAI passou a chamar de federação de bibliotecas digitais.

\subsection{Federação de Bibliotecas Digitais}

O conceito de federação surge da necessidade de se denominar processos de integração de diferentes bases de dados e sistemas distribuídos em rede. No caso das bibliotecas digitais, o termo federação aparece quando estamos nos referindo não mais a bibliotecas independentes, mas sim a sistemas que façam a integração de dados de diferentes bibliotecas distribuídas. A federação surge, portanto, como uma denominação a um novo suporte tecnológico que possibilite essa integração de dados (Marcondes e Sayão, 2001). Uma metáfora importante, um conceito que nos permitirá entender uma federação de bibliotecas como uma forma de representar uma rede de bibliotecas digitais.

Vejamos alguns exemplos de iniciativas de federações de bibliotecas digitais que nos auxiliam a perceber como o conceito de federação reflete a maneira como as bibliotecas se organizam em rede:

- Biblioteca Digital de Teses e Dissertações (BDTD) ${ }^{37}$ : é um projeto que visa a integração de diversas bibliotecas digitais de Instituições de Ensino Superior brasileiras que disponibilizam teses e dissertações.

- Networked Digital Library of Theses and Dissertations (NDLTD) ${ }^{38}$ : é um projeto que visa a integração de bibliotecas digitais de teses e dissertações de vários países do mundo. Foi a primeira experiência de uma federação.

- Networked Computer Science Technical Reference Library (NCSTRL) 39 : é um projeto

37 www.ibict.br

38 www.ndltd.org

39 www.ncstrl.org 
voltado para a agregação da produção científica da área de Ciências da Computação.

- Univerciencia.org ${ }^{40}$ : é um projeto brasileiro que visa a agregação de diversas bibliotecas digitais que disponibilizam recursos voltados para a área das Ciências da Comunicação.

Os exemplos acima apresentados permitem entendermos que uma federação de bibliotecas digitais normalmente representa uma rede temática ou de instituições com fins semelhantes.

A ideia de federação traz a visão da integração de sistemas distribuídos em rede, no caso das bibliotecas, sistemas de bibliotecas digitais. Dentro desse contexto, podemos entender uma biblioteca digital como sendo o nó de uma vasta rede, formando rede a partir de sua compatibilidade, de sua coerência, de sua padronização com outras inscrições, cada uma das quais representando uma conexão com o mundo através de uma rede (Latour, 2004, p. 49). Esse nó é visto como uma coleção de objetos digitais, juntamente com métodos para acesso e busca da informação, bem como seleção, organização e manutenção da coleção (Witten, Bainbridge e Nichols, 2010, p. 7).

A biblioteca digital acadêmica torna-se uma presença em rede que representa um contexto, o escopo de representatividade de sua coleção, de sua organização, dos grupos e pesquisadores que a utilizam como uma interface para publicação de seus resultados. O contexto da biblioteca forma um tipo de presença, de integridade conceitual da biblioteca, que empresta coesão e identidade, elementos que refletem sua visão e organização social.

Torna-se, portanto, a presença digital de todo um ciclo de comunicação científica, representando processos de pesquisa, colaboração e focos de interesse da produção ali depositada. Uma biblioteca digital científica é um elemento que representa toda uma rede de relações sociais constituídas com o objetivo de fazer ciência, publicar e compartilhar seus resultados, realimentando o ciclo virtuoso da comunicação científica facilitando a circulação e apropriação da informação publicada.

As bibliotecas digitais são produtos de um contexto sobreposto por vários elementos que convergiram em sua presença como um nó de uma vasta rede (Sayão, 2009, p. 7) :

- integração e uso das tecnologias de informação e comunicação;

- maior disponibilização de redes de computadores e tecnologias de apresentação;

- barateamento dos meios de armazenamento em massa;

- disponibilidade crescente de conteúdos digitais em escala planetária;

- possibilidade de digitalização a um custo economicamente viável de conteúdos em

40 www.univerciencia.org 
mídias convencionais;

- coerência das mídias digitais, abrindo a possibilidade singular para a concepção de novos serviços de informação a partir da integração de objetos digitais.

A biblioteca digital pode ser vista, portanto, como um expoente das novas tendências de sistemas de informação que operam no ambiente distribuído em rede da Internet, aproveitando suas características para viabilizar experiências e novos paradigmas na área da comunicação científica.

É interessante notar que um dos elementos que caracterizam seu surgimento é a possibilidade de integração de objetos digitais. A digitalização de acervos surge dentro do contexto da interoperabilidade de sistemas, já apontando tendências de produção de novas camadas de funcionalidades, bem como novos modos de organização, sistematização, circulação e apropriação da informação em rede. A biblioteca reproduz no ambiente digital seu objetivo físico, ser um espaço que promova a organização de acervos ampliando seu acesso e disseminação, sem deixar de lado sua função como espaço de encontro e agregação de produções temáticas.

\subsection{Protocolo OAI-PMH}

O protocolo OAI-PMH é um modelo de arquitetura de rede cliente-servidor que tem por objetivo regular tecnicamente como deve ocorrer o movimento dos metadados entre um provedor de dados e provedor de serviços, no contexto de um sistema federado de informações. De maneira a facilitar a adoção do protocolo, ele foi todo embasado em vários padrões tecnológicos de comunicação e infra-estrutura em rede amplamente aceitos (Cole e Foulonneau, 2007, p. 21).

O foco de interoperabilidade do protocolo, como mencionamos anteriormente, é o transporte e compartilhamento de metadados. Para que o transporte de metadados possa ocorrer, o protocolo OAI-PMH utiliza três camadas de padrões tecnológicos (ver fig. 5.2) previamente existentes como infra-estrutura de base em cima da qual seus padrões são construídos: camada de transporte dos dados, camada de linguagem de descrição dos dados e camada de semântica da descrição dos dados.

\begin{tabular}{|c|}
\hline $\begin{array}{c}\text { Camada de Semântica } \\
\text { da Descrição dos Dados } \\
\text { (DublinCore ao menos) }\end{array}$ \\
\hline $\begin{array}{c}\text { Camada de Linguagem } \\
\text { da Descrição dos Dados } \\
\text { (XML) }\end{array}$ \\
\hline $\begin{array}{c}\text { Camada de Transporte } \\
\text { dos Dados } \\
\text { (HTTP) }\end{array}$ \\
\hline
\end{tabular}

Fig.5.2 - Camadas de padrões tecnológicos de base para o protocolo OAI-PMH. 
As soluções propostas pela comunidade OAI, visando facilitar a adoção do padrão, foram baseadas nos melhores e mais amplamente aceitos padrões a disposição, evitando propor novos padrões para essas camadas. Para o transporte de dados entre provedores de dados e provedores de serviços, a escolha foi utilizar o $\mathrm{HTTP}^{41}$, procolo baseado na arquitetura cliente-servidor e que serve de base para a Web. Para a linguagem que padronizaria a forma como os metadados deveriam ser descritos, foi escolhido o padrão $\mathrm{XML}^{42}$, que havia se tornado uma recomendação oficial do World Wide Web Consortium ${ }^{43}$ (W3C) em fevereiro de 1998. Para a semântica de descrição dos metadados, o grupo técnico da OAI entendeu que seria necessário propor ao menos um padrão ao qual todos os provedores de dados deveriam respeitar, sendo o padrão escolhido o Dublin Core ${ }^{44}$. Essa escolha se deve, principalmente, ao entendimento do grupo de que incluir no protocolo OAIPMH um padrão semântico de descrição de metadados simples seria um elemento facilitador de sua adoção. Vale mencionar que o protocolo OAI-PMH permite a utilização de outros padrões semânticos de metadados, além do DublinCore, não havendo restrições em relação a isso, mas exige que ao menos o DublinCore seja ofertado por qualquer provedor de dados que utilize o padrão.

\subsubsection{Papel do HTTP}

O protocolo HTTP é baseado na arquitetura cliente-servidor e se propõe a ser um modelo simples de comunicação entre dois computadores em rede, no qual a Web é baseada. O protocolo trabalha com a ideia de sessão de comunicação. Uma sessão representa uma troca de mensagens entre cliente e servidor. O cliente emite um pedido de informação (request message) ao servidor, que envia uma mensagem de resposta (response message), encerrando a sessão entre os dois. Do ponto de vista do protocolo HTTP, qualquer nova transação entre cliente e servidor indica uma nova sessão independente de comunicação entre os dois (Cole e Foulonneau, 2007, p. 24).

Para entender como funciona o transporte de metadados na especificação OAI-PMH, é fundamental entendermos os detalhes de funcionamento do protocolo HTTP.

Um pedido de informação feito por um cliente a um servidor é constituída de 3 partes ( ver figura 3):

- request-line: descreve o método HTTP aplicado pelo cliente, o nome do recurso que o cliente deseja obter e a versão do protocolo HTTP que ele está utilizando. O nome do recurso pode ser um arquivo contendo um conteúdo desejado, como no caso da figura 5.3 o arquivo test.html, ou um script de dados que terá de ser executado pelo servidor

\footnotetext{
41 HTTP - Hypertext Transfer Protocol

42 XML - eXtended Markup Language

43 http://www.w3.org

44 http://dublincore.org
} 
para devolver a resposta ao cliente. Esse recurso é de extrema importância para viabilizar aplicações mais complexas em rede, permitindo que os clientes da aplicação passem parâmetros a serem utilizados em processamentos específicos pelos servidores;

- request headers: informa ao servidor sobre detalhes do pedido enviado, também dando mais detalhes sobre o que e quem está fazendo o pedido;

- request message body: oferece ao servidor informações adicionais sobre o recurso desejado pelo cliente, como vemos no exemplo da figura 5.3, no caso da identificação do número de um livro e nome de autor. Normalmente, parâmetros de uma consulta realizada através de formulários são enviados nesta parte numa mensagem HTTP.

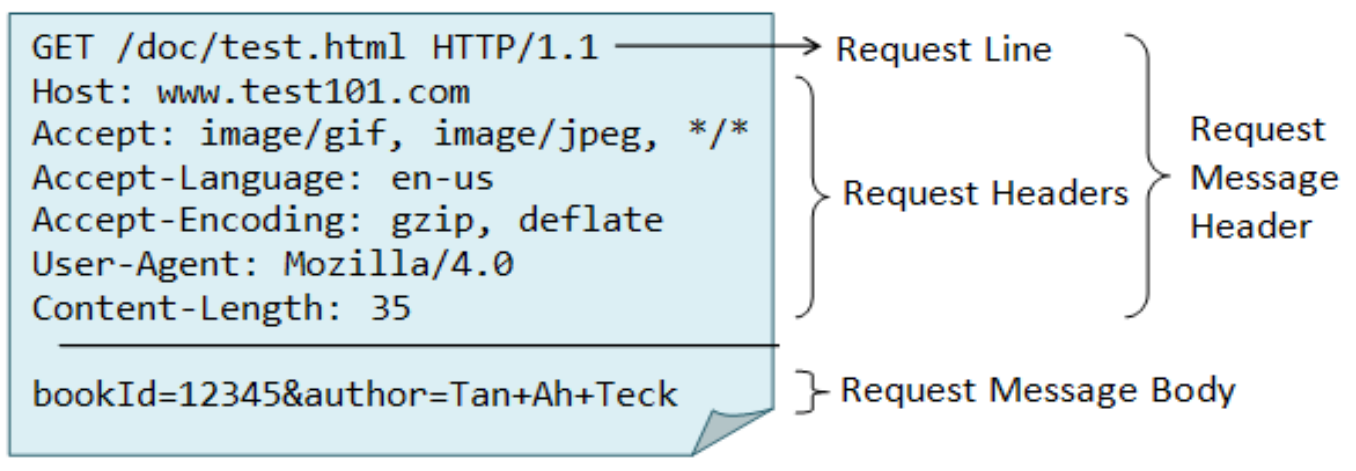

Fig. 5.3 - Request Message no padrão do protocolo HTTP.

Uma resposta a um pedido de informação também é constituído de 3 partes (ver figura 5.4):

- response status line: contém uma descrição numérica que representa o estado do servidor, indicando se ele pode ou não responder a requisição ou informando algum erro que possa ter ocorrido;

- response headers: informações sobre o servidor HTTP, sobre o tipo e tamanho de conteúdo que será enviado;

- response message body: representa a resposta enviada pelo servidor, contendo o conteúdo desejado pelo cliente, se o servidor estiver em condições de dispor o recurso. No caso da figura 5.4, o exemplo apresenta o envio do conteúdo de uma página html, conforme requisitado no exemplo da figura 5.3. 


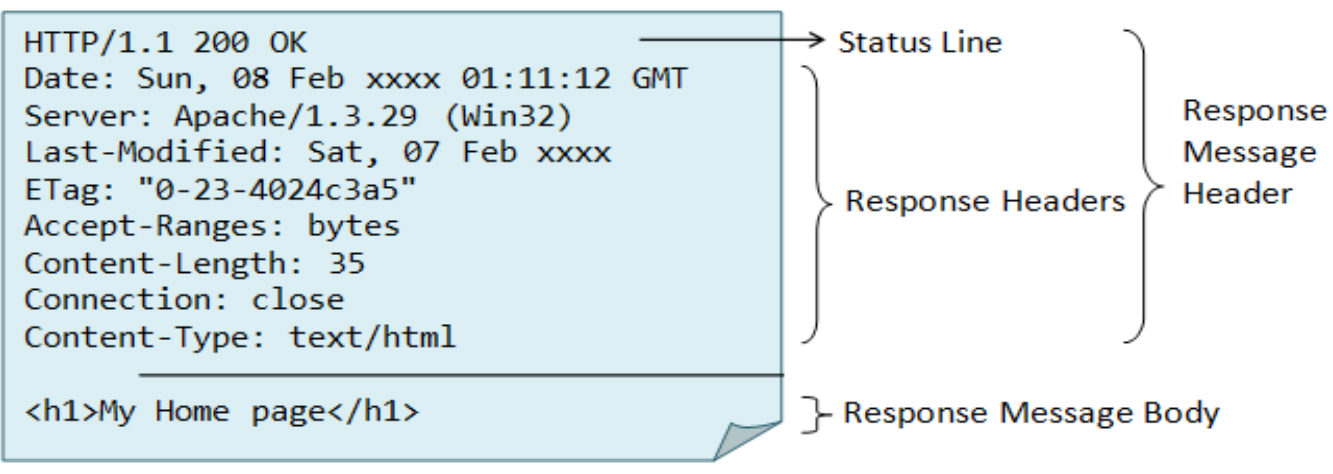

Fig. 5.4 - Response Message no padrão do protocolo HTTP.

O protocolo OAI-PMH faz um uso específico do protocolo HTTP, definindo para uma sessão de comunicação o que é um pedido de informação e uma resposta válida entre um provedor de dados e de serviços (Cole e Foulonneau, 2007, p. 25). Dessa forma, cria a possibilidade de sincronização entre os provedores, permitindo que possam se reconhecer como um provedor de dados e um provedor de serviço do padrão OAI-PMH, viabilizando o transporte de metadados entre eles.

A vantagem de uso do HTTP pelo protocolo OAI-PMH, além de ser um padrão amplamente testado e aceito, é deixar ao seu critério o controle do fluxo de mensagens entre cliente e servidor. O protocolo HTTP utiliza os padrões $\mathrm{TCP} / \mathrm{IP}^{45}$ para o gerenciamento do tamanho das sessões de comunicação, do sequenciamento de pacotes de dados e de como manipular os endereços Web entre cliente e servidor.

\subsubsection{Papel do XML}

A linguagem XML é uma linguagem de marcação utilizada para definir a estrutura de um documento, originada a partir da linguagem $\mathrm{SGML}^{46}$, um padrão internacionalmente utilizado desde 1986 como um linguagem para processamento de texto. A estrutura é definida a partir dos elementos que que constituem o documento. Elementos são marcados por um início e um fim, delimitados por uma marcação chamada de tag (ver fig. 5.5). Possui algumas regras sintáticas que organizam seus elementos de forma hierárquica, evitando dessa forma que haja sobreposição de elementos entre si.

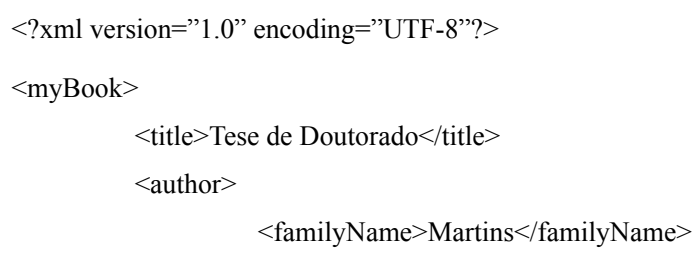

45 TCP/IP - Transport Control Protocolo/Internet Protocol 46 SGML - Standard Generalized Markup Language 


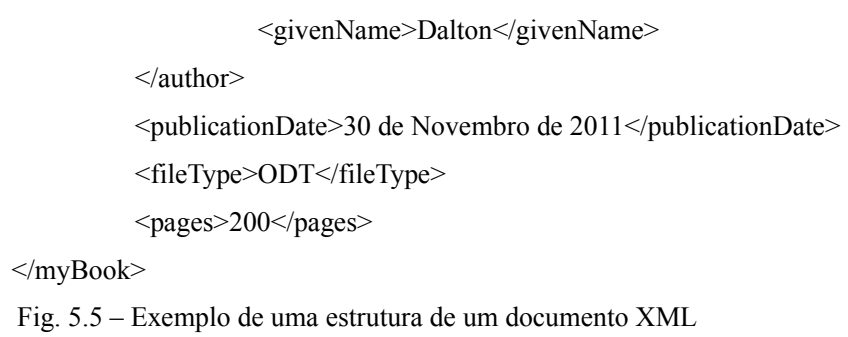

Para o uso correto das regras sintáticas da XML, alguns requisitos precisam ser respeitados (Cole e Foulonneau, 2007, p. 28):

- todos os elementos precisam ser explicitamente fechados, mesmo elementos vazios que não possuem nenhum conteúdo;

- todos os atributos de elementos precisam receber um valor e devem ser envolvidos em aspas ;

- um elemento XML e o nome de seu atributo deve ser consistente com o conjunto de caracteres utilizados;

- a codificação de caracteres Unicode UTF-8 (8-bit Unicode Transformation Format) por padrão, deve ser mantido ao longo de todo um documento XML.

A XML introduziu três inovações importantes que potencializaram diversas aplicações na Internet baseadas na interoperabilidade entre sistemas de informações, caso do protocolo OAIPMH. Vejamos quais são:

- estruturas de documentos extensíveis: a semântica da linguagem XML não é fixa, ao contrário da linguagem HTML, por exemplo. Isso permite que qualquer organização ou comunidade de usuários possa criar uma estrutura de um documento padrão e compartilhar entre si as regras semânticas de como esse documento é estruturado. Cada elemento dessa estrutura precisa ter um nome distinto e um significado específico.

- XML Schemas: de forma a explorar melhor a possibilidades de extensão de estruturas de documentos oferecidas, é importante que as aplicações que processarão um documento conheçam as regras semânticas de como ele é organizado. A linguagem XML oferece a possibilidade disso ser informado utilizando um arquivo, chamado XML Schema, que apresenta todas as regras semânticas pelas quais um conjunto de documentos é estruturado. Esse arquivo pode ser utilizado por uma aplicação cliente para entender como processar um conteúdo compartilhado em rede.

- XML Namespaces: um namespace é uma forma de explicitar e manter uma compatibilidade maior da origem das regras semânticas para a construção de um schema 
XML. Permite que aplicações utilizem um mesmo schema compartilhado entre elas. Um namespace, em termos práticos, é representado por uma $\mathrm{URI}^{47}$, que é uma forma única de endereçamento de recursos utilizados pela Web, sendo essa maneira de dar um endereço público para um schema XML, podendo ser consultado por qualquer cliente que tenha conhecimento dessa URI. As URIs podem ser criadas por comunidades que desejam declarar qual é seu padrão semântico de metadados, como, por exemplo, a comunidade de pesquisadores de botânica pode publicar uma URI contendo as especificações semânticas de como um arquivo XML deve ser estruturado para seguir seus padrões. Qualquer aplicação interessada em seguir essa convenção, pode utilizar a URI como parâmetro de construção de seus conteúdos XML. A partir deste recurso, é possível combinar diferentes namespaces públicos para criar uma convenção particular, mesclando padrões de comunidades.

Um documento XML somente é considerado válido quando ele estiver dentro dos padrões de sua estrutura e de acordo com as regras semânticas padronizadas em seu Schema. A possibilidade de validar um documento dessa forma foi uma característica importante a ser considerada pelo protocolo OAI-PMH, que entendeu ser esse recurso fundamental para ofertar um mecanismo de checagem e validação da troca de metadados entre provedores de dados e de serviços. Outro elemento utilizado pelo protocolo OAI-PMH foi o namespace, permitindo que a comunidade utilizasse namespaces já padronizados para compor sua especificação, como é o caso do padrão DublinCore. Essas duas características da XML trouxeram maior flexibilidade, utilização de conjuntos semânticos já padronizados, e robustez, possibilidade de validação da estrutura de um documento, para o protocolo OAI-PMH.

\subsubsection{Papel do DublinCore}

O padrão Dublin Core é um conjunto de metadados que foi desenvolvido para uso específico por não-especialistas, tendo por intenção ser um conjunto simples e de fácil implementação para a descrição de objetos digitais a serem compartilhados em rede, utilizando a linguagem XML como base. É resultado de um esforço colaborativo de um grande número de comunidades, envolvendo cientistas da computação, bibliotecários e grupos interessados na construções de padrões para descrição de documentos na Web. O primeiro encontro da comunidade Dublin Core ocorreu em Ohio, Estados Unidos, em 1995. O padrão recebeu aprovação do American National Standard

47 URI - Uniform Resource Identifier 
Institute (ANSI) em 2001 (Witten, Bainbridge e Nichols, 2010, p. 294).

É formado pelos conjuntos DublinCore Simplicado e DublinCore Qualificado, que é uma forma de ampliar os recursos oferecidos pelo conjunto simplificado, composto de 15 elementos, a serem descritos na tabela 5.1, a seguir.

\begin{tabular}{|l|l|}
\hline \multicolumn{1}{|c|}{ Metadados } & \multicolumn{1}{c|}{ Definição } \\
\hline Title & O nome dado a um recurso pelo seu criador ou editor \\
\hline Creator & $\begin{array}{l}\text { A pessoa ou organização primariamente responsável pelo conteúdo intelectual do } \\
\text { recurso }\end{array}$ \\
\hline Subject & O assunto do recurso \\
\hline Description & Uma descrição textual do conteúdo do recurso \\
\hline Publisher & A entidade responsável por tornar o recurso disponível \\
\hline Contributor & $\begin{array}{l}\text { A pessoa ou organização (outra, que não o criador) que é responsável por fazer } \\
\text { significativas contribuições ao conteúdo intelectual do recurso }\end{array}$ \\
\hline Date & Uma data associada com a criação ou disponibilização do recurso \\
\hline Type & A natureza ou gênero do conteúdo do recurso \\
\hline Format & O formato físico ou digital do recurso \\
\hline Identifier & $\begin{array}{l}\text { A referência não-ambígua que pode unicamente identificar o recurso em um dado } \\
\text { contexto }\end{array}$ \\
\hline Source & $\begin{array}{l}\text { Uma referência para um segundo recurso de onde o presente recurso possa ter sido } \\
\text { derivado }\end{array}$ \\
\hline Language & A linguagem na qual o conteúdo intelectual do recurso foi desenvolvido \\
\hline Relation & Uma referência a um recurso relacionado e a natureza dessa relação \\
\hline Coverage & Localização espacial e tempo que são características do conteúdo do recurso \\
\hline Rights & Informações sobre os direitos autorais relacionados ao recurso \\
\hline 5.1 Conjunto de metadados DublinCore Simplificado. Fonte: Witten, Bainbridge e Nichols (2010) \\
\hline
\end{tabular}

O conjunto qualificado foi criado para facilitar a extensão dos 15 elementos básicos, permitindo que comunidades interessadas em recursos mais expressivos para a descrição de seus conteúdos possam ser contempladas. Qualquer elemento do conjunto simplificado pode ser refinado ou qualificado. Por exemplo, o elemento date poderia ser qualificado através dos seguintes elementos date created, date valid, date available, date issued ou date modified. A característica que torna esse processo de qualificação flexível do padrão DublinCore é o fato de que um elemento qualificado poder ser convertido em simplificado apenas removendo o qualificador, permitindo, dessa forma, que os conjuntos simplificado e qualificado possam co-existir em seus sistemas de informação.

Esquemas de codificação podem regular a faixa de valores permitida para o conteúdo de alguns elementos dos metadados DublinCore. Por exemplo, formato das datas específico, como $\mathrm{mm} / \mathrm{dd} /$ yyyy, ou um vocabulário controlado para uso no elemento subject, regulando a forma como 
ele deva ser descrito. As restrições oferecidas pelos esquemas de codificação são fundamentais quando pensamos em interoperabilidade de formatos em sistemas distribuídos em rede.

A escolha do DublinCore como referência semântica para os metadados foi uma das decisões mais difíceis e polêmicas tomada pela iniciativa OAI, no entanto, foi baseada na perspectiva da utilização de um padrão estabelecido, simples e de ampla aceitação na Web.

Dentro do contexto de desenvolvimento do protocolo OAI-PMH, a escolha técnica da comunidade OAI para gerar interoperabilidade entre provedor de dados e de serviços foi da utilização do conjunto de metadados DublinCore como padrão semântico mínimo para descrição dos metadados, disponibilizando um XML Schema de descrição do DublinCore Simplificado em conjunto com o protocolo, servindo este para a validação dos dados coletados no sistema de harvesting. O schema XML é mantido como um namespace público, através da publicação de sua URI de acesso, pela Dublin Core Metadata Initiative (DCMI), permitindo que qualquer comunidade interessada possa ter acesso a como esse conjunto de metadados pode ser codificado e decodificado. Além disso, o transporte de metadados entre os provedores seria feito utilizando o protocolo HTTP. A escolha desses padrões configura o entendimento da comunidade OAI sobre como criar uma arquitetura da informação o mais interoperável possível a partir da utilização de padrões de comunicação e organização em rede já existentes.

\subsection{Metadados e normalização}

A Internet ganhou muitos adeptos e expandiu de forma expressiva antes que convenções sobre como descrever dados fossem acordadas (Dornfest e Brickley, 2001, p. 205). Fator que indica o rápido processo de apropriação e multiplicidade de serviços que foram desenvolvidos utilizando a rede, mas que também aponta desafios a serem superados quando o que se espera é a integração de sistemas.

O protocolo OAI-PMH fornece toda a estrutura para a construção de ambientes federados de informação. No entanto, além da arquitetura de informação, para que a interoperabilidade dos sistemas possa atingir todo seu potencial, devemos levar em consideração a maneira que uma organização faz a gestão de seus metadados. Estamos falando aqui de aspectos que ultrapassam convenções técnicas e têm relação direta a como essas convenções são apropriadas e utilizadas por quem faz a gestão da informação de uma biblioteca digital. Questões relacionadas a como os metadados são criados, atualizados e eliminados influenciam diretamente a política de coleta que um provedor de serviços deve operar.

Como vimos, os metadados podem ser validados de forma a garantir que se adaptam ao padrão sintático e semântico exigido para o uso em um determinado tipo de serviço. A qualidade e 
nível de adequação da especificação de metadados que são trocados entre provedor de dados e de serviços influencia diretamente no tipo e na qualidade de serviços que podem ser ofertados. No contexto do protocolo OAI-PMH, os critérios de seleção de metadados podem ser entendidos de 3 formas (Cole e Foulonneau, 2007, p. 139):

- na seleção de qual repositório coletar: indica a possibilidade de escolher qual provedor de serviços será coletado para fazer parte de uma determinada federação;

- como e quando realizar uma coleta seletiva num repositório particular: indica a possibilidade de selecionar um subconjunto de metadados de um determinado repositório.

- como e quando filtrar os metadados pós-coleta: indica a possibilidade de um provedor de serviços operar diversos procedimentos de filtragem e seleção de metadados conforme a necessidades dos serviços que deseja oferecer.

As duas primeiras formas ocorrem no nível da interação entre provedor de serviços e de dados. A terceira forma ocorre a partir de procedimentos internos que podem ser programados dentro do sistema do provedor de serviços. São procedimentos que atuam diretamente no potencial de agregação dos metadados, buscando melhorar sua qualidade sintática e semântica.

\subsubsection{Agregação de Metadados}

O processo de agregação pode ser entendido como o conjunto de procedimentos que são necessários para agrupamento dos dados coletados, permitindo que outros procedimentos possam produzir novas informações a partir dessa base comum. São essas novas informações, produto direto da agregação, que podem enriquecer a forma como os documentos compartilhados são apropriados, derivando novos tipos de usos e mecanismos de disseminação.

Provedores de serviços de sucesso, ou seja, aqueles com potencial para atrair maior número de usuários, são aqueles que oferecem serviços avançados de busca, navegação nos dados, suportando buscas a partir de diferentes tipos de entidades, tais como, nomes, títulos, datas, além de serviços de visualização, tais como geração automática de mapas dos repositórios e linhas do tempo (Chavez et al., 2007). Para a efetiva operacionalização desse tipo de serviços, os dados precisam ser tratados em procedimentos internos ao provedor de serviços, após a coleta dos metadados dos provedores de dados.

Vejamos como estes procedimentos podem ser descritos segundo Cole e Foulonneau (2007, p. 155): 


\begin{tabular}{|c|c|c|c|c|}
\hline Selecionar & Limpar & Normalizar & Aumentar & Adaptar \\
\hline $\begin{array}{l}\text { Excluir registros } \\
\text { que não } \\
\text { correspondem a } \\
\text { política de uso do } \\
\text { provedor de } \\
\text { serviços. Ex.: } \\
\text { dados que } \\
\text { possuem direitos } \\
\text { autorais } \\
\text { divergentes. }\end{array}$ & $\begin{array}{l}\text { Remover elementos } \\
\text { de concatenação. Ex.: } \\
\text { pontuações, } \\
\text { marcadores de } \\
\text { começo e fim de uma } \\
\text { sentença. }\end{array}$ & $\begin{array}{l}\text { Renomear campos } \\
\text { e/ou mapeá-los de um } \\
\text { campo para outro. } \\
\text { Ex.: um registro vem } \\
\text { com o nome do } \\
\text { campo Autor e outro } \\
\text { Author. }\end{array}$ & $\begin{array}{l}\text { Acrescentar valores } \\
\text { e/ou detalhar campos. } \\
\text { Atribuir valores- } \\
\text { padrão para todos os } \\
\text { registros de um } \\
\text { mesmo repositório. } \\
\text { Ex.: acrescentar nome } \\
\text { de instituição a dados } \\
\text { provenientes de um } \\
\text { mesmo local. }\end{array}$ & $\begin{array}{l}\text { Selecionar os } \\
\text { registros que } \\
\text { serão utilizados } \\
\text { por um } \\
\text { determinado } \\
\text { serviço. }\end{array}$ \\
\hline \multirow[t]{2}{*}{$\begin{array}{l}\text { Remover registros } \\
\text { duplicados ou } \\
\text { reconciliar } \\
\text { metadados que } \\
\text { descrevem objetos } \\
\text { com a mesma } \\
\text { URI. }\end{array}$} & $\begin{array}{l}\text { Remover campos } \\
\text { vazios. }\end{array}$ & \multirow[t]{2}{*}{$\begin{array}{l}\text { Modificar/transformar } \\
\text { valores para } \\
\text { vocabulários } \\
\text { controlados e/ou } \\
\text { normalizar os valores. } \\
\text { Ex.: padronizar a } \\
\text { forma como os } \\
\text { registros descrevem o } \\
\text { assunto que } \\
\text { representam }\end{array}$} & $\begin{array}{l}\text { Acrescentar nome de } \\
\text { uma coleção e outros } \\
\text { campos e valores que } \\
\text { forem pertinentes ao } \\
\text { contexto do } \\
\text { repositório. }\end{array}$ & $\begin{array}{l}\text { Selecionar } \\
\text { campos } \\
\text { alternativos } \\
\text { quando a } \\
\text { primeira opção } \\
\text { não estiver } \\
\text { disponível. Ex.: } \\
\text { não há nome do } \\
\text { autor, mas existe } \\
\text { o campo } \\
\text { sobrenome. }\end{array}$ \\
\hline & $\begin{array}{l}\text { Separar valores que } \\
\text { foram concatenados. } \\
\text { Ex.: separar em dois } \\
\text { campos quando nome } \\
\text { e sobrenome vierem } \\
\text { juntos. }\end{array}$ & & $\begin{array}{l}\text { Relacionar os dados a } \\
\text { uma autoridade } \\
\text { externa. Ex.: atribuir } \\
\text { aos dados o nome da } \\
\text { instituição } \\
\text { financiadora do } \\
\text { projeto. }\end{array}$ & $\begin{array}{l}\text { Decidir } \\
\text { estratégias para } \\
\text { quebrar valores e } \\
\text { listar múltiplos } \\
\text { valores. Ex.: } \\
\text { tratamento de um } \\
\text { campo data, } \\
\text { exibindo apenas } \\
\text { dia, ano ou mês. }\end{array}$ \\
\hline
\end{tabular}

Certamente, nem todos os procedimentos apresentados na tabela 5.2 precisam ser implementados por um provedor de serviços. Os procedimentos a serem utilizados vão variar em relação a qualidade de produção dos metadados dos provedores de dados, sendo que podem estar mais ou menos alinhados em torno de um mesmo propósito e de normas comuns para a publicação de informação em rede.

A título de ilustração, vale a pena mencionarmos um estudo que avaliou como os itens subject e description do padrão Dublin Core Simplificado foram utilizados por três tipos diferentes de instituições (Cole e Foulonneau, 2007, p. 170):

\begin{tabular}{|l|c|c|}
\hline \multirow{2}{*}{ Bibliotecas digitais } & \multicolumn{2}{|c|}{ \% de registros coletados contendo o elemento } \\
\cline { 2 - 3 } & Subject & Description \\
\hline Museus e sociedades históricas & 78 & 36 \\
\hline Bibliotecas acadêmicas & 93 & 93 \\
\hline
\end{tabular}

Tabela 5.3. Variação no uso de dois elementos Dublin Core por tipos de instituição. Fonte: Cole e Foulonneau (2007, p. 170) 
Um outro estudo (Ward, 2004) parece confirmar a tabela acima, indicando uma grande variação no uso de campos Dublin Core pelos provedores de dados. Analisando 82 provedores de dados e 910.919 registros de metadados no padrão Dublin Core Simplificado, os resultados indicaram que 54\% dos provedores utilizavam apenas os campos creator e identifier para aproximadamente $50 \%$ dos metadados que disponibilizam.

A variação dos dados apresentada acima nos permite concluir que, por exemplo, um serviço que pretenda fazer uma análise dos assuntos disponibilizados por essas coleções pode operar de forma significativa no contexto dos Museus e Bibliotecas Digitais, tornando-se praticamente irrelevante no contexto das Bibliotecas acadêmicas por falta de dados. O mesmo se passa no quesito descrição dos recursos, inviabilizando desta vez também as Bibliotecas Digitais por falta de informações abrangentes. Dependendo do contexto e dos recursos disponíveis para um projeto, estes campos podem ser complementados pelo provedor de serviços, ou mesmo um acordo entre provedor de serviços e de dados pode levar a melhorias nessas taxas, ampliando o nível de colaboração entre os provedores.

Sendo assim, o desenvolvimento de um novo serviço deve levar em consideração uma análise prévia da qualidade dos metadados de forma que possa projetar quais serão os procedimentos pós-coleta que precisam ser implementados.

\subsubsection{Qualidade dos Metadados}

A qualidade de um conjunto de metadados deve ser avaliada levando em consideração o propósito pelo qual um repositório foi criado. Os metadados podem atender as necessidades e demandas de um repositório, a partir de seu contexto local. Diversos tipos de problemas locais podem influenciar na qualidade dos metadados, desde erros tipográficos ao processo de conversão de dados para formatos digitais (Beal, 2005). No entanto, no contexto de uma federação a qualidade dos dados de um repositório pode decair em função da necessidade de integração com outros sistemas de informação.

A integração dos sistemas leva a três questões relacionadas diretamente a qualidade dos metadados (Nichols, McKay e Twidale, 2008). Primeiro, múltiplos formatos da semântica de metadados podem estar presentes na federação, levando a necessidade de procedimentos de conversação de um padrão em outro para formar uma coleção única, acarretando perda de informação. Segundo, diferentes projetos, mesmo utilizando o mesmo formato de metadados, podem ter entendimentos distintos de como um campo deva ser preenchido, levando a inconsistências que precisam ser tratadas quando da formação de uma coleção única. Terceiro, um repositório pode assumir um contexto local e desenvolver os seus dados a partir deste contexto não 
o explicitando em seus metadados. Um exemplo de como isso pode acarretar inconsistências é um repositório dedicado a um evento histórico específico, não descrevendo em seus metadados esse evento, levando em consideração que a busca de informações seria sempre a partir desse contexto. Quando esses dados fossem agregados em uma coleção maior, o contexto do evento teria se perdido.

Logo, essas três questões devem ser levadas em consideração quando da avaliação da qualidade dos metadados e na especificação dos procedimentos de tratamento. De forma a facilitar uma avaliação sistemática da qualidade de um conjunto de metadados, podemos avaliar seu padrão de qualidade segundo sete dimensões (Witten, Bainbridge e Nichols, 2010, p. 323):

- completude: o nível de campos que se encontram preenchidos de informação. No nosso caso, estamos falando dos campos referentes minimamente ao padrão Dublin Core;

- precisão: a quantidade de erros que pode ser encontrada;

- proveniência: a fonte de onde provém os metadados. No nosso caso, a proveniência nos será útil quando quando forem claramente reconhecidos como oriundos do campo das Ciências da Comunicação;

- ajuste aos padrões: o nível de ajuste as especificações semânticas e sintáticas. No nosso caso, ajuste aos padrões propostos pelo protocolo OAI-PMH;

- consistência lógica e coerência: o nível de consistência dentro de todo o conjunto de um repositório. No nosso caso, diz respeito a maneira e os critérios pelos quais os metadados são preenchidos pela biblioteca digital de origem, no provedor de dados;

- padrão no tempo: o nível periódico de atualização de um repositório. No nosso caso, a clareza quanto ao padrão de datas utilizados nos documentos;

- acessibilidade: a forma como os dados podem ser acessados. No nosso caso, dados disponíveis para serem coletados pelo harvester.

Uma questão importante que teremos de analisar é a qualidade, sob os critérios acima, dos metadados que iremos coletar como fonte de análise das redes sociais. Essa é uma questão determinante do nível de profundidade onde podemos chegar em nossas análises, dado que quanto mais os metadados coletados se ajustarem a esses padrões de referência maior será nossa possibilidade de manipulação dos mesmos. Se camadas expressivas de dados estiverem faltando ou operando a partir de consistências lógicas diferentes, por exemplo, teremos de encontrar alternativas para normalizar esses dados utilizando outros sistemas de informação como apoio, como por exemplo o sistema Lattes, ou teremos de descartar determinados níveis de análise, devido a possíveis dificuldades técnicas. 
Vejamos agora o portal da produção científica em Ciências da Comunicação, o Univerciencia.org, a fonte de onde iremos coletar os metadados que serão analisados em busca das redes sociais da Ciências da Comunicação.

\subsection{O portal da produção científica em Ciências da Comunicação Univerciencia.org}

O portal da produção científica em Ciências da Comunicação - Univerciencia.org - é uma iniciativa do CEDUS - Centro de Estudos em Design de Sistemas Virtuais da Escola de Comunicações e Artes da USP, que vem sendo implementado como parte dos projetos e estudos que tiveram início a partir de 2000. Segundo o próprio texto de apresentação do portal, disponível em seu site $^{48}$, ele é uma biblioteca digital federada que tem por objetivos:

1. constitui-se ponto de referência para difusão, busca, uso e compartilhamento da produção científica e acadêmica internacional em ciências da comunicação (cinema, rádio, televisão, relações públicas, publicidade, propaganda, jornalismo, editoração, cibercultura).

2. prover aos usuários uma interface única, convergente e integrada de acesso, busca e recuperação dos metadados da produção científica em ciências da comunicação (teses/dissertações, artigos de revistas, revistas, livros e capítulos de livros, trabalhos de eventos, anais, trabalhos de conclusão de curso, recursos educacionais abertos e outros) publicada em distintos países e fontes.

3. oferecer aos parceiros institucionais; gestores das fontes de informação indexadas; mecanismos para incrementar o acesso, a visibilidade, a organização e a geração de métricas e indicadores de gestão e governança de seus conteúdos.

4. Contribuir com o desenvolvimento científico da área de ciências da comunicação, proporcionando espaço e dados para visualização e mapeamento do estado da arte da produção científica nacional e internacional.

De forma a cumprir seus objetivos, o Univerciencia.org busca coletar o conjunto mais abrangente possível de fontes de informação disponíveis, segundo seus critérios, sobre a área da Ciências da Comunicação. O portal considera como sendo uma fonte de informação os portais, 48 http://www.univerciencia.org/index.php/about - Acessado em 25/06/2011. 
repositórios, revistas eletrônicas, bibliotecas digitais etc. de texto completo e em acesso aberto, divulgando distintas tipologias de recursos informacionais, cobrindo no todo ou em grande parte a área de ciências da comunicação.

Segundo o próprio texto de apresentação do portal, as fontes de informação estão catalogadas no Portal da seguinte forma:

- autoria institucional: será identificada sempre pela instituição maior seguida da unidade de ensino e departamento responsável pela procedência do conteúdo. Por exemplo, a revista “Comunicação e Educação" terá como autoria institucional: Universidade de São Paulo, Escola de Comunicações e Artes, Curso de Gestão da Comunicação.

- título da fonte: a fonte catalogada neste Portal remeterá sempre para a unidade informacional, mantida pela instituição de origem, que contém as publicações em texto completo cujos metadados estão sendo coletados. Serão portanto, as próprias revistas eletrônicas, bibliotecas digitais, repositórios institucionais, repositórios temáticos, anais eletrônicos e portais.

- país de origem: identificando-se o país de origem da instituição responsável pela fonte coletada, independentemente de onde está hospedada. Por exemplo, a Revista Media \& Jornalismo (publicada pelo Centro de Investigação Media e Jornalismo de Portugal) tem a versão eletrônica coletada do portal brasileiro Univerciencia de Revistas de Acesso Aberto, mas o país de origem continua sendo Portugal.

- local de coleta: no caso de fontes que tenham espelhos de seus conteúdos em distintos portais, serão registradas sempre a URL oficial da respectiva fonte e também a URL de coleta dos dados. A decisão de onde coletar os dados (se site oficial ou espelho) será feita a partir da análise dos registros em ambas as fontes, bem como de suas facilidades tecnológicas.

- resumo sobre as fontes: a descrição resumida das fontes de informação deverá ser feita observando-se o idioma de seu país de origem.

- conteúdo informacional: será classificado seguindo as tipologias de recursos informacionais que disponibiliza (ver definição abaixo). No caso de fontes contendo mais de um tipo de recursos, serão catalogadas na categoria miscelâneas.

Para cada fonte de informação o portal pode coletar diferentes recursos informacionais. Novamente recorremos ao texto de apresentação do portal para sua definição sobre recurso 
informacional: se reporta a tipologia dos conteúdos publicados pelas fontes que estão sendo catalogadas. Até o momento as tipologias coletados pelo Portal estão identificadas da seguinte forma:

1. anais de eventos;

2. artigos de revistas;

3. comunicações feitas em eventos;

4. livros e capítulos de livros;

5. miscelâneas (cobre relatórios, trabalhos de pesquisas, publicações técnicas dentre outras. Usado também para fontes que contém mais de um tipo de recurso.);

6. recursos educacionais abertos (REA);

7. revistas;

8. trabalhos de conclusão de curso (TCC);

9. teses e dissertações.

É importante destacar que serão esses recursos informacionais coletados pelo portal que teremos a nossa disposição para os estudos de análise de redes sociais que iremos desenvolver, sendo que utilizaremos apenas os documentos disponibilizados pelas revistas, sejam eles artigos, resenhas, entrevistas ou comunicações, além das teses e dissertações. Temos aqui representados os principais dispositivos de sistematização de informação utilizados pela comunidade acadêmica para o desenvolvimento de sua produção científica, como vimos no capítulo 3. Logo, segundo nossa análise também apresentada no capítulo 3, temos aqui representados os principais recursos que são utilizados por uma comunidade acadêmica para estabelecer, articular e promover suas redes sociais. Iremos olhar para recursos informacionais da perspectiva que eles representam espaços relacionais, locais onde a conversa entre pesquisadores, grupos, instituições e programas de pesquisa se estabelecem e podem se tornar visíveis.

Vale lembrar, ainda segundo o texto de apresentação do portal, que o padrão dos metadados que descrevem tais recursos se pauta no modelo Dublin Core, definidos e implementados diretamente pelas fontes de informação aqui coletadas. Portanto, a equipe do Portal Univierciencia.org não tem inferência sobre seu formato e conteúdo, uma vez que sua função é apenas coletar, compilar uma base de dados, implementar a interface única de busca aos respectivos metadados e encaminhar o usuário ao local de acesso ao texto completo, quando solicitado.

O portal opera como um sistema federado de informações, no caso, como um biblioteca 
digital federada específica com foco na área da Ciências da Comunicação. Logo, ele se torna um local extremamente privilegiado para estudos e análise relativas a essa área do conhecimento, pois todo o trabalho de sistematização e agregação da produção cientifica está ali concentrado, executado por dezenas, talvez centenas de pessoas, que se preocuparam em disponibilizar seus documentos em formato digital, criaram e produziram descritores de metadados no padrão Dublin Core, disponibilizaram em portais locais interoperáveis segundo os padrões OAI-PMH e permitiram que seus conteúdos fossem coletados livremente.

O Univerciencia pode ser visto como um centro agregador de redes da área da Ciências da Comunicação, que ali se entrecruzam e podem ser pesquisadas, visitadas, navegadas e analisadas a partir dos mesmos parâmetros. Ele amplia a mobilidade, a estabilidade e permutabilidade desses elementos naquilo que Bruno Latour (1998, pg. 396) chamou de centros de cálculo:

“... construir centros implica trazer para eles elementos distantes permitir que os centros dominem a distância -, mas sem trazê-los "de verdade" - para evitar que os centros sejam inundados. Esse paradoxo é resolvido criando-se inscrições que conservem, simultaneamente, o mínimo e o máximo possível, através do aumento da mobilidade, da estabilidade ou da permutabilidade desses elementos. Esse meio-termo entre presença e ausência muitas vezes é chamado de informação. Quando se tem uma informação em mãos, tem-se a forma de alguma coisa sem ter a coisa em si."

Logo, o portal é um operador fundamental para viabilizar a amostra de dados mais abrangente possível da produção científica de sua área. A possibilidade de ampliar a expressão dos dados que utilizaremos em relação aos estudos anteriores que buscaram analisar a área da Comunicação permite com que possamos obter resultados também mais expressivos. Vejamos agora de que amostra de dados estamos falando, apresentando a seguir as principais características do banco de dados do Univerciencia até o presente momento em que escrevemos. 
O portal possui 35785 documentos coletados de 17 países diferentes, representando 98 fontes de informação de 68 instituições diferentes. Vejamos como esses dados estão distribuídos na tabela 5.4.

\begin{tabular}{|l|c|c|c|c|c|}
\hline \multicolumn{1}{|c|}{ País } & Itens & Fontes & Instituições & Tipo de Recurso & \%Itens \\
\hline Brasil & 19235 & 60 & 36 & 9 & $53,75 \%$ \\
\hline França & 3310 & 1 & 1 & 1 & $9,25 \%$ \\
\hline Espanha & 3178 & 8 & 6 & 4 & $8,88 \%$ \\
\hline México & 2808 & 3 & 3 & 2 & $7,85 \%$ \\
\hline Estados Unidos & 1859 & 4 & 4 & 3 & $5,19 \%$ \\
\hline Canadá & 1807 & 2 & 1 & 1 & $5,05 \%$ \\
\hline Dinamarca & 890 & 1 & 1 & 1 & $2,49 \%$ \\
\hline Portugal & 747 & 8 & 6 & 6 & $2,09 \%$ \\
\hline Equador & 467 & 1 & 1 & 1 & $1,31 \%$ \\
\hline Colômbia & 430 & 2 & 2 & 1 & $1,20 \%$ \\
\hline Suíça & 309 & 1 & 1 & 1 & $0,86 \%$ \\
\hline Costa Rica & 290 & 1 & 1 & 1 & $0,81 \%$ \\
\hline Argentina & 205 & 2 & 1 & 2 & $0,57 \%$ \\
\hline Filipinas & 81 & 1 & 1 & 1 & $0,23 \%$ \\
\hline Venezuela & 79 & 1 & 1 & 1 & $0,22 \%$ \\
\hline Austrália & 50 & 1 & 1 & 1 & $0,14 \%$ \\
\hline Indonésia & 40 & 1 & 1 & 1 & $0,11 \%$ \\
\hline \multicolumn{1}{|c|}{$\mathbf{1 7}$} & $\mathbf{3 5 7 8 5}$ & $\mathbf{9 8}$ & $\mathbf{6 8}$ & $\mathbf{e m} \mathbf{1 2}$ & $\mathbf{1 0 0 , 0 0 \%}$ \\
\hline
\end{tabular}

Tabela 5.4. Dados da distribuição dos recursos informacionais por países - Fonte. www.univerciencia.org - Acessado em 25/06/2011.

Vejamos como esses recursos informacionais estão distribuídos nas tipologias de recursos coletados pelo portal na tabela 5.5.

\begin{tabular}{|l|c|c|c|c|c|}
\hline \multicolumn{1}{|c|}{ Tipo de Recurso } & Itens & Fontes & Instituições & Países & \%Itens \\
\hline Artigos de revistas & 16925 & 62 & 52 & 15 & $47,30 \%$ \\
\hline Miscelânea & 8214 & 5 & 5 & 4 & $22,95 \%$ \\
\hline CBCC & 3536 & 1 & 1 & 1 & $9,88 \%$ \\
\hline Dissertação/Tese & 3481 & 17 & 17 & 4 & $9,73 \%$ \\
\hline Livro/Capítulo & 2491 & 2 & 2 & 2 & $6,96 \%$ \\
\hline Comunicação em Evento & 465 & 2 & 2 & 2 & $1,30 \%$ \\
\hline Anais & 248 & 1 & 1 & 1 & $0,69 \%$ \\
\hline Anuário & 237 & 3 & 3 & 3 & $0,66 \%$ \\
\hline ENDECOM & 97 & 1 & 1 & 1 & $0,27 \%$ \\
\hline COLÓQUIO & 89 & 1 & 1 & 1 & $0,25 \%$ \\
\hline REA & 2 & 1 & 1 & 1 & $0,01 \%$ \\
\hline
\end{tabular}

Tabela 5.5. Dados da distribuição dos recursos informacionais por tipos de recursos - Fonte. www.univerciencia.org - Acessado em 25/06/2011.

Fica visível a abrangência da base de dados do portal a partir dos dados acima apresentados. Teremos à disposição mais de 35.000 recursos informacionais coletados, sendo a sua maior parte provenientes do Brasil e mais de $47 \%$ de artigos publicados em revistas científicas da área. Sem dúvida, segundo nossos estudos previamente revisados, estamos lidando com o maior banco de dados disponível da área da Comunicação. 
Veremos no próximo capítulo qual metodologia utilizaremos para analisar as redes sociais da Comunicação a partir da base de dados do portal Univerciencia.org. 


\section{Capítulo 6 \\ Procedimentos metodológicos}

"Não seja escravo do seu passado. Mergulhe em mares grandiosos,
vá bem fundo e nade até bem longe, e voltarás com respeito
por si mesmo, com um novo vigor, com uma experiência
a mais que explicará e superará a anterior"
Ralph Waldo Emerson

\subsection{Delineamento do método}

Os procedimentos metodológicos que adotamos estão baseados no princípio de que nossa pesquisa tem uma abordagem quantitativa podendo ser classificada quanto aos seus meios como uma pesquisa de campo. Partimos desse princípio e dado que nosso objetivo é demonstrar que um ambiente federado de bibliotecas digitais fornece as condições necessárias para a agregação dos metadados da produção científica de uma área do conhecimento, viabilizando o mapeamento dos padrões de constituição de suas redes sociais, evidenciando as estratégias de formação de importantes planos de relação sociais dos pesquisadores participantes dessa área, bem como os efeitos nesses planos das políticas de regulação da área. Logo, quanto mais abrangentes forem os dados coletados daquilo que entendemos por ser o nosso campo de análise, em melhores condições estaremos de avaliar esse mesmo objetivo de trabalho.

"A pesquisa de campo, no ambiente natural, é particularmente importante na pesquisa social, apropriada para estudos de indivíduos, grupos, comunidades, organizações, sociedades, considerando que, para a pesquisa social, mais importante que encontrar soluções é explicar os fenômenos, entender realidades, criar significados sociais” (Michel, 2009, pg.40)

Estamos em busca de explicar como operam as redes sociais a partir do que pode ser obtido de uma federação de bibliotecas digitais, entendendo por operar a possibilidade de descrevermos quais são as principais estratégias utilizadas pelos pesquisadores quando de sua atuação na área, quais são suas estruturas e dinâmicas que podem ser descritas como padrões característicos, em nosso caso, da área da Comunicação, além dos efeitos que podem ser percebidos da política científica no modo como essa rede se organiza.

As redes sociais produzem e surgem a partir de espaços de relação entre as pessoas. Nossa escolha tem sido analisar o espaço da produção científica dos pesquisadores, sobretudo, devido a sua alta relevância como estratégia fundamental do desenvolvimento científico da comunidade 
acadêmica. Faremos isso a partir da coleta e análise de sua produção científica agregada em uma biblioteca digital federada. O nosso campo está, portanto, configurado pelos limites, fronteiras e definições do que é hoje considerado como sendo a produção científica da comunidade de pesquisadores da área da Comunicação que pode ser coletada para análise na biblioteca digital federada Univerciencia.org. Vejamos a seguir, na tabela 6.1, os principais dispositivos que são utilizados pela comunidade científica como espaços de relação. Os dados apresentados são baseados em nossa revisão bibliográfica.

\begin{tabular}{|c|c|c|c|}
\hline Dispositivo & $\begin{array}{c}\text { Espaço de Produção } \\
\text { científica }\end{array}$ & $\begin{array}{c}\text { Nível de } \\
\text { formalidade }\end{array}$ & Característica \\
\hline & & & \\
\hline \multirow{5}{*}{ Co-autoria } & Artigo & Formal & \multirow{5}{*}{$\begin{array}{l}\text { Dois ou mais pesquisadores atuando em parceria } \\
\text { no desenvolvimento de uma pesquisa }\end{array}$} \\
\hline & Capítulo de livro & Formal & \\
\hline & Livro & Formal & \\
\hline & Anais de congresso & Formal & \\
\hline & Relatório & Formal & \\
\hline & & & \\
\hline \multirow[b]{2}{*}{ Banca de defesa } & Teses & Formal & \multirow{2}{*}{$\begin{array}{l}\text { Pesquisadores que participam de uma banca de } \\
\text { defesa, tecendo críticas e sugestões no } \\
\text { desenvolvimento do trabalho }\end{array}$} \\
\hline & Dissertações & Formal & \\
\hline & & & \multirow{7}{*}{$\begin{array}{l}\text { Encontro informal entre dois ou mais } \\
\text { pesquisadores, conversando a respeito de seus } \\
\text { trabalhos }\end{array}$} \\
\hline \multirow{6}{*}{ Conversação } & Reuniões & Informal & \\
\hline & Palestras & Informal & \\
\hline & Seminários & Informal & \\
\hline & Congressos & Informal & \\
\hline & Cursos & Informal & \\
\hline & Workshops & Informal & \\
\hline $\begin{array}{l}\text { Mensagem } \\
\text { eletrônica }\end{array}$ & Internet & Informal & $\begin{array}{l}\text { Troca de mensagem entre dois ou mais } \\
\text { pesquisadores, conversando a respeito de seus } \\
\text { trabalhos. }\end{array}$ \\
\hline
\end{tabular}

Tabela 6.1. Espaços de relação da comunidade científica

A pesquisa que realizaremos está baseada naquilo que consideramos como sendo os dispositivos formais, ou seja, as relações de co-autoria na produção científica e as relações formadas pela participação dos pesquisadores em bancas de defesa de teses e dissertações. Os espaços de relação que chamamos de informais na tabela 6.1 não serão considerados em nossa pesquisa devido, sobretudo, a falta de dados disponíveis sistematizados que pudessem ser levados em consideração. No entanto, nossa hipótese parte do princípio de que as relações de co-autoria e participação dos pesquisadores em bancas de defesas estabelecem são relevantes e estratégicas o suficiente para podermos analisar seus padrões de formação e, eventualmente, inferirmos resultados que possam ser válidos para a própria área em análise.

A pesquisa quantitativa é aquela que trata a atividade de pesquisa utilizando a quantificação tanto do ponto de vista da coleta dos dados quanto no seu tratamento através de técnicas estatísticas das mais simples às mais complexas (Michel, 2009, pg. 37). Utilizaremos como método 
quantitativo de análise em nossa pesquisa a análise estrutural e dinâmica de redes sociais. Vejamos na tabela 6.2 as principais características que levaremos em consideração sobre esse método de análise, segundo nossa revisão bibliográfica.

\begin{tabular}{|c|c|c|}
\hline Áreas de pesquisa & Recursos & Elementos \\
\hline \multirow{12}{*}{ Dados } & \multirow{4}{*}{ Tipos de dados } & Contexto \\
\hline & & Objetos \\
\hline & & Atributos \\
\hline & & Relações \\
\hline & \multirow{2}{*}{ Categorias de amostras } & Totalmente obs ervada \\
\hline & & Inferida \\
\hline & & \\
\hline & \multirow{5}{*}{ Formas de coleta: dados empíricos } & Observação \\
\hline & & Entrevistas \\
\hline & & Questionários \\
\hline & & Bases de dados de sistemas de informação \\
\hline & & Outras técnicas e experimentos \\
\hline \multirow{2}{*}{ Métodos } & Análise Estrutural & $\begin{array}{l}\text { Análise dos padrões relacionais: modelo matemático da } \\
\text { Teoria dos Grafos }\end{array}$ \\
\hline & Análise Dinâmica & $\begin{array}{l}\text { Análise dos padrões dinâmicos: modelo matemático da } \\
\text { Física Es tatística/Processos estocásticos }\end{array}$ \\
\hline \multirow{3}{*}{ Sistemas } & Visualização & Sistemas de visualização dos objetos e suas relações. \\
\hline & Processamento dos dados & $\begin{array}{l}\text { Sistemas de proces samento dos dados, permitindo } \\
\text { aplicando os modelos matemáticos es truturais e dinâmicos } \\
\text { para obtenção de indicadores e simulações. }\end{array}$ \\
\hline & Bases de dados para coleta & $\begin{array}{l}\text { Sistemas de interação entre pessoas, podendo ser } \\
\text { des enhados para coletar as relações do forma explícita }\end{array}$ \\
\hline
\end{tabular}

Tabela 6.2. Principais características do paradigma de pesquisa das redes sociais.

A seguir, descrevemos como aplicamos cada um dos elementos da tabela 6.2 para a análise das redes sociais oriundas das bases de dados da Univerciencia.org:

- Dados:

- Tipos de dados:

- Contexto: co-autoria e participação em bancas de defesa de teses e dissertações;

- Objetos: documentos de produção científica;

- Atributos: autores, participantes, data, instituição, titulação, local de publicação;

- Relações: autoria e participação na banca;

- Categoria das amostras: totalmente observada, pois todos os dados disponíveis serão coletados para análise ;

- Forma de coleta: banco de dados da biblioteca digital federada Univerciencia.org, apresentada no capítulo 4;

- Métodos:

- Análise estrutural: analisamos os grafos dos padrões relacionais das redes;

- Análise dinâmica: analisamos a evolução no tempo da formação das redes; 


\section{- Sistemas:}

- Visualização: utilizamos os sistemas Pajek $^{49}$ e Visone ${ }^{50}$ para visualização e animação dos sociogramas;

- Processamento dos dados: os dados foram processados utilizando a linguagem $\mathrm{SQL}^{51}$ para consultas ao banco de dados, bem como o uso de planilhas de cálculo do sistema Libre Office ${ }^{52}$ como apoio.

- Base de dados para coleta: banco de dados $\mathrm{MySql}^{53}$.

\subsection{Tratamento dos dados}

Os dados coletados foram tratados de forma que possamos reduzir ao máximo problemas técnicos, semânticos ou operacionais que possam eventualmente prejudicar nossa análise. Utilizamos os passos descritos na tabela 5.2 do capítulo 5 .

Vale dizer que para a etapa "aumentar" os dados recorremos a sistemas de apoio, como a plataforma Lattes, de forma a obtermos maiores informações sobre os pesquisadores que foram úteis para nossas análises. Já na etapa de normalização, consideramos aqui o efeito das diferentes formas que os nomes dos pesquisadores podem aparecer em suas publicações, avaliando seu impacto no tamanho de nossa amostra de dados, conforme vimos no item 3.7 do capítulo 3 .

Vejamos agora qual o conjunto de indicadores que utilizamos da análise estrutural e dinâmica das redes sociais.

\subsection{Indicadores da análise estrutural e dinâmica}

Apresentamos a seguir, na tabela 6.3, um resumo de todos os indicadores que foram comentados em nossa revisão bibliográfica da perspectiva da análise estrutural de redes, considerando os três níveis, rede, subgrupos e atores, nos quais esses indicadores podem ser utilizados.

49 http://pajek.imfm.si/doku.php - Acessado em 26/06/2011

50 http://visone.info/ - Acessado em 26/06/2011

51 Structured Query Language

52 http://www.libreoffice.org/ - Acessado em 26/06/2011

53 http://www.mysql.com/ - Acessado em 26/06/2011 


\begin{tabular}{|c|c|c|}
\hline Níveis & Indicadores & Significado \\
\hline \multirow{3}{*}{ Rede } & Densidade & Taxa de conectividade da rede \\
\hline & Diâmetro & Maior distância entre dois atores numa rede \\
\hline & Afiliação & $\begin{array}{l}\text { Configuração das redes modo-2, caracterizando dois tipos } \\
\text { de vértices na rede: atores e organizações }\end{array}$ \\
\hline \multirow{7}{*}{ Subgrupos } & Centro e periferia & $\begin{array}{l}\text { Distinção entre atores de maior e menor grau de } \\
\text { centralidade }\end{array}$ \\
\hline & Componentes & Subgrupos independentes na rede \\
\hline & Componentes fortes & Subgrupo fortemente conectado \\
\hline & Componentes fracos & Subgrupo fracamente conectado \\
\hline & Cliques & subgrupo completo que contém três ou mais vértices \\
\hline & m-slices & $\begin{array}{l}\text { subgrupo contendo um número mínimo de linhas m e os } \\
\text { vértices que são relacionados por essas linhas }\end{array}$ \\
\hline & $\mathrm{k}$-core & $\begin{array}{l}\text { subgrupo onde cada vértice estabelece relação com um } \\
\text { número mínimo k de outros vértices. }\end{array}$ \\
\hline \multirow{6}{*}{ Atores } & Distância & Número de conexões existentes entre dois atores numa rede \\
\hline & Grau de centralidade da rede & número de linhas incidentes em um vértice do grafo \\
\hline & Grau de centralidade por interposição & $\begin{array}{l}\text { habilidade de um indivíduo de se conectar aos círculos } \\
\text { importantes da rede }\end{array}$ \\
\hline & Grau de centralidade por vizinhança & $\begin{array}{l}\text { representa a habilidade de um indivíduo monitorar o fluxo } \\
\text { de informação e enxergar o que está acontecendo na rede }\end{array}$ \\
\hline & Equivalência estrutural & $\begin{array}{l}\text { Medida que avalia o quanto dois atores possuem um } \\
\text { padrão de conexão semelhante. }\end{array}$ \\
\hline & Brokers & $\begin{array}{l}\text { Distinção de papéis de intermediação que um ator pode } \\
\text { desempenhar, dependendo do contexto da rede. }\end{array}$ \\
\hline
\end{tabular}

Tabela 6.3- Indicadores estruturais

Analisaremos as redes considerando os três níveis de indicadores mencionados na tabela 6.3. Inicialmente, caracterizamos a rede de forma geral, partindo para uma identificação, através dos métodos sugeridos, dos subgrupos que a compõem e, por final, analisamos as características individuais dos seus atores. Dessa maneira, analisamos o comportamento em separado de eventuais subgrupos que foram descobertos, podendo inclusive compará-los entre si, sobretudo no caso dos componentes e sua forma na rede. O mesmo é válido para os atores da rede, dado que analisamos seu nível de centralidade e influência a partir de suas possíveis estratégias de conectividade dentro da rede.

Apresentamos a seguir, na tabela 6.4, um resumo de todos os indicadores que foram apresentados em nossa revisão bibliográfica da perspectiva da análise dinâmica de redes

\begin{tabular}{|l|l|l|}
\hline \multicolumn{1}{|c|}{ Níveis } & \multicolumn{1}{|c|}{ Indicadores } & \multicolumn{1}{c|}{ Significado } \\
\hline \multirow{3}{*}{ Rede } & \multicolumn{1}{|c|}{ Cis tribuição de probabilidade } & Como se distribui graus de conectividade dos nós \\
\hline & Evolução no grau médio de centralidade & Como evolui a conectividade média dos nós \\
\cline { 2 - 3 } & Coeficiente de clusterização & Avalia o grau de influência e transitividade na rede \\
\cline { 2 - 3 } & Evolução na distância média entre os nós & Como evolui a distância entre os nós \\
\cline { 2 - 3 } & Evolução do padrão estrutural & Probabilidade de como a estrutura da rede evolui \\
\hline
\end{tabular}

Tabela 6.4- Indicadores dinâmicos 
Utilizamos a análise dinâmica em apenas um nível de análise, possibilitando com que analisemos o padrão dinâmico da rede como um todo. Foi através desses indicadores que avaliamos a evolução da rede ao longo do tempo. Para isso, analisamos o tamanho da amostra de dados em relação a faixa temporal de sua representatividade, de forma a subdividirmos em períodos para comparação entre si.

\subsection{Análise e interpretação dos dados}

A análise de redes sociais não é apenas um conjunto de métodos analíticos mas também uma forma, um modo de pensar sobre determinados problemas em que desejamos analisar padrões de conexão ou interação entre partes de um sistema qualquer. Sem dúvida, o potencial da análise está em transformar o problema de estudo da conexão entre as partes num problema tratável, fornecendo dados, camadas visuais e padrões de referência que podem ser utilizados como base para tomada de decisões e interpretações daquilo que estamos analisando.

"Uma rede é representação simplificada que reduz um sistema para uma estrutura abstrata capturando apenas o básico do padrão de conexão e um pouco mais. Nós e conexões numa rede podem ser classificadas com atributos adicionais tais como nomes e graus de importância de forma a capturarmos mais detalhes do sistema, no entanto, mesmo assim muita informação é normalmente perdida no processo de redução de um sistema completo para sua representação em rede. Certamente isso traz algumas desvantagens, mas traz várias vantagens também" (Newman, 2010).

O que analisamos tem relação com a descoberta e interpretação desse padrão básico de conexão que permitiu caracterizar as redes sociais. Sem dúvida, não analisamos a totalidade dos movimentos sociais de uma comunidade, mas analisando seus padrões a partir das principais estruturas e documentos que sistematizam a longa cadeia de conversações que operam como vínculos de uma rede.

Para caracterizar e interpretar os dados que obtivemos, utilizamos como referências de análise e comparação os principais padrões estruturais e dinâmicos que foram identificados em redes sociais a partir de nossa revisão bibliográfica.

Apresentamos na tabela 6.5 um resumo dos padrões estruturais. 


\begin{tabular}{|c|c|c|}
\hline Padrão Estrutural & Origem & Característica \\
\hline \multirow{9}{*}{ Tipos de nós } & \multirow{4}{*}{$\begin{array}{l}\text { Variação no número de conexões } \\
\text { que um nó possui }\end{array}$} & $\begin{array}{l}\text { isolado: se um nó não recebeu e } \\
\text { não gerou nenhuma conexão }\end{array}$ \\
\hline & & $\begin{array}{l}\text { transmissor: se o nó apenas gerou } \\
\text { conexões, não recebendo nenhuma }\end{array}$ \\
\hline & & $\begin{array}{l}\text { receptor: se o nó apenas recebeu } \\
\text { conexões, não gerando nenhuma }\end{array}$ \\
\hline & & $\begin{array}{l}\text { ordinário: se o nó possui algumas } \\
\text { conexões que gerou e outras que } \\
\text { recebeu }\end{array}$ \\
\hline & \multirow{5}{*}{$\begin{array}{c}\text { Estudo dos papéis estruturais de } \\
\text { intermediação de relações - } \\
\text { Brokers }\end{array}$} & Papel de coordenação \\
\hline & & Papel de intermediação \\
\hline & & Papel de representação \\
\hline & & Papel de articulação \\
\hline & & Papel de conexão \\
\hline Diâmetro & $\begin{array}{l}\text { Estudo da distância máxima entre } \\
\text { dois nós }\end{array}$ & 6 níveis de separação \\
\hline Grau de influência e contágio & $\begin{array}{l}\text { Estudo dos padrões de } \\
\text { disseminação de fluxos }\end{array}$ & 3 graus de influência \\
\hline \multirow{2}{*}{ Nível de coesão } & \multirow{2}{*}{$\begin{array}{l}\text { Estudo dos padrões de distribuição } \\
\text { de conexões entre os nós }\end{array}$} & Rede fortemente coesa \\
\hline & & Rede fracamente coesa \\
\hline
\end{tabular}

Tabela 6.5- Padrões estruturais

Apresentamos na tabela 6.6, a seguir, um resumo dos padrões dinâmicos.

\begin{tabular}{|c|c|c|}
\hline Padrão Dinâmico & Origem & Característica \\
\hline Redes livre escala (scale free) & Grau de centralidade dos nós & $\begin{array}{l}\text { Alguns poucos nós apresentam alto } \\
\text { grau de centralidade e a maioria } \\
\text { apresenta baixo grau de } \\
\text { centralidade }\end{array}$ \\
\hline $\begin{array}{l}\text { Redes mudo pequeno (small } \\
\text { world) }\end{array}$ & Distância entre os nós & $\begin{array}{l}\text { Alto nível de clusterização entre os } \\
\text { nós vizinhos na rede e algumas } \\
\text { conexões pontuais com outras } \\
\text { áreas, gerando o efeito mundo } \\
\text { pequeno }\end{array}$ \\
\hline \multirow{6}{*}{ Eventos evolutivos } & \multirow{6}{*}{$\begin{array}{c}\text { Formas de evolução da estrutura da } \\
\text { rede }\end{array}$} & crescimento \\
\hline & & junção \\
\hline & & nascimento \\
\hline & & contração \\
\hline & & divisão \\
\hline & & morte \\
\hline
\end{tabular}

Tabela 6.6. Resumo dos padrões dinâmicos

Além da identificação e análise dos padrões, confrontamos os dados coletados dos indicadores dinâmicos e estruturais da área da Ciências da Comunicação com os dados de referência que foram revisados nas tabelas 3.2 e 3.3 do item 3.7 do capítulo 3, buscando identificar semelhanças, divergências e tendências que possam ser contextualizadas para o campo da comunicação. 
Entendemos que as escolhas de como realizar as etapas envolvidas na análise não são apenas escolhas técnicas, mas modos de tratamento da informação que influenciam em nossa capacidade de olhar e identificar padrões que fornecem pistas das tendências e fenômenos sociais daquilo que estudamos.

Logo, vale frisar de antemão que o procedimento de análise envolveu diversas etapas de processamento dos dados de modo que obtivéssemos a maior abrangência e qualidade possível. Para tanto, nos momentos em que foi possível, desenvolvemos a automatização de determinados processos produzindo programas de computador que auxiliassem sobretudo na identificação de padrões e campos utilizados dos metadados disponíveis. Outros processos foram realizados de modo manual, como a checagem do número de registros coletados pela biblioteca Univerciencia.org e os registros disponíveis nos sites originais de cada revista e biblioteca digital de tese e dissertação, quando existiam de modo independente. Essa composição de instrumentos de análise, ora automatizados e ora manuais, nos permitiu uma imersão nas escolhas e modos de tratamento dos dados de cada revista e biblioteca analisada, o que nos permite problematizar como esses modos podem ser vistos quando nosso objetivo é a integração dos dados e construção de uma possível visão comum.

Descrevemos a seguir todas as etapas envolvidas na coleta, tratamento e produção dos resultados que serão utilizados como base para nossas discussões. Vejamos a seguir cada uma dessas etapas, seu objetivo, os resultados obtidos e as questões metodológicas envolvidas. Iniciamos apresentando como os dados foram tratados.

\subsubsection{Tratamento dos dados}

Os dados foram manipulados e tratados em 5 etapas, envolvendo desde a avaliação inicial das fontes de informação até a construção de arquivos pré-formatados para análise das redes sociais no software Pajek. Descrevemos essas etapas a seguir.

\section{Revisão das fontes de informação}

O processo de revisão das fontes de informação teve por objetivo checar se o número de registros coletados pelo Univerciencia.org estava de fato atualizado e de acordo com os últimos registros publicados pelas fontes. Nosso objetivo era garantir que não teríamos deixado de coletar material disponível por eventuais problemas técnicos ou checar dados não coletados mas que não estavam devidamente configurados para coleta pelas próprias fontes de informação. Além disso, encontramos alguns casos onde números antigos de revistas estavam sendo disponibilizados em 
formato aberto apenas nos últimos meses, logo, checamos as fontes também para garantir que havíamos coletado os últimos números disponibilizados.

Desse modo, para garantir que estávamos com os últimos dados disponíveis em formato aberto para coleta em cada fonte de informação, ao final de dezembro de 2011, rodamos o harvester para realizar a última coleta de metadados. Ao final desta coleta contávamos com 142 fontes de informação em potencial contabilizando um total de 54.347 registros no banco de dados.

No entanto, no meio destes registros haviam diversos conteúdos que não seriam utilizados para o desenvolvimento de nosso trabalho de análise, dado que estávamos em busca apenas da produção científica em revistas e bibliotecas digitais de teses e dissertações brasileiras. Vale lembrar, conforme apresentamos no capítulo 5 nas tabelas 5.4 e 5.5 , que a biblioteca Univerciencia.org coleta produção científica não apenas brasileira e não apenas de revistas e bibliotecas de teses e dissertações. Logo, filtrando o banco de dados com esse objetivo em vista terminamos essa etapa com 49 fontes de informação de revistas científicas contabilizando 9864 registros, 12 bibliotecas digitais contabilizando 1961 registros, sendo portanto esse universo de 61 fontes de informação e de 11.825 registros que utilizamos como base de nossas análises, conforme sintetizado na tabela 6.7 .

\begin{tabular}{|l|c|c|}
\hline \multicolumn{1}{|c|}{ Categorias } & Fontes de informação & Registros \\
\hline Revistas científicas & 49 & 9864 \\
\hline Bibliotecas de teses e dissertações & 12 & 1961 \\
\hline \multicolumn{1}{|c|}{ Total } & $\mathbf{6 1}$ & $\mathbf{1 1 8 2 5}$ \\
\hline
\end{tabular}

Tabela 6.7. Síntese da base de dados utilizada para análise.

Apresentamos nas figuras 6.1 e 6.2, a seguir, a distribuição de frequência do número de registros coletados em nossa base de dados por fonte de informação, especificando o nome da fonte.

\section{Bibliotecas Digitais de Teses e Dissertações}

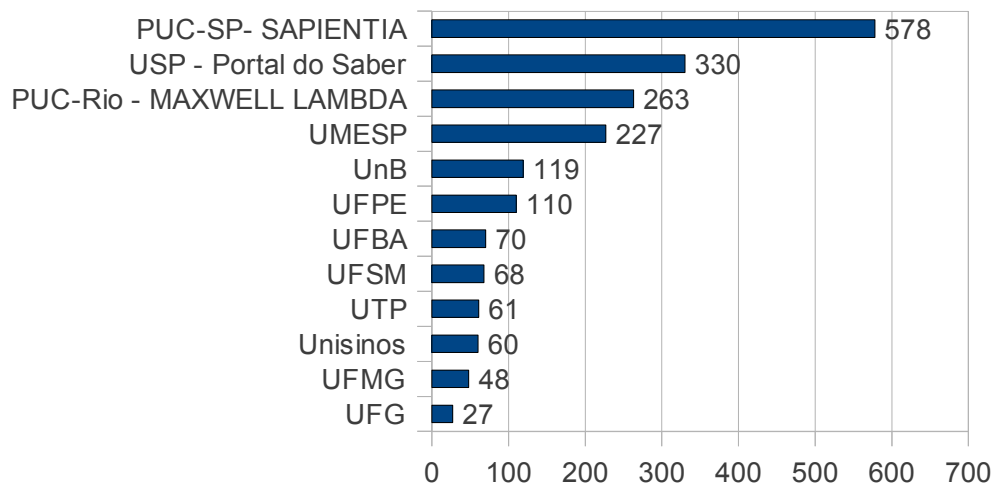

Figura 6.1. Distribuição da frequência do número de registros coletados por fonte de informação das bibliotecas digitais. 
Vale frisar que os primeiros documentos datam de 1986, da PUC-SP, e os últimos documentos coletados são de 2011.

\section{Revistas científicas}

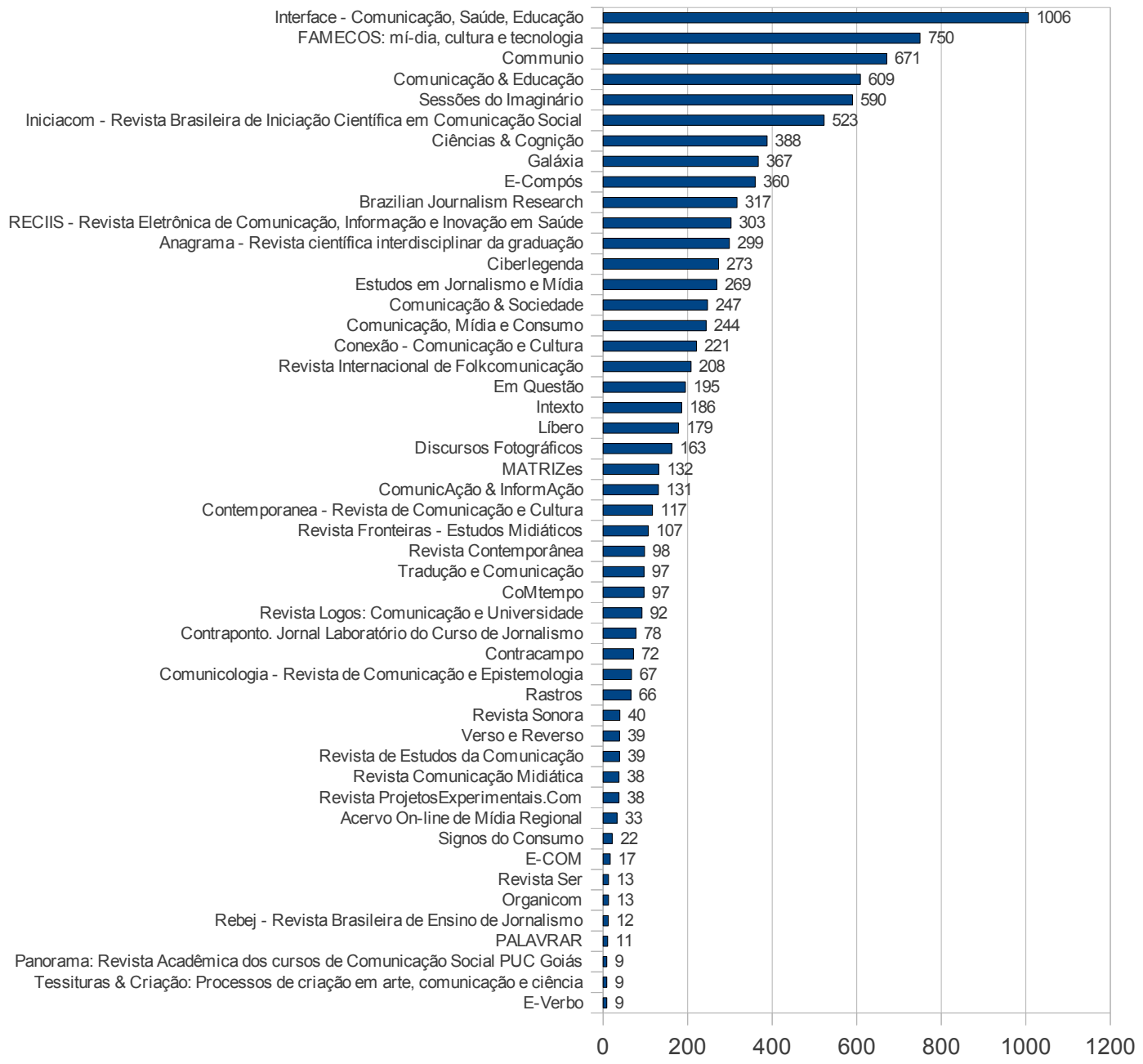

Figura 6.2. Distribuição da frequência do número de registros coletados por fonte de informação das revistas científicas.

Vale frisar que os primeiros documentos datam de 1997 e os últimos documentos coletados são de 2011.

\section{Extração do banco de dados}

Após identificarmos qual seria o universo de registros de nosso banco de dados com os quais iríamos trabalhar, o próximo passo no tratamento dos dados foi extrair esses registros de modo que pudéssemos trabalhar apenas com os campos de metadados do formato Dublin Core que eram de 
nosso interesse. Como nosso objetivo é o estudo das redes sociais seja de coautores na produção de um artigo científico, seja de coparticipantes de uma banca de defesa de uma dissertação ou tese, estávamos apenas interessados nos metadados que descrevem as pessoas envolvidas num determinado documento, além da data do registro, que consideramos ser a data de publicação do documento para podermos avaliar o processo dinâmico de evolução das redes.

Todas as 61 fontes de informação com a qual estávamos trabalhando utilizaram ao menos o formato de metadados Dublin Core simplificado, seguindo os padrões de campos conforme apresentamos na tabela 5.1 do capítulo 5. Logo, dos 15 campos disponíveis para utilização pelo formato simplificado, apenas 3 campos eram de nosso potencial interesse para identificação das pessoas e datas, a saber: creator, contributor e date.

Os dados foram extraídos do banco de dados por fonte de informação e foram salvos em arquivos separadamente com o nome de cada fonte de informação. Após a separação dos dados, construímos um programa que realizou automaticamente a extração desses 3 campos de cada registro, avaliando inicialmente se eles existiam e se estavam devidamente preenchidos. Por meio desse procedimento que pudemos avaliar quantos registros estariam de fato disponíveis para utilizarmos e quantos registros estariam com problemas técnicos de formatação ou com falta de informação suficiente para que pudéssemos considerá-los em nossas análises. Apresentamos na tabela 6.8 a seguir os resultados da validação dos metadados extraídos.

\begin{tabular}{|c|c|c|}
\hline \multirow[b]{2}{*}{ Categorias } & \multicolumn{2}{|c|}{ Registros } \\
\hline & Coletados & Validados \\
\hline Revistas científicas & 9864 & $9638(97,7 \%)$ \\
\hline Bibliotecas de teses e dissertações & 1961 & $1953(99,6 \%)$ \\
\hline Total & 11825 & $11591(98,0 \%)$ \\
\hline
\end{tabular}

Tabela 6.8. Resultados do processo de validação dos metadados.

A extração e validação dos dados apresentou uma redução mínima em relação ao número de registros coletados e aqueles que foram utilizados para nossas análise, conforme vemos na tabela 6.8. Os principais problemas que encontramos no tratamento dos metadados foram de dois tipos: falta de informação no campo ou campos mal formados, ou seja, que não seguiam de modo estrito a forma como deveriam ser escritos segundo os parâmetros XML especificados pelo formato Dublin Core. Esses problemas foram detectados de modo esparso pelas diferentes fontes de informação e, como os dados ajudam a demonstrar, mais se configuram como exceção no modo de constituição desses metadados do que regra.

A saída gerada por nosso programa de análise dos metadados criava um arquivo separado para cada fonte de informação contendo em cada linha os nomes das pessoas e a data extraída de 
cada registro. Esse arquivo permitia termos um controle do conjunto de nomes que apareceram em cada fonte de informação, bem como da data em que apareceram. Além disso, esse formato permitia ao nosso programa contar de modo automático o número de autores, no caso das revistas científicas, que participaram de cada produção científica analisada. Apresentaremos no próximo capítulo uma análise sobre a distribuição de coautoria pelas revistas científicas, bem como uma avaliação geral da evolução da coautoria média de nossa base ao longo do tempo.

\section{Junção dos arquivos de saída}

Os arquivos de saída do processo de extração dos dados foram importantes para que pudéssemos ter uma panorama geral dos resultados de participação das pessoas em cada revista. Porém, para que pudéssemos analisar a formação das redes sociais considerando cada autor com uma identificação única, o que permitiria identificar sua presença em diferentes revistas e bancas de defesa, seria necessário unificar esses arquivos de saída. Nosso objetivo nessa etapa era criar as condições básicas para que pudéssemos em etapa posterior normalizar todos os nomes e criar um controle mínimo de autoridades, por mais diversos que fossem o modo como seus nomes seriam representados.

A junção dos arquivos de saída foi feita já considerando a distribuição temporal de cada registro, o que nos permitiria em etapa posterior organizar e filtrar os registros por faixas de tempo. Desse modo, criamos uma base de dados onde constava o número único de identificação de um documento conforme o registro original na base Univerciencia.org, o conjunto de autores e/ou colaboradores que participaram daquele registro e sua data.

Foram criados dois bancos de dados, já separando as relações estabelecidas nas revistas científicas e as relações estabelecidas nas bancas de defesas. Vale frisar que o objetivo dessa separação é analisarmos de forma distinta os padrões estruturais e dinâmicos que são característico de cada nível de rede, permitindo inferirmos diferenças, tendências e os modos com que esses níveis de relação podem ser descritos.

\section{Normalização dos nomes}

O processo de normalização dos nomes consistia em criarmos um identificador numérico único para cada pessoa que aparecesse em um determinado banco de dados. Inicialmente, compatibilizamos o modo com o qual cada nome era escrito, ou seja, garantindo que teríamos em cada registro uma estrutura que fosse composta pelo primeiro nome seguido dos possíveis sobrenomes de cada pessoa. Esse procedimento foi feito de modo automático, identificando e 
substituindo pelo modo correto de escrita os marcadores de separação de nomes em cada registro.

Após a unificação do método de escrita dos nomes, os mesmos foram organizados por ordem alfabética e comparados entre si por um programa de identificação automática. Os nomes iguais foram agrupados sob a mesma a identificação numérica. De modo a garantir maior consistência nos dados e afetar o menos possível a dinâmica de rede que estamos buscando investigar, foi realizada uma avaliação manual dos resultados de agrupamento dos nomes, permitindo identificarmos pequenas variações nos modos de escrita, melhorando assim a formação de grupos que antes poderiam ser considerados como nomes diferentes. Apresentamos na tabela 6.9 a seguir os resultados dessa etapa.

\begin{tabular}{|l|c|c|}
\multicolumn{1}{c|}{} & \multicolumn{2}{c|}{ Normalização de nomes } \\
\hline \multicolumn{1}{|c|}{ Categorias } & Antes (nomes) & Depois (nomes) \\
\hline Revistas científicas & 10393 & $9587(92,2 \%)$ \\
\hline Bibliotecas de teses e dissertações & 2513 & $2465(98,1 \%)$ \\
\hline
\end{tabular}

Tabela 6.9. Resultados do processo de normalização de nomes.

A normalização permitiu reduzirmos em praticamente $8 \%$ os nomes presentes na base de dados das revistas científicas e $2 \%$ na base de bibliotecas de teses e dissertações. A base de revistas apresenta uma quantidade maior de registros, logo, seria esperado que tivesse um universo maior de pessoas que de algum modo se vinculassem a produção de um documento. Já na base de bibliotecas o universo é menor, sobretudo devido ao número de documentos disponíveis.

É importante destacar que essa redução de nomes é fundamental numa análise de rede social, pois aumenta a precisão da análise no que consiste a identificação dos nós mais centrais, da formação de grupos e reduz uma potencial fragmentação na rede por estarmos considerando pessoas separadas que de fato são as mesmas.

\section{Produção do arquivo para análise de redes}

O software Pajek para análise das métricas e geração das imagens de formação das redes sociais que utilizamos nesta tese exige uma formatação dos dados de entrada que lhe é característica. Logo, tínhamos a necessidade de compatibilizar nossos bancos de dados que pudessem gerar, para as redes analisadas, arquivos que estivessem adaptados a esse formato, o que exige uma descrição inicial de quais são os nós presentes na rede e uma lista que descreva como estão conectados entre si. Apresentamos na figura 6.3, a seguir, como esse formato é constituído. 


$$
\begin{aligned}
& \text { *Vertices } 4 \\
& 1 \text { "v979" } \\
& 2 \text { "v1374" } \\
& 3 \text { "v1379" } \\
& 4 \text { "v2394" } \\
& \text { *Edges } \\
& \begin{array}{lll}
1 & 4 & 1 \\
2 & 3 & 1
\end{array}
\end{aligned}
$$

Figura 6.3. Exemplo de formato de arquivo para análise no software Pajek.

Como vemos na figura 6.3, o arquivo exige uma listagem inicial de quais são os nós presentes na rede, o que consiste na seção "vertices", onde aparecem o número de cada nó e seu respectivo nome entre aspas. Esse nome é o identificador único que criamos na etapa de normalização dos nomes. Logo abaixo, na seção "edges" o formato Pajek pede que listemos em cada linha as relações que foram estabelecidas entre os nós. No nosso exemplo, vemos que a primeira linha da seção mostra o nó 1 se relacionando com o nó 4 e o nó 2 se relacionando com o nó 3. O número 1 ao lado de cada relação pode ser utilizado para classificar de algum modo a força das relações. Em nosso caso, utilizamos esse número igual para todas as relações, dado que decidimos não ponderar de modo diferente as relações entre os nós.

Desse modo, produzimos dois arquivos no formato descrito acima, sendo um para a rede de coautoria entre os participantes das revistas científicas e outro para a rede de participantes das defesas de teses e dissertações.

Através dessas 5 etapas de tratamento dos dados, tivemos um panorama geral dos principais resultados da coleta de informação gerada pela arquitetura federada da biblioteca Univerciencia.org, bem como os procedimentos utilizados para que tivéssemos dados em condições de serem analisados para a identificação da formação e evolução das redes sociais.

Apresentamos no capítulo a seguir uma descrição das características gerais de cada base de dados gerada como produto dessa fase de tratamento dos dados. 


\section{Capítulo 7}

\section{Resultados}

"Frente a informações cada vez mais numerosas e variadas, a comunicações e a colaborações cada vez maiores entre as pessoas, fontes de verdadeira vertigem informacional, não se trata mais de uma ou duas variáveis a estudar, nem de alguns valores a resumir. Mas é de uma profusão de variáveis que se deve dar conta e, portanto, de uma profusão de valores numéricos que se deve analisar. É assim difícil escolher quais as variáveis e as relações que se deve analisar." Yves-François Le Coadic

\subsection{Descrição das bases de dados de análise}

\subsubsection{Base de revistas científicas}

A base de revistas científicas é constituída por 49 revistas, já apresentadas no capítulo anterior, e conta com 9638 documentos válidos para análise. Vejamos na figura 7.1, a seguir, como esses documentos são distribuídos ao longo do tempo.

\section{Distribuição temporal dos documentos}

\section{Revistas Científicas - Univerciencia.org}

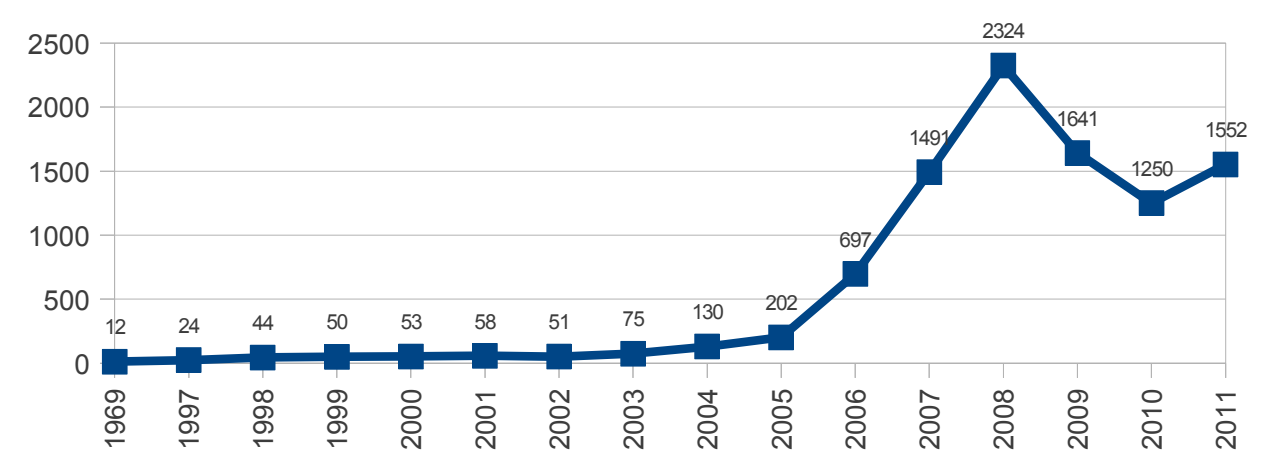

Figura 7.1. Distribuição temporal dos documentos na base de revistas científicas.

A distribuição tem início no ano de 1969, com um salto de datas até o ano de 1997, depois passando a ser regular em relação aos anos dos documentos, sendo o período regular de 15 anos de dados. Descartamos em nossa análise os dados relativos a 1969 de modo a não prejudicar nossa escala temporal. É interessante notarmos o salto de crescimento na disponibilização de documentos datados sobretudo a partir de 2006, quando percebemos um aumento significativo na taxa de crescimento do número de documentos publicados, passando de 202 em 2005 para 697 em 2006, 
um crescimento de $345 \%$ em questão de um ano. Nos remetendo a seção 4.2 do capítulo 4 , podemos observar que esse crescimento parece acompanhar os dados relatados nos relatórios trienais da CAPES, mostrando que do ano 2000 para 2009 houve um crescimento de 260\% no número de programas de pós-graduação no Brasil na área da Ciências da Comunicação.

No entanto, não podemos relacionar diretamente o crescimento do número de programas de pós-graduação com o crescimento da produção científica em formato aberto que pode ser coletada por uma biblioteca digital federada. Outro fator parece se somar ao crescimento do número de programas de pós-graduação na área: o maior incentivo a criação e desenvolvimento de revistas científicas em formato aberto no Brasil impulsionado por financiamento direto da CAPES e CNPq. Juntos, esses órgãos passaram a investir em torno de R $\$ 4.8$ milhões de reais a partir de $2007^{54} \mathrm{em}$ editais públicos visando incentivar a produção de revistas, inclusive mencionando explicitamente no texto dos editais ao longo desses anos que as revistas devem ser de acesso aberto, como vemos a seguir na declaração de objetivo do edital de 2008:

“Apoiar e incentivar a editoração e a publicação de periódicos científicos brasileiros, em todas as áreas do conhecimento, sendo considerado prioritário o apoio às revistas divulgadas por meio eletrônico, na Internet, em modo de acesso aberto, ou de forma impressa/eletrônica simultaneamente." ${ }^{55}$

Observando na figura 7.2, a seguir, a curva de revistas ativas que estão publicando efetivamente ao longo dos anos de produção e sendo coletados pela biblioteca Univerciencia.org, percebemos claramente que há um salto de 17 revistas para 32 ativas de 2007 para 2008, representando um crescimento de $188 \%$ no número de revistas nesse período. Entendemos por revistas ativas aquelas que possuem documentos publicados com datas no mesmo ano em que é considerada ativa. Por exemplo, há 50 documentos de uma revista datados de 2008, logo consideramos a revista ativa neste ano, mesmo que esses documentos tenham sido disponibilizados para acesso apenas em outro ano. No momento em que não registramos nenhum documento da revista num respectivo ano, ela deixa de ser considerada ativa para nossa análise. A intenção dessa categorização é perceber a quantidade de anos consecutivos que temos revistas disponibilizando documentos nesses anos.

54 Ver notícia CAPES: http://www.capes.gov.br/servicos/sala-de-imprensa/36-noticias/1589

55 Ver edital CNPq: http://www.cnpq.br/resultados/2008/ 


\section{Revistas ativas (publicaram no ano)}

\section{Repositório Univerciencia.org}

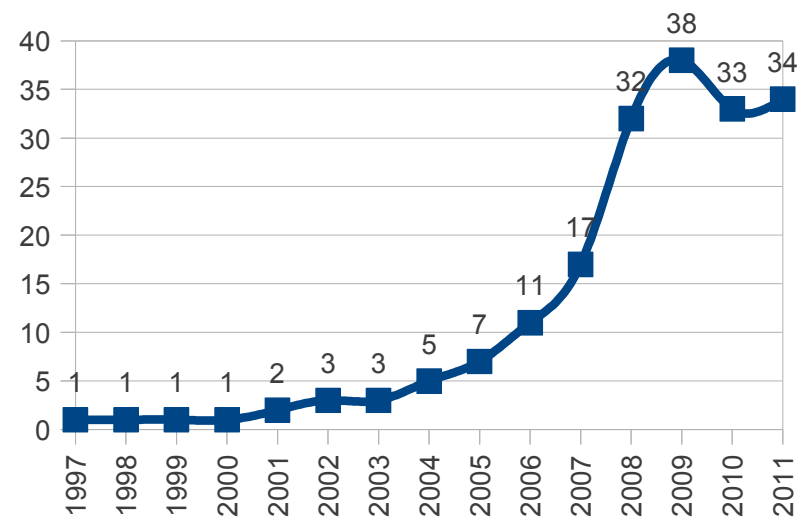

Figura 7.2. Distribuição temporal de revistas ativas na base Univerciencia.org.

Quando avaliamos em que ano essas revistas estão iniciando a publicação de artigos que foram coletados na Univerciencia, encontramos a curva apresentada na figura 7.3, a seguir, mostrando como há um expressivo número de revistas iniciando suas atividades de 2007 para 2008, com um crescimento de 6 novas revistas em 2007 para 15 novas revistas em 2008, representando um crescimento de $250 \%$ no período. Consideramos uma revista como nova na data do documento mais antigo que ela disponibilizou para acesso, sendo a intenção dessa categorização a mesma para revistas ativas.

\section{Revistas iniciando (primeira publicação neste ano)}

\section{Repositório Univerciencia.org}

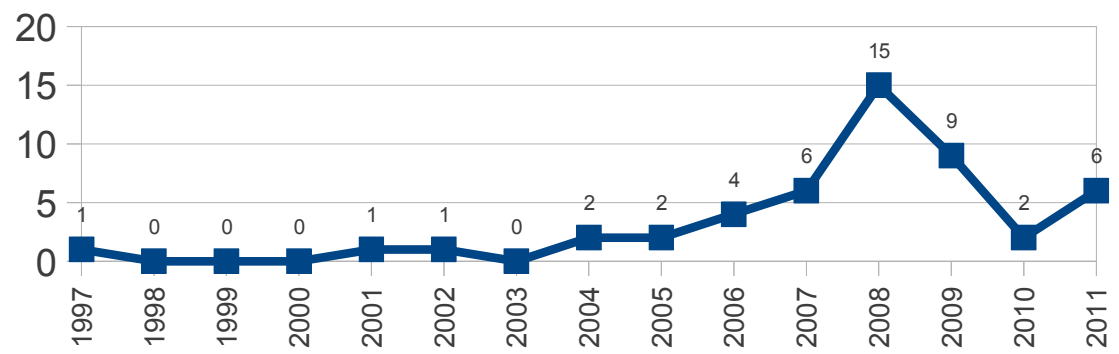

Figura 7.3. Distribuição temporal de novas revistas na base Univerciencia.org.

Quando observamos os resultados dos editais de $2006^{56}$ e $2007^{57}$, encontramos algumas importantes revistas da área da Ciência da Comunicação em termos de quantidades de documentos 
que foram coletados pela Univerciencia.org, como por exemplo, Interface - Comunicação, Saúde e Educação e Ciências \& Cognição. Ao que tudo indica, a soma dos fatores envolvendo o crescimento no número de programas de pós-graduação na área das Ciências da Comunicação com o maior incentivo para o desenvolvimento de revistas científicas em acesso aberto, essencialmente ações de uma política pública científica, parece ter causado o impacto observado no crescimento de documentos e revistas científicas na Univerciencia.org.

Outro fator que vale mencionar é a queda no número documentos sendo publicados e no número de novas revistas surgindo na área entre os anos de 2008 e 2010, com uma recuperação nas taxas de crescimento percebida no ano de 2011. Não identificamos fatores explícitos, seja na dinâmica da política científica ou social, que pudessem explicar fatores que tenham levado a esse comportamento. Um fator importante a mencionar é que a partir de 2010 a coordenação do projeto Univerciencia.org não tem realizado ações sistemáticas de identificação de revistas da área da Comunicação em acesso aberto para inseri-las em sua base de dados. É fato que observamos, naquilo que pode ser visto a partir das lentes proporcionadas por uma biblioteca federada, como a Univerciencia.org, uma redução no ritmo de publicação nas revistas que ali são indexadas, chegando mesmo a termos revistas que deixam de ser disponibilizar documentos em um determinado ano. Outros fatores que extrapolam os limites desta tese podem ser levados em consideração como meio de explicar esse acontecimento, como o fato de pesquisadores estarem sendo levados a buscarem outras revistas específicas de classificação Qualis que não são disponibilizadas em formato aberto e, portanto, não foram coletadas na base Univerciencia.

O que é fundamental ter em questão quando da explicitação de nossas análises é a limitação com a qual estamos lidando, ou seja, estamos avaliando uma determinada biblioteca digital federada, o que de fato não nos permite generalizar essas inferências para a área toda com segurança.

Apresentamos na figura 7.4, a seguir, a distribuição de coautoria média por revista científica. Observamos que apenas 9 revistas apresentam uma média acima do valor de 1,5, sendo estas as revistas que terminam por contribuir com a maior quantidade de relações entre pesquisadores por artigo, impactando desse modo na maneira como a rede social dos pesquisadores irá se organizar. 


\section{Distribuição de coautoria média por revistas}

\section{Repositório Univerciencia.org}

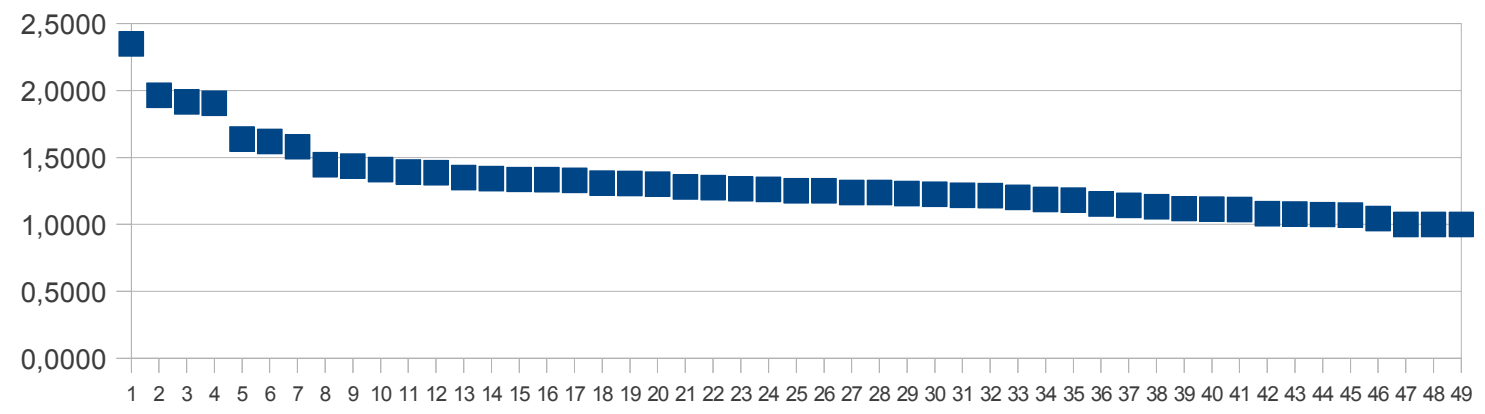

Figura 7.4. Distribuição de coautoria média por revistas.

A média ponderada geral da coautoria na base Univerciencia.org é de 1,43 autores por artigo, sendo que se considerarmos apenas o último ano analisado, em 2011, teremos uma coautoria média de 1,57 autores por artigo. Comparando esse resultado com o apresentado no ítem 3.4 do capítulo 3, onde mostramos que a média na área de Ciências da Comunicação era de 1,75 autores por artigo na base Web of Science, percebemos que há uma diferença $11 \%$ nesse valor, entendendo que o Web of Science mostra dados de produção científica internacional e o Univerciencia.org, em nossa análise, apenas produção científica em revistas brasileiras.

Apresentamos na figura 7.5, a seguir, quais são as revistas que apresentam um padrão de coautoria maior que a média de 1,43, visando conhecermos quais são as revistas que mais contabilizam relações de colaboração entre pesquisadores por artigo publicado.

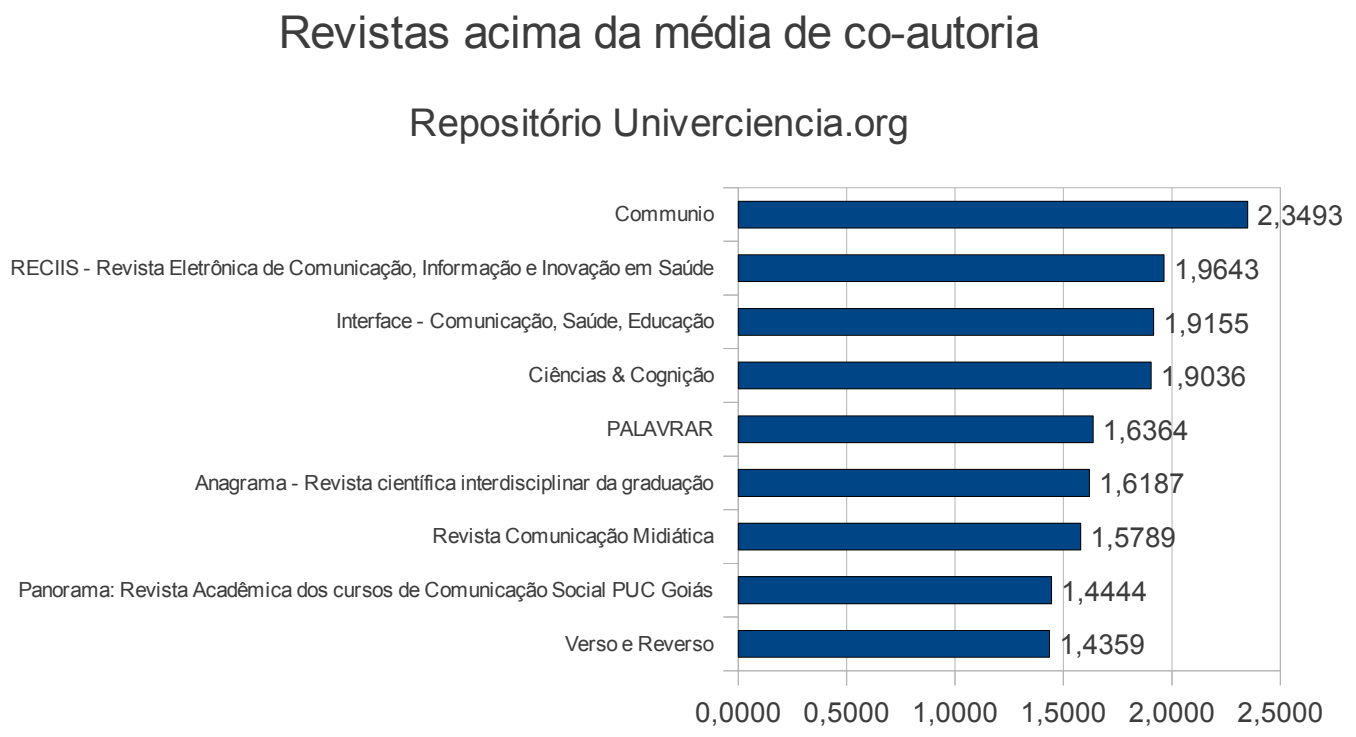

Figura 7.5. Distribuição de coautoria média por revistas. 
É interessante observamos que das 4 principais revistas com maior média de coautoria por artigo, temos 3 revistas que fazem de alguma maneira relações com a área da saúde: RECIIS Revista Eletrônica de Comunicação, Informação e Inovação em Saúde, Interface - Comunicação, Saúde e Educação e Ciências \& Cognicação, que é promovida e hospedada pelo Centro de Ciências da Saúde, da Universidade Federal do Rio de Janeiro. De fato, como apresentamos no capítulo 3, a área da saúde sem dúvida apresenta uma maior média de coautoria como estratégia de produção científica daqueles que ali atuam. Considerando que estamos falando de revistas multidisciplinares, que relacionam as questões da comunicação com as questões da saúde, percebemos aqui que encontramos estratégias de produção científica que parecem elevar a média de coautoria da área da Ciências da Comunicação quando analisamos essas revistas em conjunto e sob o olhar da área.

Apresentamos na tabela 7.1, a seguir, como se dá a distribuição total de documentos por faixa de coautoria na base Univerciencia.org.

\begin{tabular}{|c|c|c|}
\hline Coautores & Documentos & $\%$ \\
\hline 1 & 7216 & $74,75 \%$ \\
\hline 2 & 1564 & $16,20 \%$ \\
\hline 3 & 439 & $4,55 \%$ \\
\hline 4 & 189 & $1,96 \%$ \\
\hline 5 & 112 & $1,16 \%$ \\
\hline 6 & 60 & $0,62 \%$ \\
\hline 7 & 34 & $0,35 \%$ \\
\hline 8 & 18 & $0,19 \%$ \\
\hline 9 & 9 & $0,09 \%$ \\
\hline 10 & 7 & $0,07 \%$ \\
\hline 11 & 1 & $0,01 \%$ \\
\hline 12 & 3 & $0,03 \%$ \\
\hline 15 & 1 & $0,01 \%$ \\
\hline 17 & 1 & $0,01 \%$ \\
\hline Total & 9654 & $\mathbf{1 0 0 , 0 0 \%}$ \\
\hline
\end{tabular}

Tabela 7.1. Distribuição de documentos por faixa de coautoria

Comparando os resultados obtidos com os estudos apresentados no item 4.3 do capítulo 4 , onde mostramos dois estudos, em um 76,6\% dos artigos eram assinados por um único autor e no outro $88 \%$ eram de um único autor, percebemos que nossos resultados nos colocam como confirmando esses resultados, quando temos em torno de $75 \%$ de toda a produção científica de revistas brasileiras na base Univerciencia.org é assinada por apenas um autor, sendo que $25 \%$ são distribuídos de 2 até o número máximo de 17 autores por artigo. De fato, os resultados confirmam que a maioria da produção científica da área continua sendo assinada por apenas um único autor. No entanto, como podemos visualizar na figura 7.6, essa tendência parece estar mudando gradativamente, sobretudo do ano de 2008 para frente. 


\section{Distribuição de coautoria}

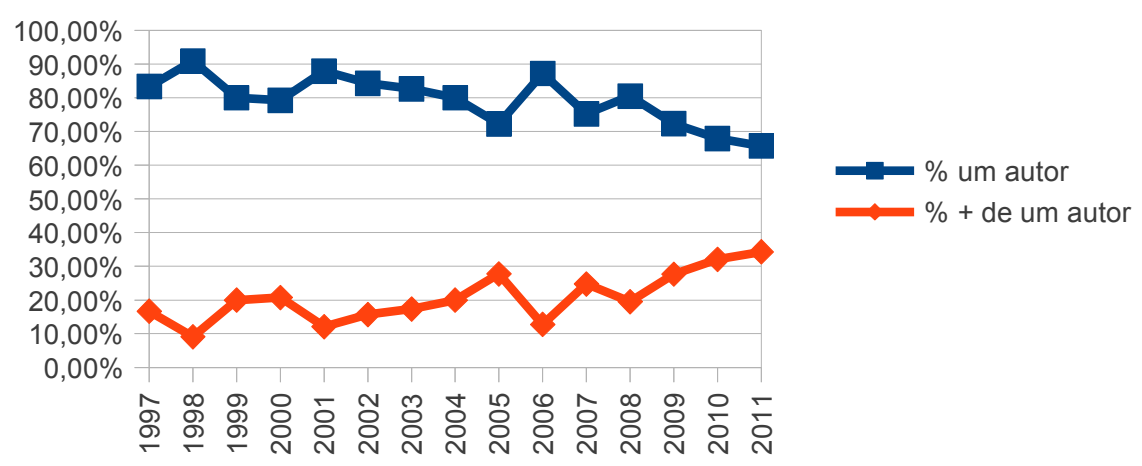

Figura 7.6. Distribuição de faixas coautoria por ano.

Analisando a figura 7.6, percebemos uma tendência de crescimento na coautoria de 2008 para 2011 , levando a uma taxa de $20 \%$ dos artigos em coautoria para próximo de $40 \%$ em 2011 . O perfil da área, a partir do que vemos no Univerciencia.org, parece estar se modificando, seguindo a tendência mundial e de diversas áreas do conhecimento, como vimos no capítulo 3, que é de ampliação de sua taxa de coautoria como estratégia de organização da produção científica de pesquisadores e estudantes. É interessante também notarmos que a proposta do sistema Qualis, em termos de categorias de avaliação muda no ano 2008, outro fator que pode, de certa forma, impulsionar uma mudança de estratégia de no modo de operar coautorias para a área da Comunicação.

A apresentação das características gerais da base de revistas científicas teve por objetivo demonstrar quais são os principais elementos desses dados que são relevantes para compreendermos a formação estrutural e dinâmica das redes sociais em análise. Caracterizamos sobretudo o modo como se produziram as relações de coautoria e a dinâmica de produção de documentos e revistas utilizadas na formação da base, levando em consideração sua distribuição ao longo do tempo. Esses elementos nos ajudarão a contextualizar as estratégias de formação de redes, bem como avaliar em perspectiva seu processo dinâmico de constituição. Vejamos agora as características da base de bibliotecas digitais de teses e dissertações.

\subsubsection{Base de bibliotecas digitais de teses e dissertações}

A base de bibliotecas digitais de teses e dissertações é constituída por 12 bibliotecas, já apresentadas no capítulo anterior, e conta com 1953 documentos válidos para análise. Vejamos na 
figura 7.7, a seguir, como esses documentos são distribuídos ao longo do tempo. A distribuição tem início no ano de 1986 e segue de modo regular até o ano de 2011, caracterizando um período amostral de 26 anos.

Distribuição de Teses e dissertações

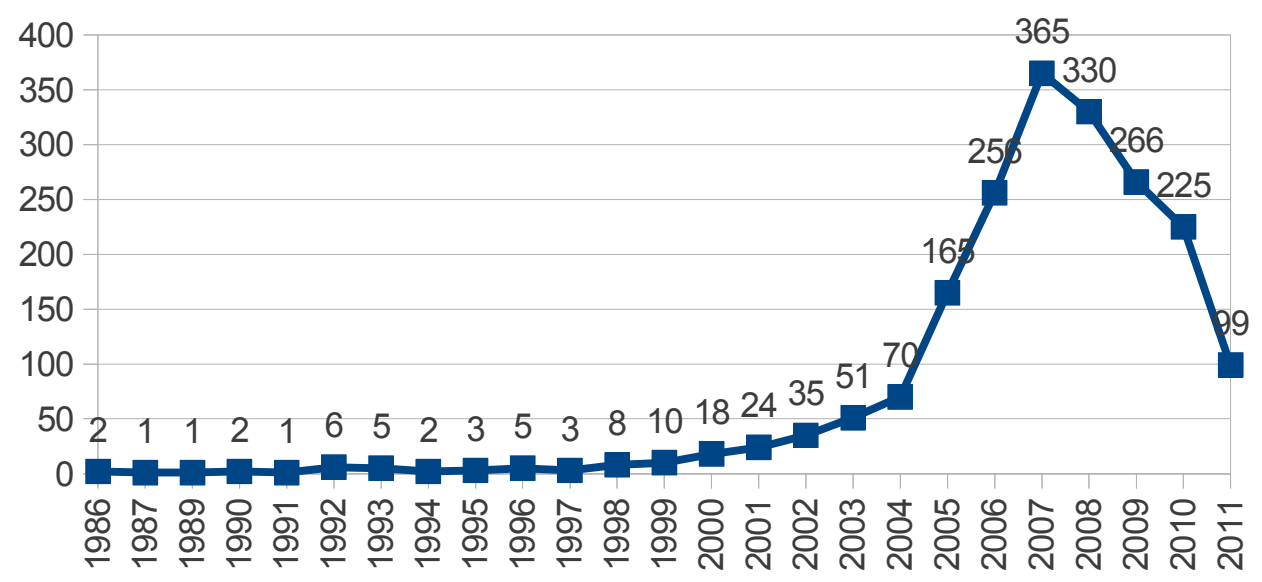

Figura 7.7. Distribuição teses e dissertações ao longo do tempo.

É interessante observarmos como a base entra num período de crescimento mais intenso a partir do início dos anos 2000, tendo um pico em sua taxa de crescimento do ano de 2004 para 2005, quando passa de 70 documentos para 165 documentos, representando um crescimento de 235\% no período. Esse crescimento se mantém até atingir um pico em 2007, a partir de então caindo ano após ano até atingir 99 trabalhos no ano de 2011. É importante ressaltar que devemos considerar para o ano de 2011 que a extração final da base de dados foi feita no final de dezembro deste ano, sendo que possivelmente muitos documentos de teses defendidas nos últimos meses do ano poderiam ainda não ter sido digitalizadas e disponibilizadas em suas bibliotecas digitais para coleta. No entanto, mesmo excluindo o ano de 2011 em nossas considerações, observamos uma queda de 38\% na disponibilização de teses e dissertações nessas bibliotecas digitais para coleta do ano de 2007 para 2010. Levantamos algumas hipóteses para esse resultado adiante no texto.

Observando a listagem da $\mathrm{CAPES}^{58}$ para os programas de pós-graduação na área de Comunicação, encontramos um total de 39 programas diferentes. Quando observamos nossas fontes de informação estamos tratando apenas de 12 bibliotecas digitais. Logo, estamos coletando em torno de $30 \%$ dos programas. Sem dúvida, vale mencionar que não coletamos mais dados devido

58 Ver CAPES: http://conteudoweb.capes.gov.br/conteudoweb/ProjetoRelacaoCursosServlet? acao $=$ pesquisarles $\&$ codigoArea $=60900008 \&$ descricaoArea $=\mathrm{CI}$ $\%$ CANCIAS+SOCIAIS+APLICADAS+\&descricaoAreaConhecimento=COMUNICA $\% \mathrm{C} 7 \% \mathrm{C} 3 \mathrm{O} \& d$ escricaoAreaAvaliacao $=\mathrm{CI} \% \mathrm{CANCIAS}+\mathrm{SOCIAIS}+\mathrm{APLICADAS}+\mathrm{I}$ 
aos programas não disponibilizarem sua produção de teses e dissertações em formato aberto compatível com protocolo OAI-PMH, o que viabilizaria a construção de bibliotecas digitais federadas mais abrangentes e representativas da área.

Vejamos agora, na tabela 7.2, a abrangência temporal de cada uma das bibliotecas digitais coletadas. Por abrangência temporal entendemos o intervalo de tempo entre a data do documento mais antigo e mais novo disponibilizado para coleta pela biblioteca.

\begin{tabular}{|c|c|c|c|}
\hline Nome & Ano inicial & Ano final & Dados de banca \\
\hline Biblioteca Digital de Teses e Dissertação da PUC-SP- SAPIENTIA & 1986 & 2011 & $\mathrm{NÃO}$ \\
\hline Biblioteca Digital de Teses e Dissertações da UnB & 1992 & 2011 & NÃO \\
\hline Biblioteca Digital de Teses e Dissertações da USP - Portal do Saber & 1994 & 2011 & NÃO \\
\hline Biblioteca Digital de Teses e Dissertações da UFBA & 2001 & 2010 & SIM \\
\hline Biblioteca Digital de Teses e Dissertações da UFPE & 2001 & 2009 & NÃO \\
\hline Biblioteca Digital de Teses e Dissertações da UTP & 2002 & 2009 & $\mathrm{NÃO}$ \\
\hline Biblioteca Digital de Teses e Dissertações da UMESP & 2002 & 2011 & SIM \\
\hline Biblioteca Digital de Teses e Dissertações da Unisinos & 2003 & 2008 & NÃO \\
\hline Biblioteca Digital de Teses e Dissertações da UFSM & 2004 & 2011 & NÃO \\
\hline Biblioteca Digital de Teses e Dissertações da PUC-Rio - MAXWELL LAMBDA & 2005 & 2011 & SIM \\
\hline Biblioteca Digital de Teses e Dissertações da UFMG & 2005 & 2011 & SIM \\
\hline Biblioteca Digital de Teses e Dissertações da UFG & 2008 & 2011 & NÃO \\
\hline
\end{tabular}

Tabela 7.2. Abrangência temporal das bibliotecas digitais.

Observamos que do ano de 1986 até 1991, a biblioteca da PUC-SP é a única a ter seu acervo disponível em formato aberto para coleta, sendo seguida em 1992 pela UnB e em 1994 pela USP. Esse fator deve ser levado em consideração no número de documentos disponíveis em nossa base, sendo que a PUC sozinha é responsável por aproximadamente $30 \%$ dos documentos coletados, logo nesse período o que observarmos em termos de redes sociais reflete apenas o que está acontecendo com as instituições que disponibilizaram seus documentos em formato aberto. Até o ano de 2001 são apenas essas três instituições que estão presentes em nossa base, sendo que a partir de 2001 outras instituições entram gradativamente disponibilizando seus documentos. Também vale notarmos que a Unisinos, a UFBA, a UFPE e a UTP não disponibilizaram documentos para coleta até o final do período, considerando o ano de 2011. Possíveis problemas em seus sistemas de informação ou questões de gestão podem ter inviabilizado esse trabalho. No entanto, vale considerar que isso produz efeitos na queda da produção científica que temos observado.

Desse modo, o que observamos como uma queda na produção científica a partir do ano de 2007 deve ser contextualizado segundo essa perspectiva, ou seja, de que estamos olhando para apenas 30\% dos programas de pós. Seria fundamental para uma possível conclusão mais abrangente observarmos o que tem acontecido na produção científica de outros programas de pós-graduação, inclusive pelo fato de que estamos diante de um processo de descentralização da produção científica na área das Ciências da Comunicação, como vimos no capítulo 4, onde o aumento no número de 
programas de pós-graduação em outras regiões além do Sudeste tem permitido com que vários estudantes que antes se dirigiam a programas mais antigos e consolidados possam agora se direcionar para outras instituições e programas. Aqui, mais uma vez, apontamos para o fato de que estamos observando a produção científica que é disponibilizada em formato aberto para coleta e produção de bibliotecas digitais federadas que permitem o tipo de análise que apresentamos.

Outra informação importante e que terá grande impacto nos resultados de nossas análises de redes sociais é não termos uma uniformidade nos dados dos membros de bancas presentes em todas as bibliotecas digitais no formato Dublin Core Simplificado. Como apresentamos na tabela 7.2, apenas 4 bibliotecas digitais mostram dados dos membros participantes das bancas de defesa, sendo elas a UFBA, UMESP, PUC-RIO e UFMG. As outras bibliotecas apenas apresentam dados dos orientadores e autores dos respectivos trabalhos. Isso, sem dúvida, reduz a abrangência do estudo de rede que poderíamos realizar se tivéssemos esses dados completos. No entanto, nos permitirá analisar diferentes efeitos que são produzidos na dinâmica das redes sociais quando as bibliotecas que disponibilizam bancas começam a se encontrar na mesma faixa temporal com as bibliotecas que não disponibilizam. Veremos diferentes efeitos e padrões que nos permitirão analisar o que esses dados causam, levando a questões que nos permitem problematizar o modo como a construção de bibliotecas digitais e a escolha de seus metadados impacta em futuras pesquisas realizadas em seus acervos.

Uma vez apresentadas as características mais relevantes de nossa base de dados para o efeito do estudo das formação das redes sociais ali presentes, passemos agora à apresentação dos resultados da análise de redes.

\subsection{Resultados da análise de redes sociais}

O objetivo desta seção é apresentarmos uma análise dos dados que foram gerados como resultado da aplicação dos principais indicadores e técnicas de análise de redes sociais conforme apresentamos no capítulo 2, sobretudo nas seções 2.5 e 2.6, onde discutimos a análise estrutural e dinâmica. Antes de iniciarmos a apresentação dos resultados, vale destacar algumas premissas de análise que foram utilizadas e que irão fundamentar o modo como escolhemos apresentar os resultados aqui relatados.

Inicialmente, organizamos os intervalos mínimos de tempo para análise numa faixa anual, ou seja, consideramos que tudo o que acontece num determinado ano de registro em nossa base de dados faz parte do mesmo extrato temporal. De modo a permitir um olhar no qual pudéssemos contemplar diferentes eventos e maneiras que possam influenciar o desenvolvimento dinâmico de uma rede social, organizamos nossa análise em termos temporais de dois modos. O primeiro modo, 
chamado nesta tese de modo acumulado, considera que a rede social evolui gradativamente de ano para ano, ou seja, a cada ano $\mathrm{n}$ a rede possui um conjunto de nós e links aos quais são incorporados os novos nós e links do ano $\mathrm{n}+1$, criando desse modo um acúmulo de nós e links de todas as relações que foram estabelecidas e registradas em nossa base de dados quando chegarmos no último ano de análise. Acreditamos, desse modo, que com essa escolha teremos uma visão conjunta dos principais movimentos de uma rede, inclusive podendo identificar tendências que se estabilizam ou divergem ao longo do tempo. O segundo modo, chamado nesta tese de modo ano-a-ano, considera que a rede social se constitui das relações estabelecidas apenas num determinado ano, ou seja, a rede no ano n é apenas composta dos nós e links que foram estabelecidos naquele ano, sendo que no ano $\mathrm{n}+1$ os nós e links do ano passado são descartados e são apenas analisados as novas relações estabelecidas. Acreditamos, desse modo, que podemos avaliar melhor os acontecimentos singulares, os movimentos temporais e as novas estratégias de relação quando apenas consideramos os eventos de um determinado ano, descartando as relações passadas, logo sua influência acumulada.

A junção desses dois modos de análise visa contemplar diferentes aspectos e tendências estruturais e dinâmicas de nossas redes sociais, permitindo uma análise complementar que pode auxiliar em nossa capacidade de percepção e síntese do objeto social de nossa investigação. Os efeitos temporais podem ser visualizados de dois modos diferentes, permitindo analisarmos seus efeitos acumulados e singulares dentro das faixas de tempo propostas, o que pode facilitar a identificação de padrões emergentes e tendências estabelecidas, sendo essas fundamentais para a análise das principais estratégias de conectividade que levam a uma rede ter o formato que possui.

Como modo de melhor organizar a apresentação dos resultados da análise de redes, construímos uma matriz de indicadores que apresentamos a seguir juntamente com as referências teóricas que foram utilizadas para embasar o sentido de cada indicador escolhido. A matriz tem por objetivo sintetizar todos os indicadores utilizados, além de mostrar de modo unificado como esses indicadores evoluíram ao longo do tempo. Vejamos a matriz na tabela 7.3. 


\begin{tabular}{|c|c|}
\hline Indicadores & Significado \\
\hline Artigos/Teses e dissertações & Número de artigos/teses e dissertações. \\
\hline Coautoria média & $\begin{array}{l}\text { Coautoria média dos artigos publicados (Somente } \\
\text { válido para a análise de redes das revistas } \\
\text { científicas). }\end{array}$ \\
\hline Nós & Número de pessoas que participaram da rede. \\
\hline Links & Número de links estabelecidos entre as pessoas. \\
\hline Densidade média & $\begin{array}{l}\text { Número relativo de conexões estabelecidas em } \\
\text { relação ao máximo possível. Ver seção } 2.5 .1 \text {, do } \\
\text { capítulo } 2\end{array}$ \\
\hline Componentes & $\begin{array}{l}\text { Número de pedaços da rede que estão isolados } \\
\text { de outras partes. Ver seção } 2.5 .2 \text {, do capítulo } 2 \text {. }\end{array}$ \\
\hline$\%$ dos nós no maior componente & $\begin{array}{l}\text { Porcentagem de todos os nós da rede que faz } \\
\text { parte do maior componente. Conforme revisão de } \\
\text { bibliografia na seção } 3.7 \text { do capítulo } 3 \text {. }\end{array}$ \\
\hline Tamanho do maior componente & $\begin{array}{l}\text { Quantidade de nós que faz parte do maior } \\
\text { componente. Conforme revisão de bibliografia na } \\
\text { seção } 3.7 \text { do capítulo } 3 \text {. }\end{array}$ \\
\hline Tamanho do segundo maior componente & $\begin{array}{l}\text { Quantidade de nós que faz parte do segundo } \\
\text { maior componente. Conforme revisão de } \\
\text { bibliografia na seção } 3.7 \text { do capítulo } 3 \text {. }\end{array}$ \\
\hline Grau de conectividade médio & $\begin{array}{l}\text { Número médio de conexões diretas pelos nós da } \\
\text { rede. Ver seção } 2.5 .1 \text {, do capítulo } 2 \text {. }\end{array}$ \\
\hline Grau de centralização da rede & $\begin{array}{l}\text { Grau de centralização ponderado por todos os } \\
\text { nós da rede. Ver seção } 2.5 .1 \text {, do capítulo } 2 \text {. }\end{array}$ \\
\hline Maior grau de conectividade & $\begin{array}{l}\text { Maior quantidade de relações diretas que um nó } \\
\text { estabeleceu na rede. }\end{array}$ \\
\hline Menor grau de conectividade & $\begin{array}{l}\text { Menor número de relações diretas que um nó } \\
\text { estabeleceu na rede. }\end{array}$ \\
\hline Distância geodésica & $\begin{array}{l}\text { Maior distância em termos de links entre dois nós } \\
\text { dentro de um mesmo componente. Ver seção } \\
2.5 .1 \text {, do capítulo } 2 \text {. }\end{array}$ \\
\hline Coeficiente de Clusterização & $\begin{array}{l}\text { Coeficiente que determina a transitividade de } \\
\text { relações relativas entre os nós da rede. Ver } \\
\text { seção } 2.6 .1 \text {, do capítulo } 2 .\end{array}$ \\
\hline
\end{tabular}

Tabela 7.3. Matriz de indicadores de análise de redes sociais

Aplicaremos essa matriz de indicadores para cada ano de nossa base de dados, tanto no modo acumulado como no ano-a-ano, a partir de onde geramos gráficos com a intenção de demonstrar os padrões de evolução de cada indicador segundo as faixas de tempo estabelecidas.

Vejamos a seguir os resultados apresentados inicialmente para a rede social das revistas científicas e depois para as bancas de teses e dissertações.

\subsubsection{Análise da rede social de relações de coautoria entre pesquisadores nas revistas científicas}

Apresentamos inicialmente as matrizes geradas nos dois modos de organização do tempo, modo acumulado e modo ano-a-ano, após entraremos em detalhes na análise individual de cada indicador. 


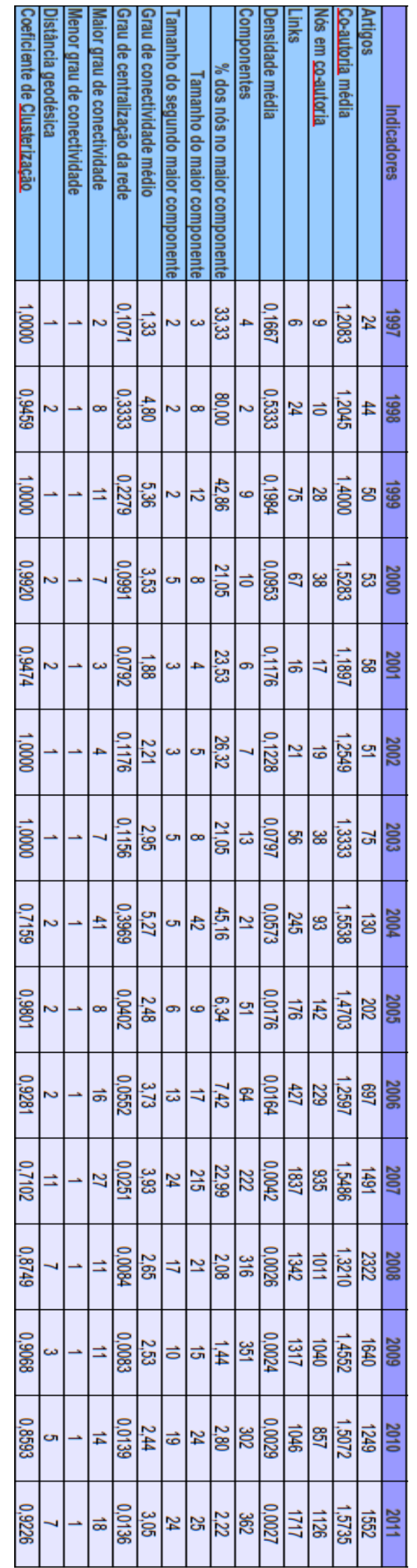

\begin{tabular}{|c|c|c|c|c|c|c|c|c|c|c|c|}
\hline 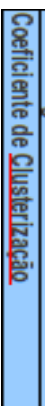 & 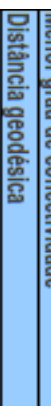 & 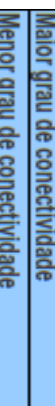 & 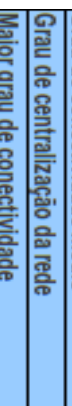 & 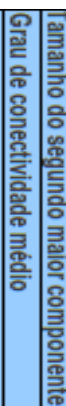 & 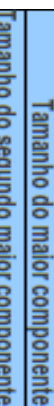 & 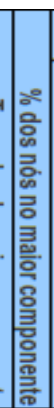 & 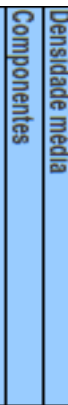 & 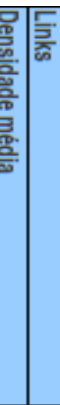 & 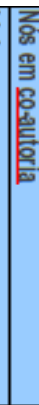 & 屃 & \\
\hline 离 & & $\rightarrow$ & $\sim \stackrel{ }{\vec{\theta}}$ & $\overrightarrow{\tilde{\omega}} \sim$ & $\omega$ & $\begin{array}{l}\omega \\
\omega \\
\tilde{\omega}\end{array}$ & $\rightarrow \overrightarrow{8}$ & क् & $\infty$ & $\overrightarrow{\widetilde{\Xi}}$ & $\approx$ \\
\hline 这 & & $\rightarrow \sim$ & 谵 & $\omega$ & $\omega$ & 용 & ज & \begin{tabular}{l|l}
0 \\
$\vec{c}$ \\
$\bar{c}$
\end{tabular} & $\vec{\infty}$ & 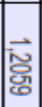 & $\infty$ \\
\hline 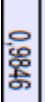 & $\omega$ & $\rightarrow$ & 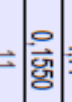 & $\stackrel{\forall}{*}$ & $0 \vec{N}$ & $\underset{\mathbb{N}}{\mathbb{*}}$ & $\vec{\omega} \stackrel{\overrightarrow{\vec{\theta}}}{\circ}$ & : & E & $\overrightarrow{\tilde{\Xi}}$ & $\overrightarrow{\vec{\infty}}$ \\
\hline : & 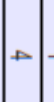 & $\rightarrow$ & 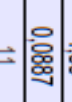 & $\overrightarrow{\mathcal{G}}=$ & $\vec{N}$ & \begin{tabular}{|l|}
$\overrightarrow{\mathrm{v}}$ \\
$\overrightarrow{\mathrm{c}}$
\end{tabular} & 표영 & 嶒 & Oా & 応 & $\overrightarrow{\underline{\prime}}$ \\
\hline 영 & $\rightarrow$ & $\rightarrow \Rightarrow$ & $=$ & $\overrightarrow{8}=$ & $\Rightarrow \vec{N}$ & $\overrightarrow{\stackrel{\vec{v}}{\exists}}$ & ज这 & 兽| & 9 & \begin{tabular}{|l}
$\overrightarrow{\vec{\omega}}$ \\
$\vec{\Phi}$ \\
$\dot{\Phi}$
\end{tabular} & $\mathbb{\widetilde { E }}$ \\
\hline 递 & $\rightarrow$ & $\rightarrow \Rightarrow$ & = & $\omega$ & $\vec{\omega}$ & $\overrightarrow{\underline{9}}$ & $\omega$ 总 & 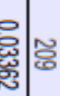 & $\vec{N}$ & $\overrightarrow{\underline{\Xi}}$ & $\widetilde{z}$ \\
\hline 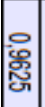 & 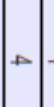 & $\rightarrow$ & 二| & $\underset{\omega}{\omega}$ & $\vec{\omega}$ & $\stackrel{\infty}{\infty}$ & 位莣 & 怘 & $\vec{\infty}$ & $|\overrightarrow{\underline{\omega}}|$ & $\mathscr{W}$ \\
\hline 잉 & $\rightarrow$ & $\rightarrow \triangleq$ & 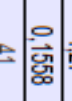 & $\overrightarrow{\mathbb{N}}$ & $\vec{E}$ & $\overrightarrow{\mathrm{v}}$ & 오 & 空 & 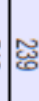 & $\overrightarrow{\vec{\omega}}$ & 孛 \\
\hline 월 & $\rightarrow$ & $\rightarrow \stackrel{\Delta}{A}$ & 焉 & $\omega$ & \% & \begin{tabular}{|l}
$\vec{\omega}$ \\
$\vec{B}$ \\
\end{tabular} & 효응 & 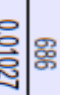 & $\mathscr{H}$ & $\overrightarrow{\vec{c}}$ & \&) \\
\hline 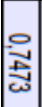 & $\oplus$ & $\rightarrow$ & : & 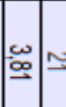 & 8 & $\overrightarrow{\mathrm{O}}$ & ज্ স্ট্র & 兽 & \% & $\overrightarrow{\vec{\omega}}$ & 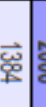 \\
\hline 君 & $\Rightarrow$ & $\rightarrow$ & 及 & $\overrightarrow{8}$ & $\mathbb{N}$ & $\overrightarrow{\mathrm{E}}$ & 事遂 & 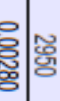 & 趝 & 喜 & 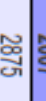 \\
\hline 於 & $\vec{N}$ & - & 突: & $\omega$ & $\omega$ & $\begin{array}{l}\overrightarrow{\mathrm{s}} \\
\mathrm{s}\end{array}$ & 席 용 & 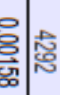 & $\tilde{\widetilde{u}}$ & $\overrightarrow{\underline{\mathbf{q}}}$ & 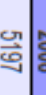 \\
\hline 岁 & & -8 & s: & $\omega$ & 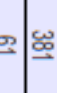 & $\overrightarrow{8}$ & 코응 & 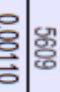 & $\stackrel{\omega}{\infty}$ & 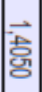 & 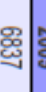 \\
\hline 罾 & & $\rightarrow 8$ & 3 远 & $\begin{array}{c}\omega \\
\text { A }\end{array}$ & 考 & $\overrightarrow{\mathrm{G}}$ & 迆 & 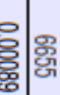 & 慈 & \begin{tabular}{|l|}
$\overrightarrow{\vec{*}}$ \\
离
\end{tabular} & \\
\hline 艿 & $\vec{\omega}$ & $\rightarrow 8$ & 잉 & $\omega$ & $\infty$ ్ㅐㅇ & $\overrightarrow{\vec{\infty}}$ & 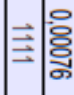 & 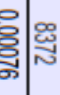 & 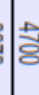 & & 离 \\
\hline
\end{tabular}

Tabela 7.4. Matriz de indicadores - Revistas Científicas modo ano a ano. Tabela 7.5. Matriz de indicadores - Revistas Científicas modo acumulado 
Vejamos agora uma análise detalhada de cada indicador apresentado nas tabelas 7.4 e 7.5.

\subsubsection{Nós e links}

Apresentamos em conjunto a evolução dos nós e links estabelecidos na rede de coautoria. Vejamos nas figuras 7.8 e 7.9 seus resultados.

Modo ano-a-ano: nós e links

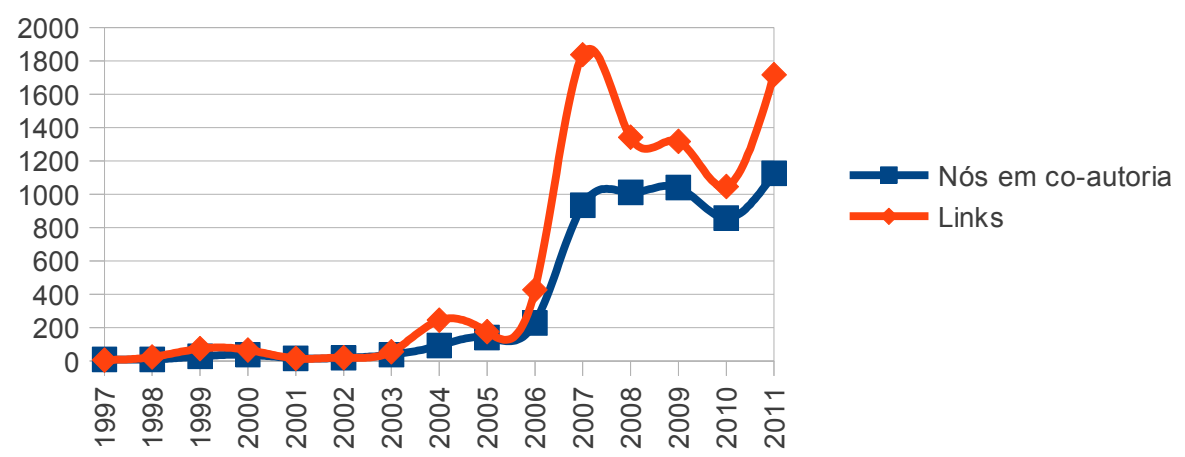

Figura 7.8. Modo ano-a-ano: nós e links

Modo acumulado: nós e links

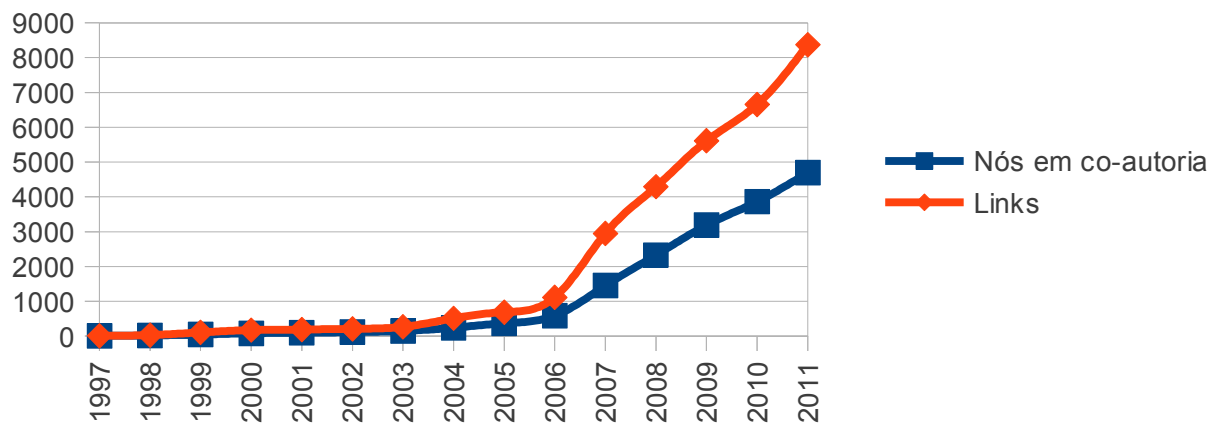

Figura 7.9. Modo acumulado: nós e links.

Na figura 7.8, observamos para a curva de links um importante salto do ano de 2006 para 2007, passando de 400 conexões para em torno de 1800 no período, representando um crescimento de $450 \%$. Esse crescimento é acompanhado no mesmo gráfico pelo número de nós em coautoria, que passa de 200 para 1000, representando um crescimento semelhante de $500 \%$ no período. Sem dúvida alguma, algum evento marcante nessa transição de 2006 para 2007 indica um crescimento extremamente significativo no modo como a rede estava se organizando. De início imaginamos que esse evento teria alguma relação com o aumento do número de revistas científicas e, logo, de documentos disponíveis nesse período. No entanto, quando analisamos os gráficos e dados 
apresentados na seção 7.1 deste capítulo, observamos que o aumento expressivo no número de revistas iniciando na base se dá do ano de 2007 para 2008, além do que o pico no número de documentos publicados num mesmo ano se dá no ano de 2008 e não 2007 como poderia sugerir a análise da figura 7.8. Seria preciso utilizarmos outra técnica de análise para buscar entender o que de fato nossas curvas de crescimento de links e nós estavam indicando.

De modo a buscar entender o que estava de fato se passando nesse período, através do software de análise de redes sociais Pajek, geramos imagens dos sociogramas apenas dos nós e links do ano de 2006 e 2007, onde então conseguimos identificar uma nova formação em 2007 que parecia indicar uma entrada de um grupo altamente articulado de nós e links, modificando abruptamente a dinâmica de desenvolvimento da rede social até então, como a figura 7.8 deixa evidente. Vejamos nas figuras 7.10 o sociograma da rede em 2006 e na figura 7.11 o de 2007.

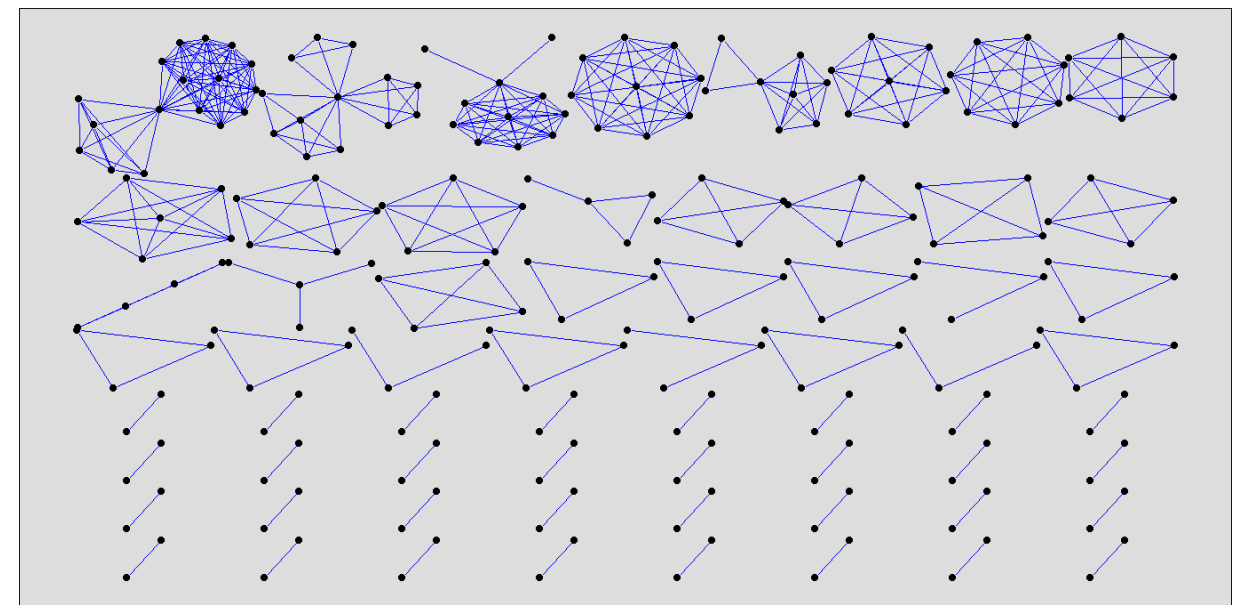

Figura 7.10. Sociograma da rede de coautoria no ano de 2006 - Modo ano-a-ano - Revistas Científicas.

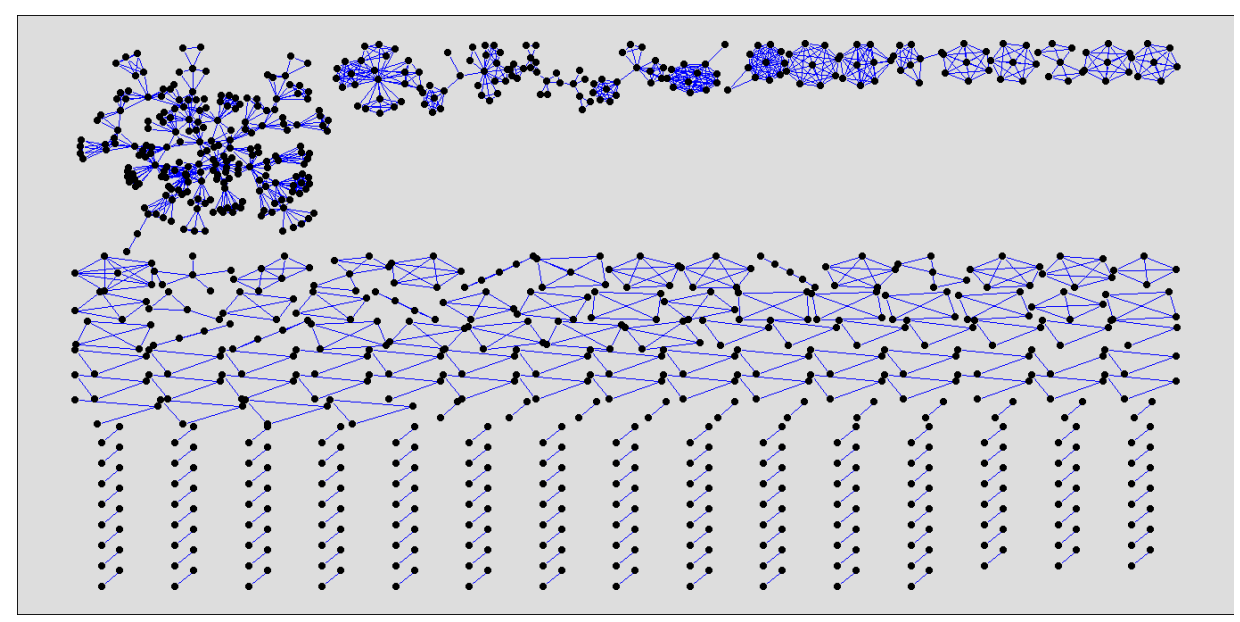

Figura 7.11. Sociograma da rede de coautoria no ano de 2007 - Modo ano-a-ano - Revistas Científicas.

Observando as diferença no sociograma de 2006 para 2007, identificamos na rede de 2007 
um componente composto de um grande número de nós e links entre si, o que pode ser percebido pelo primeiro componente no alto a esquerda na imagem. Logo, nossa análise nos levou a compreender que esse aumento de links e nós no ano de 2007 não se deu apenas pelo fato de que mais pessoas e mais conexões entre elas foram estabelecidas, supondo que isso poderia ter ocorrido por um aumento de intensidade de participação de autores nas revistas coletadas pela base Univerciencia.org. O que de fato estávamos observando era que o aumento se deu por um único componente na rede, levando a crer uma massa expressiva de pessoas e conexões tinham se articulado em apenas um único ano.

Esse fato, mais uma vez, nos chamou a atenção e nos levou a revisar nossos dados em busca de alguma razão que justificasse de onde vieram esses nós e se de fato estávamos observando um crescimento na articulação da área ou outro evento que pudesse explicar nossos resultados. Analisando a base de dados, descobrimos que todos esses nós do maior componente de 2007 estavam vindo de uma mesma revista, a Comunicação \& Educação da Universidade de São Paulo. Analisando os metadados, observamos que de fato o que estava acontecendo era que a revista quando disponibilizou seu acervo em formato aberto para coleta no padrão OAI-PMH registrou todos seus números de 1994 até 2007 com a data marcada nos metadados com o ano de 2007. Ou seja, o que estávamos observando nas figuras 7.8 e nos sociogramas das figuras 7.10 e 7.11 era uma entrada retardada de 13 anos de relações de coautoria entre autores que, de certo modo, colaboravam publicando seus trabalhos numa revista.

Sem dúvida, isso nos chama atenção para o nível de precisão do preenchimento dos metadados quando da disponibilização de documentos em formato digital e que tipo de impacto isso pode causar em estudos posteriores que sejam feitos com base nesses documentos. Em nosso caso, o que poderia se esperar como um crescimento gradativo no número de nós e links é visto como um crescimento anormal em relação a taxa de crescimento anterior da rede. Ao investigar essa possível anormalidade, descobrimos que não estávamos diante de um fenômeno social característico da área da Ciência da Comunicação e expressa nos dados coletados, mas sim diante de uma falta de procedimento técnico normalizado para disponibilização de um acervo em formato digital.

Já quando observamos a figura 7.9, as curvas de crescimento acumulado apenas demonstram que a rede passa a crescer numa taxa praticamente constante a partir do ano 2006. O efeito da entrada de massiva de nós e links em 2007 é atenuada no processo de acumulação de links e nós, sendo que essa dinâmica passa a seguir sua tendência de evolução natural a partir de 2007. Ainda na figura 7.8, observamos uma queda dos anos de 2008 para 2010 e uma retomada no crescimento em 2011, o que condiz com as observações feitas sobre o número de documentos e revistas ativas na seção 7.1 deste documento. Ou seja, o número de links e nós acompanha o crescimento e 
decrescimento no número de documentos publicados, o que é de se esperar dado que quanto mais documentos publicados mais possibilidades de coautoria existem.

\subsubsection{Densidade média e grau de centralização}

Apresentamos as curvas de densidade média e grau de centralização da rede de coautoria nas revistas científicas nas figuras 7.12, modo ano-a-ano, e na figura 7.13, modo acumulado.

Densidade média e grau de centralização: modo ano-a-ano

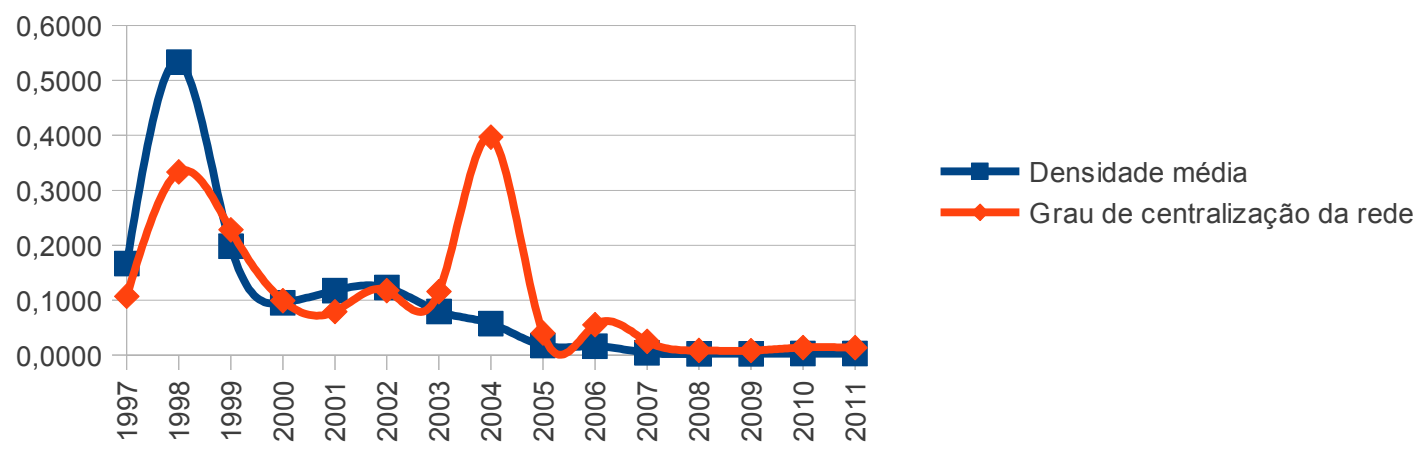

Figura 7.12. Curvas de densidade média e grau de centralização - Modo ano-a-ano - Revistas Científicas.

Densidade média e grau de centralização: modo acumulado

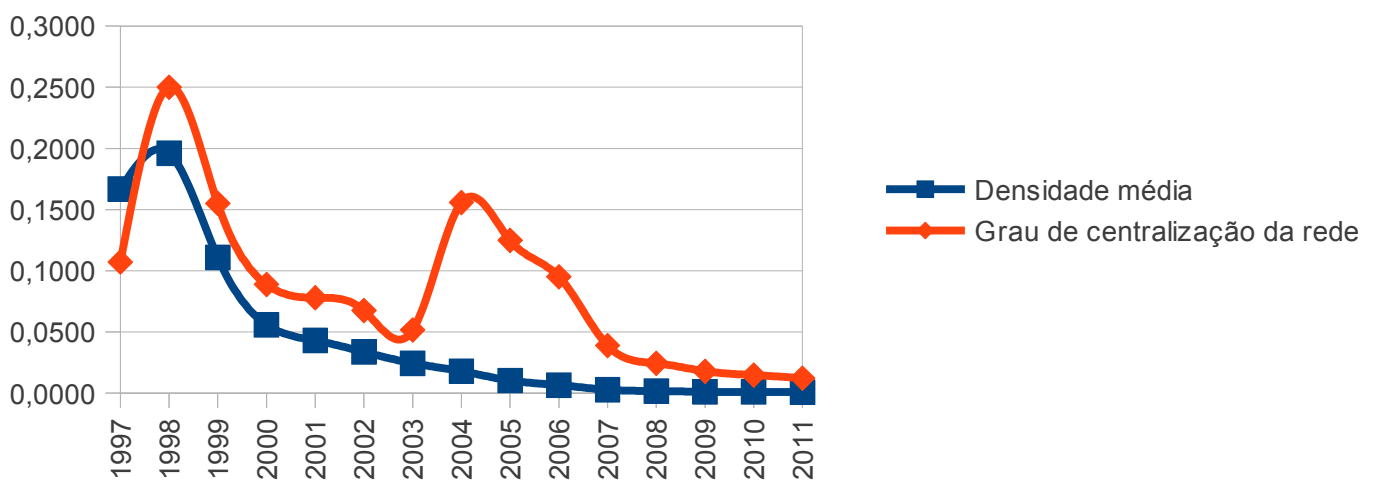

Figura 7.13. Curvas de densidade média e grau de centralização - Modo acumulado - Revistas Científicas.

A densidade média, nos dois gráficos, apresenta valores mais altos no início e vai se atenuando até atingir valores bem próximos de zero ao final do período. Esse tipo de comportamento já é esperado no processo evolutivo de uma rede, dado que a densidade é uma razão entre todas as conexões estabelecidas numa rede e todas as conexões que potencialmente poderiam ser feitas. Logo, quanto mais uma rede cresce em termos de nós presentes, se esses nós apenas 
executarem algumas poucas conexões na rede, que é o que ocorre em nosso caso quando sabemos que apenas $25 \%$ dos artigos publicados na área são em coautoria conforme apresentado na seção 7.1 deste capítulo, a densidade tende a decair rapidamente.

Já para a curva de grau de centralização observamos um fenômeno parecido até o ano de 2004, quando ocorre um pico no grau, que é visível tanto na figura 7.12 quanto na figura 7.13, levando a entendermos que nesse momento houve algum evento na dinâmica da rede social que a tornou mais centralizada em torno de alguns nós. Vale lembrar que o grau de centralização mede o quanto uma rede é centralizada, ou seja, quanto maior o grau mais há na rede alguns nós que possuem muitas conexões e outros com bem poucas conexões, em termos relativos. Novamente, de modo a entender o que estávamos visualizando nos gráficos acima apresentados geramos os sociogramas dos anos de 2003, 2004 e 2005, para melhor identificarmos as transições que estariam acontecendo nessas redes, dado que em 2005 o grau de centralização cai abruptamente. Vejamos essas imagens nas figuras 7.14, 7.15 e 7.16 .

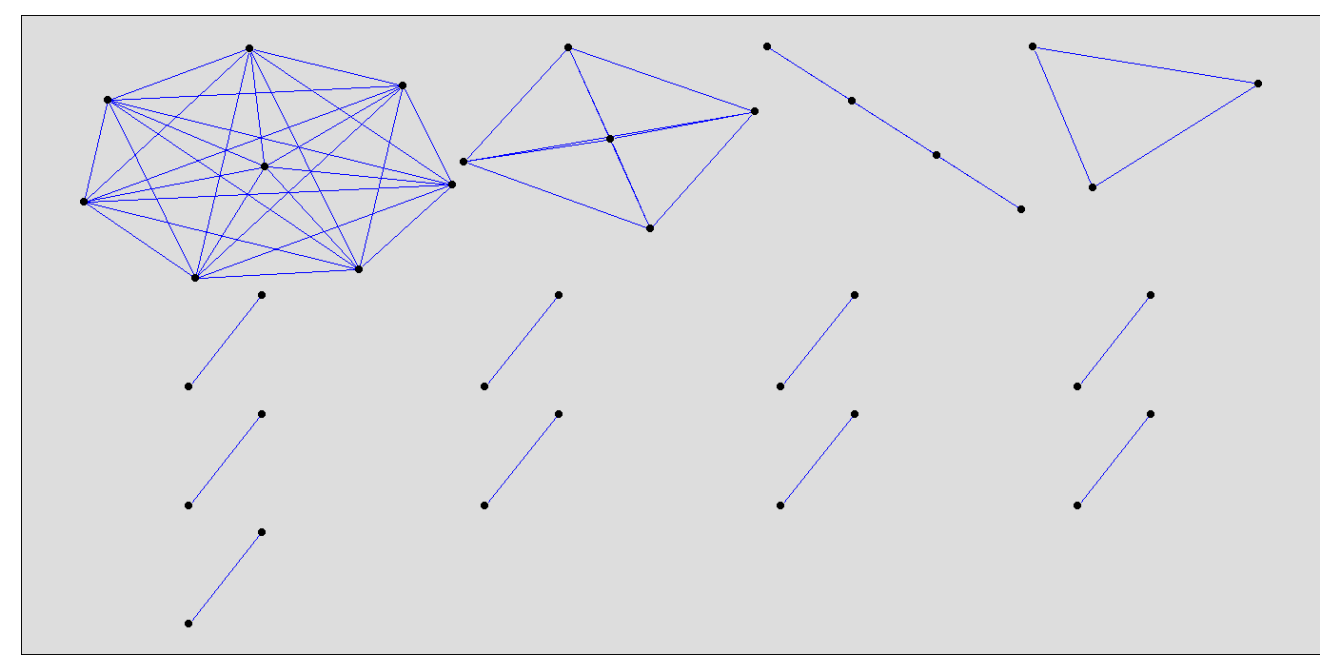

Figura 7.14. Sociograma da rede de coautoria no ano de 2003 - Modo ano-a-ano - Revistas Científicas.

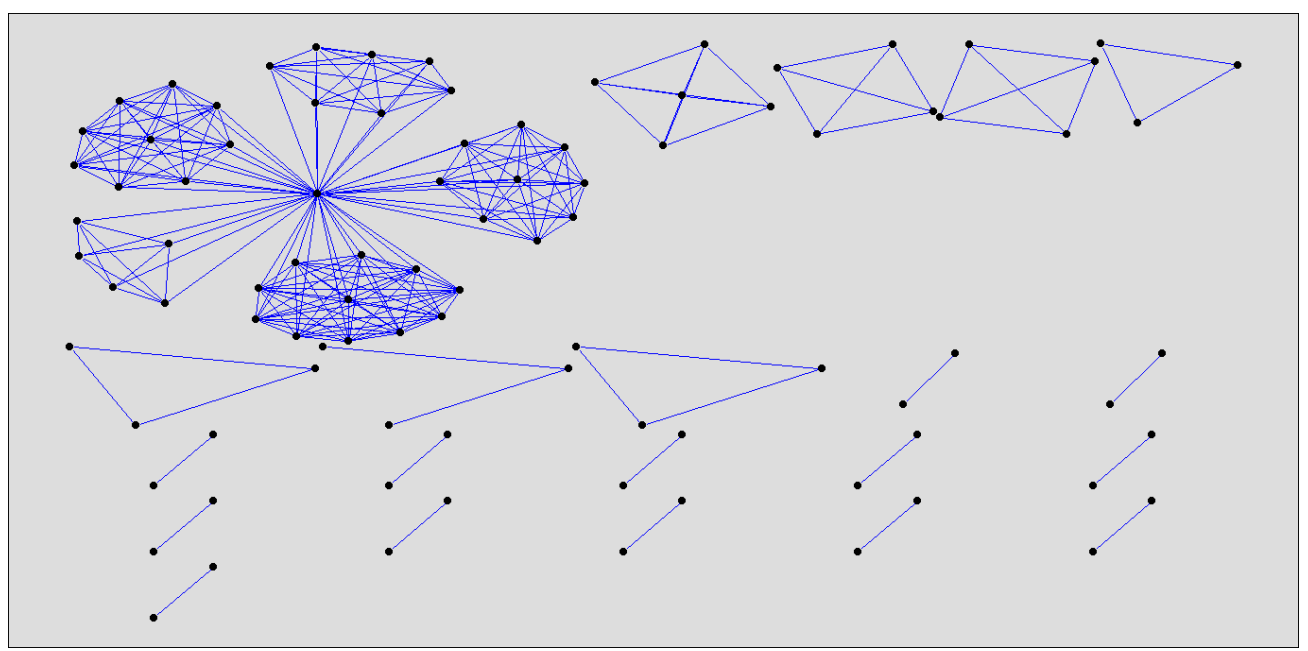

Figura 7.15. Sociograma da rede de coautoria no ano de 2004 - Modo ano-a-ano - Revistas Científicas. 


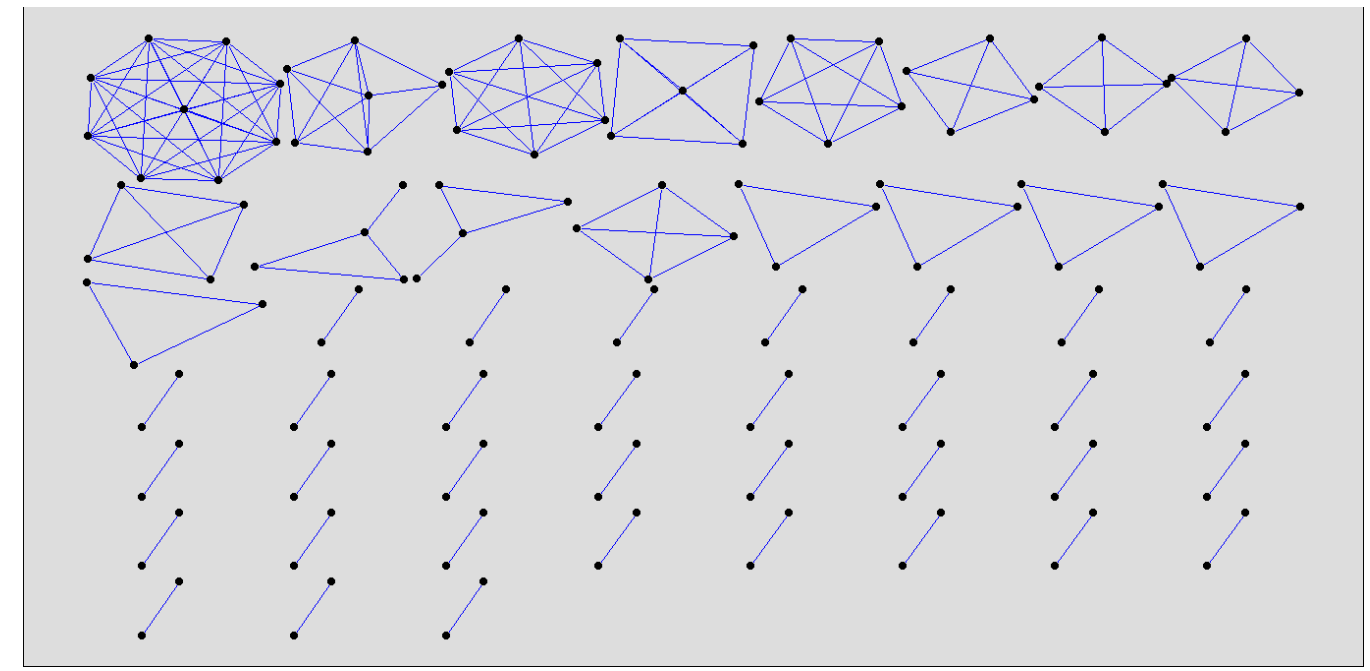

Figura 7.16. Sociograma da rede de coautoria no ano de 2005 - Modo ano-a-ano - Revistas Científicas.

Observando as figuras acima, notamos que o que de fato ocorre no ano de 2004 é a entrada de um autor que publica 5 artigos com um grande número de coautores, sendo o menor com outros 5 autores e o maior com outros 12 autores, o que pode ser percebido pelo maior componente no alto a esquerda na figura 7.15. Esse padrão de publicação não está presente na dinâmica da rede nos anos de 2003 e 2005, o que faz com que o grau de centralização seja bem diferente nesses dois anos. Investigando em nossa base de dados, percebemos que essa entrada se dá por um autor na revista Ciências \& Cognição, umas das revistas ligadas a área da Saúde.

O que percebemos é que esse tipo de entrada muda a dinâmica da rede social, evidenciando um fenômeno de maior concentração das conexões estabelecidas entre os nós, como o indicador do grau de centralização nos leva a observar. Na figura 7.13, o que vemos no gráfico acumulado é que esse grau de centralização vai se atenuando ao longo dos anos, dado que esse fenômeno parece não se repetir com a mesma intensidade na dinâmica da rede social, pois há a cada ano mais nós em termos absolutos, o que vai reduzindo a influência desse tipo de entrada na rede no seu grau de centralização.

\subsubsection{Componentes}

Apresentamos nas figuras 7.17, 7.18 e 7.19, a seguir, as curvas que mostram a evolução do número de componentes e do maior e segundo maior componentes na rede social de coautoria em revistas científicas. 
Componentes: modo ano-a-ano

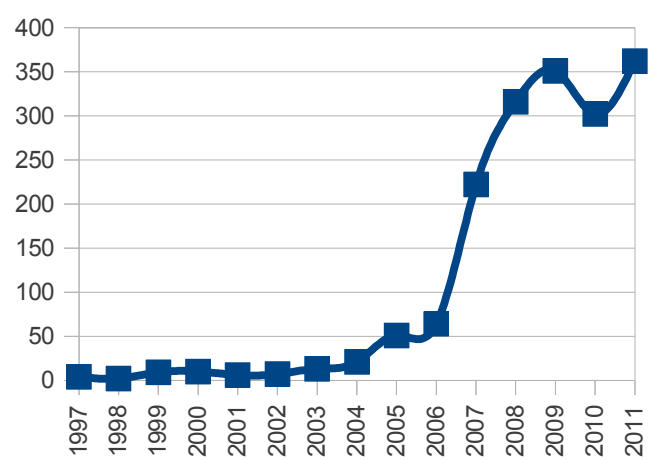

Figura 7.17. Evolução dos componentes - Modo ano-a-ano
Maior e segundo maior componente: modo ano-a-ano

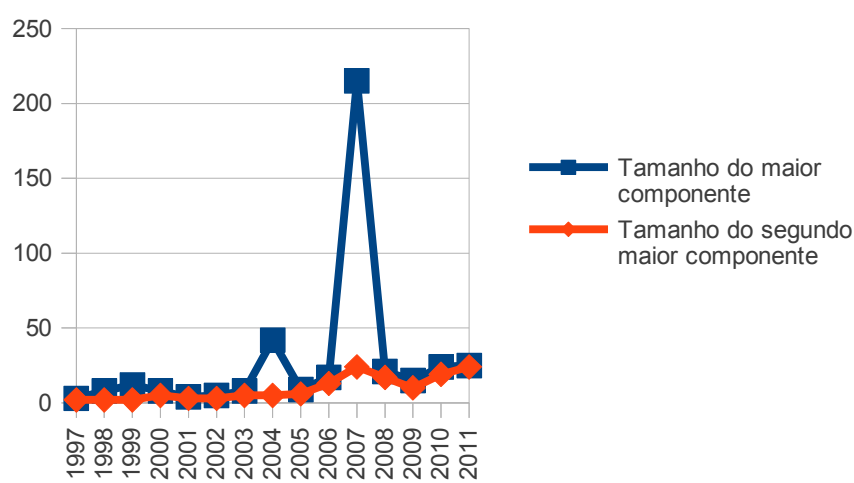

Figura 7.18. Maior e segundo maior componente - Modo ano-a-ano

Componentes

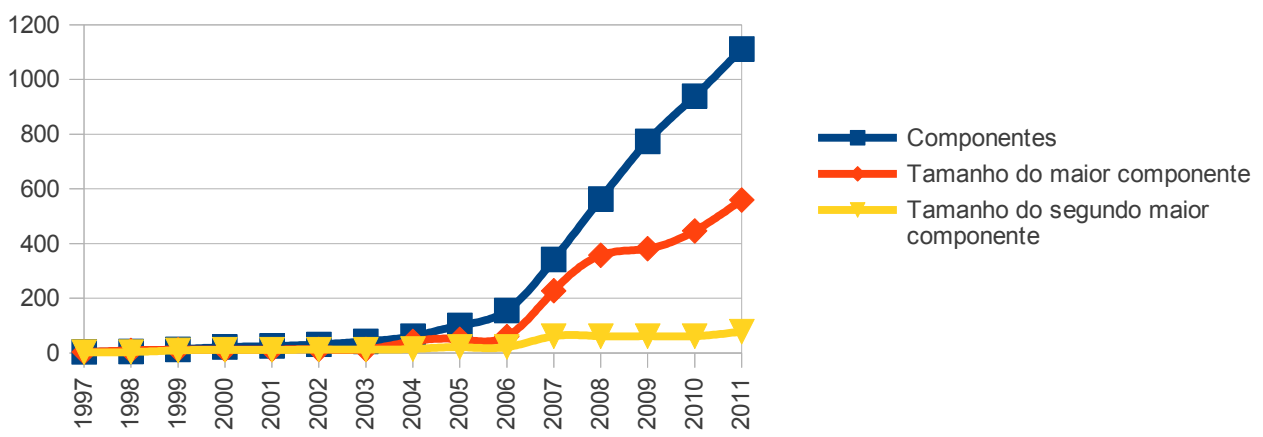

Figura 7.19. Evolução dos componentes, maior e segundo maior componente - Modo acumulado.

$\mathrm{Na}$ figura 7.17, observamos um crescimento no número de componentes que parece acompanhar o crescimento no número de documentos publicados, conforme apresentado na seção 7.1 deste capítulo. Essa informação nos revela um comportamento importante na dinâmica da rede social e que merece nos atentarmos com cuidado em sua interpretação. O crescimento ano-a-ano da rede indica que ela não cresce apenas em número de nós e links, mas também cresce em termos do número de componentes presentes na rede. Esse fato indica que vários novos componentes, elementos isolados, fragmentados na rede, vão chegando a cada ano, ou seja, não há na dinâmica dessa rede um grande componente de autores que vai se formando e passa a escrever juntos a cada ano, o que também pode ser confirmado da figura 7.18. Na figura 7.18, observamos que há dois picos expressivos no tamanho do maior componente em relação ao segundo maior componente, que são respectivamente nos anos de 2004 e 2007. Esses picos são relativos aos eventos que já foram mencionados neste capítulo, onde identificamos a chegada de um grande componente atrasado na 
rede no ano de 2007 advindo da revista Comunicação \& Educação e a articulação que ocorre entre vários autores e um autor central no ano de 2004 advindo da revista Ciências \& Cognição. Esses dois eventos demarcam a chegada de um grande componente na rede em seus anos.

Quando observamos a tabela 7.1 na seção 7.1 deste capítulo, onde apresentamos a distribuição de faixas de coautoria que ocorrem na rede de revistas científicas, percebemos que os gráficos de componentes traduzem a mesma informação no processo dinâmico de evolução da rede social. As parcerias entre autores são feitas de modo minoritário e fragmentado, favorecendo que quanto mais autores cheguem na rede eles continuem chegando de modo isolado, ou seja, aumentando o número de componentes que podem ser observados.

Observando a figura 7.19, o número de componentes cresce a uma taxa constante na rede em modo acumulado. O tamanho do maior componente cresce a uma taxa menor, mas apresenta um crescimento contínuo. Isso nos indica que observando a rede acumulada em sua dinâmica, há uma tendência de que um conjunto de nós ampliem seu horizonte de parcerias ao longo do tempo, formando mais conexões acumuladas que levam a constituição de um maior componente com cerca de 600 (6,22\% do total) participantes acumulados no ano de 2011. Ao que tudo indica, esses nós formam a estrutura central da rede de coautoria em análise, onde há um caminho de conexão que pode levar de qualquer nó até outro por intermediação de outras relações estabelecidas em coautoria. Sem dúvida, esse é um espaço privilegiado de articulação, do ponto de vista da estrutural da rede social aqui apontada. No entanto, a presente demonstra que estamos visualizando uma área que não se articula, trabalhando de forma bastante isolada.

De forma a visualizarmos melhor como ocorre esse processo dinâmico de formação da rede e quais elementos fundamentam essa formação, fizemos um cruzamento entre a curva de crescimento dos programas de pós-graduação, do número de revistas ativas e do número de componentes a cada ano. Vejamos na figura 7.20.

\section{Relação componentes, revistas e programas}

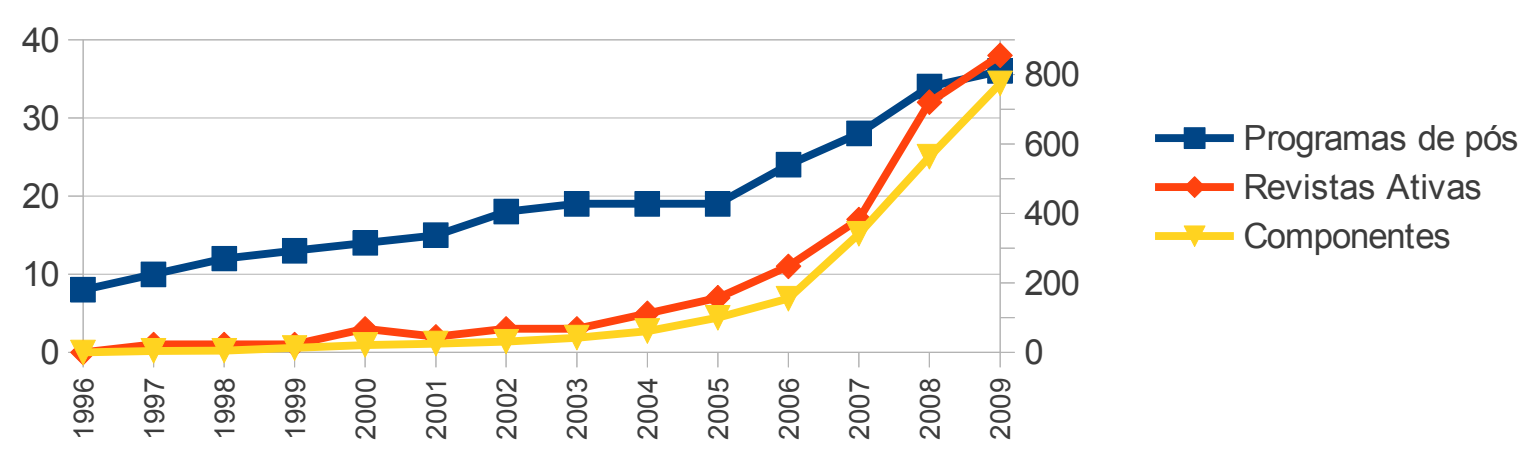

Figura 7.20. Relação entre componentes, revistas e programas de pós-graduação. 
Notamos que a curva de crescimento de componentes, orientada no eixo secundário do gráfico, tem praticamente o mesmo padrão de crescimento da curva de revistas ativas, orientada no eixo primário. A curva dos programas de pós, também orientada no eixo primário, começa com valores maiores que a curva de revistas ativas, sendo que estas se encontram ao final de nosso período de análise. Inferimos dois movimentos importantes de destacarmos: o número de componentes na rede parece crescer em conjunto com o número de revistas ativas, levando a termos como hipótese, que a cada nova revista ativa novos grupos de articulação locais são inseridos na rede e que o crescimento do número de programas de pós, ao também impulsionar a formação de novas revistas, é em parte responsável pela inserção desses novos grupos locais na rede. O movimento dinâmico de formação dessa rede, ao que tudo vem indicando, responde diretamente aos movimentos de promoção da política científica da área, sobretudo na abertura de novos cursos e espaços de publicação científica, servindo como pontos de apoio para a inserção de novos grupos de pesquisadores a própria rede.

De modo a visualizarmos essa estrutura de componentes da rede social, apresentamos na figura 7.21 um sociograma da rede acumulada no ano de 2011. Observamos que os 600 nós que mencionamos no parágrafo anterior compõem o componente central com o maior número de conexões entre si no centro de nossa imagem.

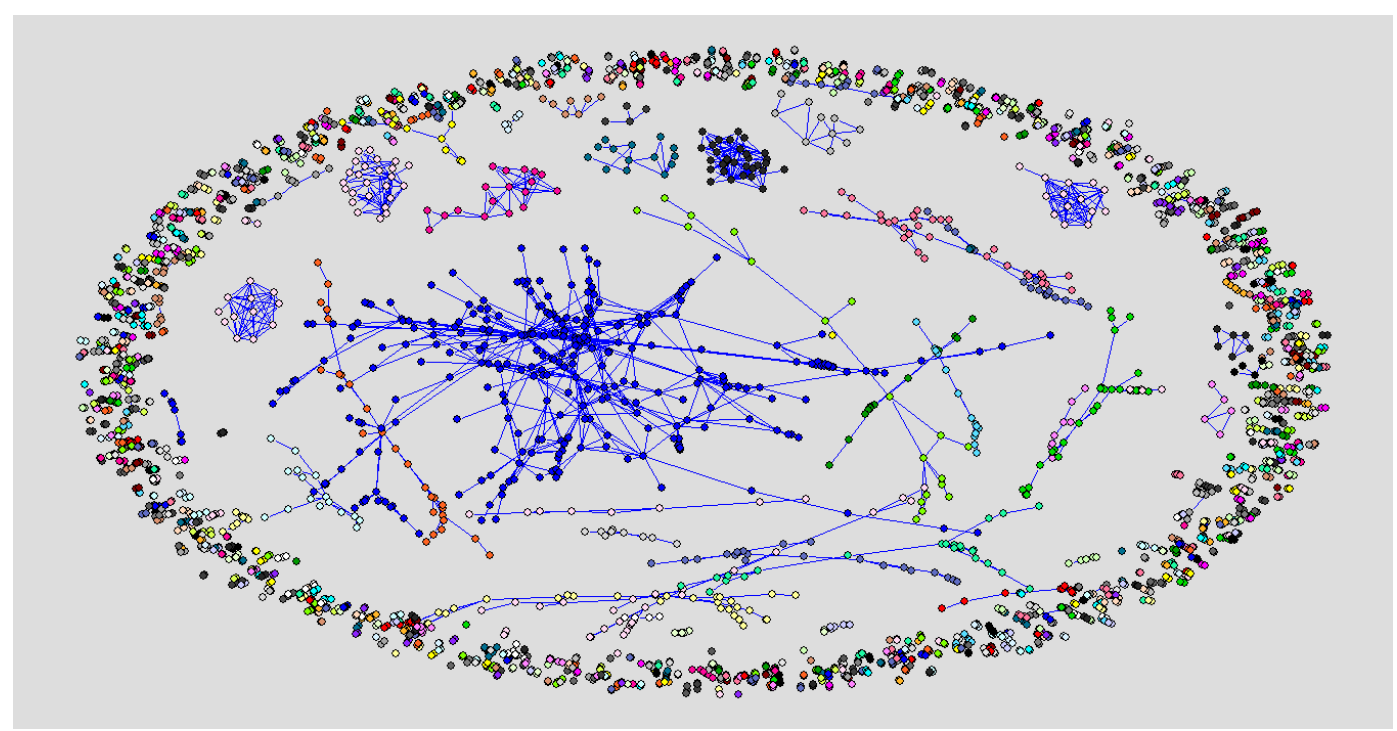

Figura 7.21. Componentes - modo acumulado - Rede de revistas científicas.

Observamos na figura 7.21 outros componentes menores envolta do componente central e no anel que circula toda a imagem, diversos componentes menores constituídos por relações menores de 2, 3, 4 ou mais autores que demarcam eventos de colaboração único desses autores ao longo do todo o período de análise de nossa base de dados. Esses componentes representam 
relações de coautoria que foram estabelecidas em torno da publicação de um ou dois artigos em nossas revistas analisadas, sendo que após essa publicação esses autores não mais participaram de nenhuma outra revista científica aqui analisada. Para ilustrar isso de outra forma, que pode facilitar percebermos o que afirmamos anteriormente, vejamos a mesma rede apresentada na figura 7.21, porém em outra configuração que deixa mais evidente o modo de organização de seus componentes na figura 7.22 .

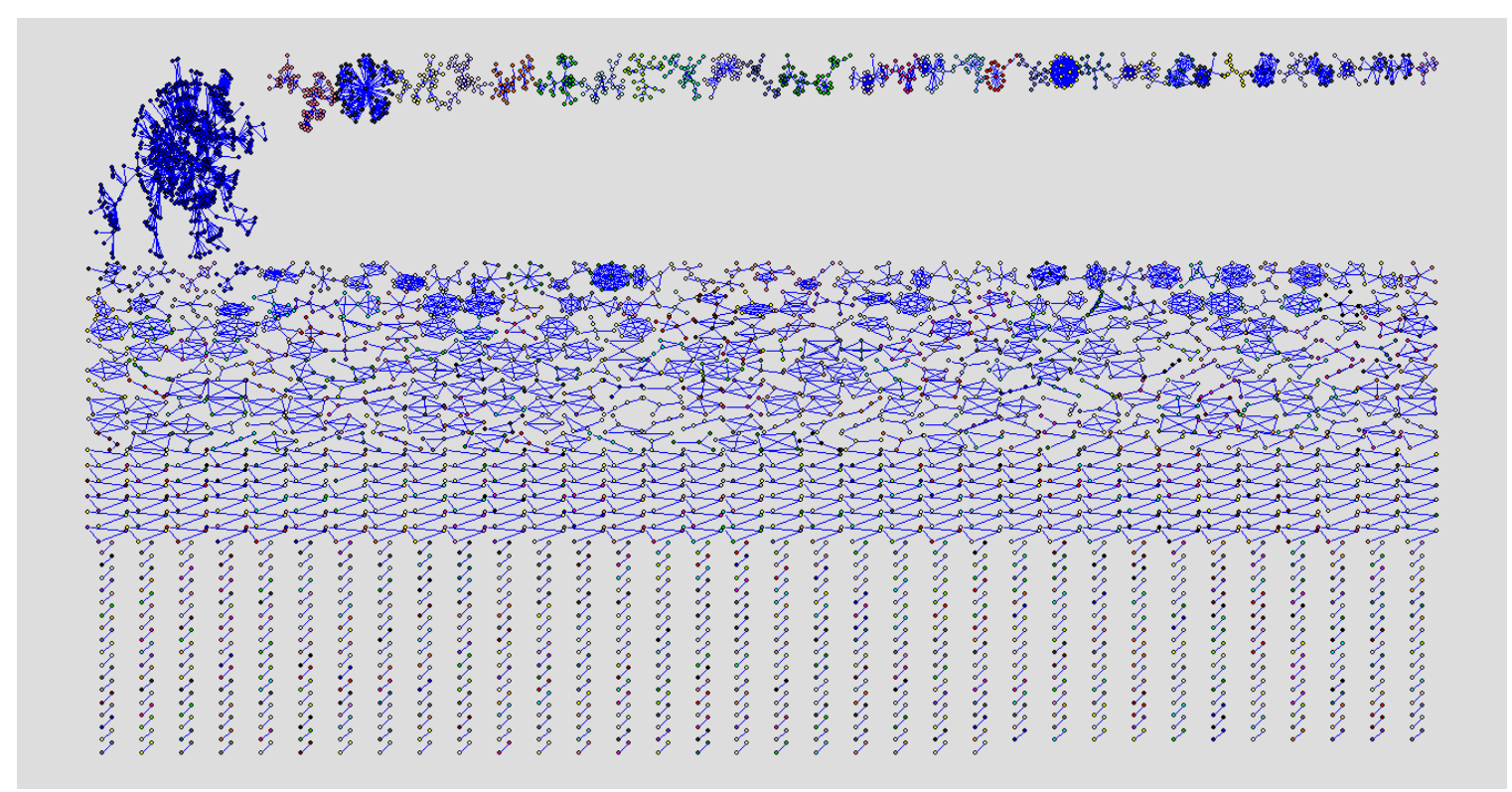

Figura 7.22. Componentes - modo acumulado - Rede de revistas científicas.

$\mathrm{Na}$ base da figura 7.22, vemos todos os componentes formados por uma relação de coautoria entre dois autores, sendo que essas relações vão aumentando para três, quatro até chegarmos no maior componente na rede, no alto a esquerda da imagem, com em torno de 600 membros. Essa estrutura deixa evidente como a rede se organiza ao longo do tempo, tendo um componente central de maior relevância em termos de nós e links, e outros componentes menores que se articulam de maneira isolada, além de diversos componentes que aparecem na rede apenas uma única vez, não retornando mais.

Essa estratégia aqui relatada, na forma como as relações são estabelecidas entre os pesquisadores, parece ter relação com o aumento de documentos e no número de programas de pós-graduação na área. De fato, podemos estar aqui observando o modo como novos pesquisadores estão chegando e constituindo sua dinâmica de relações na rede aqui observada, formando novos componentes e publicando artigos em novas revistas científicas que vão sendo criadas por seus programas de pós-graduação.

Para observarmos como ocorre essa distribuição dinâmica dos nós em relação ao maior componente, analisamos o percentual de nós que fazem parte do maior componente na rede ao 
longo do tempo. Vejamos essa distribuição nas figuras 7.23 e 7.24.

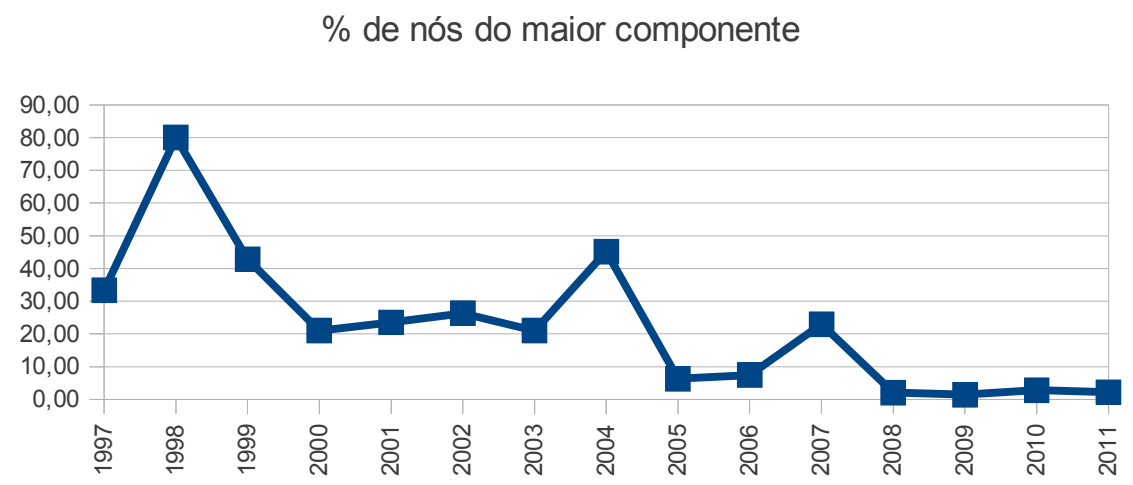

Figura 7.23. Percentual de nós no maior componente - modo ano-a-ano - Rede de revistas científicas.

$\%$ do maior componente

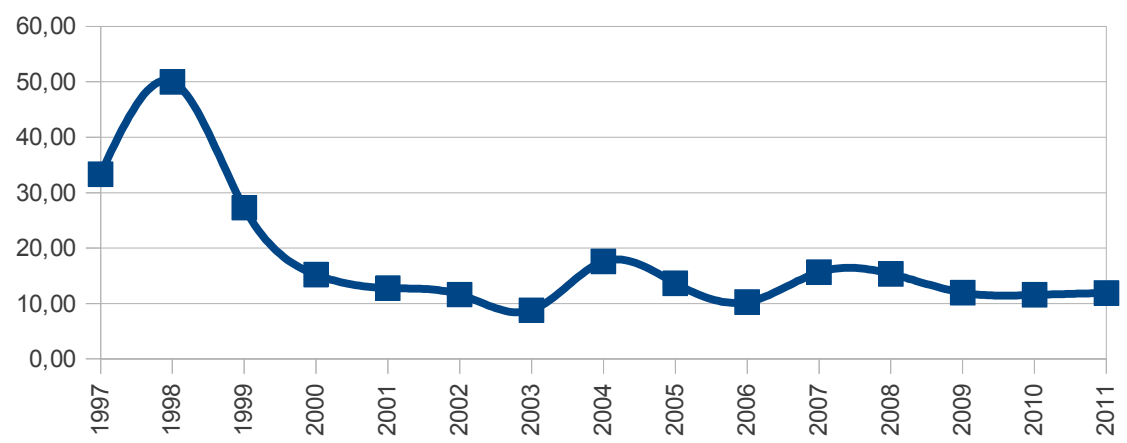

Figura 7.24. Percentual de nós no maior componente - modo acumulado - Rede de revistas científicas.

Observando a figura 7.23, percebemos que a exceção do segundo ano da rede em 1998, quando temos $80 \%$ dos nós no maior componente, porém em torno de 2 componentes na rede, temos apenas dois picos nos anos 2004 e 2007, causados pelos mesmos eventos já relatados anteriormente neste capítulo. O que nos chama atenção é o fato de termos um valor em torno de $2 \%$ a 3\% dos nós no maior componente a partir do ano de 2008 até 2011. Isso indica que a dinâmica da rede nesses últimos anos evidencia menos articulação entre os pesquisadores de modo em geral, havendo uma dispersão entre as relações de coautoria em diferentes componentes. Como temos nesse período sempre mais de 30 revistas ativas publicando conteúdo e menos de 17 revistas de 2007 para trás, conforme apresentado na figura 7.2 na seção 7.1 deste capítulo, observamos que essa redução no número de componentes tem relação com a dispersão dos pesquisadores em diferentes fontes de informação disponíveis no momento de escolha de para onde direcionar seu conteúdo de publicação. Mais programas de pós-graduação, mais pesquisadores publicando, mais 
revistas científicas disponíveis para publicação, baixa taxa de colaboração, logo mais dispersão dos pesquisadores em torno de menores componentes, resultando em um componente central de expressão insignificante de 2008 em diante.

Já na figura 7.24, notamos o mesmo fenômeno, porém uma certa tendência do ano de 2003 em diante do número de nós presentes no maior componente estar oscilando em torno do valor de 10\%, com alguns momentos maior. Analisando em conjunto essa informação com a figura 7.19, anteriormente apresentada, percebemos que o componente principal cresce a uma taxa constante na rede em modo acumulado, mostrando a dinâmica pela qual esses pesquisadores estão se articulando, não mostrando ampliação significativa na colaboração entre os pesquisadores.

\subsubsection{Grau de conectividade médio}

Apresentamos nas figuras 7.25 e 7.26 a dinâmica do grau de conectividade médio para a rede de coautoria nas revistas científicas. Vale lembrar que o grau de conectividade médio indica a média do número de conexões relativa a todos os nós presentes na rede.

\section{Grau de conectividade médio}

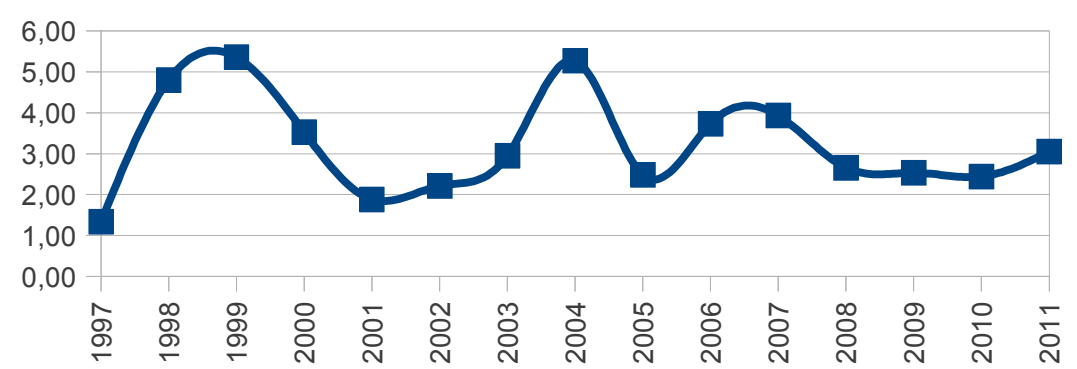

Figura 7.25. Grau de conectividade médio - modo ano-a-ano - Rede de revistas científicas.

\section{Grau de conectividade médio}

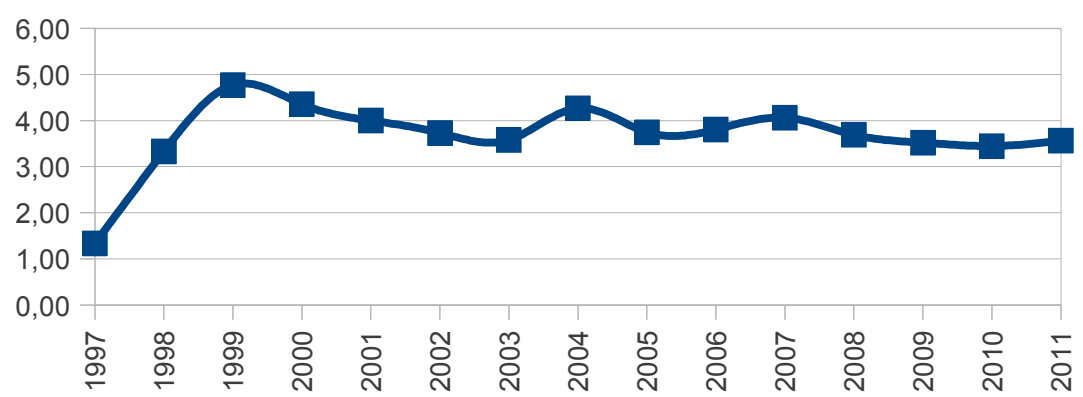

Figura 7.26. Grau de conectividade médio - modo acumulado - Rede de revistas científicas.

Observamos na figura 7.25 que o grau oscila porém dentro de limites que variam de 2 até 
aproximadamente 6, tendendo a se estabilizar nos últimos anos em torno de 3. Já na figura 7.26, observamos uma variação menor, tendendo o grau médio a se estabilizar em torno de 4 . Na figura 7.22, apresentada anteriormente, notamos a quantidade pequena de componentes que fazem parte da rede social e que vão se acumulando ao longo do tempo, levando a uma distribuição de grau de conectividade como observamos aqui. Vale mencionar na figura 7.25, que o pico observado no ano de 2004 é relativo ao fenômeno já mencionado anteriormente, quando da chegada de um autor com muitas conexões simultâneas, o que tende a aumentar sensivelmente o grau médio.

\subsubsection{Maior e menor grau de conectividade}

Apresentamos nas figuras 7.27 e 7.28 a evolução do maior grau de conectividade. Vale lembrar que o maior grau de conectividade representa o número máximo de conexões que um mesmo nó estabeleceu na rede. Não apresentamos um gráfico do menor grau de conectividade, pois ele se manteve no valor 1 para todo o período de análise de nossa base de dados.

Maior grau de conectividade: modo ano-a-ano

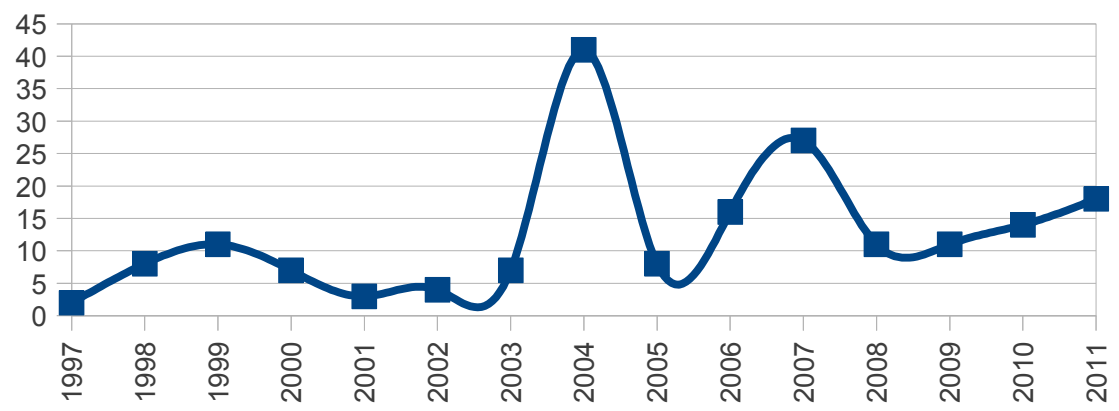

Figura 7.27. Maior grau de conectividade - modo ano-a-ano - Rede de revistas científicas.

Maior grau de conectividade: modo acumulado

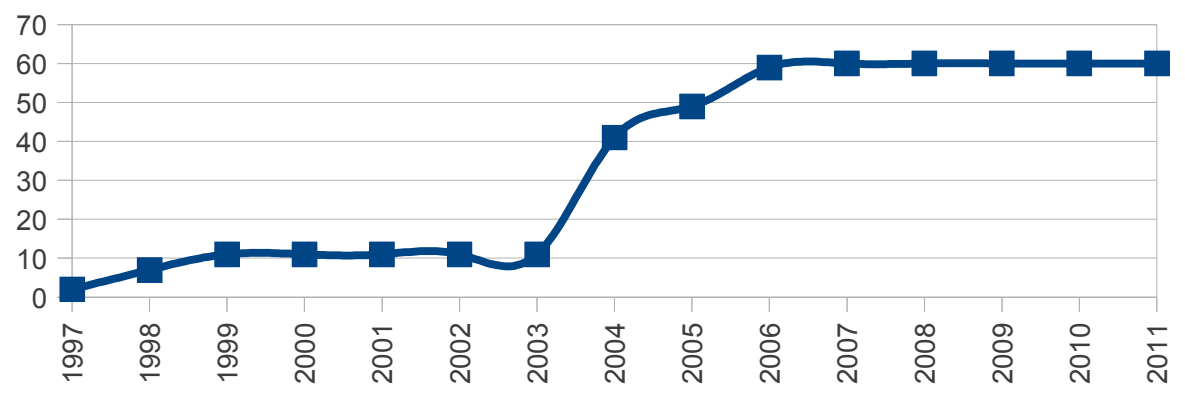

Figura 7.28. Maior grau de conectividade - modo acumulado - Rede de revistas científicas.

Notamos na figura 7.27, os dois picos que já tem sido característicos de nosso gráficos, 
representando os eventos já mencionados nos anos de 2004 e 2007. Em 2004, observamos que a entrada do autor altamente central eleva o número da maior conexão para em torno de 40, mostrando o número máximo de pessoas que esse autor se conectou naquela ocasião. Já em 2007, com a entrada retardada dos artigos da revista Comunicação \& Educação, notamos que o maior grau de conectividade salta para um valor em torno de 27, mostrando que ao longo de 1994 até 2007 dos autores que publicaram na revista houve um máximo de 27 conexões estabelecidas por um mesmo autor com outros colaboradores. Afora esses eventos pontuais, notamos um crescimento do maior grau de 2008 para 2011, saltando para em torno de 10 para 20, o que também é condizente com o aumento de relações de coautoria em nossa rede, conforme apresentado na figura 7.6 da seção 7.1 deste capítulo. O aumento nas relações de coautoria parece ser também acompanhado em um aumento no número máximo de conexões que alguns nós isoladamente estabelecem entre si na rede, tendo por consequência autores individuais com maior nível de conectividade.

Já na figura 7.28, nos chama atenção para uma certa tendência de estabilização em torno do número 60 do maior grau de conectividade da rede em modo acumulado. Podemos interpretar esse fato como um certo limite na dinâmica da rede social aqui analisada, onde temos que não houve nenhum nó que se conectou com mais de 60 pessoas durante todo o período de 1997 até 2011 . Não temos evidências aqui para afirmar que esse limite representa um limite no número de pessoas máximo com que um pesquisador parece colaborar em termos de produção científica em sua carreira na área da Comunicação, mas é um limite interessante de pontuar a partir de nossos dados.

\subsubsection{Distância geodésica}

Apresentamos nas figuras 7.29 e 7.30 a dinâmica da distância geodésica para nossa rede social de revistas científicas. Vale lembrar que a distância representa o número máximo de nós que existem entre dois nós em um determinado componente.

\section{Distância geodésica: modo ano-a-ano}

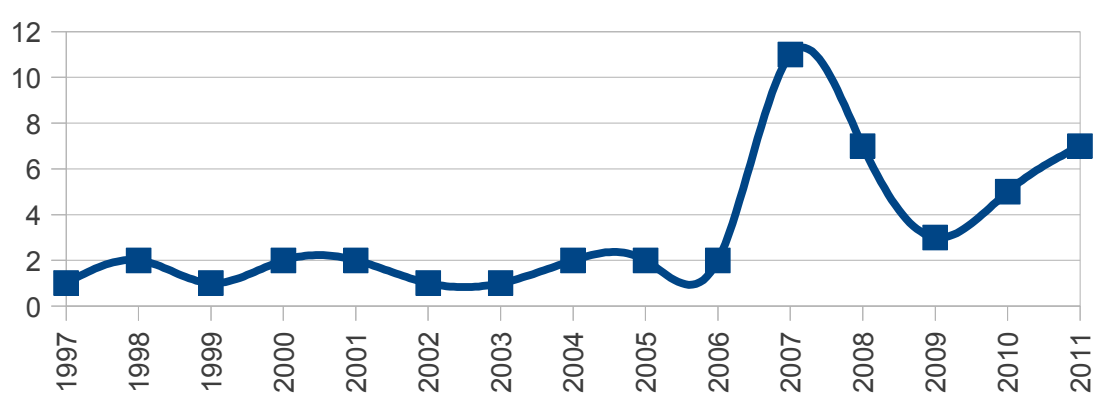

Figura 7.29. Distância geodésica - modo ano-a-ano - Rede de revistas científicas. 


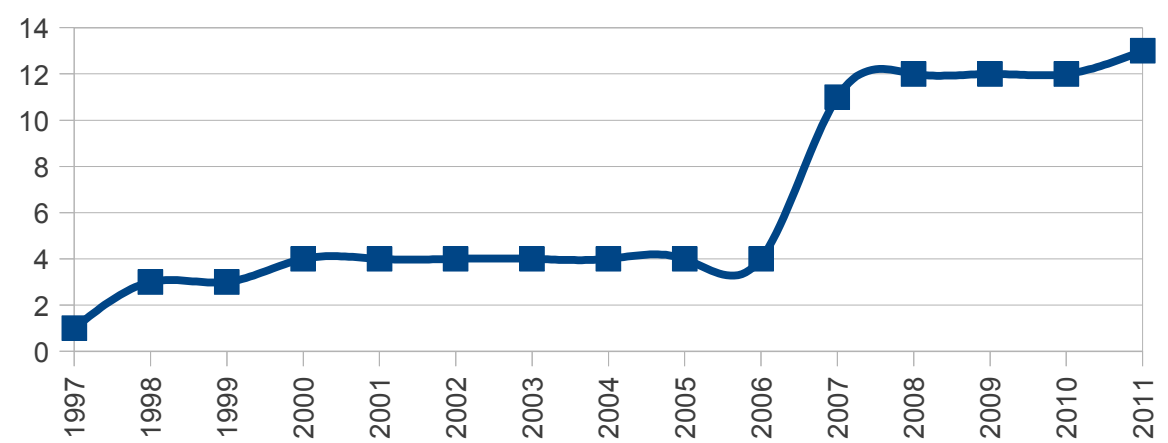

Figura 7.30. Distância geodésica - modo acumulado - Rede de revistas científicas.

Observamos na figura 7.29 um pico na distância geodésica, que se aproxima do valor 12, no ano de 2007. Esse fato se deve a entrada retardada de um grande componente na rede de uma só vez, trazendo relações que foram estabelecidas ao longo de anos como presentes na rede apenas de um ano para o outro. Esse valor observado representa um acúmulo de relações e não uma distância gerada no ano de 2007 entre dois nós na rede.

Já na figura 7.30, observamos que esse valor acumulado não presente na rede gera um salto em 2007, ficando estável desde então, tendo um pequeno aumento de 2010 para 2011. O que notamos é novamente uma certa tendência de estarmos diante de um limite no número máximo da distância geodésica entre dois nós em nossa rede. Esse é um fato esperado, dado que a estabilização denota o padrão estrutural de uma rede "mundo pequeno", como apresentamos na seção 2.5.2 do capítulo 2 desta tese.

\subsubsection{Coeficiente de clusterização}

O coeficiente de clusterização é um indicador que avalia a probabilidade média de que dois nós que são vizinhos de um mesmo nó se tornem conectados em algum momento. $\mathrm{O}$ coeficiente indica a transitividade de relações que existem em uma rede, ou seja, o fato de que duas pessoas que se articulam com uma pessoa em comum tem maior ou menor chance de transferir essa relação direta entre essas duas pessoas. Logo, se tivermos uma rede onde temos apenas dois nós e esses dois nós já estiverem conectados entre si, essa transitividade será de 100\%. Usaremos esse parâmetro de referência para nossas análises logo a seguir. Apresentamos alguns valores de referência em nossa revisão bibliográfica, na tabela 3.2 da seção 3.7 do capítulo 3 desta tese. Ali, observamos valores que variam de $6,6 \%$ até $72 \%$ de probabilidade média de que essas relações ocorram, sendo o maior 
valor para a rede de coautoria de físicos de alta energia e o menor valor para uma rede de coautores em biomedicina. Apresentamos nas figuras 7.31 e 7.32 a dinâmica do coeficiente de clusterização para nossa rede de coautoria em revistas científicas para a área de Ciências da Comunicação.

\section{Coeficiente de clusterização: modo ano-a-ano}

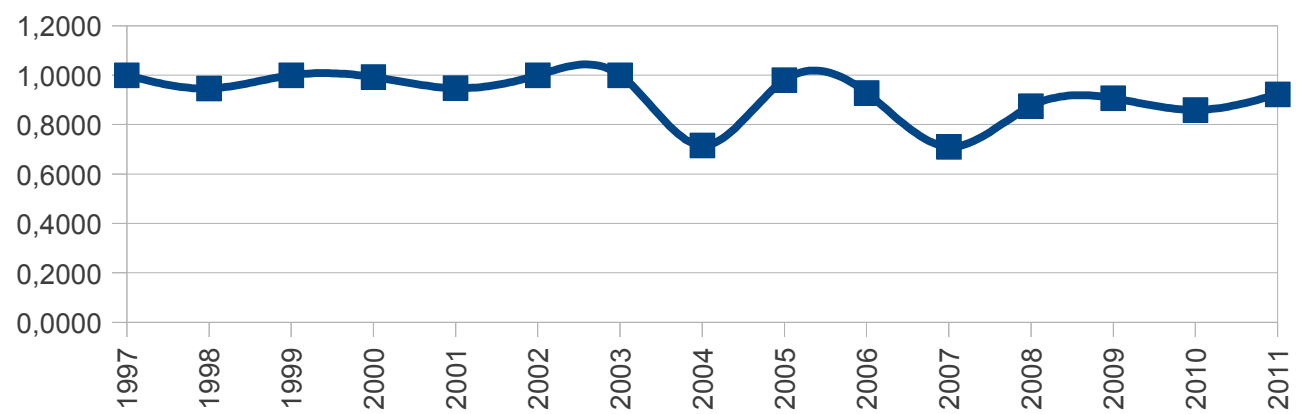

Figura 7.31. Coeficiente de clusterização - modo ano-a-ano - Rede de revistas científicas.

Coeficiente de clusterização: modo acumulado

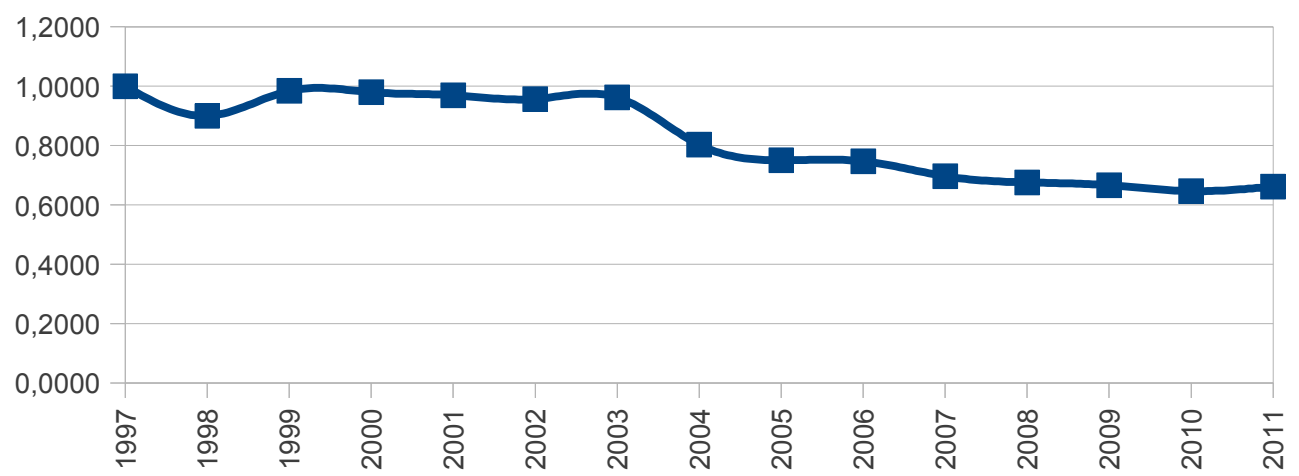

Figura 7.32. Coeficiente de clusterização - modo acumulado - Rede de revistas científicas.

Observando a figura 7.31, o coeficiente é em torno de $100 \%$, apresentando quedas apenas no ano de 2004 e 2007, tendo uma pequena redução de 2008 em diante. O mesmo parece acontecer o gráfico da figura 7.32, onde analisamos o coeficiente na rede em modo acumulado. $\mathrm{O}$ coeficiente segue em torno de $100 \%$ até o ano de 2004, quando parece cair gradativamente a uma pequena taxa, chegando em torno de $60 \%$ em 2011. Aparentemente e analisando isoladamente esse indicador, poderíamos pensar que estamos diante de uma rede com alta taxa de transitividade entre os pesquisadores, ou seja, alto nível de articulação entre eles, fazendo com que as relações de coautoria sejam extremamente dinâmicas, onde um autor apresenta os autores com que se relacionou e eles passam a produzir em coautoria a partir desse momento. No entanto, é preciso observamos outros 
parâmetros da dinâmica dessa rede antes de chegarmos uma conclusão sobre o significado específico desses valores do coeficiente de clusterização.

Para fundamentar nossa análise, apresentamos a seguir como ocorre a distribuição dos nós em relação ao tamanho dos componentes que pertencem para os três últimos anos da rede em modo ano-a-ano na tabela 7.6.

\begin{tabular}{|c|c|c|c|}
\hline Componente & $\mathbf{2 0 0 9}$ & $\mathbf{2 0 1 0}$ & $\mathbf{2 0 1 1}$ \\
\hline 2 & $55,84 \%$ & $63,91 \%$ & $57,73 \%$ \\
\hline 3 & $23,36 \%$ & $19,21 \%$ & $22,38 \%$ \\
\hline 4 & $8,55 \%$ & $8,61 \%$ & $7,46 \%$ \\
\hline Total & $\mathbf{8 7 , 7 5 \%}$ & $\mathbf{9 1 , 7 2} \%$ & $\mathbf{8 7 , 5 7 \%}$ \\
\hline
\end{tabular}

Tabela 7.6. Distribuição de nós por faixa de componentes - 2009, 2010 e 2011 - rede modo ano-a-ano - Revistas científicas.

Ao observamos os resultados da tabela 7.6 e também aqueles apresentados pela tabela 7.1 da seção 7.1 deste capítulo, que apresenta a distribuição de documentos por faixa de coautoria, podemos afirmar um mínimo de autores que participa de componentes com mais de 5 outros autores em conexão. Na tabela 7.1 da seção 7.1 deste capítulo, temos que mais de $80 \%$ dos nós participantes da rede em modo ano-a-ano faz parte de componentes até no máximo 4 nós em relação. Se considerarmos que essas relações ano-a-ano explicitam relações de coautoria que ocorreram naquele mesmo ano, temos que a maioria desses nós já se encontram conectados entre si.

O modo como os nós se distribuem em relação ao tamanho de seus componentes faz com que o coeficiente de clusterização apresente um alto valor, como observado nas figuras 7.31 e 7.32. No entanto, esse alto valor não se deve a uma grande capacidade de articulação da rede, mas sim pelo fato da rede ser composta de muitos pequenos componentes onde os nós já se encontram em sua maioria conectados entre si, ou seja, já chegam com alto grau de transitividade, porém de modo isolado em núcleos locais de relação.

$\mathrm{Na}$ figura 7.32, o coeficiente cai gradativamente a partir do ano de 2004 e com maior intensidade a partir de 2006. Essa queda tem relação, seguindo nosso raciocínio anteriormente apresentado, com o crescimento gradativo do maior componente na rede em modo acumulado, como apresentado na figura 7.19 anteriormente. Ao crescer o maior componente da rede, mais nós deixam de fazer parte de pequenos componentes e passam a estar em relação indireta com mais nós, o que faz com que o coeficiente de clusterização caia em seu valor, dado que agora esses nós possuem de fato mais relações para explorarem em termos de transitividade do que tinham quando alocados em pequenos componentes.

Vale ressaltar aqui que a análise da transitividade complementada pela análise dos 
componentes de uma rede nos permite visualizarmos importantes relações dinâmicas e estruturais no modo como a rede se organiza, considerando as principais estratégias de conectividade e formação de grupo de seus nós, evidenciando e reconfirmando esse crescimento fragmentado que temos apontado ao longo de nossa análise.

\subsubsection{Coeficiente de potência}

O coeficiente é o valor do expoente da lei potência apresentada na figura 2.25 da seção 2.6.2 do capítulo 2 desta tese. Esse valor indica o nível de centralidade de uma rede, mostrando o quanto os nós mais centrais podem estar próximos ou distantes em termos de número de conexões dos nós mais periféricos. Tipicamente, como apresentado na mesma seção, esse valor varia entre 2 e 3. Vale também lembrar, como apresentamos na seção 3.7 do capítulo 3, que o valor 2 em relação ao coeficiente de potência é um divisor entre dois comportamentos diferentes na estrutura das redes: abaixo de 2 a rede é dominada por poucos indivíduos que possuem um número muito grande de colaboradores, sendo que para expoentes acima de 2, a rede é dominada por muitos grupos com poucos colaboradores.

Para termos curvas mais precisas do ponto de vista de uma distribuição exponencial e calcular seu expoente, utilizamos em nossa análise apenas os valores da rede em modo acumulado a partir do ano de 2006, que é quando passamos a ter mais de 1000 nós presentes na rede. Apresentamos na figura 7.33 a curva do coeficiente de potência.

\section{Coeficiente de potência: modo acumulado}

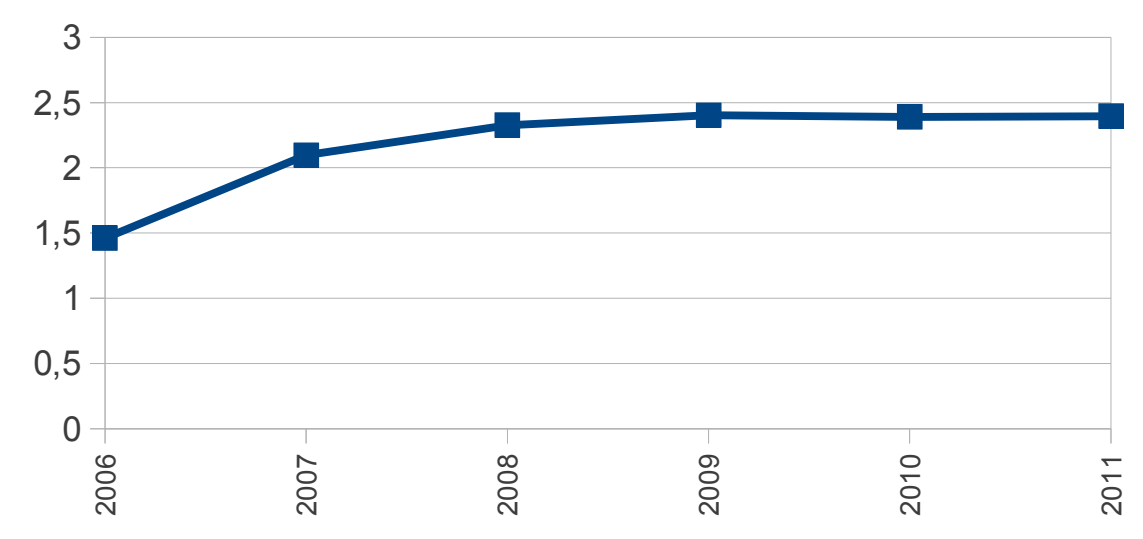

Figura 7.33. Coeficiente de potência - modo acumulado - Rede de revistas científicas.

Observamos que os valores tendem ao longo do tempo para 2,5. Conforme nossa análise de componentes acima apresentada também nos auxilia a confirmar, o valor de nosso coeficiente 
estando em torno de 2,5 demonstra o efeito de dispersão da rede, ou seja, sendo ela dominada por muitos grupos dispersos com poucos colaboradores cada um. Novamente, esse valor confirma uma visão de crescimento fragmentado em pequenos grupos locais dominados por nós com alto grau de centralidade.

\subsubsection{Evolução do grafo}

Como meio de facilitarmos a compreensão da dinâmica de evolução de uma rede social e ampliarmos nossa percepção de como esses movimentos de rede acontecem, construímos um vídeo que apresenta uma animação gráfica de como evoluiu no tempo a rede de coautoria em modo ano-aano. Esse vídeo se encontra disponível no canal Youtube do autor desta tese e pode ser acessado pelo link: http://www.youtube.com/watch?v=SreT0qs7pQ0. Para a melhor compreensão do vídeo, é importante considerar que a cada ano estão presentes apenas os nós que publicaram um conteúdo naquele ano e que na transição de um ano para o outro, ficam apenas os nós que estavam no ano anterior, sendo que novas conexões podem ser visualizadas em verde e conexões que existiam e deixaram de existir são visualizadas em vermelho.

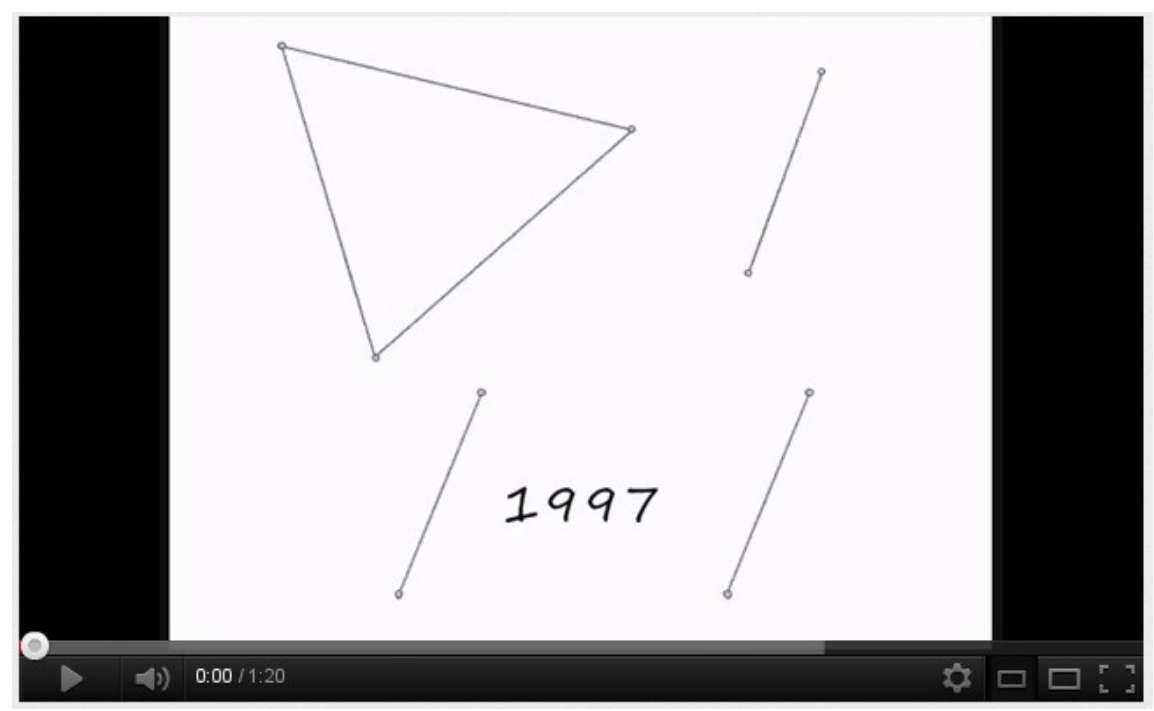

Figura 7.34. Animação gráfica da evolução temporal da rede de coautoria - modo ano-a-ano - Revistas científicas.

\subsubsection{Comunidades: principais agrupamentos}

Apresentamos nesta seção uma análise dos principais agrupamentos em termos institucionais que existem na rede de coautoria nas revistas científicas de nossa base. Para tanto, avaliamos apenas os nós mais centrais de nossa rede, ou seja, consideramos em nossa análise apenas os nós que possuíam acima de 14 conexões diretas com outros pares. Esse número de referência de conexões tinha por objetivo selecionar aproximadamente os 100 nós mais centrais da 
rede em modo acumulado no ano de 2011, permitindo com que identificássemos a que instituições pertenciam e qual sua influência na dinâmica da rede apresentada nos itens anteriores de nossa análise. Realizando o corte no número de nós presentes na rede pelo número de 14 conexões ou mais terminamos com uma rede de 93 nós, a qual apresentamos na figura 7.35.

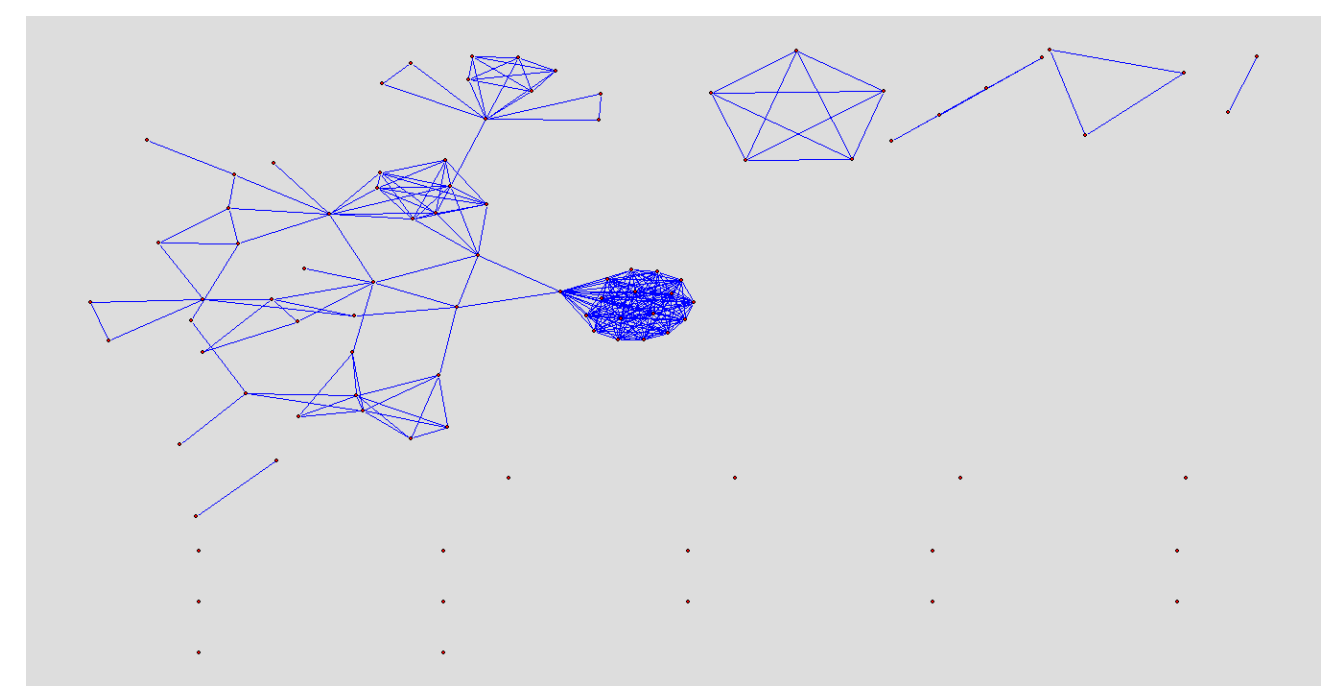

Figura 7.35. Rede dos 93 nós mais centrais no ano de 2011 - modo acumulado - Rede de revistas científicas.

Após esse corte de nós, buscamos complementar as informações que tínhamos disponível em nossa base de dados, identificando com auxílio da análise do currículo Lattes dos pesquisadores mais centrais qual instituição cada um descrevia em seu perfil como sua instituição atual de trabalho. Desse modo, teríamos condições de avaliar institucionalmente como se daria atualmente a distribuição desses nós. Apresentamos na figura 7.36, a seguir, como a rede dos nós apresentados na figura 7.35 poderia ser agrupada em torno de suas instituições atuais de origem. 


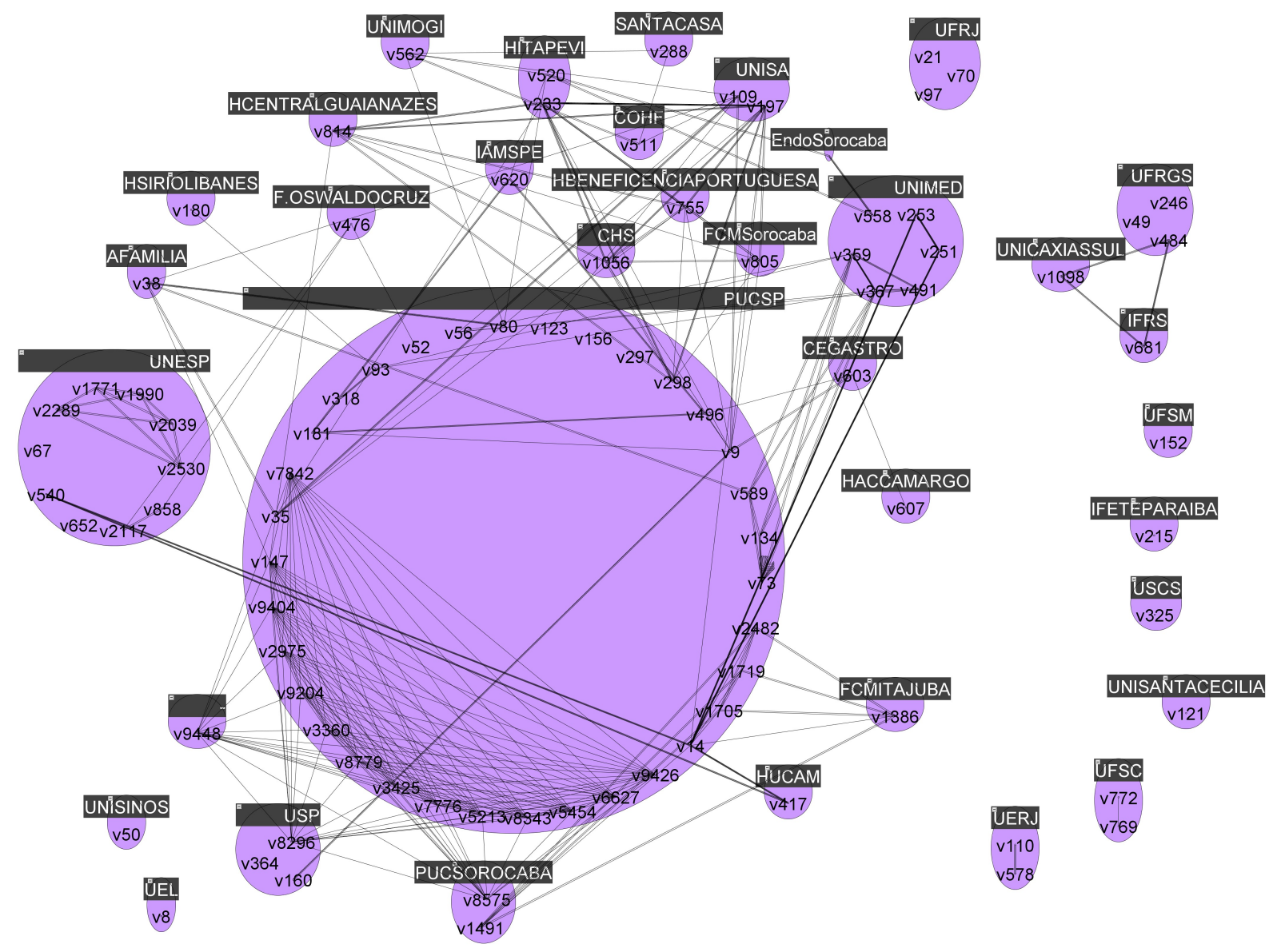

Figura 7.36. Agrupamento por instituição da rede dos 93 nós mais centrais no ano de 2011 - modo acumulado - Rede de revistas científicas.

$\mathrm{Na}$ figura 7.36, os nós foram agrupados por instituição de origem e o tamanho de cada agrupamento é relativo ao número de nós que ele possui. Para facilitar nossa análise da frequência de nós por instituições, apresentamos na tabela 7.7, a seguir, como ocorre essa distribuição. 


\begin{tabular}{l|c|}
\hline \multicolumn{1}{|c|}{ Instituição } & Nós \\
\hline PUCSP & 34 \\
\hline UNESP & 10 \\
\hline UNIMED & 6 \\
\hline UFRGS & 3 \\
\hline UFRJ & 3 \\
\hline USP & 3 \\
\hline Hospitalltapevi & 2 \\
\hline PUCSOROCABA & 2 \\
\hline UERJ & 2 \\
\hline UFSC & 2 \\
\hline UNISA & 2 \\
\hline AssociaçãoSaúdeFamília & 1 \\
\hline Centro Especializado em Cirurgia do Aparelho Digestivo & 1 \\
\hline CentroEndocrinologiaSorocaba & 1 \\
\hline CHS & 1 \\
\hline COHF & 1 \\
\hline FaculdadeCienciasMedicasSorocaba & 1 \\
\hline FaculdadeMedicinaltajuba & 1 \\
\hline Fundação Oswaldo Cruz & 1 \\
\hline Hospital Beneficência Portuguesa & 1 \\
\hline Hospital Central de Guaianazes/ Pró Life & 1 \\
\hline HospitalACCamargo & 1 \\
\hline HospitalSirioLibanes & 1 \\
\hline HUCAM & 1 \\
\hline IAMSPE & 1 \\
\hline IFETParaíba & 1 \\
\hline IFRS & 1 \\
\hline Santa Casa de Rio Claro & 1 \\
\hline UEL & 1 \\
\hline UFSM & 1 \\
\hline UNISINOS & 1 \\
\hline Universidade Santa Cecilia & 1 \\
\hline UniversidadeMogiDasCruzes & 1 \\
\hline USCS & 1 \\
\hline & 1 \\
\hline
\end{tabular}

Tabela 7.7. Distribuição de frequência dos nós mais centrais por instituição - Revistas científicas.

Para nossa surpresa, ao analisarmos a figura 7.36 e a tabela 7.7, identificamos muitas instituições que têm conexão direta com a área da saúde, incluindo hospitais, faculdades de ciências médicas e associações. No entanto, analisando esse resultado em conjunto com a figura 7.5 na seção 7.1 deste capítulo, observamos as revistas com maior média de coautoria por artigo tinham relação direta com a área da saúde, que também estão entre as revistas que possuem mais artigos na base, segundo a figura 6.2 do capítulo 6. Logo, o que estamos observando quando analisamos os nós mais centrais em termos de conexões direta em nossa rede em modo acumulado estamos observando aqueles que se conectarem com mais pessoas diretamente ao longo do período. Sem dúvida, quanto mais coautores por artigo ao longo do tempo um pesquisador teve, mais central ele vai se tornar, mesmo que tenha publicado muito menos artigos do que outro pesquisador que publicou a maioria de sua produção isoladamente ou com poucos colaboradores. Desse modo, o que estamos observando aqui é a influência direta que essa conexão com a área da saúde produz na dinâmica da rede social, criando níveis de centralidade que terminam por influenciar diretamente a estrutura da rede. 
Analisando a figura 7.35, percebemos um grande componente com outros poucos componentes isolados e alguns nós embaixo da imagem isolados. O que notamos ali, além do componente central, são nós que possuem alta centralidade local, de algum modo formando pequenas redes localizadas onde eles possuem muitas conexões com outros colaboradores que não se conectam a muitos outros nós em nossa rede, criando essa dimensão de isolamento que percebemos na imagem. Já para o maior componente, percebemos os nós mais centrais que fazem parte do componente principal acumulado da rede, sendo eles, sem dúvida os maiores articuladores de conexões de nossa estrutura principal de rede. Quando analisamos esse agrupamento e comparamos com a figura 7.36, percebemos o efeito predominante que a instituição PUC-SP tem na estrutura da rede, não só agrupando a maioria dos nós de forma majoritária, como vemos na tabela 7.7, mas também produzindo conexões diretas com várias outras instituições de nossa rede. Percebemos ali a dimensão estrutural em nossa rede do encontro de áreas, onde vemos diferentes tipos de parcerias institucionais sendo estabelecidas em torno da colaboração na produção científica de áreas como a comunicação e a saúde.

\subsubsection{Análise da rede social de relações em bancas de defesa de teses e dissertações}

Apresentamos inicialmente as matrizes geradas nos dois modos de organização do tempo, modo acumulado e modo ano-a-ano, após entraremos em detalhes na análise individual de cada indicador. 


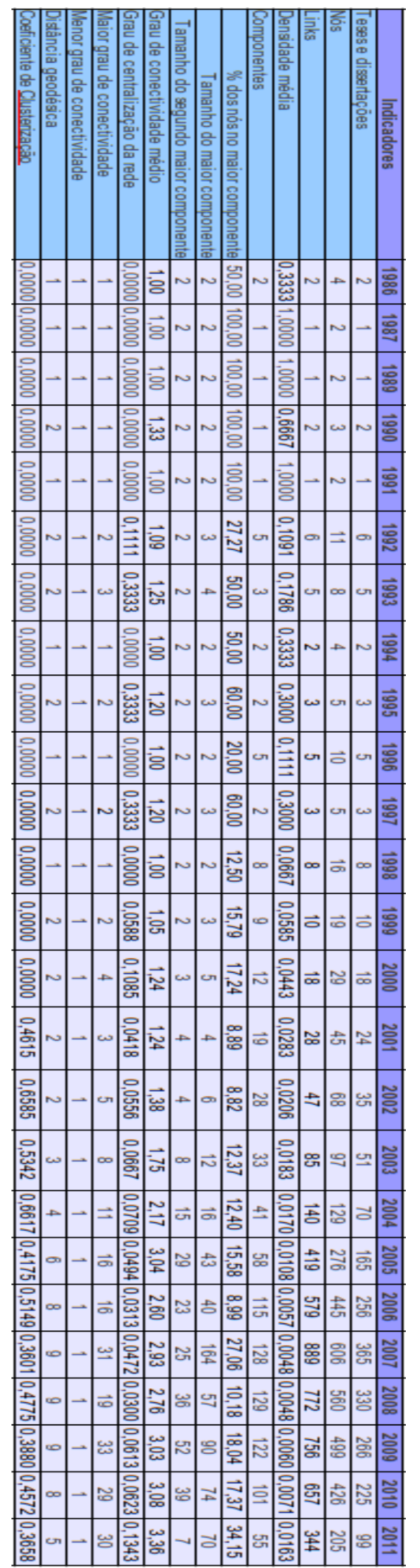

Tabela 7.8. Matriz de indicadores - Teses e dissertações - modo ano a ano.

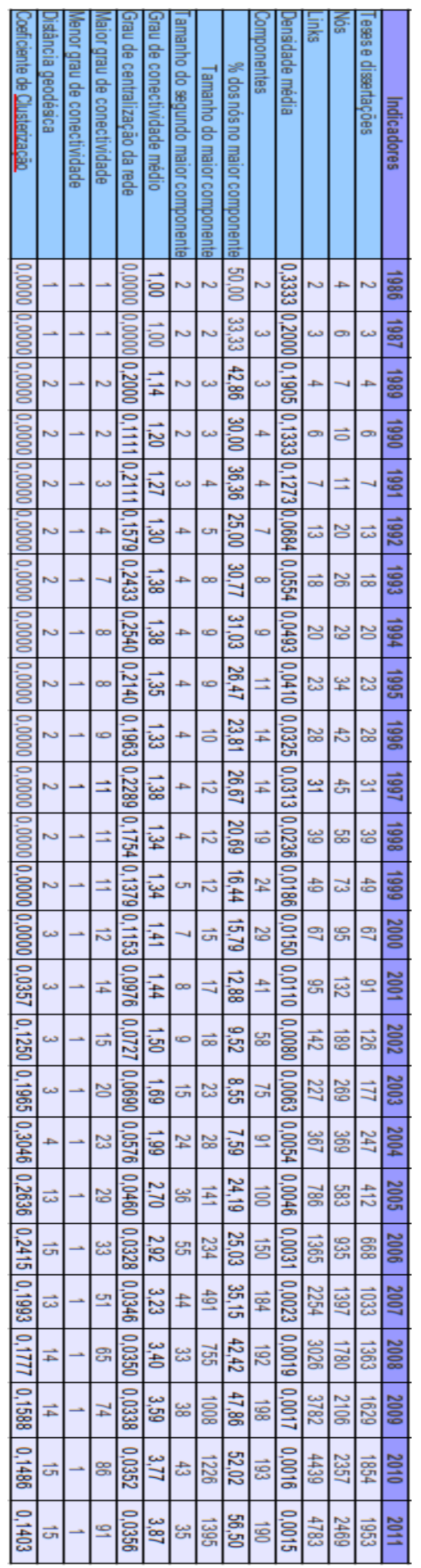

Tabela 7.9. Matriz de indicadores - Teses e dissertações- modo 


\subsubsection{Nós e links}

Apresentamos em conjunto a evolução dos nós e links estabelecidos na rede de pessoas que colaboram em torno das defesas de teses e dissertações. Vejamos nas figuras 7.37 e 7.38 seus resultados.

Nós e links: modo ano-a-ano

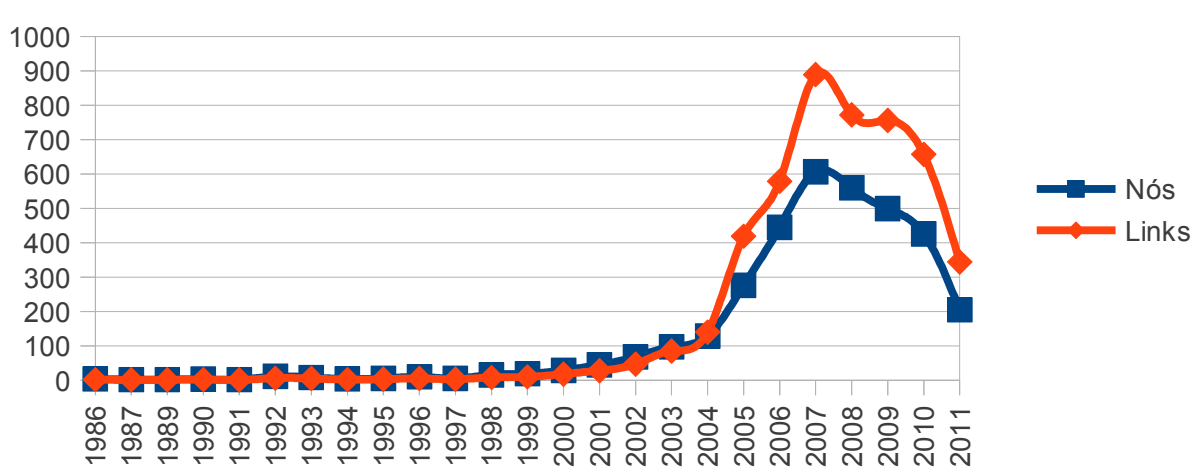

Figura 7.37. Nós e links - modo ano-a-ano - Bibliotecas Digitais de Teses e Dissertações

Nós e links: modo acumulado

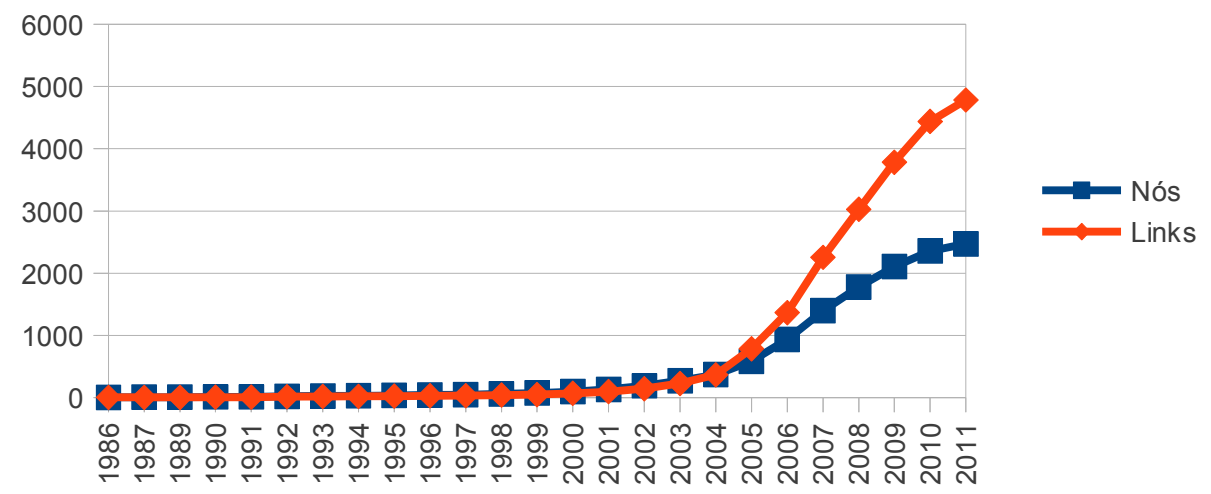

Figura 7.38. Nós e links - modo ano-a-ano - Bibliotecas Digitais de Teses e Dissertações

Observando a figura 7.37, notamos que ela segue a mesma linha de tendência da figura 7.7 apresentada na seção 7.1 deste capítulo, onde mostramos a curva de evolução do número de teses e dissertações sendo publicadas nas bibliotecas digitais de nossa base de análise. Percebemos aqui, portanto, uma relação direta entre o número de documentos sendo produzidos e o número de nós e links sendo estabelecidos na rede. É importante ressaltarmos aqui que o número de nós segue a mesma tendência do número de links, ou seja, mais conexões ocorrendo nessa rede significa mais pessoas atuando nas relações sociais e não um aumento na intensidade das conexões entre os nós ali 
já existentes. Observamos a mesma tendência na figura 7.38.

Como já analisamos anteriormente, é preciso considerar que os resultados para o ano de 2011 não são absolutos, dado que algumas teses e dissertações estariam disponíveis na base de dados de suas bibliotecas digitais um período após sua defesa, o que pode variar para a dinâmica de cada biblioteca digital. Como também já mencionamos anteriormente, não podemos afirmar que a queda no número de nós e links a partir de 2007 represente uma perda de intensidade de produção científica da área, mas uma redução no número de documentos sendo disponibilizados nessas bibliotecas digitais que estamos diretamente analisando.

Analisando o gráfico da figura 7.37, notamos que do ano de 2004 para 2005 ocorreu um aumento de aproximadamente $280 \%$ no número de links, sendo que quando observamos o aumento no número de documentos na figura 7.7 , essa taxa é de em torno de $230 \%$. Isso nos chamou atenção, dado que esperávamos que esse crescimento se desse de modo similar, sabendo que o número de participantes de uma banca tende a ser o mesmo em cada uma das modalidades de teses e dissertações. Porém, analisando a tabela 7.2 da seção 7.1 deste capítulo, percebemos que no ano de 2005 há a entrada de duas bibliotecas digitais em nossa base que disponibilizam informações sobre os membros participantes das bancas de defesa, sendo elas a UFMG e PUC-Rio. Dado que em períodos anteriores tínhamos apenas duas bibliotecas digitais em nossa base disponibilizando esse tipo de informação, é de se esperar que tenhamos um aumento significativo a partir desse período no número de links sendo estabelecidos. Para ilustrar como ocorre essa transição em termos estruturais, mostramos nas figuras 7.39 e 7.40 os sociogramas da rede de relações em 2004 e 2005 .

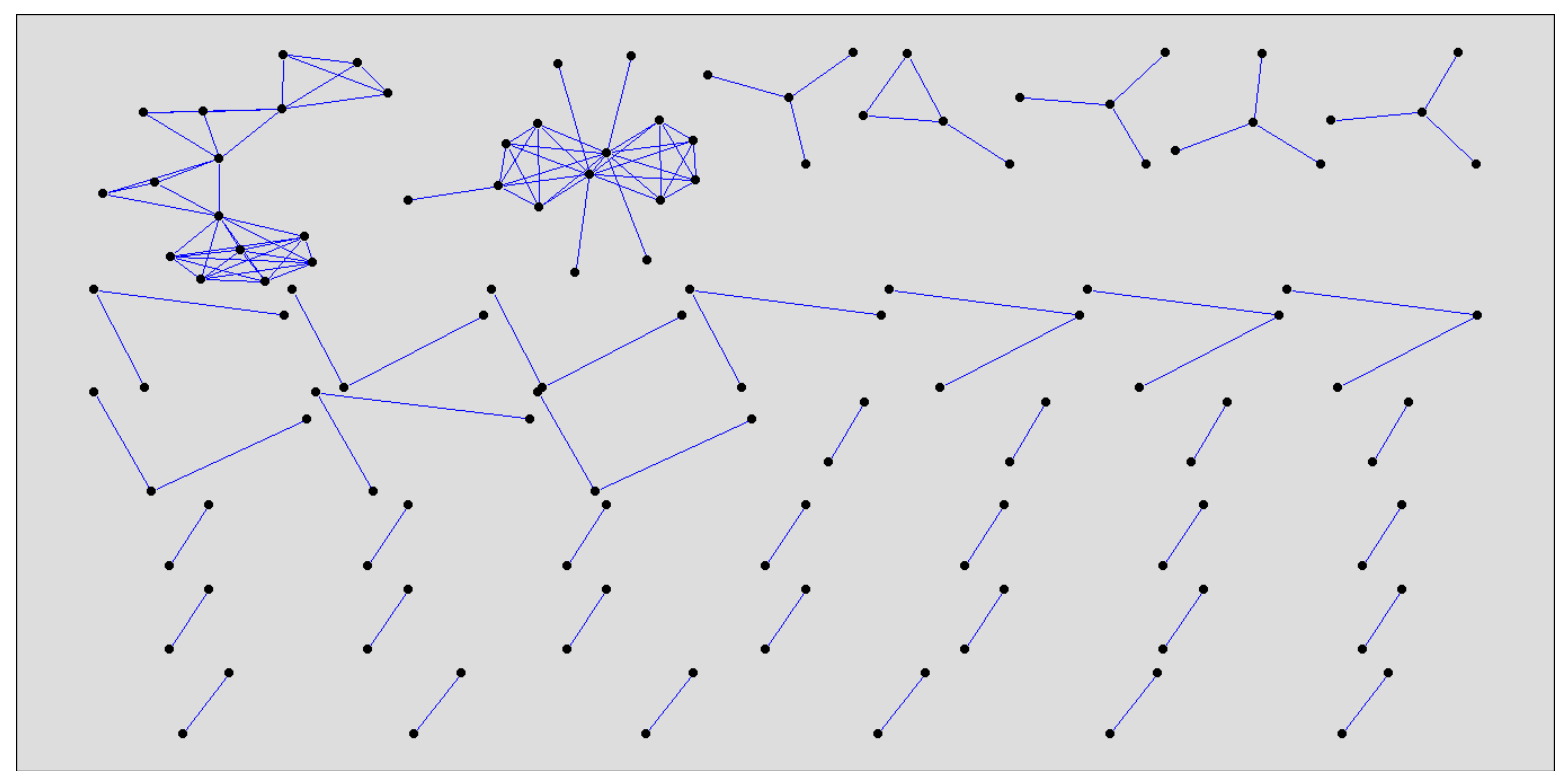

Figura 7.39. Rede de relações em bancas de defesas no ano de 2004 - modo ano-a-ano - Bibliotecas Digitais de Teses e Dissertações 


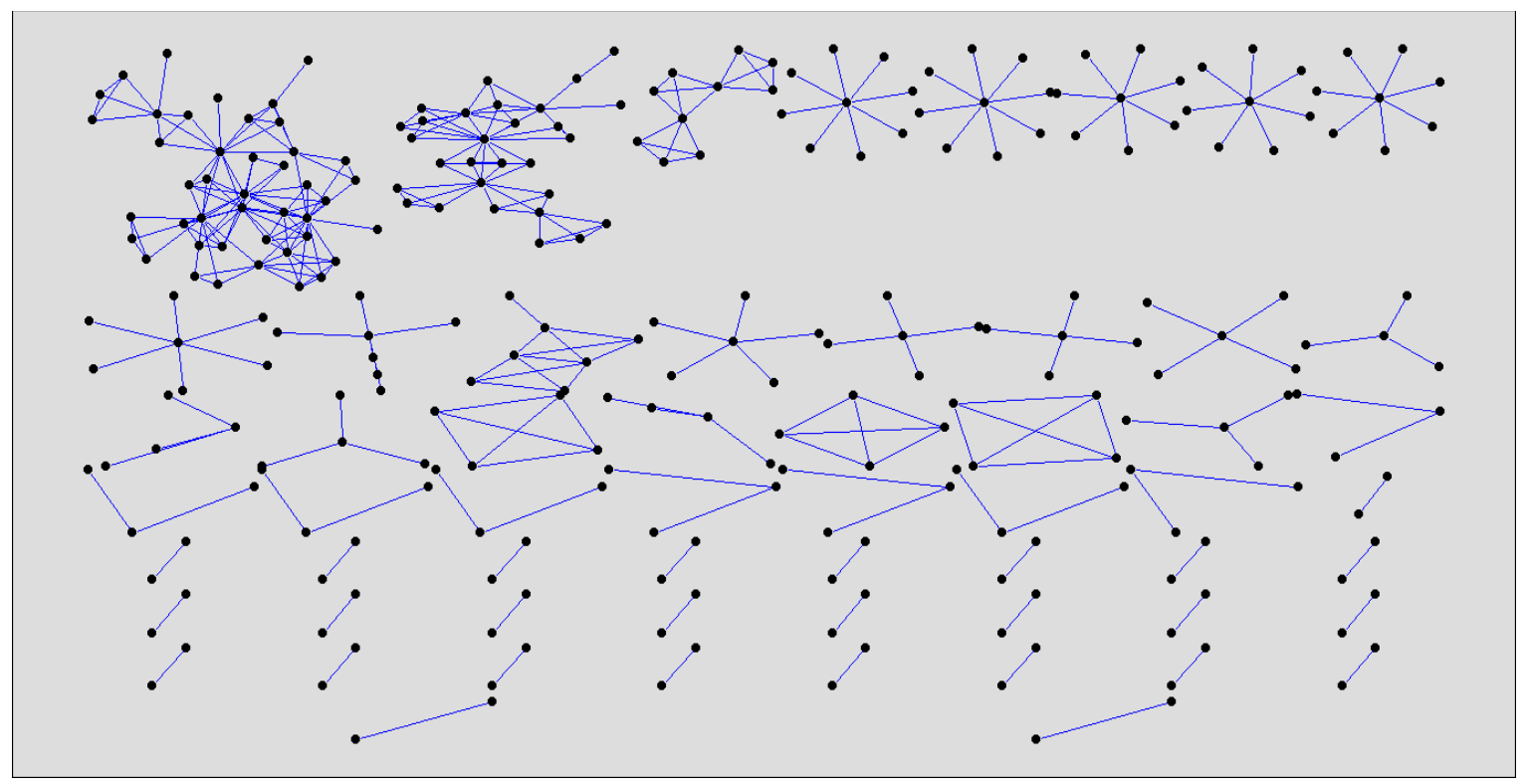

Figura 7.40. Rede de relações em bancas de defesas no ano de 2005 - modo ano-a-ano - Bibliotecas Digitais de Teses e Dissertações

Analisando as duas imagens, percebemos que os componentes mais simples, ou seja, aqueles formados por duas ou três relações representam metadados gerados por bibliotecas que apenas mostram as relações criadas entre orientadores e orientandos. Os componentes em formato estrela, presentes mais intensamente na figura 7.40, também representam esse tipo de relação, porém indicam orientadores que tiveram mais de 2 orientandos que defenderam suas teses ou dissertações no mesmo ano. Já a principal diferença na estrutura das duas redes, o que é sinalizado pelo número de links que cresce do modo como relatamos acima, é termos componentes maiores e com maior número de articulações no ano de 2005 em relação ao ano de 2004. Isso é produto direto não só do fato de termos mais documentos sendo produzidos em 2005, mas pelo fato de termos mais bibliotecas digitais que apresentam em seus metadados as relações de todos os pesquisadores que participaram de uma banca de defesa e não apenas a relação entre orientadores e orientados. Sem dúvida, como esses dados demonstram, termos essas informações completas nos permitem avaliar com maior precisão a dinâmica e estrutura de evolução de uma rede social de participantes.

\subsubsection{Densidade média e grau de centralização}

Apresentamos as curvas de densidade média e grau de centralização da rede de participantes das bancas nas figuras 7.41 e 7.42 . 


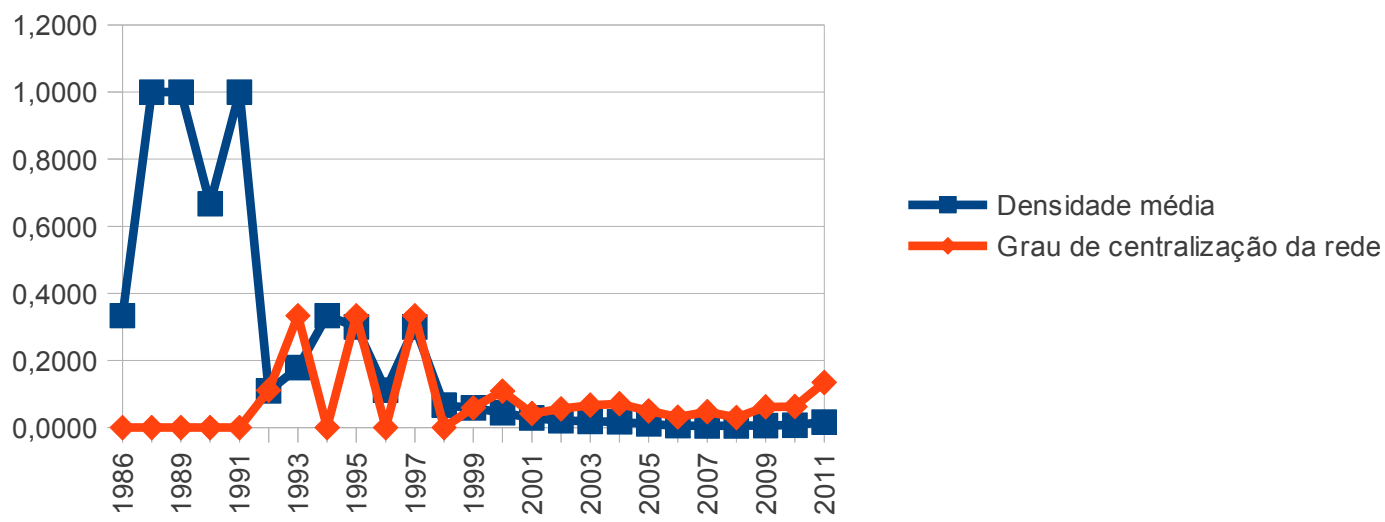

Figura 7.41. Densidade média e grau de centralização - modo ano-a-ano - Bibliotecas Digitais de Teses e Dissertações.

Densidade média e grau de centraliação: modo acumulado
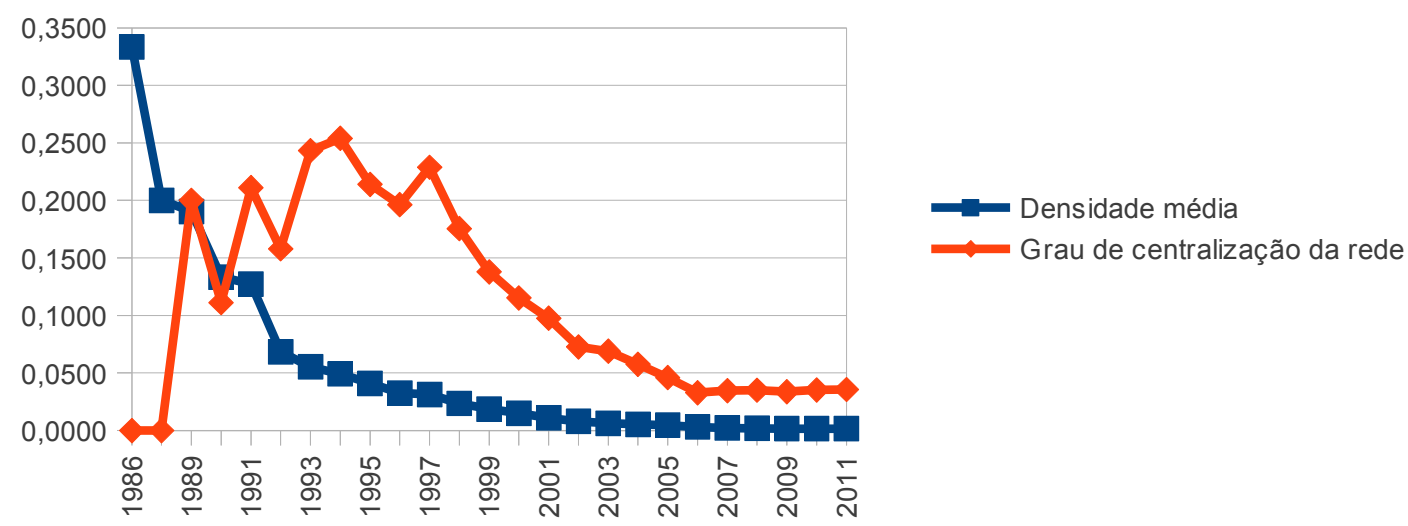

Figura 7.42. Densidade média e grau de centralização - modo acumulado - Bibliotecas Digitais de Teses e Dissertações.

Observando a figura 7.41, notamos que a densidade média atinge valores relativos bastante altos no começo do período de análise de nossa base de dados, decaindo abruptamente no ano de 1992, tendo pequena recuperação nos próximos anos, porém seguindo a partir de 1998 em valores próximo a 0 . Quando observamos a figura 7.42, a densidade média na rede acumulada decai gradativamente até atingir patamares próximo a zero a partir do ano de 2001, seguindo essa mesma tendência até o final do período de análise. Conforme o aumento no número de nós em uma rede, é natural esperarmos que a densidade média da rede tenda a se reduzir, dado que os nós entram na rede com algumas poucas conexões, sobretudo quando consideramos que estamos aqui retratando relações estabelecidas na participação de bancas de defesas de teses e dissertações. Para ilustrarmos como isso ocorre em termos estruturais, tomemos como exemplo os anos de 1991 e 1992, onde 
apresentamos a seguir as imagens de seus sociogramas.

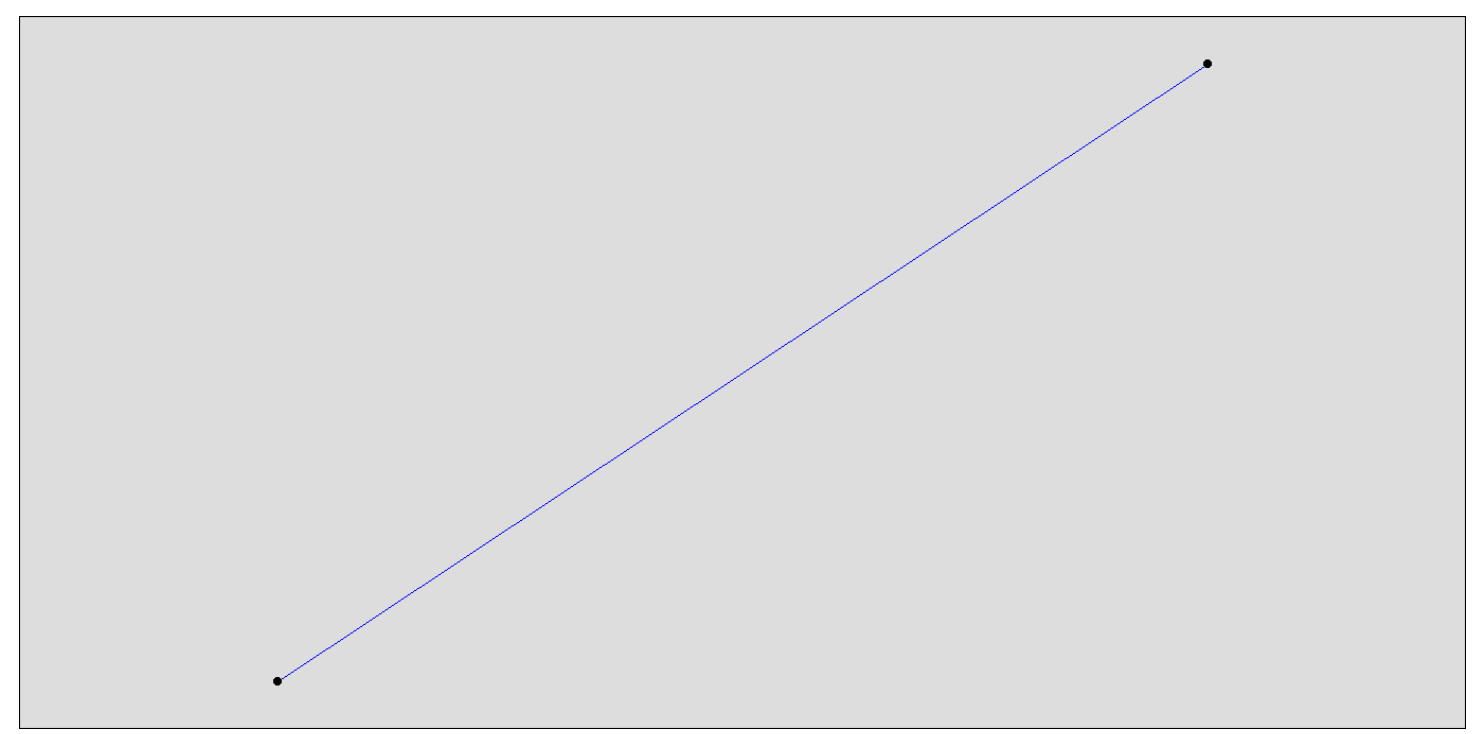

Figura 7.43. Rede de relações em bancas de defesas no ano de 1991 - modo ano-a-ano - Bibliotecas Digitais de Teses e Dissertações

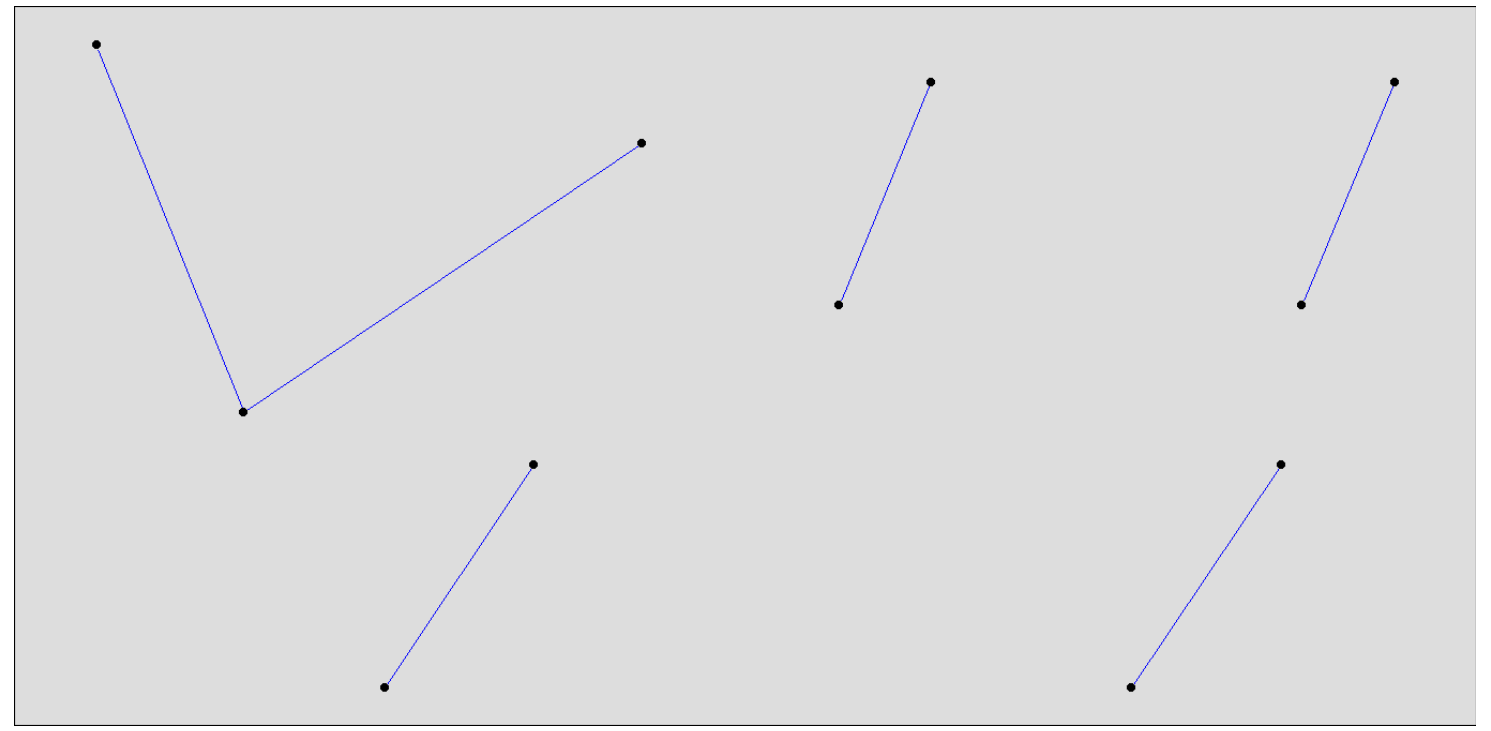

Figura 7.44. Rede de relações em bancas de defesas no ano de 1992 - modo ano-a-ano - Bibliotecas Digitais de Teses e Dissertações

Observando a rede na figura 7.43, no ano de 1991, notamos que todas as relações que poderiam ser estabelecidas dado que temos apenas um único componente na rede estão estabelecidas, ou seja, não existem conexões em potencial a serem realizadas na rede. Isso faz com que a densidade média da rede seja considerada $100 \%$, o que percebemos no gráfico da figura 7.41 . Já na figura 7.44, no ano de 1992, temos uma pequena mudança estrutural na forma da rede, onde notamos um orientador que se relaciona com dois orientandos, mas que não possuem relações diretas entre si. Nesse caso, a densidade da rede cai, dado que há relações em potencial que poderiam ter sido estabelecidas e não foram. 
Quando observamos o grau de centralização nas figuras 7.41 e 7.42 , notamos que ele começa com valores zero nos primeiros anos da rede, tendo picos nos anos de 1993, 1995 e 1997 e novamente seguindo em valores próximos a zero desde então até o fim do período de análise na rede modo ano-a-ano. Já na rede em modo acumulado, notamos que o grau tem um pico em 1987, aumentando e decaindo até atingir um novo pico em 1994 e decaindo gradativamente desde então até o fim do período de análise. Esses dados nos mostram um fenômeno interessante de analisar em termos de como evoluiu o padrão estrutural dessa rede. O que nossos gráficos nos levam a concluir é que a rede produz formas que concentram centralidade até o ano de 1997, passando a partir de então essas formas terem menos influência no modo de organização.

$\mathrm{Na}$ rede em modo acumulado, essas formas podem ser traduzidas pelo fato de um orientador ir acumulando orientações ao longo de seu tempo de atuação profissional, fazendo com sua rede de interação tome a forma de uma espécie de estrela, com ele no centro. Como não temos a presença de dados de participação dos membros de bancas até o ano de 2001, a partir de quando há documentos na biblioteca digital UFBA disponibilizando essa informação em seus metadados, entendemos esse fenômeno de centralização atrelado diretamente ao acúmulo de orientações realizadas por determinados orientadores em nossa rede. Essa influência é menos perceptível na rede em modo ano-a-ano, dado que orientações realizadas em um ano n não são reconhecidas como relações na rede no ano $\mathbf{n + 1}$, fenômeno que acaba sendo responsável pelos picos e vales que observamos dos anos de 1993 até 1997 na curva do grau de centralização, na figura 7.41. Para ilustrar esse fato, apresentamos a seguir os sociogramas de dois anos desse período, 1996 e 1997.

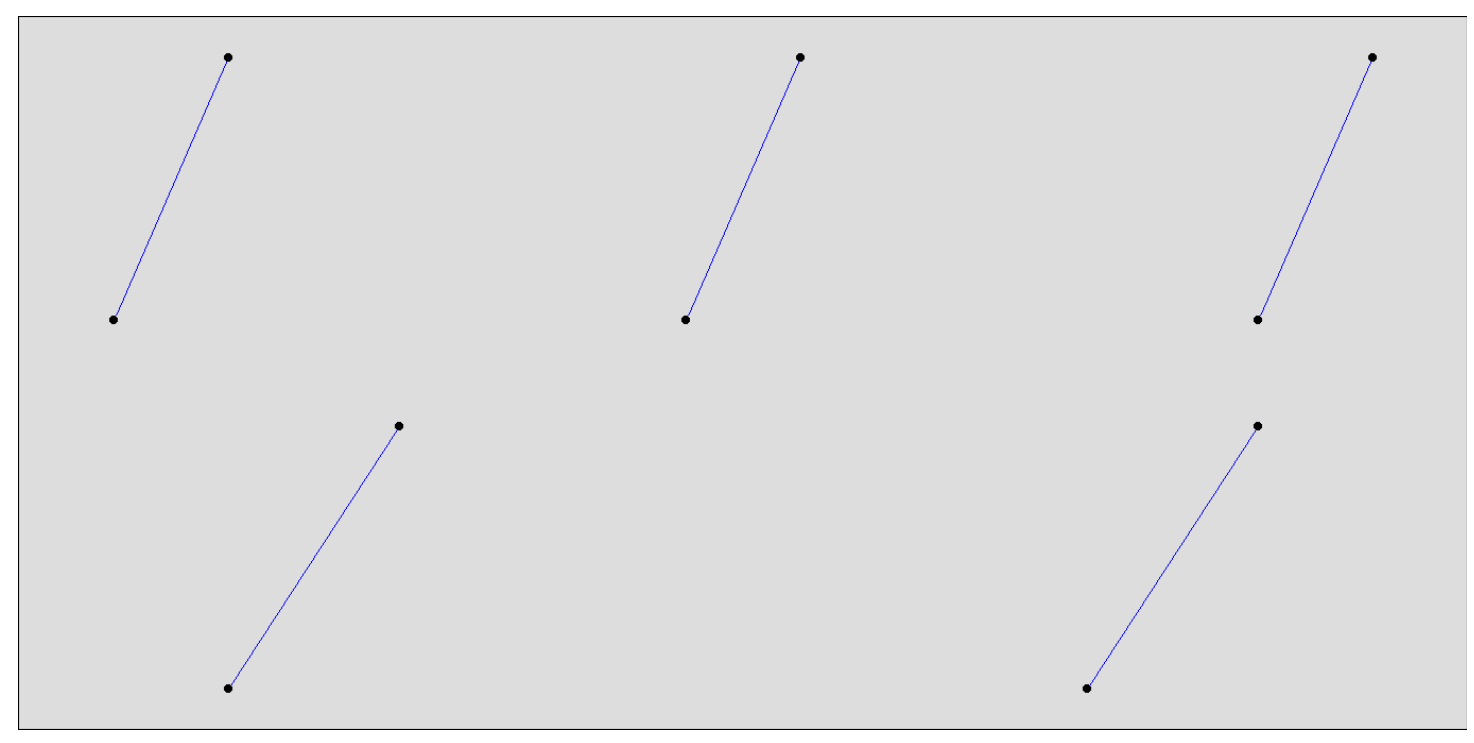

Figura 7.45. Rede de relações em bancas de defesas no ano de 1996 - modo ano-a-ano - Bibliotecas Digitais de Teses e Dissertações 


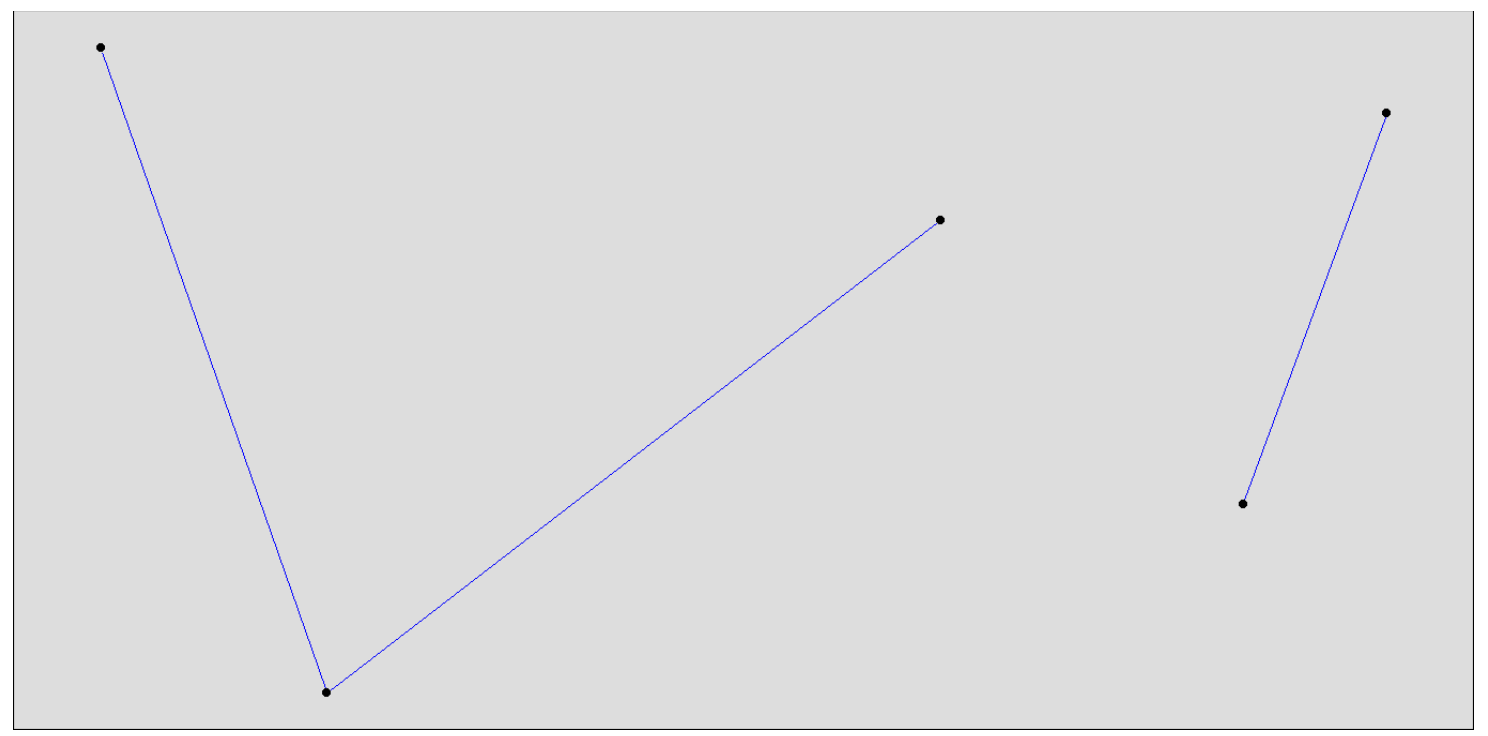

Figura 7.46. Rede de relações em bancas de defesas no ano de 1997 - modo ano-a-ano - Bibliotecas Digitais de Teses e Dissertações

No ano de 1996, na figura 7.45, quando o grau de centralização é zero, a figura não demonstra nenhuma forma de concentração de centralidade na rede, dado que todos os nós ali presentes estão de forma homogênea, mostrando relações diretas entre orientadores e orientandos. Já no ano de 1997, na figura 7.46, temos uma pequena mudança estrutural que leva a uma concentração de centralidade na rede, onde notamos um orientador que se relaciona com dois orientandos, sendo que esses não se relacionam diretamente entre si. Logo, são mudanças desse modo que levam aos efeitos que notamos nas curvas apresentadas.

De qualquer modo, vale ressaltar que esses eventos são bastante sensíveis em uma rede com poucos nós e links como é nossa rede, sobretudo em seus primeiros anos de existência. Ao longo do tempo, tanto a densidade média quanto o grau de centralização tendem a se estabilizar, dado que não ocorre nenhum evento que impacta tão sensivelmente a estrutura da rede quando temos mais nós e links do que nos períodos iniciais.

\subsubsection{Componentes}

Apresentamos nas figuras a seguir, as curvas que mostram a evolução do número de componentes, da porcentagem de nós no maior componente e do maior e segundo maior componentes na rede social de participantes das bancas de defesas de teses e dissertações. 
Componentes: modo ano-a-ano

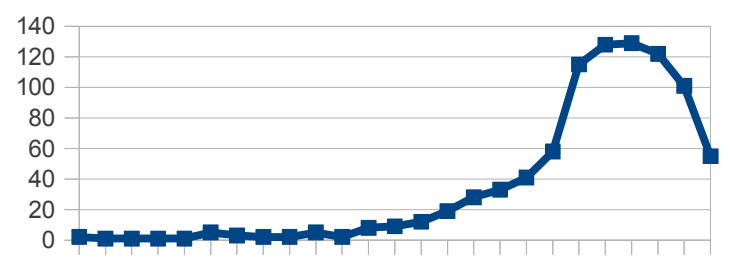

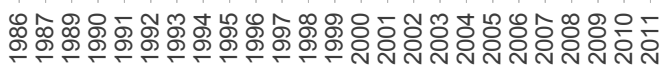

Figura 7.47. Componentes - modo ano-a-ano
Componentes: modo acumulado

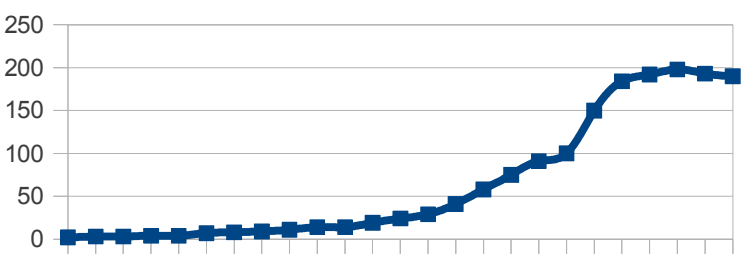

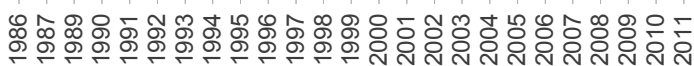

Figura 7.48. Componentes - modo acumulado

Bibliotecas Digitais de Teses e Dissertações.

Observando a figura 7.47, notamos que o número de componentes na rede em modo ano-aano atinge um pico em torno do ano de 2008, caindo gradativamente desde então. Podemos imaginar que isso se deve ao fato de haver uma redução no número de nós e links participando da rede no mesmo período, conforme nos mostram o gráfico da figura 7.37, anteriormente apresentado. No entanto, quando observamos o gráfico da figura 7.48, notamos que o número de componentes se estabiliza a partir do ano de 2007 até o final do período de análise. Novamente, observando o gráfico da figura 7.38, no mesmo período a rede em modo acumulado continua recebendo nós em sua estrutura, porém a uma taxa menor que anteriormente. É notável que esse comportamento não se reproduz em relação ao número de componentes acumulados na rede. Logo, podemos concluir que os novos nós que vão chegando na rede a partir de 2007 não formam novos componentes, mas sim, em sua maioria, vão se agregando a componentes já existentes na rede, inclusive diminuindo o seu número ali presentes. De algum modo, aparentemente a estrutura da rede vai tendendo gradativamente a formação de um conjunto de componentes ou um componente que se torna um atrator majoritário das conexões que são estabelecidas. Para avaliarmos isso de outra perspectiva, apresentamos nas figuras 7.49 e 7.50, a seguir, a dinâmica da percentagem de nós que fazem parte do componente principal de nossa rede.
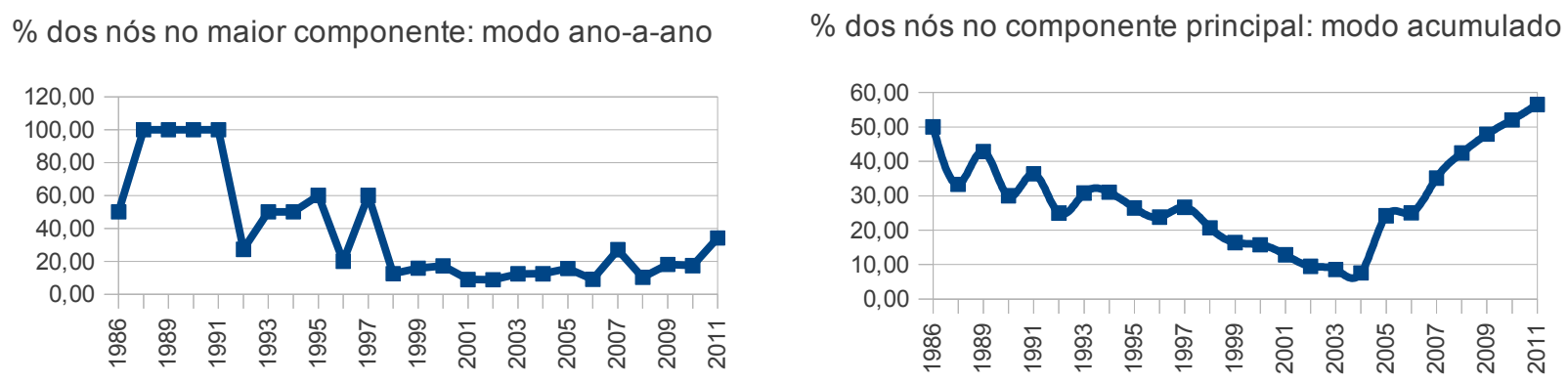

Figura 7.49. Percentagem de nós no maior componentes - modo ano-a-ano Figura 7.50. Percentagem de nós no maior componentes - modo acumulado - Bibliotecas Digitais de Teses e Dissertações. 
Observando o gráfico da figura 7.49, percebemos que a partir de 1998, a rede em modo anoa-ano possui um maior componente que tende a receber em torno de $20 \%$ dos nós presentes na rede a cada ano. Esse número cai gradativamente do início do período, tendo momentos de picos e vales até o ano de 1998. Quando analisamos a figura 7.49 em relação a figura 7.47, percebemos que nesse período até 1998 a rede contava com um número mínimo de componentes, o que explica, complementando com os dados que mostram uma pequena quantidade de nós presentes na rede na figura 7.37 no mesmo período, que os nós ali presentes estivessem distribuídos em poucos componentes, logo, formando parte dos mais centrais.

Já a figura 7.50, nos mostra um efeito interessante de ser notado na passagem do ano de 2004 para 2005, onde percebemos um aumento significativo e que se mantém nos próximos anos no número de nós que passam a fazer do maior componente da rede. Vale observar que é exatamente no ano de 2005 que temos disponível em nossa base os dados dos membros participantes das bancas da PUC-Rio e da UFMG. Ao que parece, a entrada desses dados cria um efeito de atração dos nós da rede em torno de um maior componente, que chega a $60 \%$ dos nós em 2011. É importante analisarmos aqui que termos os dados de banca de participantes amplia de forma sistemática a capacidade de identificarmos diferentes pontos da rede se articularem entre si, o que antes só poderia acontecer por relações de orientação direta entre pesquisadores. Quando esses dados entram na rede, sua dinâmica muda, pois o efeito de relação altera sabendo que agora estamos visualizando não apenas relações de orientação, mas sim também de participação de pesquisadores em bancas. Esse evento, ao que parece, traz uma maior mobilidade para os nós da rede trazendo como consequência que diferentes componentes que antes se apresentavam de modo isolado agora passem a estar unidos, pois quando um orientador de um componente participa de uma banca com outros orientadores de outros componentes eles passam a formar uma única rede de relações, tornando-se facilmente visível quando analisamos a rede em modo acumulado, dado que ali registramos essa mobilidade ao longo dos anos. Apresentamos a seguir nas figuras 7.51 e 7.52 como evolui ao longo do tempo o maior e o segundo maior componente de nossa rede.
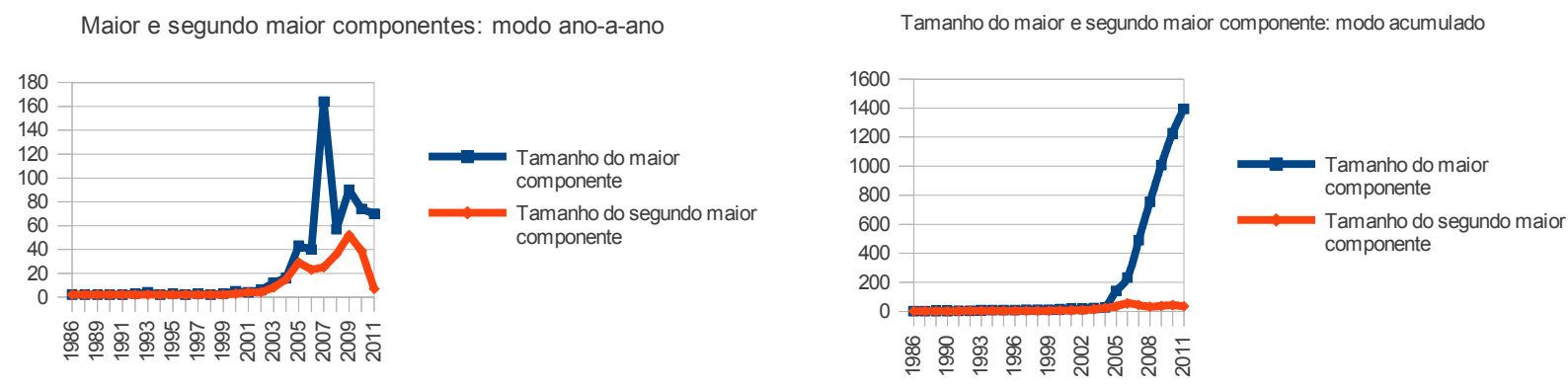

Figura 7.51. Maior e segundo maior componentes - modo ano-a-ano Figura 7.52. Maior e segundo maior componentes - modo acumulado Bibliotecas Digitais de Teses e Dissertações. 
Observando a figura 7.51, na rede em modo ano-a-ano, notamos um crescimento expressivo no tamanho do maior componente no ano de 2007, quando ele passa de 40 nós em 2006 para aproximadamente 160 em 2007, representando um crescimento de 400\% no período. Vale lembrar, como apresentamos na figura 7.7 da seção 7.1 deste capítulo que o ano de 2007 é o ano onde há a maior quantidade de documentos sendo disponibilizados em nossas bibliotecas digitais. Além disso, considerando que nesse ano temos 4 bibliotecas de nossa base de dados que apresentam dados de membros participantes de banca, podemos perceber que o crescimento no número de documentos em nossa rede social não só leva a um aumento no número de nós presentes na rede, como vemos na figura 7.37 apresentada anteriormente, mas também a um aumento significativo no tamanho do maior componente de nossa rede. Podemos interpretar esse fenômeno como representativo de uma maior visibilidade de pesquisadores que é registrada em nossa base de dados, dado que eles aparecem nas bancas de defesas que estão ocorrendo nesse período terminando por conectarem mais intensamente os componentes dos quais fazem parte em anos anteriores. Para ilustrar esse evento, apresentamos a seguir nas figuras 7.53 e 7.54 os sociogramas dos anos de 2006 e 2007 para a rede em modo ano-a-ano.

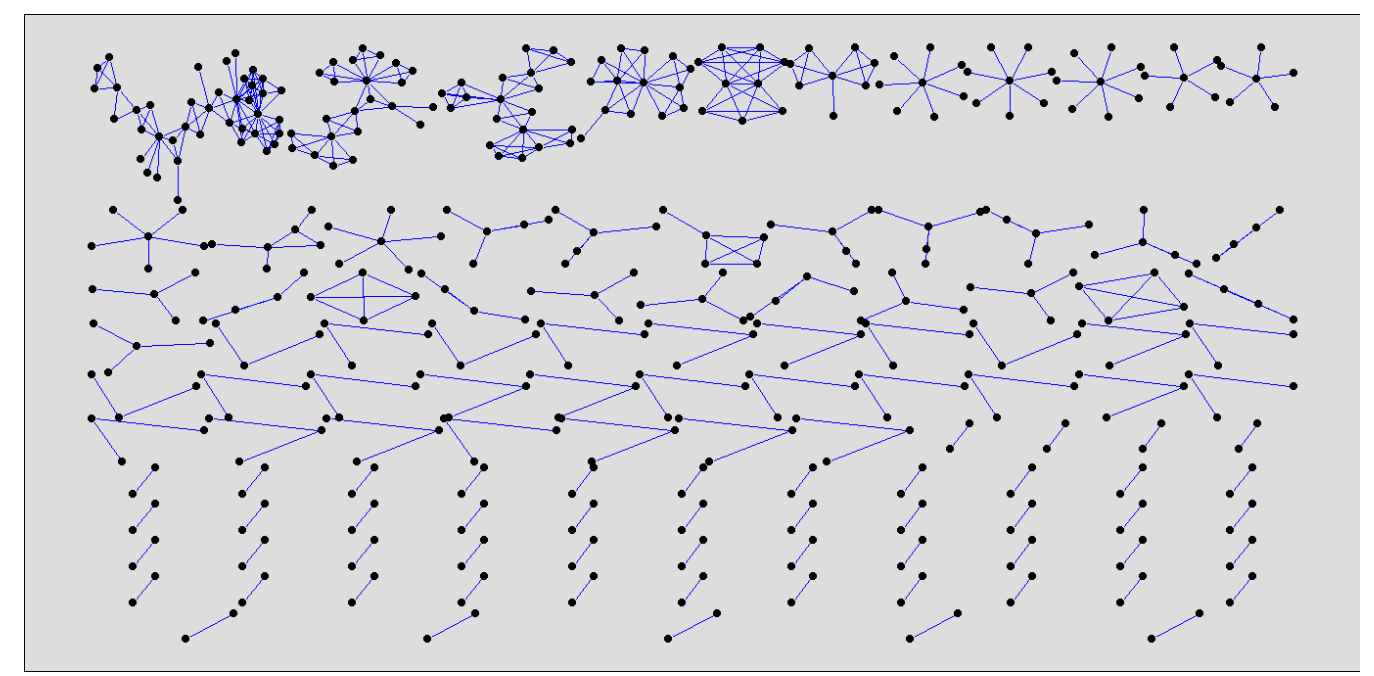

Figura 7.53. Rede de relações em bancas de defesas no ano de 2006 - modo ano-a-ano - Bibliotecas Digitais de Teses e Dissertações 


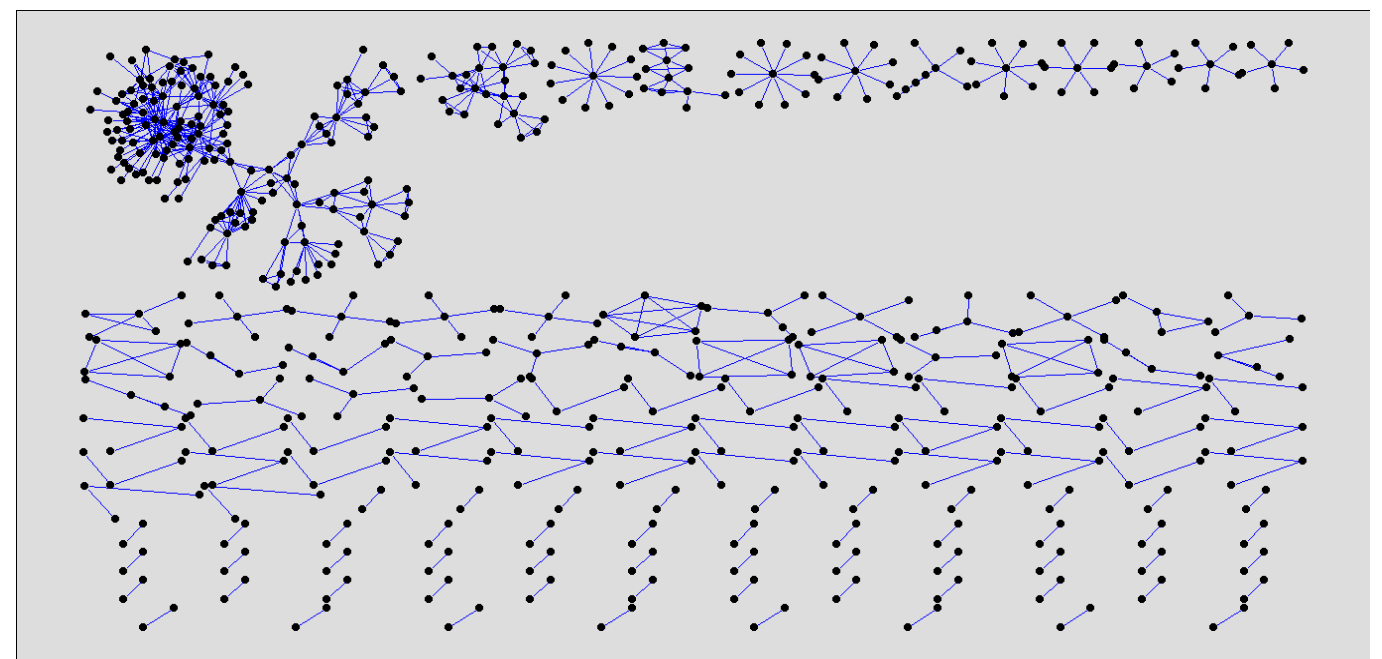

Figura 7.54. Rede de relações em bancas de defesas no ano de 2007 - modo ano-a-ano - Bibliotecas Digitais de Teses e Dissertações

No ano de 2006 temos 115 componentes na rede, sendo que no ano de 2007 temos 128 componentes, uma diferença de pouco mais de $10 \%$ entre eles. Porém, analisando o número de nós, em 2006, temos 445, sendo que em 2007 temos 606 nós, uma diferença de mais de 36\% entre eles. Como observamos nas figuras 7.53 e 7.54, essa diferença ocorre devido ao fato de termos mais nós fazendo parte de um mesmo componente. O que estamos observando aqui é um evento de maior agregação social dos nós participantes da rede, o tal efeito atrator que mencionamos anteriormente, sendo que eles começam a se articular de modo significativo em um mesmo componente, facilitando, em tese, com que existam caminhos de conexão direta e indireta entre vários pesquisadores, o que não havia antes desse evento. Vale ressaltar que isso somente é possível de ser percebido quando registramos em nossos metadados os membros participantes das bancas de defesas.

Para concluir essa seção, apresentamos a seguir na figuras 7.55 a imagem da rede em modo acumulado do ano de 2011, demonstrando no centro o seu principal componente. Apresentamos na figura 7.56 a mesma rede, porém em uma configuração visual que nos facilite perceber sua divisão em diferentes componentes. 


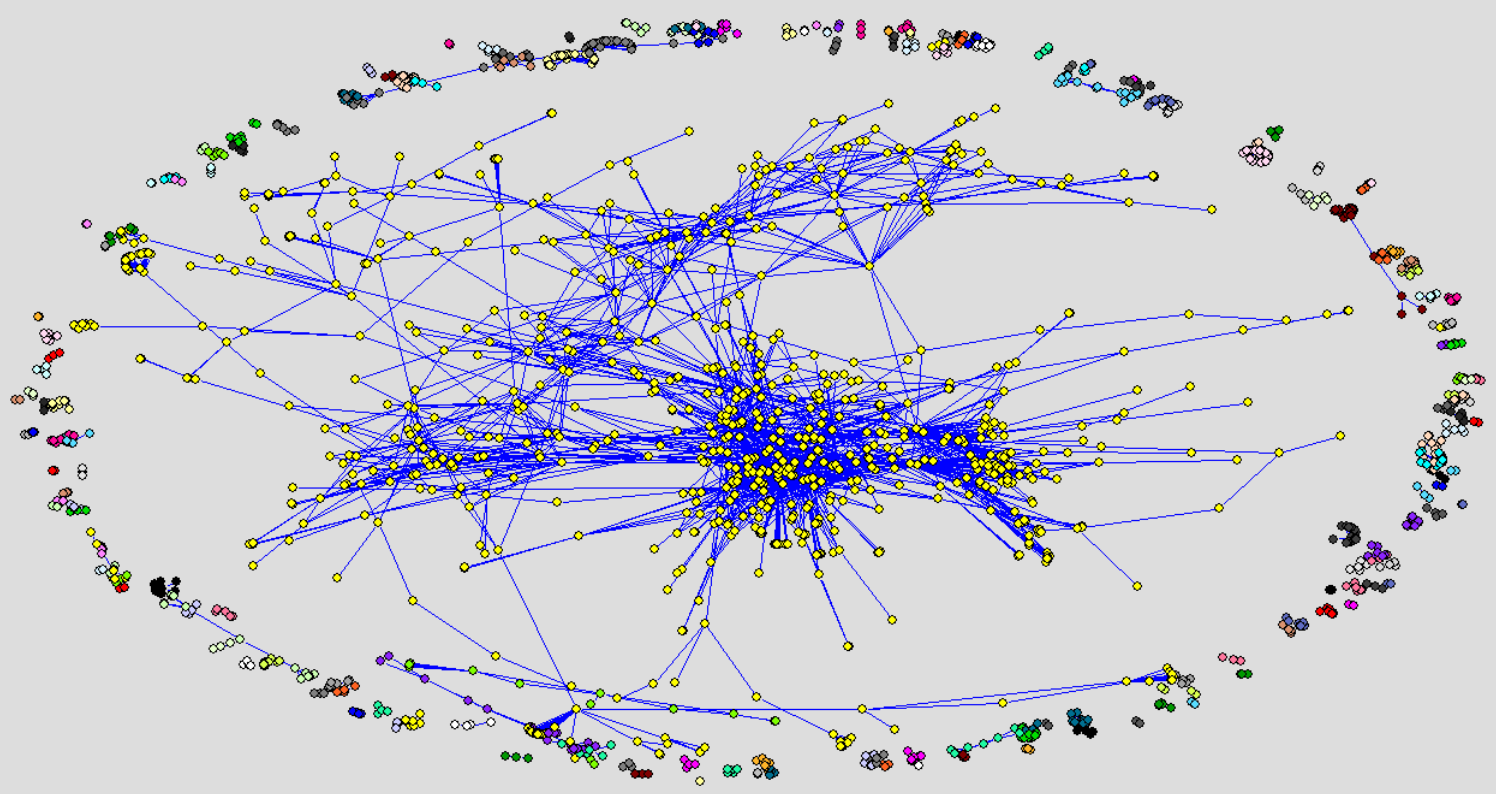

Figura 7.55. Rede de relações em bancas de defesas no ano de 2011 - modo acumulado - Bibliotecas Digitais de Teses e Dissertações

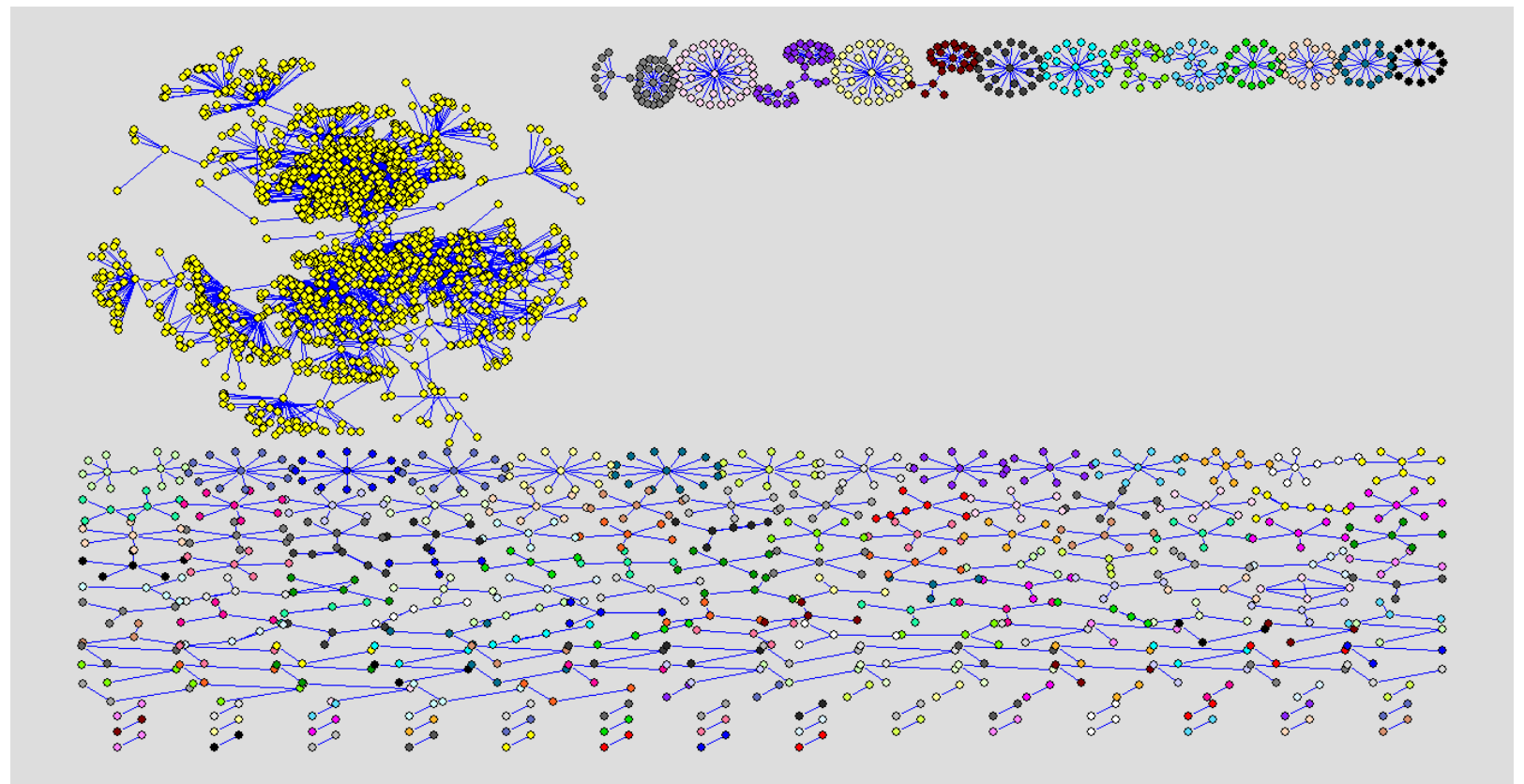

Figura 7.56. Rede de relações em bancas de defesas no ano de 2011 - modo acumulado - Bibliotecas Digitais de Teses e Dissertações

Como podemos notar nas duas imagens acima, o maior componente concentra a maior parte dos nós e conexões da rede, chegando a ter mais de $60 \%$ dos nós ali inseridos, mostrando o modo de conexão preferencial em termos de organização dos componentes que aqui ocorrem.

\subsubsection{Grau de conectividade médio}

Apresentamos nas figuras 7.57 e 7.58 a dinâmica do grau de conectividade médio para a rede de participantes das bancas de teses e dissertações. Vale lembrar que o grau de conectividade 
médio indica a média do número de conexões relativa a todos os nós presentes na rede.

Grau de conectividade médio: modo ano-a-ano

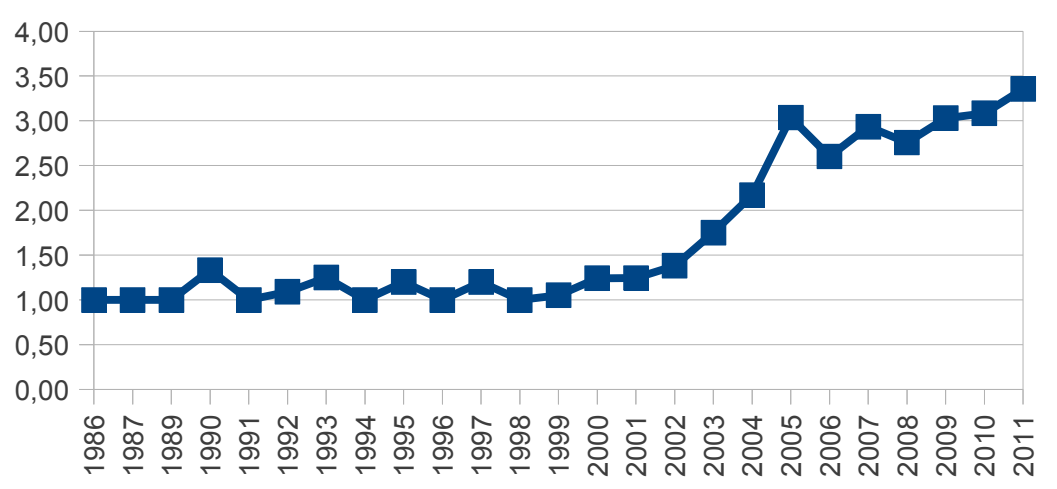

Figura 7.57. Grau de conectividade médio - modo ano-a-ano - Bibliotecas Digitais de Teses e Dissertações

\section{Grau de conectividade médio: modo acumulado}

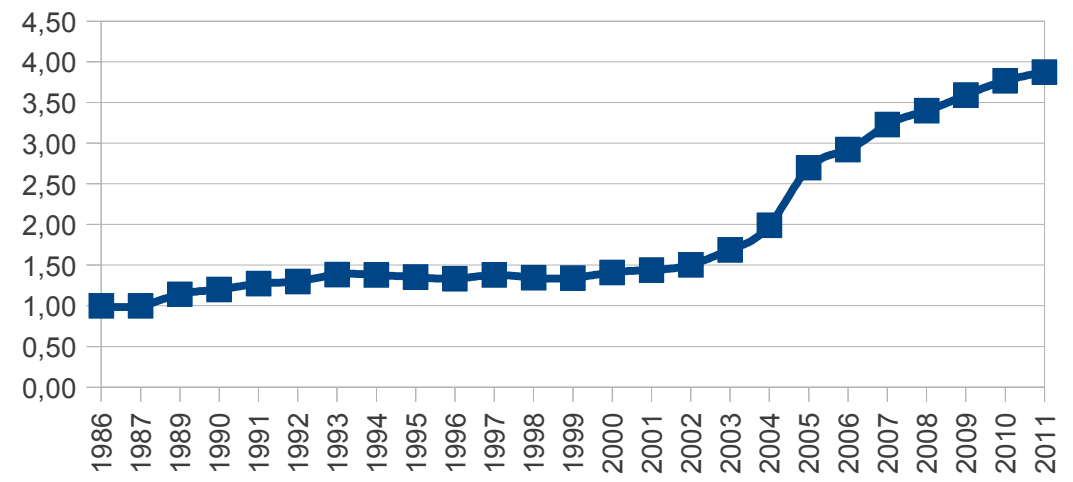

Figura 7.58. Grau de conectividade médio - modo acumulado - Bibliotecas Digitais de Teses e Dissertações

Observando o gráfico da figura 7.57, percebemos que o grau de conectividade médio oscila em torno do valor 1 até aproximadamente o ano de 2001, que é quando entra em nossa base de dados a primeira biblioteca digital, a UFBA, que disponibiliza informações sobre os membros participantes das bancas de defesas. É a partir daí que o grau de conectividade médio começa a crescer gradativamente, atingindo um novo pico em 2005, quando entram a PUC-Rio e UFMG, novamente disponibilizando dados sobre os membros das bancas de defesas. O que podemos inferir dessas informações é que o fato de registrarmos a presença de pesquisadores em bancas de defesas aumenta de forma significativa a possibilidade desse pesquisador se conectar com mais pessoas do que apenas seus possíveis orientandos. Isso muda a dinâmica da rede em análise, criando novos dispositivos de relação que registram de forma mais abrangente o número de pessoas com as quais um pesquisador se relaciona, o que traz influencias diretas para o modo como observamos o grau de 
conectividade médio de nossa rede.

Observamos o mesmos efeitos, porém de forma menos acentuada, no gráfico da figura 7.58 , para a rede em modo acumulado, onde também encontramos um aumento a partir do ano de 2001 e um pico em 2005. A diferença dessa figura para a anterior é que o grau de conectividade em modo acumulado vai aumentando de 1 para 1,5 nos primeiros anos da rede, o que mostra a dinâmica média de conectividade entre os orientadores e orientandos, quando ainda não temos a presença de bibliotecas digitais que registrem as bancas de defesa.

\subsubsection{Maior e menor grau de conectividade}

Apresentamos nas figuras 7.59 e 7.60 a evolução do maior grau de conectividade. Vale lembrar que o maior grau de conectividade representa o número máximo de conexões que um mesmo nó estabeleceu na rede. Não apresentamos um gráfico do menor grau de conectividade, pois ele se manteve no valor 1 para todo o período de análise de nossa base de dados.

Maior grau de conectividade: modo ano-a-ano

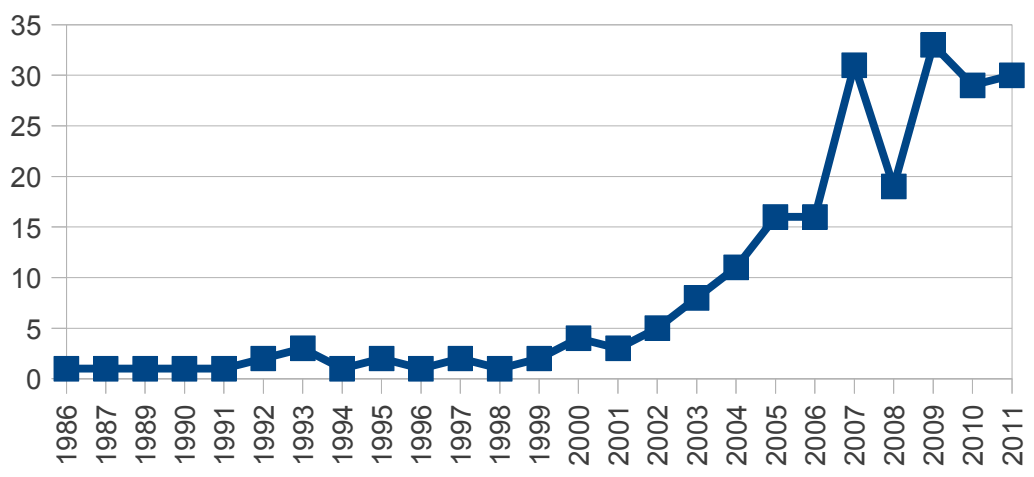

Figura 7.59. Maior grau de conectividade - modo ano-a-ano - Bibliotecas Digitais de Teses e Dissertações

Maior grau de conectividade: modo acumulado

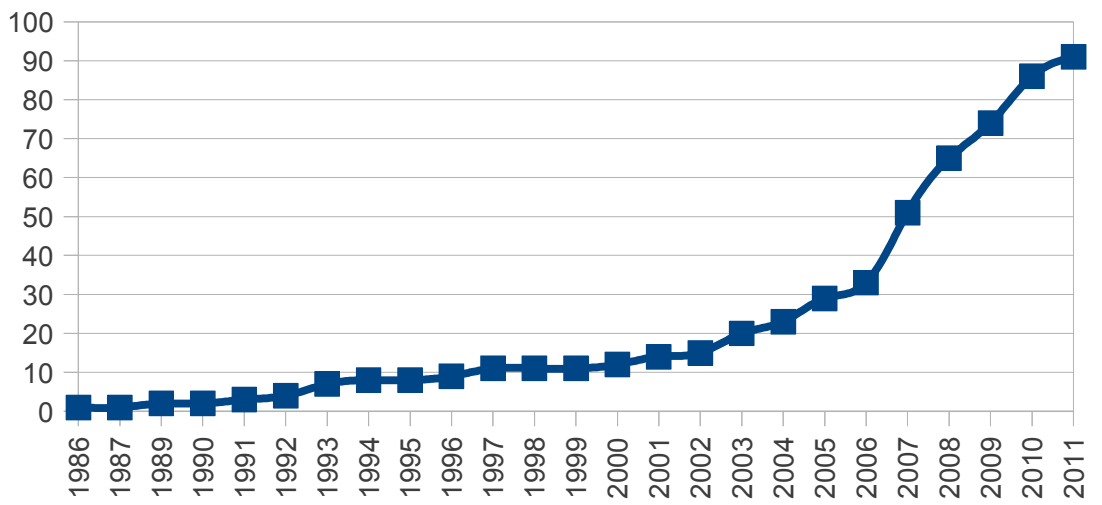

Figura 7.60. Maior grau de conectividade - modo acumulado - Bibliotecas Digitais de Teses e Dissertações 
Observando a figura 7.59, para a rede em modo ano-a-ano, notamos que o maior grau de conectividade começa a aumentar a partir do ano de 2001, atingindo um pico em 2007, não cessando de crescer até o fim de nosso período de análise. Novamente, temos aqui um fenômeno que diz respeito a entrada na rede das bibliotecas digitais que disponibilizam informação sobre os membros das bancas de defesa em 2001. Já em 2007, esse aumento expressivo no maior grau de conectividade salta de aproximadamente 15 para 30, praticamente dobrando de um ano para o outro, expressando a combinação de efeitos já relatados anteriormente, onde temos o maior ano de produção de documentos de nossa base conjuntamente com o maior número de bibliotecas que registram os membros de bancas. Esses elementos em conjunto criam campo para que tenhamos registro de mais conexões realizadas entre os pesquisadores, o que permite portanto identificarmos esse número máximo de 30 conexões realizadas em 2007, sendo possivelmente de um pesquisador que tenha participado de 4 a 5 bancas no mesmo ano. O mesmo não ocorre em 2008, quando já começamos a ter uma redução no número de documentos em nossa rede, porém em 2009 percebemos que novamente é possível identificarmos o mesmo padrão de maior grau de conectividade.

Já no gráfico da figura 7.60, para a rede em modo acumulado, percebemos os mesmos eventos relatados anteriormente, onde temos um maior crescimento no grau a partir de 2001, com um pico significativo em 2007 e uma leve redução em sua taxa de crescimento até o fim do período. Vale notarmos aqui que o maior grau de conectividade atingido por um mesmo pesquisador em nosso período de análise é de 90 pessoas, indicando que durante todo o período temos pesquisadores que chegaram a se conectar através da participação em diferentes bancas de defesas de teses e dissertações com 90 outros pesquisadores. É importante destacarmos que para nossa rede em análise, esse representa o maior grau de mobilidade atingido por um pesquisador até então.

\subsubsection{Distância geodésica}

Apresentamos nas figuras 7.61 e 7.62 a dinâmica da distância geodésica para nossa rede social de participantes nas bibliotecas digitais de teses e dissertações. Vale lembrar que a distância representa o número máximo de nós que existem entre dois nós em um determinado componente. 


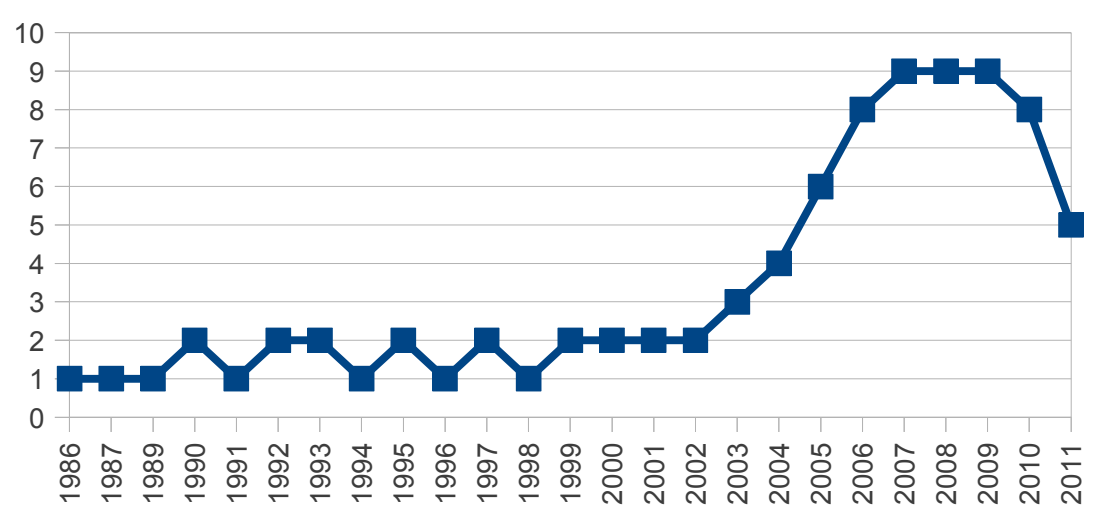

Figura 7.61. Distância geodésica - modo ano-a-ano - Bibliotecas Digitais de Teses e Dissertações

\section{Distância geodésica: modo acumulado}

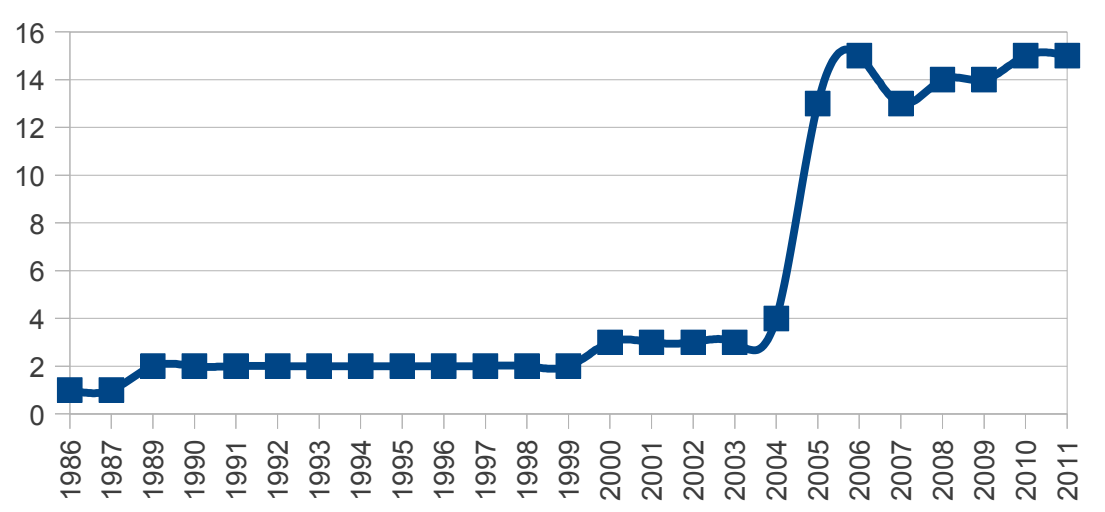

Figura 7.62. Distância geodésica - modo acumulado- Bibliotecas Digitais de Teses e Dissertações

Observando as curvas da figura 7.61 e 7.62, notamos que elas se assemelham a dinâmica das curvas das figuras 7.47 e 7.48 deste capítulo, quando apresentamos a dinâmica de evolução do número de componentes de nossa rede em análise. Sendo a distância geodésica a maior distância entre dois nós dentro de um componente, é natural esperarmos que quanto mais componentes e quanto maior forem esses componentes, maior será a distância geodésica entre nós ali presentes.

Quando o número de componentes começa a reduzir na rede, conforme a figura 7.47, a distância geodésica também se reduz. O que estamos observando aqui é que a redução no número de componentes a partir de 2009 é também acompanhada de uma redução de nós e links na rede, levando a termos menores componentes nesse período para a rede. Menores componentes, segundo nossas análise, causam menores distâncias geodésicas entre os nós.

Já na curva da figura 7.62, observamos um salto na distância geodésica do ano de 2004 para 2005, quando a mesma cresce de um valor 4 para 13 , representando um crescimento de $325 \%$ no 
período. Esse crescimento reflete, como descrevemos nas figuras 7.39 e 7.40 deste capítulo, o aumento de nós na rede com a chegada de um grande componente interconectado causando um sensível aumento na distância geodésica entre os nós. Este aumento de 2005 praticamente estabiliza a maior distância geodésica da rede em torno do valor 14, mostrando que novas conexões que são feitas desde então não ampliam a periferia desse maior componente, mas são feitas a partir de nós estabelecidos em seu centro.

\subsubsection{Coeficiente de clusterização}

O coeficiente de clusterização é um indicador que avalia a probabilidade média de que dois nós que são vizinhos de um mesmo nó se tornem conectados em algum momento. Apresentamos nas figuras 7.63 e 7.64 a dinâmica do coeficiente de clusterização para nossa rede de coautoria em revistas científicas.

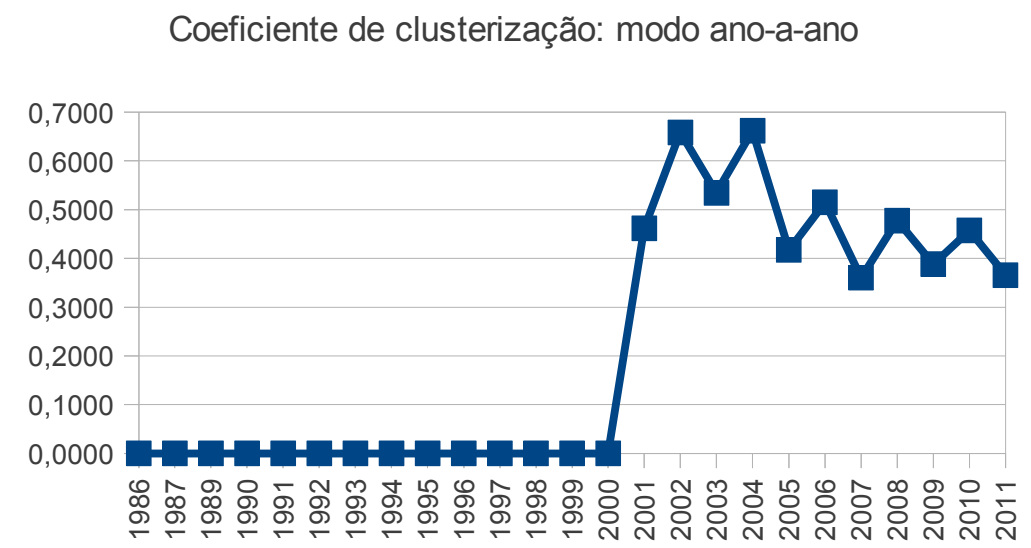

Figura 7.63. Coeficiente de clusterização - modo ano-a-ano - Bibliotecas Digitais de Teses e Dissertações

Coeficiente de clusterização: modo acumulado

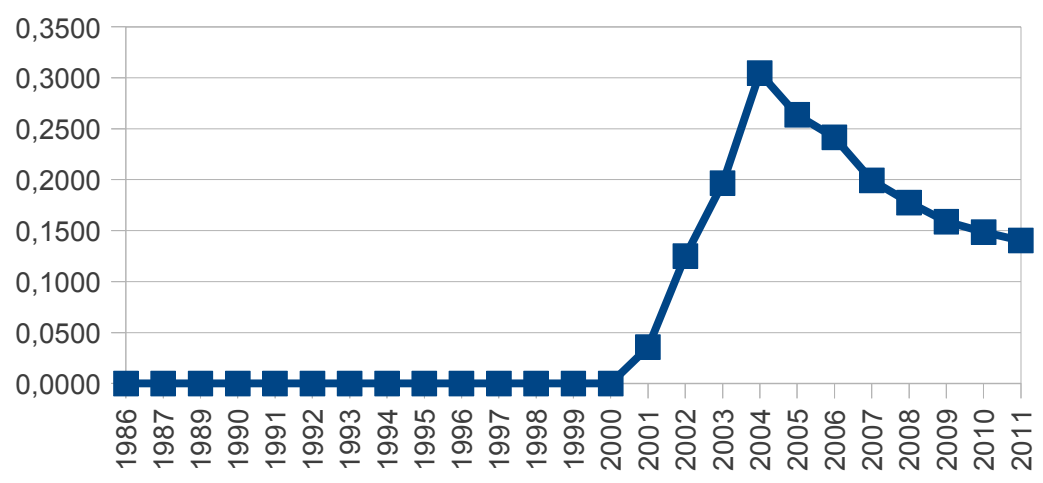

Figura 7.64. Coeficiente de clusterização - modo acumulado - Bibliotecas Digitais de Teses e Dissertações 
Observando os gráficos das figuras 7.63 e 7.64, notamos que o coeficiente de clusterização possui valor zero até o ano de 2001. Essa informação nos mostra que não houve transitividade de relações nessa rede até então, onde temos que dois nós que tenham se conectado a um terceiro não se conectaram entre si até então. Esse resultado é de se esperar, dado que até o ano de 2001 não temos em nossa base nenhuma biblioteca digital que apresente dados dos membros que participaram em suas bancas de defesas, ou seja, o que estamos aqui observando são as relações diretas entre orientadores e orientandos não havendo registros de conexões entre orientadores ou mesmo entre orientandos em nossa base. Já a partir de 2001 essa dinâmica muda, com a entrada dos dados da biblioteca digital da UFBA, já mostrando as primeiras relações entre membros de bancas. Para ilustrar como esse fato se dá em termos estruturais de nossa rede em análise, mostramos nas figuras 7.65 e 7.66 os sociogramas da rede em modo ano-a-ano para os anos de 2000 e 2001.

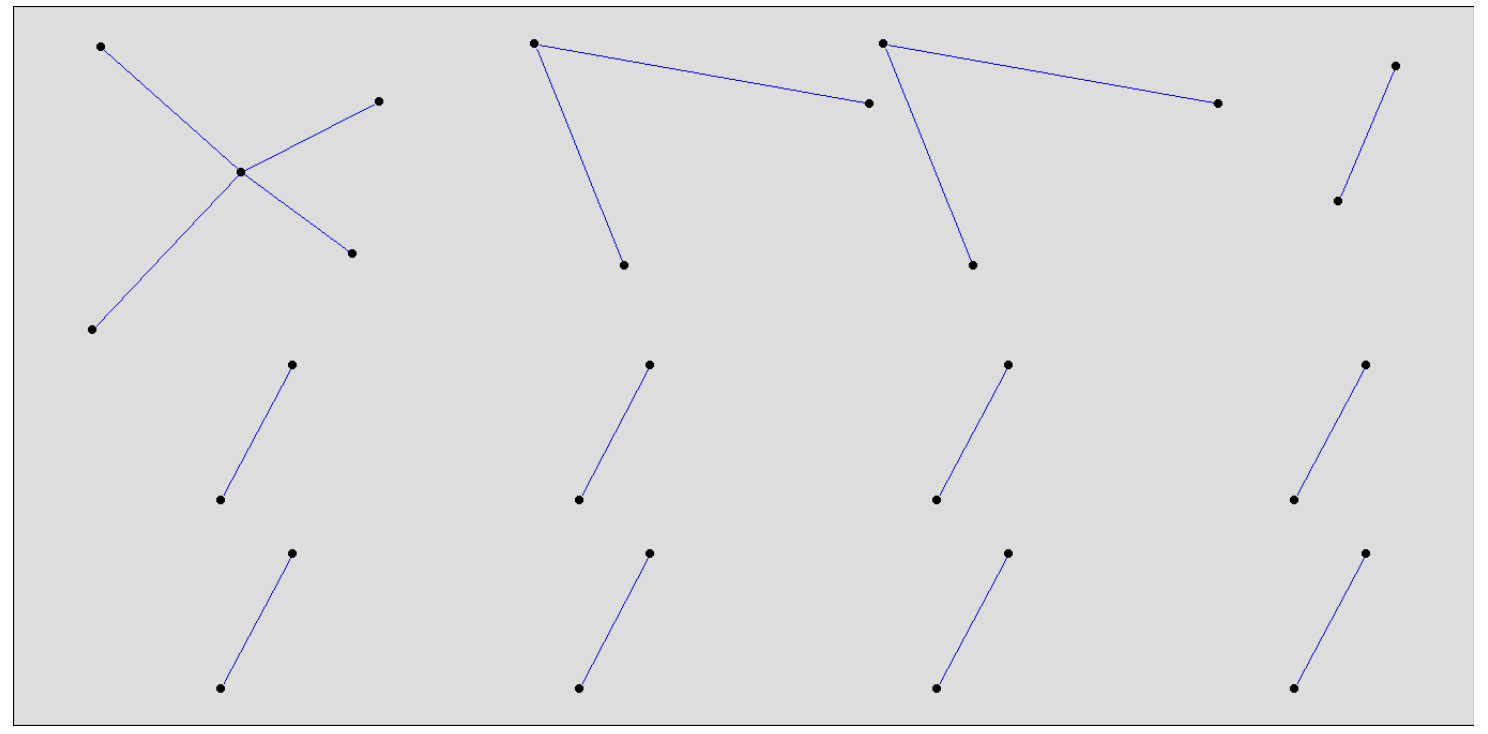

Figura 7.65. Rede de relações em bancas de defesas no ano de 2000 - modo ano-a-ano - Bibliotecas Digitais de Teses e Dissertações

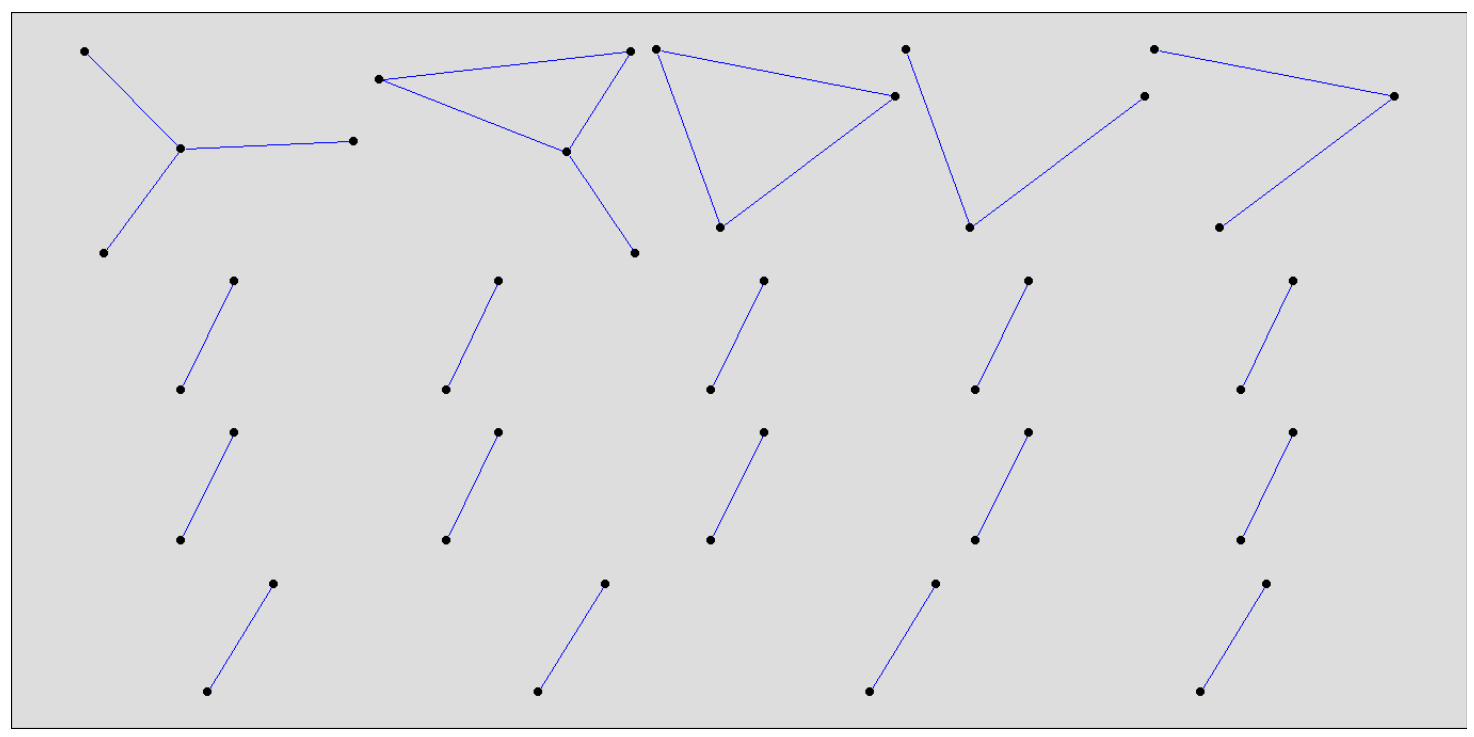

Figura 7.66. Rede de relações em bancas de defesas no ano de 2001 - modo ano-a-ano - Bibliotecas Digitais de Teses e Dissertações 
Observando a rede da figura 7.65, para o ano de 2000, não identificamos nenhuma transitividade de relação entre os pesquisadores, apenas relações diretas entre orientadores e orientandos. Já na figura 7.66, notamos os primeiros triângulos a se formarem na rede, mostrando ao menos três pesquisadores que se relacionaram diretamente entre si, evidenciando outra dinâmica de relação que passa a estar presente em nossa rede. É, portanto, essa dinâmica que vai elevando gradativamente o coeficiente de clusterização até o ano de 2004 para a rede vista pelos modos anoa-ano e acumulado. Isso indica que mais triângulos vão se formando, ampliando a taxa de transitividade entre os pesquisadores.

No entanto, a partir do ano de 2005 esse coeficiente passa a cair gradativamente até o final de nosso período. Esse evento condiz exatamente com o mesmo momento em nossa rede que os componentes estão começando a se juntar e gerando um componente principal de maior relevância na dinâmica organizacional dos nós. Ao formarem um componente principal mais significativo em termos de nós participantes, nossos dados aqui relatados indicam que ao mesmo tempo a rede diminui a sua taxa de transitividade, deixando de atuar em pequenos componentes onde os triângulos tem menos nós em potencial para se formarem passando a ser composta por maiores componentes com mais nós em potencial para transitarem entre si.

Esse crescimento da rede diminui sua taxa de transitividade, chegando a 15\% em 2011 para a rede em modo acumulado, indicando que é essa a probabilidade dos nós transitarem entre si ao final de nosso período, valor que ainda se encontra dentro da faixa documentada em nossa revisão bibliográfica para outras redes sociais. Já para a rede em modo ano-a-ano, o valor final do período é em torno de $40 \%$, apresentando um valor relativo maior de transitividade entre os participantes de nossa rede que participam em conjunto anualmente. Isso nos leva a inferir que se considerarmos apenas os participantes ativos em um determinado ano, eles possuem uma probabilidade maior de transitarem entre si do que quando consideramos a rede em modo acumulado. Fato que era de se esperar, dado que pessoas somente podem se articular entre si quando ativas e produtivas numa determinada área do conhecimento. 


\subsubsection{Coeficiente de potência}

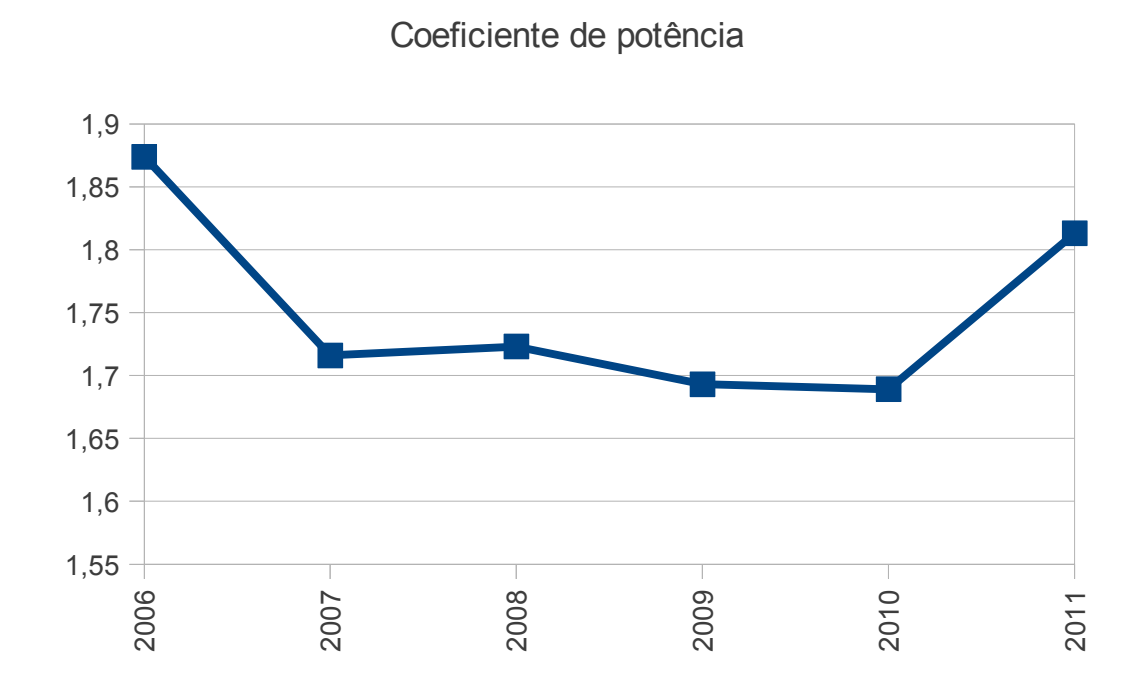

Figura 7.67. Coeficiente de potência - modo acumulado - Bibliotecas Digitais de Teses e Dissertações

A curva do coeficiente de potência para a rede em modo acumulado é apresentada na figura 7.67. Vale dizer que consideramos em nossa análise apenas a rede em modo acumulado, de maneira a termos a maior quantidade possível de nós presentes na rede para melhorar a precisão do cálculo do coeficiente de potência.

O coeficiente oscila do valor 1,9 caindo para 1,7 de 2007 até 2010 e subindo novamente para um 1,8 em 2011. Observamos que os valores são abaixo de 2,0 durante todo o período, o que nos leva a concluirmos que a rede é dominada, conforme mencionados em nossa revisão bibliográfica, por poucos indivíduos que possuem um número muito grande de colaboradores, normalmente, os orientadores de muitos alunos e participantes de requisitados de bancas registramos nos dados disponíveis pelas bibliotecas digitais em análise.

Vale mencionar aqui para reforçar esse argumento o fato de termos um maior componente expressivo nesta rede, além do crescimento contínuo do maior grau de conectividade, demonstrando que há nós em nossa rede que terminam por obter altos níveis de centralidade em relação aos demais.

\subsubsection{Evolução do grafo}

Como meio de facilitarmos a compreensão da dinâmica de evolução de uma rede social e 
ampliarmos nossa percepção de como esses movimentos de rede acontecem, construímos um vídeo que apresenta uma animação gráfica de como evoluiu no tempo a rede de participantes nas bibliotecas digitais em modo acumulado. Esse vídeo se encontra disponível no canal Youtube do

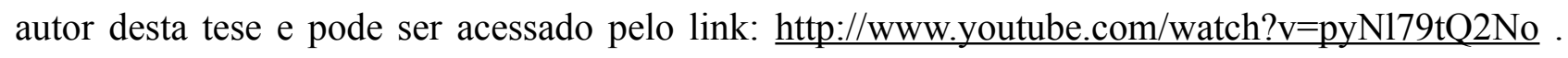
Para a melhor compreensão do vídeo, é importante considerar que a cada ano estão presentes apenas os nós que publicaram um conteúdo naquele ano e que na transição de um ano para o outro, ficam apenas os nós que estavam no ano anterior, sendo que novas conexões podem ser visualizadas em verde e conexões que existiam e deixaram de existir são visualizadas em vermelho.

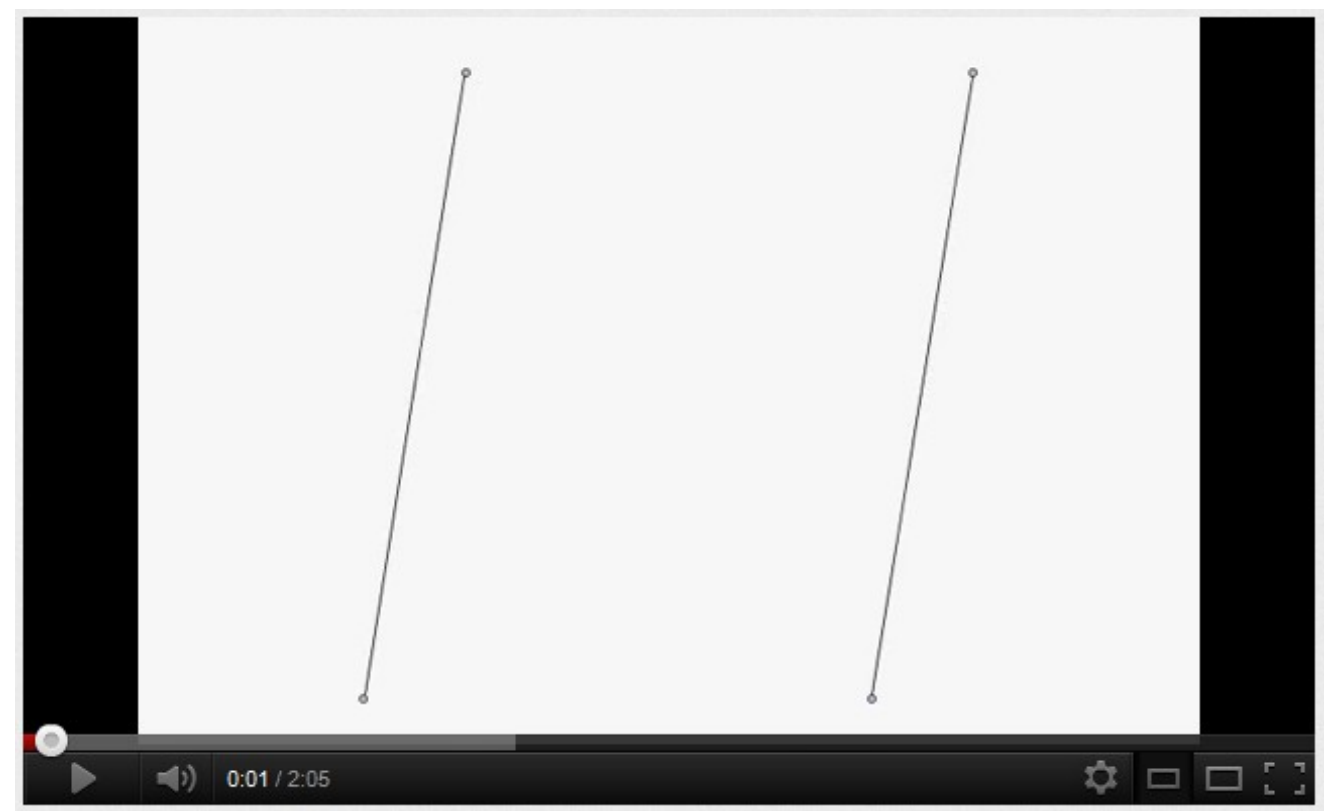

Figura 7.68. Animação gráfica da evolução temporal da rede de coautoria - modo ano-a-ano - Bibliotecas Digitais de Teses e Dissertações.

\subsubsection{Comunidades: principais agrupamentos}

Apresentamos nesta seção uma análise dos principais agrupamentos em termos institucionais que existem na rede de participantes nas bibliotecas digitais de teses e dissertações de nossa base. Para tanto, avaliamos apenas os nós mais centrais de nossa rede, ou seja, consideramos em nossa análise apenas os nós que possuíam acima de 14 conexões diretas com outros pares. Esse número de referência de conexões tinha por objetivo selecionar aproximadamente os 100 nós mais centrais da rede em modo acumulado no ano de 2011, permitindo com que identificássemos a que instituições pertenciam e qual sua influência na dinâmica da rede apresentada nos itens anteriores de nossa análise. Realizando o corte no número de nós presentes na rede pelo número de 14 conexões ou mais terminamos com uma rede de 97 nós, a qual apresentamos na figura 7.69. 


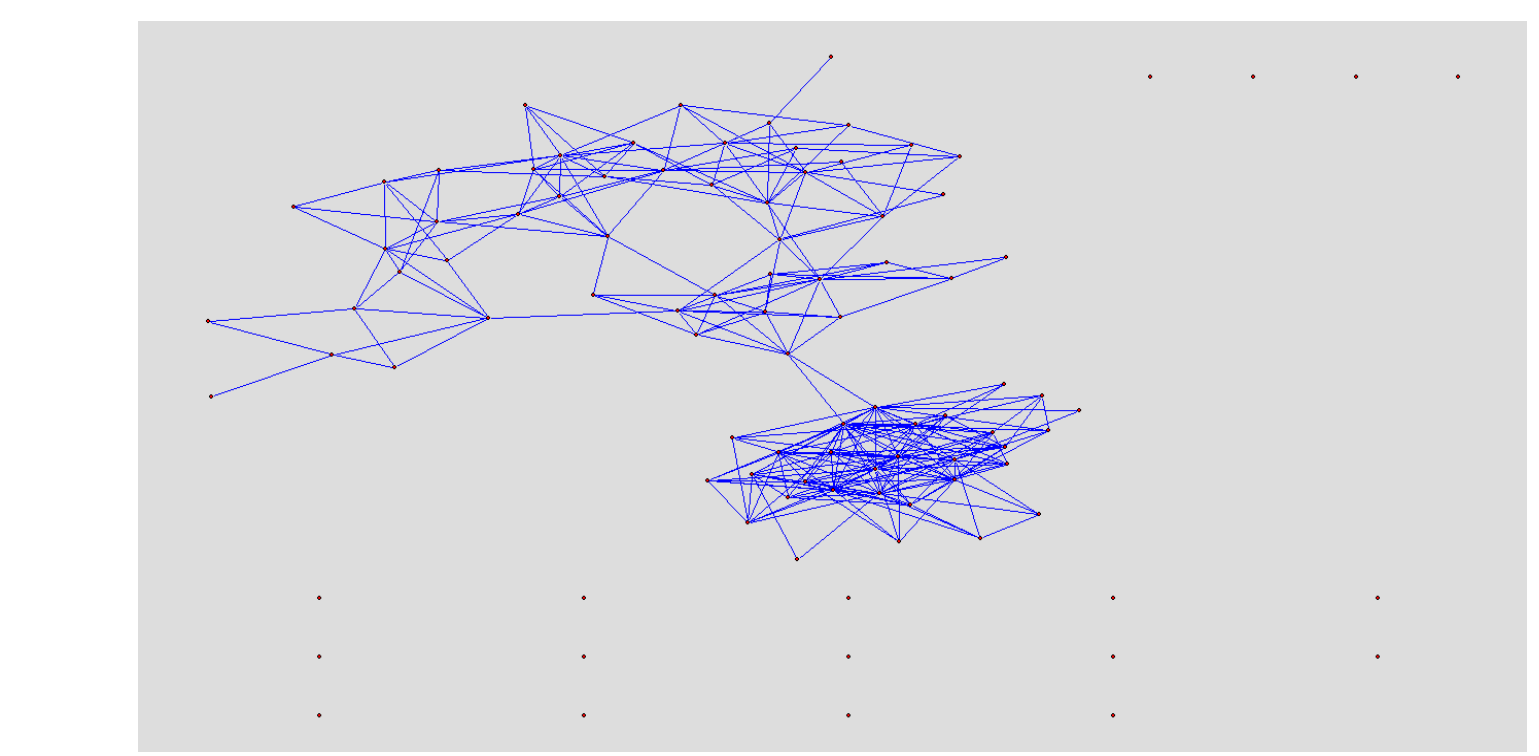

Figura 7.69. Rede dos 97 nós mais centrais de relações em bancas de defesas no ano de 2011 - modo acumulado - Bibliotecas Digitais de Teses e Dissertações

Após esse corte de nós, buscamos complementar as informações que tínhamos disponível em nossa base de dados, identificando com auxílio da análise do currículo Lattes dos pesquisadores mais centrais qual instituição cada um descrevia em seu perfil como sua instituição atual de trabalho. Desse modo, teríamos condições de avaliar institucionalmente como se daria atualmente a distribuição desses nós. Apresentamos na figura 7.70, a seguir, como a rede dos nós apresentados na figura 7.69 poderia ser agrupada em torno de suas instituições atuais de origem. 


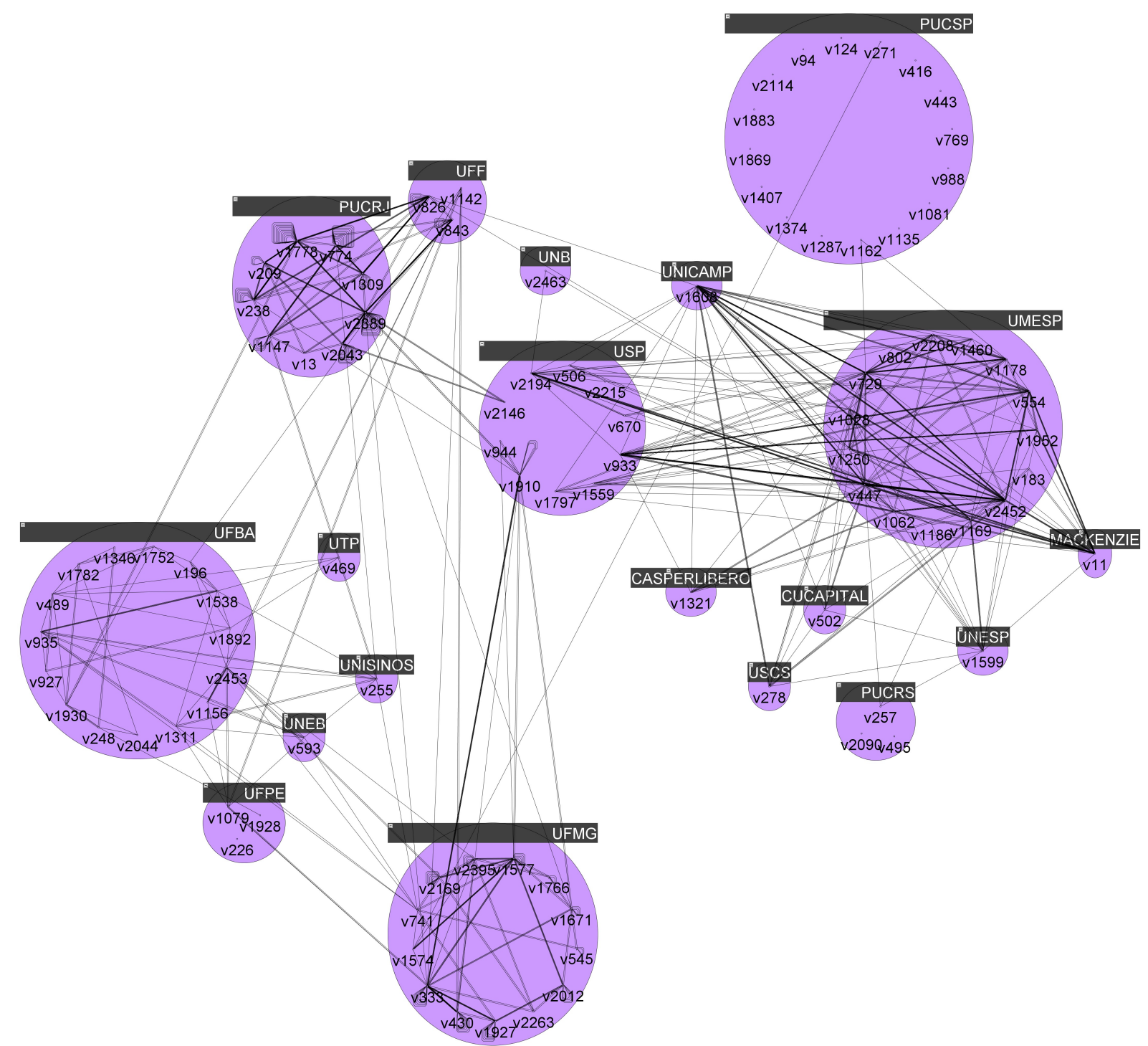

Figura 7.70. Agrupamento por instituição da rede dos 97 nós mais centrais de relações em bancas de defesas no ano de 2011 - modo acumulado Bibliotecas Digitais de Teses e Dissertações

$\mathrm{Na}$ figura 7.70, os nós foram agrupados por instituição de origem e o tamanho de cada agrupamento é relativo ao número de nós que ele possui. Para facilitar nossa análise da frequência de nós por instituições, apresentamos na tabela 7.10, a seguir, como ocorre essa distribuição. 


\begin{tabular}{|l|c|}
\hline \multicolumn{1}{|c|}{ Instituição } & Nós \\
\hline PUCSP & 16 \\
\hline UFBA & 15 \\
\hline UMESP & 15 \\
\hline UFMG & 13 \\
\hline USP & 10 \\
\hline PUCRJ & 9 \\
\hline PUCRS & 3 \\
\hline UFF & 3 \\
\hline UFPE & 3 \\
\hline C.U.CAPITAL & 1 \\
\hline CASPERLIBERO & 1 \\
\hline MACKENZIE & 1 \\
\hline UNB & 1 \\
\hline UNEB & 1 \\
\hline UNESP & 1 \\
\hline UNICAMP & 1 \\
\hline UNISINOS & 1 \\
\hline USCS & 1 \\
\hline UTP & 1 \\
\hline & $\mathbf{9 8}$ \\
\hline
\end{tabular}

Tabela 7.10. Distribuição de frequência dos nós mais centrais por instituição - Bibliotecas Digitais de Teses e Dissertações

Analisando a figura 7.69, notamos apenas um componente principal na rede acompanhado de vários nós isolados. O componente principal demonstra a relação entre os principais pesquisadores mais centrais de nossa rede, considerando aqueles que foram registrados ao menos alguma vez em nas bibliotecas digitais que apresentam dados de membros das bancas. A presença do pesquisador em uma das bancas facilita com que ele faça parte do componente central, dado que teremos seu registro de interação com outros pesquisadores, facilitando identificarmos sua mobilidade, bem como registrarmos seu maior grau de centralidade. Os outros pesquisadores que aparecem como nós isolados na figura, em sua maioria, registram alto número de conexões diretas com vários orientandos, acima de 14 devido ao nosso corte, demonstrando seu nível de centralidade local.

Já observando a figura 7.70 e a analisando com base nos dados apresentados na tabela 7.10, notamos alguns eventos interessantes em termos da estrutura de conexão de nossa rede em análise. A PUCSP tem o maior número de nós presentes na rede, porém quando observamos seu padrão de conexão institucional, percebemos apenas duas conexões para fora de seu ciclo de nós. Dentro do agrupamento institucional da PUCSP, terminam por se concentrar os vários nós que aparecem isolados na figura 7.69, o que ocorre por dois fatores em conjunto. A PUCSP é a biblioteca digital que disponibiliza dados mais antigos em nossa base, desde 1986, além disso a PUCSP não registra em seus metadados os membros de bancas de defesa. Esses dois fatores fazem com que os membros da PUC mais centrais apresentem alto nível de centralidade por terem orientado muitas pessoas ao 
longo de sua carreira e nós aqui termos o registro desses eventos, porém eles se relacionam com poucas pessoas, pois temos apenas registrado em nossa base seus movimentos quando eles foram convidados para bancas em outras instituições que registram em seus metadados os membros de bancas. Em perspectiva, esse modo de tratar os metadados termina por criar esses eventos de centralidade local que identificamos em nossa rede.

Quando notamos na tabela 7.10 as cinco próximas instituições após a PUCSP, percebemos que quatro delas, UFBA, UFMG, UMESP e PUC-RJ são instituições que registram em seus metadados os membros participantes de bancas. Novamente, o que estamos observando é uma dinâmica de rede condicionada pelo modo com que as instituições organizam seus metadados. A presença intensa dessas instituições pautando fortemente a estrutura da rede em nossa figura 7.70 se deve a soma de dois fatores. As instituições começam a apresentar dados a partir do ano de 2001, ou seja, são 15 anos mais recentes do que os dados disponíveis pela PUCSP, no entanto, como elas registram a presença das membros de bancas de defesa e como é natural de esperarmos que em cada banca estejam presentes membros da própria instituição, além do orientador, esses dois fatores aumentam a centralidade dessas instituições, fazendo com que elas acabem formando e articulando intensamente o maior componente de nossa rede. Esse efeito no modo de organização dos metadados termina por fazer com que essas instituições acabem se tornando atratores de conexão, aumentando sua centralidade relativa e sua presença na dinâmica e estrutura da rede em análise.

\subsection{Comparando padrões e estudos de referência}

Na seção 2.6.2 do capítulo 2, apresentamos um conjunto de seis princípios de organização das redes complexas, também retomados no capítulo 6, a respeito da metodologia deste trabalho: redes de livre escala, redes mundo-pequeno, evolução das redes pela conexão preferencial com os pontos mais centrais, competição entre os nós, robustez e formação de agrupamentos configurando espécies de comunidades.

O que notamos de nossos resultados acima apresentados é que os dois planos de relação que analisamos, seja da coautoria em documentos de revistas científicas, seja da participação em bancas de defesas de teses e dissertações, as redes seguem esses mesmos padrões, reconfirmando as evidências sobre os processos de formação das redes sociais que apresentamos no capítulo 2 .

Retomamos aqui, também para efeito de comparação e melhor análise de nossos resultados, as tabelas 3.2 e 3.3 do capítulo 4, onde apresentamos o resultado de outras análises de redes sociais com alguns dos indicadores que utilizamos em nosso trabalho, mas sobretudo em áreas científicas distintas e internacionais, como a Biomedicina, a Física de Alta Energia, Ciência da Computação, Sociologia, Administração e Matemática, além de áreas específicas brasileiras como a Gestão de 
Operações e Estratégias e Estudos Organizacionais. Vale lembrar que esses estudos apenas analisam a colaboração científica em torno da coautoria na produção de documentos para revistas científicas.

De forma a aproveitarmos esses resultados e analisarmos em perspectiva com nossos resultados para a área da Ciência da Comunicação, produzimos a tabela 7.11, que agrega todos esses resultados. Os dados da Comunicação são os valores dos indicadores no ano de 2011 em modo acumulado. É importante notar que os estudos não utilizaram todos os indicadores que propusemos nesta tese.

\begin{tabular}{|c|c|c|c|c|c|c|c|c|c|}
\hline Indicadores & $\begin{array}{l}\text { Univerciencia.org } \\
\text { Comunicação }\end{array}$ & $\begin{array}{c}\text { Medline } \\
\text { Medicina }\end{array}$ & $\begin{array}{l}\text { Spires } \\
\text { Física }\end{array}$ & $\begin{array}{c}\text { NCSTRL } \\
\text { Computação }\end{array}$ & Administração & Matemática & Sociologia & $\begin{array}{l}\text { Gestão de } \\
\text { Operações }\end{array}$ & $\begin{array}{c}\text { Estratégia e } \\
\text { Estudos } \\
\text { organizacionais }\end{array}$ \\
\hline Artigos & 9638 & 2163923 & 66652 & 13169 & - & - & - & - & - \\
\hline Co-autoria média & 1,4453 & 3,754 & 8,96 & 2,22 & 2,86 & 3,9 & 1,88 & 2,52 & 2,25 \\
\hline Nós em co-autoria & 4700 & 1520251 & 56627 & 11994 & 10176 & 253339 & 197976 & 3148 & 2072 \\
\hline Links & 8372 & - & - & - & - & - & - & - & - \\
\hline Densidade média & 0,00076 & - & - & - & - & - & - & - & - \\
\hline Componentes & 1111 & - & - & - & - & - & - & - & - \\
\hline$\%$ dos nós no maior componente & 11,89 & 92,6 & 88,7 & 57,2 & 45,4 & 82 & 34,5 & 48,5 & 37,9 \\
\hline Tamanho do maior componente & 559 & 1395693 & 49002 & 6396 & - & - & - & - & - \\
\hline Tamanho do segundo maior componente & 78 & 49 & 69 & 42 & - & - & - & - & - \\
\hline Grau de conectividade médio & 3,56 & - & - & - & - & - & - & - & - \\
\hline Grau de centralização da rede & 0,0121 & - & - & - & - & - & - & - & - \\
\hline Maior grau de conectividade & 60 & - & - & - & - & - & - & - & - \\
\hline Menor grau de conectividade & 1 & - & - & - & - & - & - & - & - \\
\hline Distância geodésica & 13 & 24 & 19 & 31 & - & - & - & - & - \\
\hline
\end{tabular}

A seguir, apresentamos algumas observações sobre a tabela 7.11:

- as amostras de dados variam bastante em termos de quantidade de documentos analisados e nós participantes das redes;

- as faixas de tempo (observação retirada dos estudos) é também bastante variável, em geral abrangendo final dos anos 1990 e começo dos anos 2000. É fundamental levarmos isso em consideração em nossa análise. No entanto, mais do que sermos precisamos em termos de comparação, nos interessa os contrastes e tendências que podemos observar a partir deles;

- a coautoria média na área da Comunicação é a mais baixa de todas as áreas analisadas, estando mais próximo da Sociologia $(1,88)$ e mais distante da Física $(8,96)$;

- a porcentagem de nós no maior componente apresenta uma das maiores diferenças observadas entre todas as áreas. A Comunicação tem apenas em torno de $12 \%$ dos seus nós nesse componente, sendo que a rede com menor quantidade de nós na sequência seria a Sociologia, mas já com $34,5 \%$ dos nós. É um resultado que mostra um nível de agrupamento desses componentes bastante interessante, deixando bem evidente uma fragmentação expressiva na área da Comunicação; 
- A distância geodésica é a menor na rede da Comunicação. No entanto, devemos também levar em consideração que essa rede é a que possui o menor componente principal de todos, logo, tendo menos nós que poderiam potencialmente ampliar essa distância. Dizendo de outra maneira, não devemos levar esse resultado como um indício de que a rede apresenta uma menor distância entre seus nós, mas sim como um efeito dela ter um componente principal pouco expressivo, logo de menor dimensão em relação ao conjunto de nós da rede;

- O coeficiente de clusterização é bastante próximo entre as áreas da Comunicação, Física e Computação, sendo que a Medicina apresenta o menor em relação a todos os outros. Para interpretar esse resultado de forma a entendermos o comportamento da rede como um todo, precisamos levar em consideração qual a contribuição do maior componente da rede para o cálculo da clusterização. Nas redes de Medicina, Física e, até mesmo, Computação, o maior componente tem efeito o maior número de nós da rede, logo, podemos afirmar que a transitividade de nós na área da Física e Computação é consideravelmente maior que a Medicina, que parece apresentar um comportamento de alto nível de centralização de suas conexões. Quando analisamos no caso da Comunicação, o componente principal tem baixa influência na dinâmica da rede, logo, mesmo o coeficiente de clusterização sendo alto, isso indica muito mais que nos fragmentos da rede há alta transitividade do que entre os fragmentos. Logo, a Comunicação parece mostrar alta fragmentação, mas fragmentos bem conectados.

Como breve conclusão desse pequeno exercício de comparação, entendemos que a Comunicação, de modo geral, apresenta uma rede altamente fragmentada, evidenciando características de isolamento e baixa articulação entre os seus componentes. Vale frisar que essa afirmação reforça os resultados que apresentamos ao longo deste capítulo.

Sem dúvida, a análise de rede mostra importantes características que nos permitem descrever cada uma das áreas acima apresentadas, facilitando visualizar os efeitos dos comportamentos de cada área e contribuindo para investigações que busquem mapear as causas sociais e políticas que podem ser responsáveis por seus efeitos.

Com isso, concluímos a apresentação dos resultados obtidos em nossas análises das redes sociais de coautoria nas revistas científicas e das relações em bancas de defesas de teses e dissertações disponíveis no banco de dados da biblioteca digital federada Univerciencia.org. 


\title{
Capítulo 8
}

\section{Considerações finais}

\author{
"O importante é fazer as coisas com gosto. \\ E se escolheu um tema que lhe interessa, se decidiu dedicar realmente à tese \\ o período, mesmo curto, que lhe foi prefixado (...), verá agora que a tese \\ pode ser vivida como um jogo, como uma aposta, como uma caça ao tesouro." \\ Umberto Eco
}

Chegamos as considerações finais no ponto de analisar que efeitos e que percepções nos trazem esse percurso que realizamos, do momento onde nos propusemos a enxergar possíveis planos de relações que poderiam ser analisados a partir dos dados coletados por uma biblioteca digital federada até a realização dessas análises e o conjunto de inferências que pudemos ali propor.

De modo a melhor organizar essas considerações finais e destacarmos os tipos de contribuições que a realização desta tese produziu em nosso conhecimento, dividimos este capítulo em 3 seções que expressam o encontro de 3 pontos de vista deste trabalho: considerações sobre a análise de redes sociais, sobre as Ciências da Comunicação e sobre a própria área da Ciência da Informação.

No entanto, antes de entrarmos no detalhamento dessas considerações, gostaríamos de pontuar com maior destaque uma percepção geral sobre os resultados desta tese. A dinâmica e a estrutura das redes sociais aqui analisadas denotam padrões, movimentos e estruturas que funcionam e refletem, sobretudo, respostas às demandas e regras do jogo instauradas pela política científica vigente no campo de nosso estudo. Sem dúvida, há que se considerar as especificidades do campo nesses resultados obtidos, o que faremos a seguir em um dos 3 pontos de vista de nossas considerações finais, mas é essa percepção geral que nos permite colocarmos em questão e jogarmos uma luz sob o fato de que o processo que leva a formação dessas redes sociais, os seus eventos de promoção e geração de conectividade entre seus participantes são sistematicamente influenciados e, poderíamos até dizer, determinados por essas regras da política científica.

Se entendemos, como vimos no capítulo 3, que o que determina um campo do conhecimento é a produção de discurso e a sistematização desse discurso em dispositivos de produção científica que giram em torno de objetos de pesquisa, técnicas, conceitos e interesses em comum, seja em forma de colaboração ou mesmo disputa, também entendemos que esse discurso não se expressa apenas na produção científica de um campo, mas, sobretudo, se expressa definindo as regras do jogo que são utilizadas para demarcar o próprio campo. Logo, percebemos que o que estava em análise como objeto de pesquisa desta tese eram as relações sociais criadas pelos pesquisadores em 
torno da produção desse discurso refletidas nas articulações em torno dos documentos oriundos das revistas científicas e das bibliotecas digitais de teses e dissertações.

"A disciplina é um princípio de controle da produção do discurso. Ela lhe fixa os limites pelo jogo de uma identidade que tem a forma de uma reatualização permanente das regras. Tem-se o hábito de ver na fecundidade de um autor, na multiplicidade dos comentários, no desenvolvimento de uma disciplina, como que recursos infinitos para a criação dos discursos. Pode ser, mas não deixam de ser princípios de coerção; e é provável que não se possa explicar seu papel positivo e multiplicador, se não se levar em consideração sua função restritiva e coercitiva" (Foucault, 2011, p.36).

Mas, de que lugar percebemos essa relação entre a política científica e os resultados apontados pela análise de redes sociais? Como ela ocorreu e pode ser percebida como reflexo nesses movimentos de rede? Algumas características deste trabalho precisam ser aqui descritas para que possamos melhor mapear esse lugar de onde falamos. Ao trabalharmos com a produção científica coletada de 49 revistas, mais de 9000 documentos e mais de 9000 pessoas expressas na sua produção, além de 12 bibliotecas digitais de teses e dissertações com aproximadamente 2000 documentos e 2500 pessoas, representando em torno de 30\% dos programas de pós-graduação da área, não podemos de fato afirmar que temos uma visão que fale em nome da totalidade do campo da Ciência da Comunicação, mas podemos e devemos aqui considerar, com base em nossos próprios resultados, que o universo de pesquisa desta tese reflete e é determinantemente influenciado pelo o que acontece na área como um todo.

Esses movimentos são percebidos como reflexos de políticas específicas de estímulo a produção científica, como o caso dos editais de apoio a revistas científicas em formato aberto, sendo também percebidos em políticas mais gerais e que afetam a área, como o caso da ampliação do número de programas de pós-graduação. São também percebidos a partir dos causas que regulam como devem ocorrer a formação de bancas de defesas de teses e dissertações, sobretudo na exigência da presença de membros externos e promoção da mobilidade dos pesquisadores, levando a formação de maiores agrupamentos de nós e links, além das causas de classificação da qualidade de uma revista científica e os impactos que isso traz para a avaliação de programas de pósgraduação a partir da produção científica de seus docentes e discentes, levando a um crescimento fragmentado dos componentes da rede e a estratégias de composição de grupos locais em busca de maior produtividade e melhores avaliações para seus respectivos trabalhos. 
De certa forma, o que temos percebido e para onde apontam os nossos resultados é que esses movimentos de rede operam sob o efeito de uma certa forma de racionalidade e é essa mesma racionalidade que faz com que esses movimentos aconteçam. Racionalidade que é aqui entendida como o que produz e é produzido pelo próprio jogo da ciência, com foco específíco em como esse jogo é vivenciado por um determinado campo do conhecimento.

Uma escolha metodológica e que nos favoreceu a construção desse olhar é o fato de termos observado dois planos de relação entre os pesquisadores do campo da Comunicação, o plano da coautoria em documentos de revistas e o plano das relações de participação em bancas de defesa de teses e dissertações. Como são dois planos praticados por um universo similar de pessoas em torno de seu fazer científico, a percepção do contraste e a singularidade na composição de seus movimentos tornou mais evidente que diferentes causas poderiam ali estar em ação. Ao entendermos melhor as regras do jogo que orientam a produção científica de documentos para revistas e a formação de bancas de defesas tornou-se evidente a influencia dessas regras nos modos de constituição de cada um dos planos de relação em análise.

É interessante destacarmos, para concluir essa visão geral das considerações finais, a potencialidade dos métodos estruturais e dinâmicos da análise de redes sociais, sobretudo quando operados em conjunto e sob a luz de uma visão que busca contextualizar os fenômenos sociais e políticos de constituição das redes.

\subsection{Considerações sobre a análise de redes sociais}

A análise de rede sociais é um campo ainda em desenvolvimento e amadurecimento no Brasil com poucos trabalhos acadêmicos, teses e dissertações defendidas utilizando seus princípios de análise. A área apresenta ainda suas primeiras experiências e resultados de larga escala na área das Ciências da Informação, carecendo de estudos que permitam experimentarmos diferentes composições de indicadores, modos de observação estruturais, mas também maior exploração da análise dinâmica de redes, o que foi um de nossos focos de experiência com esta tese. Acreditamos que nosso estudo, pela abrangência e escala temporal, permitiu experimentarmos de modo significativo a análise dinâmica de redes, criando campo de experiência para o aprofundamento de técnicas e possibilidades de pesquisa em estudos futuros, sobretudo no que concerne a sua aplicação na área de bibliotecas digitais. Vale ressaltar aqui o interessante efeito visual que a produção das animações de evolução dos grafos de colaboração trouxe para o desenvolvimento da pesquisa. Entendemos que novos experimentos que busquem tornar mais próximo do cotidiano das pessoas o que entendemos por ser a evolução das relações em uma rede podem ser importantes contribuições para a pesquisa científica na área da Ciência da Informação. 
Em relação ao conjunto de indicadores e a nossa matriz de análise, vale dizer que ela se mostrou bastante adequada para o tipo de análise a que nos propusemos. Através dessa composição de indicadores utilizados, pudemos identificar diferentes movimentos, padrões estruturais e dinâmicos em nossas redes analisadas, facilitando com que pudéssemos integrar nossa análise percebendo efeitos distintos e compostos. Os indicadores facilitaram encontrarmos os principais eventos que influenciaram a dinâmica de cada uma das redes, inclusive nos permitindo checarmos os dados encontrados e identificar importantes resultados registrados nos metadados que do contrário seriam difíceis de perceber, como o caso da entrada retardada dos documentos da revista Comunicação \& Educação, o caso dos efeitos da relação com a área da Saúde em termos das revistas científicas e também o efeito da análise em conjunto das bibliotecas que registram dados de participação em defesas de teses e dissertações e daquelas que não registram.

Em relação a escolha de realizarmos as análises em dois modos temporais, chamados nesta tese de acumulado e ano-a-ano, vale dizer que eles se mostraram de fundamental importância por mostrarem diferentes tendências quando nos interessa o efeito da evolução dinâmica da rede. Pudemos ali identificar com facilidade eventos pontuais e marcantes na dinâmica da rede em um determinado ano, através do uso dos indicadores nas redes em modo ano-a-ano, além de identificarmos tendências, estabilidades e mudanças ao longo do tempo nas redes em modo acumulado. A composição da matriz de indicadores proposta com esses dois modos de organização temporal se mostrou um instrumento de pesquisa que facilita identificarmos a emergência de padrões, tendências e movimentos que influencia o desenvolvimento dinâmico e estrutural de nossas redes analisadas.

\subsection{Considerações sobre o campo das Ciências da Comunicação}

Os resultados apresentados no capítulo anterior mostram diferentes movimentos de formação de redes sociais em torno da produção científica de pessoas oriundas do campo da Comunicação. Ao mapearmos o que e como se constitui esse campo no capítulo 4, percebemos importantes tendências que entendemos também estarem refletidas nos nossos resultados obtidos.

De uma forma esquemática e com o objetivo de sintetizar as características do campo da Comunicação e os efeitos que entendemos serem reflexos dessas características nos indicadores de redes sociais utilizados para análise, apresentamos a tabela 8.1 a seguir. É importante ressaltar, como modo de leitura da tabela, que não há uma correspondência unívoca entre as duas colunas, ou seja, não entendemos que um único fator da primeira coluna é o causador do resultado da segunda, mas sim que esses fatores em conjunto levam aos resultados obtidos. Outro ponto importante a ressaltar é que observamos aqui apenas os resultados da rede de coautoria da área, dado que muitas 
das reflexões mapeadas no capítulo 4 foram originadas de estudos que analisaram a produção científica da Comunicação pelo prisma da produção de artigos para revistas e eventos científicos.

\begin{tabular}{|c|c|}
\hline Características da área da Comunicação & Resultados da Análise de Redes Sociais - Coautoria \\
\hline acirramento na disputa de recursos & $74,5 \%$ dos documentos são de um único autor \\
\hline visão tecnicista e fragmentada da área & Nós e links crescemem conjunto com programas de pós-graduação da área \\
\hline abrangência temática & $\begin{array}{l}\text { Crescimento da rede por meio de componentes fragmentados. Não se } \\
\text { identifica a formação de um núcleo expressivo. }\end{array}$ \\
\hline forte relação multidisciplinar & $\begin{array}{l}\text { Coeficiente de clusterização alto, indicando agrupamentos dispersos com } \\
\text { muita relação local, mas baixa conexão entre os núcleos. }\end{array}$ \\
\hline $\begin{array}{l}\text { área em construção, sem referenciais terminológicos consensuais } \\
\text { entre os pesquisadores; }\end{array}$ & $\begin{array}{l}\text { Coeficiente de potência acima de } 2 \text {, indicando que a rede é dominada por } \\
\text { muitos agrupamentos com poucos colaboradores cada um }\end{array}$ \\
\hline $\begin{array}{l}\text { não há uma fronteira muita clara estabelecida entre as pesquisas } \\
\text { desenvolvidas; }\end{array}$ & $\begin{array}{l}\text { Agrupamentos interdisciplinares, sobretudo influenciados pela área da } \\
\text { Saúde. }\end{array}$ \\
\hline maior parte da produção científica é realizada por autores individuais & \\
\hline $\begin{array}{l}\text { um crescimento expressivo nos último } 10 \text { anos de programas de pós- } \\
\text { graduação }\end{array}$ & \\
\hline
\end{tabular}

Tabela 8.1 - Características da área da Comunicação e resultados da análise de redes sociais.

O que observamos na tabela 8.1 é que as características da área que a definem como fragmentada e pouco articulada entre si, seja pela abrangência temática, pela falta de fronteira entre as pesquisas, falta de referenciais terminológicos consensuais, relação multidisciplinar ou mesmo pelo acirramento na disputa de recursos entre os pesquisadores possuem um efeito direto nos resultados da análise de redes sociais de coautoria. Os indicadores de componentes, coeficiente de clusterização, coeficiente de potência e análise de agrupamento institucional apenas confirmam esses resultados já sinalizados pelas estudos que apresentamos no capítulo 4.

O que é interessante notar aqui é que esses indicadores podem servir como instrumentos de reflexão da área sobre si mesma, sendo úteis no acompanhamento de políticas ou ações que tenham, eventualmente, interesse em discutir e colocar em questão essas características da área apresentadas na tabela 8.1. Trabalhar essas características e perceber seus efeitos através da análise de redes sociais, com os indicadores aqui propostos, na coautoria de revistas científicas da área é um modo de olhar sobre si mesmo que pode ser melhor explorado pela própria política científica da área.

Dessa forma, como já indicamos no início deste capítulo e agora aprofundamos com a análise específica da área da Comunicação, entendemos que nossas duas primeiras hipótese de pesquisa tornam-se válidas, a saber:

A análise de redes sociais fornece condições metodológicas para o mapeamento de planos de relações sociais, facilitando perceber os efeitos das políticas que regulam essas relações e se propõe a operar como estratégias de atuação em suas características estruturais e dinâmicas.

A produção científica de uma área do conhecimento, em nosso caso a área 
da Ciências da Comunicação, constitui um plano de comunicação singular a partir do qual podemos analisar suas relações sociais mediadas pela necessidade de produção científica, além dos efeitos, impactos e influências que são geradas pelas políticas científicas que regulam o funcionamento da área.

\subsection{Considerações sobre a Ciência da Informação}

A biblioteca digital federada se mostrou ao longo deste trabalho como um sistema de informação fundamental para a agregação de dados que do contrário se encontrariam dispersos em diversas fontes de informação e diferentes formatos de dados, chegando mesmo a inviabilizar uma possível agregação de documentos na quantidade e intervalo de tempo que foram aqui analisados. Trabalhamos ao todo com mais de 11.800 documentos coletados e 61 diferentes fontes de informação. Na base de revistas científicas, obtivemos dados num intervalo de 15 anos e na base de bibliotecas digitais, um intervalo de 26 anos, o que permitiu ao nosso estudo uma das maiores abrangências em termos de volume na área da Ciência da Comunicação no Brasil, segundo nossa própria revisão bibliográfica. Vale dizer que dificilmente teríamos conseguido agregar tal volume de dados neste intervalo de tempo se não tivéssemos um modo técnico homogêneo para que todas as fontes de informação pudessem se enquadrar, permitindo a disponibilização e coleta de seus dados. Sem dúvida, trata-se de um esforço coletivo da maior relevância para a área científica, permitindo que estudos como este presente possam ser realizados.

Além disso, vale aqui destacarmos os resultados em termos de qualidade dos metadados que aqui foram coletados. Tivemos de descartar apenas $2 \%$ do número total de documentos que coletamos, dado que esses apresentavam problemas técnicos de formatação ou falta de informação para que pudessem ser considerados em nossa análise. Entendemos que essa perda de informação se tornou praticamente irrelevante para os resultados aqui apresentados, permitindo que possamos analisar com a maior abrangência possível a estrutura e dinâmica das redes sociais a que nos propusemos, encontrando apenas limitações do ponto de vista dos dados que não tínhamos, mas não daqueles já coletados. No entanto vale refletirmos aqui que quanto mais ricos e completos forem esses metadados, maiores possibilidades de enriquecer a análise de relações sociais teríamos a nossa disposição, tais como dados sobre a filiação de cada pesquisador, se são alunos, professores ou assistentes técnicos colaborando em uma pesquisa.

Em relação a abrangência de nosso estudo, vale ressaltar também a limitação que encontramos se estivéssemos interessados em caracterizar uma determinada área do conhecimento. 
Como demonstramos ao longo do trabalho, há hoje em torno de 39 programas de pós-graduação na área da Ciência da Comunicação e nós tínhamos à disposição apenas dados de 12 bibliotecas digitais de instituições que possuem programas de pós-graduação na área. Isso cria um efeito que é fundamental considerarmos como produto desta tese, sendo que o que conseguimos observar e relatar em nosso estudo é muito mais a dimensão alcançada por uma determinada federação de bibliotecas digitais do que propriamente a dinâmica social de uma determinada área do conhecimento, mesmo sabendo, como apontamos acima que esse universo reflete tendências da área. É importante evidenciarmos isso, pois não seria possível afirmarmos que nossos resultados servem para a área da Ciência da Comunicação como um todo, dado que muitos possíveis dados importantes não foram aqui coletados e analisados, sendo que não era esse o nosso objetivo, assim como também não era avaliar se nossa amostra poderia ser significativa estatisticamente para que pudéssemos afirmar que estávamos de fato obtendo conclusões para a área.

No entanto, vale aqui considerarmos alguns efeitos dessa análise. Se as revistas científicas de modo geral, assim como as instituições que possuem programas de pós-graduação em uma determinada área do conhecimento disponibilizarem seu acervo de produção científica em formato aberto nos padrões do OAI-PMH, seguindo os mesmos padrões de qualidade e organização dos metadados que aqui relatamos, podemos afirmar que teríamos condições de construirmos uma federação de bibliotecas digitais que nos permitiria coletar e analisar de modo abrangente a dinâmica social de formação de redes e colaborações entre os pesquisadores dessa área. Desse modo, teríamos condições de generalizar nosso método de análise aqui apresentado com enfoque em uma determinada federação de bibliotecas digitais para uma área do conhecimento de modo geral. O que notamos a partir de nossos resultados é que o ambiente de uma biblioteca digital federada não apenas pode coletar e sistematizar a produção científica de uma área do conhecimento, mas pode influenciar de modo decisivo nos meios de organização dessa área, sendo uma fonte importante de indicadores, métricas e base para eventuais pesquisas que busquem entender as tendências dessa área.

Desse modo, entendemos que torna-se válida nossa terceira hipótese de pesquisa desta tese, saber:

O ambiente federado de bibliotecas digitais constitui um sistema de informação que permite ampla agregação da produção científica em formato aberto disponibilizada por diversas instituições, tais como revistas e bibliotecas digitais de teses e dissertações, se tornando um ambiente favorável para o estudo das redes sociais mediadas pela necessidade de 
produção científica de uma ou mais áreas do conhecimento.

Já no que concerne a questões da dinâmica de seus sistemas de informação, notamos uma diferença importante nas bibliotecas digitais, dado que apenas uma minoria, em torno de $33 \%$ das bibliotecas, disponibilizam dados dos participantes das bancas de defesas. Seria fundamental que outras bibliotecas pudessem também aderir a esse formato, permitindo com que pudéssemos ter uma análise mais completa da dinâmica de relação entre os pesquisadores que colaboram em torno desses eventos científicos. Em relação as revistas científicas, não percebemos nenhuma diferença significativa em termos do modo de organização de seus metadados.

Além disso, entendemos que a análise de redes sociais, do modo como apresentado aqui, é um instrumento de pesquisa de importante contribuição para área da Ciência da Informação como um todo, podendo ser aplicada em diversos estudos que busquem analisar modos relacionais de produção, consumo, apropriação e acesso a informação. Vivemos cada vez mais em tempos de excesso de informação, onde a capacidade de síntese e análise do pesquisador se torna um elemento singular em busca pelo conhecimento científico, logo, a análise de redes sociais parece se tornar uma ferramenta de fundamental importância para o pesquisador da área.

Outro ponto importante em relação ao campo da Ciência da Informação é explicitarmos aqui o uso crítico da análise de redes sociais nas pesquisas realizadas. É fundamental que procuremos investigar as causas sociais, as forças políticas e seus respectivos modos de organização que levam a constituição característica de cada rede em análise. O padrão estrutural e dinâmico que obtemos como resposta a uma determinada pergunta que fazemos a um conjunto de dados se insere em um contexto, bem como o próprio modo de organização dos dados e, sobretudo, os eventos que geram e estimulam as conexões que estão sob análise. Entender que contexto é esse e que forças são colocadas em jogo favorece a ampliação do campo reflexivo e crítico que pode ser gerado pelo uso da análise de redes sociais, o que nos parece uma importante característica a ser desenvolvido dentro do próprio campo da Ciência da Informação.

\subsection{Recomendações de pesquisas futuras}

Dado os limites de nossas pesquisas e o foco escolhido para nossa análise, entendemos que há ainda muito por ser analisado. Desse modo, apresentamos a seguir possíveis recomendações para pesquisas futuras:

- Analisar os principais temas de pesquisa das revistas científicas, teses e dissertações através da análise de seus descritores de tema, buscando relacionar a grupos de 
pesquisadores que formam redes por colaborarem entre si em torno desses temas. A perspectiva aqui é de avaliar a evolução na formação do vocabulário e do discurso utilizado pelos pesquisadores na produção de suas pesquisas, buscando identificar se há favorecimento da formação de um comum ou um aumento na dispersão dos núcleos temáticos das pesquisas produzidas;

- Analisar as avaliações Qualis de cada uma das revistas, buscando identificar as redes sociais formadas no âmbito de cada uma delas. Desse modo, teríamos condições de avaliar se há diferenças expressivas de padrões estruturais e dinâmicos em cada uma das categorias do Qualis, ampliando nossa análise do efeito e da influência da política científica na formação das redes sociais;

- Aplicar a matriz de indicadores e os modos temporais de análise de redes a outras bibliotecas digitais federadas de outras áreas de conhecimento, buscando comparar efeitos, resultados e identificar a emergência de novos padrões e estratégias de conectividade;

- Experimentar outros modos de animação gráfica dos grafos de evolução das redes, buscando mostrar a evolução de comunidades e agrupamentos dos nós ao longo do tempo;

- Analisar outros planos de comunicação para além daqueles mediados pela produção científica de uma área do conhecimento, tais como trocas de e-mails entre pesquisadores, blogs de sistematização de grupos de pesquisa, participação em congressos e outros;

- Por fim, aprofundar a reflexão de como se forma, sua origem e história da política científica por meio do estudo de suas práticas, buscando produzir correlações com indicadores de diferentes tipos de redes sociais, seja de grupos de pesquisa, de áreas temáticas, universidades e programas de pós-graduação. 


\section{Capítulo 9}

\section{Referências}

ATLAN, H., A organização biológica e a teoria da informação. Ed. Instituto Piaget. 2006. 370p.

BALANCIERI, R., BOVO, A. B., KERN, V. M., PACHECO, R. C. S., BARCIA, R. M. A análise de redes de colaboração científica sob as novas tecnologias de informação e comunicação: um estudo da Plataforma Lattes. Ci. Inf., Brasília, v. 34. n. 1, p. 64-77, jan./abr. 2005.

BARABASI, A., JEONG, H., NÉDA, Z., RAVASZ, E., SCHUBERT, A., VICSEK, T. Evolution of the social network of scientific collaborations. Physica A: Statistical Mechanics and its Applications Volume 311, Issues 3-4, 15 August 2002, Pages 590-594 BARABASI, A., Linked. Plume. 2003. 256p.

BARABASI, A., The architecture of complexity: from network structure to human dynamics. IEEE Control System Magazine, August, 2007.

BARABASI, A., Bursts: the hidden pattern behind everything we do. Dutton. 2010. 310 .

BARABASI, A. The structure of web. Oral presentation in Web Science: a new frontier.

The Royal Society. 2010. Disponível em:

http://royalsociety.tv/dpx_royalsociety/dpx.php?

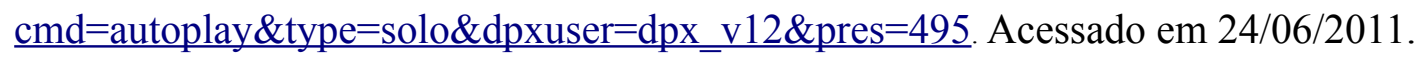

BARBALHO, C. R. S. Produção científica no âmbito do ENDOCOM: uma análise bibliométrica dos trabalhos apresentados no período de 2002-2006. In. Anais do XXX Congresso Brasileiro de Ciências da Comunicação. 2007.

BEAL, J., Metadata and data quality problems in the Digital Library. Journal of Digital 
Information, Vol 6, No 3 (2005).

BEAVER, D. Reflections on scientific collaboration (and its study): past, present and future. SCIENTOMETRICS Volume 52, Number 3, 365-377, 2001.

BARROS, R. B. Grupo: a afirmação de um simulacro. Sulina. 2007. 350p.

BERTALANFFY, L. v., General System Theory. George Braziller ed., 1968. 295p.

BOLLEN, J., VAN DE SOMPEL, H., RODRIGUEZ, M. A. Towards usage-based impact Metrics: first results from the MESUR project. JCDL'08 June 16-20, 2008.

BOLLEN, J., VAN DE SOMPEL, H., HAGBERG, A., CHUTE, R. A principal component analysis of 39 scientific impact measures. Plos One. Volume 4. Issue 6. June, 2009.

BOURDIEU, P., O campo científico. In.. ORTIZ, Renato (org.). Bourdieu - Sociologia. São Paulo: Ática. Coleção Grandes Cientistas Sociais, vol. 39. p. 122-155. 1983.

BRANDÃO, W. C., PARREIRAS, F. S., SILVA, A. B. O., Redes em ciência da informação: evidências comportamentais dos pesquisadores e tendências evolutivas das redes de coautoria. Inf. Inf., Londrina, v. 12, n. Esp., 2007.

BRANDES, U., KENIS, P., RAAB, J., La explicacion a través de la visualización de redes. REDES - Revista hispana para el análisis de redes sociales. Vol 9, no. 6, Diciembre, 2005.

BRITTO, J., Redes empresariais: elementos estruturais e conformação interna. In. Duarte, F., Quandt, C., Souza, Q. (orgs). O tempo das redes. Perspectiva. 2008. 259p.

BROWN, J. S., DUGUID, P.. Organizing Knowledge. California Management Review. Vol. 40. No. 3 - 1998.

BUFREM, L. S., Colaboração científica: revisando vertentes na literatura em Ciência da Informação no Brasil. Pesq. Bras. Ci. Inf., Brasília, v. 3, n.1, p. 127-151, jan./dez. 2010. 
BUFREM, L. S., GABRIEL JR., R. F., GONÇALVES, V. Práticas de co-autoria no processo de comunicação científica na pós-graduação em Ciência da Informação no Brasil. Inf. Inf., Londrina, v. 15. n. esp. p. 110-129, 2010.

CAPES. Avaliação Trienal. 2007. Disponível em:

http://www.capes.gov.br/avaliacao/criterios-de-avaliacao/2284. Acessado em 24/06/2011.

CAPES. Cadernos de indicadores. 2009. Disponível em:

http://conteudoweb.capes.gov.br/conteudoweb/CadernoAvaliacaoServlet. Acessado em 24/06/2011.

CAPES. Critérios de classificação dos qualis por área. 2009. Disponível em:

http://qualis.capes.gov.br/arquivos/avaliacao/webqualis/criterios2007_2009/Criterios_Qualis 2008 31.pdf. Acessado em 25/06/2011.

CAPRA, F., As conexões ocultas. Editora Cultrix - Amana-Key. $1^{\text {a }}$ Ed. 2002. 296p.

CAPRA, F., Vivendo redes. In. Duarte, F., Quandt, C., Souza, Q. (orgs.). O tempo das redes. Perspectiva. 2008. 259p.

CHAVEZ, R., CRANE, G., SAUER, A., BABEU, A., PACKEL, A., WEAVER, G. ,Services make the repository. Journal of Digital Information. Vol.8, no. 2, 2007.

CHRISTAKIS, N. A., FOWLER, J. H. O poder das conexões: a importância do networking e como ele molda nossas vidas. Campus. 2010. 308p.

COLE, T. W., FOULONNEAU, M., Using Open Archives Initiative Protocol for metadata harvesting. Libraries Unlimited. 2007. 224p.

CORRêA,C.H.W.; et al. Periódicos da Área de Comunicação: mapeamento da temática e autoria dos artigos. In: CONGRESSO BRASILEIRO DE CIÊNCIAS DA COMUNICAÇÃO, 28., 2005. Rio de Janeiro. Anais... São Paulo: Intercom, 2005

CUNNINGHAM, S. J., DILLON, S. M. Authorship patterns in Information Systems. 
SCIENTOMETRICS Volume 39, Number 1, 19-27. 1997.

DING, Y., FOO, S. CHOWDHURY, G. A bibliometric analysis of collaboration in the field of Information Retrieval. The International Information \& Library Review, 30, pag. 367-376, 1999.

DODDS, P., MUHAMAD, R,; WATTS, D., An Experimental Study of Search in Global Social Networks. Science 301 (5634): 827-829. 2003.

DORNFEST, R., BRICKLEY, D. Metadados. In. Oram, A. (org.) Peer-to-peer: o poder transformador das redes ponto a ponto. Editora Berkeley. 2001. 447p.

DUARTE, F., FREY, K., Redes urbanas. In. Duarte, F., Quandt, C., Souza, Q. (orgs.) O tempo das redes. Perspectiva. 2008. 259p.

ERDOS, P., RÉNYI, A., On random graphs I. Publicationes Mathematicae 6: 290-297. 1959.

EPSTEIN, I. Produção científica em rede. In. Poblacion, D. A., Ramos, L. M. V. S. C., Mugnaini, R., Epstein, I. (org.). Redes sociais e colaborativas em informação científica. Volume 1. Angellara, São Paulo, 2009, pag. 13-53. 660p.

FAUST, K., SKVORETZ, J. Comparing networks across space, and time, size and species. Sociological Methodology, Volume 32, Number 1, 1 January 2002 , pp. 267-299(33)

FELLMAN, P. V., WRIGHT, R., Modelando redes terroristas. In. Duarte, F., Quandt, C., Souza, Q. (orgs.). O tempo das redes. Perspectiva. 2008.259p.

FERREIRA, S. M. S. P., SOUTO, L. F., Dos sistemas de informação federados à federação de bibliotecas digitais. Revista Brasileira de Biblioteconomia e Documentação, Nova Série, São Paulo, v. 2, n. 1, p. 23-40, jan/jun. 2006.

FERREIRA, S. M. S. P., MORAIS, M. H., MUCHERONI, M., PEREZ, J., Estudo sobre como autores de artigos de revistas de Ciências da Comunicação verbalizam seus 
objetos de estudos em termos de palavras chave. Em Questão, Porto Alegre, v. 15, n. 2, p. 151-167. 2009.

FERREIRA, S. M. S. P., Ferramenta de busca federada de Teses e Dissertações para aplicação em áreas especializadas. Relatório Técnico. Processo CNPq. no. 480927/2007-3. 2009

FIANI, R., Teoria dos Jogos. Editora Campus. $3^{\text {a }}$ ed. 2009. 394p.

FOUCAULT, M. A ordem do discurso. Edições Loyola. 21 a ed. 2011. 79p.

FREEMAN, L. C., The development of social network analysis: a study in the sociology of science. Empirical Press. 2004. 205p.

GARDIN, J. -C.. Vers un remodelage des publications savantes: ses rapports avec sciences de l'information. In: Chaudiron, Stéphane, Fhlur, Christian. Filtrage et résumé automatique de l' information sur les réseaux. Conference invitée - Colloque ISKOFrance, 3. 5-6 juillet, 2001. Univesité de Nanterre - Paris X, 2001.

GROSSMAN, J. W. The Evolution of the Mathematical Research Collaboration Graph. Proceedings of the Thirty-third Southeastern International Conference on Combinatorics, Graph Theory and Computing (Boca Raton, FL, 2002). Congressus Numerantium. Vol. 158 (2002), pp. 201-212.

HOU, H., KRETSHMER, H., LIU, Z. The structure of scientific collaboration networks in Scientometrics. SCIENTOMETRICS Volume 75, Number 2, 189-20. 2008.

ISSLER, B. Objetos de pesquisa e campo comunicacional. In. Tensões e objetos da pesquisa em comunicação. WEBER, M. H., BENTZ, I., HOHLFELDT, A. (orgs.). Editora Sulina. 2002. 293p.

KATZ, J. S., MARTIN, B. R. What is research collaboration? Research Policy, 26, pp 1$18,1997$. 
KUHN, T. S., A estrutura das revoluções científicas. Ed. Perspectiva. $9^{\mathrm{a}}$ ed. 2005. 264p.

LAGOZE, C., VAN DE SOMPEL, H., The Open Archives Initiative: building a low-barrier interoperability framework. JCDL'01, June 17-23, 2001.

LAPASSADE, G. Grupos, organizações e instituições. Francisco Alves. 1977. 316p.

LARA, M. L. G. ; LIMA, V. M. A. . Termos e conceitos sobre redes sociais colaborativas. In: Dinah Aguiar Población; Rogério Mugnaini; Lúcia Maria S. V. Costa Ramos. (Org. ).

Redes sociais e colaborativas em informação científica. 1 ed. São Paulo: Angellara, 2009, v.1, p. 605-653. 660p.

LATOUR, B. Ciência em ação: como seguir cientistas e engenheiros sociedade afora.

Ed. Unesp. 1998. 438p.

LATOUR, B. Razão que a razão desconhece: laboratórios, bibliotecas, coleções. In.

Parente, A.(org.), Tramas da Rede. Sulina. 2004. 303p.

LE COADIC, Y., A Ciência da Informação. Editora Briquet de Lemos. 2a Ed. 2004. 124p.

LEE, D., GOH, K. I., KAHNG, B., KIM, D. Complete trails of co-authorship network evolution. Fonte: http://www.arxiv.org/abs/1007.1914v2. Acessado em 20 de abril 2010.

LEYDESDORFF, L., PROBST, C., The delineation of an interdisciplinary specialty in terms of a journal set: The case of communication studies. Journal of the American Society for Information Science and Technology Volume 60, Issue 8, pages 1709-1718, August 2009

LEVY, P., A inteligência coletiva: por uma antropologia do ciberespaço. Ed. Loyola. $6^{\mathrm{a}}$ Edição, 2010. 214p.

LIU, X., BOLLEN, J., NELSON, M. L., VAN DE SOMPEL, H. Co-authorship networks in the Digital Library Research Community. Information Processing and Management. 41 (2005) 1462-1480. Elsevier, 2008. 
LOPES, L. C., Ciências da comunicação, possibilidades e problemas. Ciberlegenda. n. 3. 2000 .

LOPES, M. I. V., ROMANCINI, R. Teses e dissertações: estudo bibliométrico na área de comunicação. In. Poblacion, D. A., Witter, G., Silva, J. F. M. (org.). Comunicação e produção científica: contexto, indicadores, avaliação. Angellara, São Paulo, 2006, pag. $138-161.428 \mathrm{p}$.

LOPES, M. I. V., ROMANCINI, R. A rede social da comunicação em seus grupos de pesquisa. In. Poblacion, D. A., Ramos, L. M. V. S. C., Mugnaini, R., Epstein, I. (org.). Redes sociais e colaborativas em informação científica. Volume 1. Angellara, São Paulo, 2009, pag.503-530. 606p.

MAHLCK, P., PERSSON, O. Socio-bibliometric mapping of intra-departmental networks. Scientometrics. Vol. 49. n. 1, p-81-91. 2000.

MAIA, M. F. S., CAREGNATO, S. E. Co-autoria como indicador de redes de colaboração científica. Perspectivas em Ciência da Informação, v. 13, n.2, p.18-31, maio/ago. 2008.

MARCONDES, C. H., SAYÃO, L. F., Integração e interoperabilidade no acesso a recursos informacionais eletrônicos em C\&T: a proposta da Biblioteca Digital Brasileira. Ci. Inf. Vol. 30, no.3 Brasília, set/dez 2001.

MARTELETO, R. M., Informação, rede e redes sociais - fundamentos e transversalidades. Inf. Inf., Londrina, v. 12, n. esp., 2007.

MARTELETO, R. M. Redes sociais, mediação e apropriação de informações: situando campos, objetos e conceitos na pesquisa em Ciência da Informação. Pesq. Bras. Ci. Inf., Brasília, v. 3, n. 1, p. 27-46, jan./dez. 2010.

MATHEUS, R. F., SILVA, A. B., Análise de redes sociais como método para a Ciência da Informação. DatagramaZero - Revista de Ciência da Informação - v. 7 n.2, abr. 2006. 
MARTINS, G. S., ROSSONI, L., CSILlAG, J. M., MARTINS, M. E., PEREIRA, S. C. F., Gestão de operações no Brasil: uma análise do campo científico a partir da rede social de pesquisadores. RAE-eletrônica, v. 9, n. 2, Art. 8, jul/dez. 2010.

MATURANA, H., A ontologia da realidade. Org. Magro, C., Graciano, M., Vaz, N. Editora UFMG. 1997. 350p.

MATURANA, H., YÁÑEZ, X. D., Habitar humano em seis ensaios de Biologia-Cultural. Ed. Palas Athena. $1^{\text {a }}$ Ed. 2009. 320p.

MEADOWS, A. J., A comunicação científica. Briquet de Lemos. 1999. 268p.

MICHEL, M. H. Metodologia e pesquisa científica em Ciências Sociais. Atlas. 2ed. 2009. $210 \mathrm{p}$.

MILGRAM, S., The Small-world problem. Psychology Today, Vol. 1 (May 1967), pp. 6167.

MIRANDA, M. L. C., A organização do conhecimento e as redes sociais. In. Poblacion, D. A., Ramos, L. M. V. S. C., Mugnaini, R., Epstein, I. (org.). Redes sociais e colaborativas em informação científica. Volume 1. Angellara, São Paulo, 2009, pag. 93-139. 606p.

MOODY, J. The Structure of a Social Science Collaboration Network: Disciplinary Cohesion from 1963 to 1999. American Sociological Review, 2004, VOL. 69 (April: 213 $-238)$

MORIN, E., O Método 1: a natureza da natureza. Editora Sulina. 2a Ed. 2008. 480p.

MUGNAINI, R., CARVALHO, T., CAMPANATTI-OSTIZ, H., Indicadores de produção científica: uma discussão conceitual. In. Poblacion, D. A., Witter, G., Silva, J. F. M. (org.). Comunicação e produção científica: contexto, indicadores, avaliação. Angellara, São Paulo, 2006, pag. $314-340.428$ p.

MUSSO, P., A filosofia da rede. In. Parente, A. (org.), Tramas da Rede. Editora Sulina. 
2004. 303p.

NETO, A. F. Condições da pesquisa em comunicação no Brasil. Revista Famecos. Porto Alegre. $\mathrm{n}^{\circ}$ 5. novembro 1996.

NETO, A. F. A pesquisa vista "de dentro de casa": ou reflexões sobre algumas práticas de construção de objetos de pesquisa em comunicação. In. Tensões e objetos da pesquisa em comunicação. WEBER, M. H., BENTZ, I., HOHLFELDT, A. (orgs.). Editora Sulina. 2002. $293 p$.

NEWMAN, M. E. J. The structure of cientific collaboration networks. PNAS, pg. 404-409, vol. 98, no. 2 , January 16, 2001.

NEWMAN, M. E. J. Scientific collaboration networks: network construction and fundamentals results. Physical Review E., volume 64, 2001 a.

NEWMAN, M. E. J. Scientific collaboration networks: shorthest paths, weighted networks and centrality. Physical Review E., volume 64, 2001 b.

NEWMAN, M. E. J. Co-authorship networks and patterns of scientific collaboration. PNAS, vol 101. 2004.

NEWMAN, M. E. J. Networks: an introduction. Oxford. 2010. 720p.

NEWMAN, M., BARABASI, A., WATTS, D. The structure and dynamics of networks. Princeton University Press, 2006. 624p.

NICHOLS, D. M., McKAY, D., TWIDALE, M. B., A lightweight metadata quality tool. JCDL'08, june 16-20, 2008.

NOOY, W., MRVAR, A., BATAGELJ, V. Exploratory Social Networks Analysis with Pajek. Structural Analysis in the Social Sciences Series. Cambridge University Press. 2005. $362 p$. 
NUSSENZVEIG, H. M., Introdução à complexidade. In. Nussenzveig, H. M. (org.). Complexidade e Caos. Editora UFRJ/COPEA. p. 09-26. $3^{\text {a }}$ ed. 2006. 276p.

OLIVEIRA, E. F. T., GRÁCIO, M. C. C. Rede de colaboração científica no tema "Estudos métricos": um estudo de co-autorias através dos periódicos do Scielo da área de Ciência da Informação. BJIS, v. 2, n.2, p. 35-49, jul./dez. 2008.

OTTE, E., ROUSSEAU, R. Social network analysis: a powerful strategy, also for the information sciences. Journal of Information Science, 28 (6), pp. 441-453, 2002.

PALLA, G., BARABASI, A., VICSEK, T., Quantifying social group evolution. Nature, vol. 446. p. 664-667. 2007.

PARENTE, A. Enredando o pensamento: redes de transformação e subjetividade. In. Parente, A. (org.), Tramas da Rede. Sulina. 2004. 303p.

PINTO, A. L., BARQUÍN, B. A. R., EFRAIN-GARCIA, P., GONZÁLEZ, J. A. M. Visualização da informação das redes sociais através de programas de cienciografia. In. Poblacion, D. A., Ramos, L. M. V. S. C., Mugnaini, R., Epstein, I. (org.). Redes sociais e colaborativas em informação científica. Volume 1. Angellara, São Paulo, 2009, pag. 289312. $606 \mathrm{p}$.

PISCIOTTA, K. Redes sociais: articulação com pares e com a sociedade. In. Poblacion, D. A.,Witter, G., Silva, J. F. M. (org.). Comunicação e produção científica:contexto, indicadores, avaliação. Angellara, São Paulo, 2006, pag. 115 - 135. 428p.

PRIGOGINE, I., O fim das certezas: tempo, caos e as leis da natureza. Editora Unesp. 1996. 199p.

PRIMO, A., STUMPF, I., CONSONI, G., SILVEIRA, S. C. Análise de citações dos trabalhos da COMPÓS 2008. Revista da Associação Nacional dos Programas de PósGraduação em Comunicação. E-Compós, Brasília, v.11, n.3, set/dez 2008.

RAIDER, H., KRACKHARDT, D. J., Intraorganizational Networks. In. Joel, A. C. B. (ed) 
Companion to organizations. Pp. 58-74. Oxford, UK:Blackwell. 2001.

SAYÃO, L. F., Afinal, o que é biblioteca digital? In.: Bibliotecas Digitais/Bibliotecas Virtuais. Revista USP. D zembro/janeiro/fevereiro 2008-2009.

SILVA, A. B. O., PARREIRAS, F. S., MATHEUS, R. F., PARREIRAS, T. A. S., Análise de redessociais como metodologia de apoio para a discussão de interdisciplinaridade na ciência da informação. Ci. Inf., Brasília, v. 35. n. 1, p. 72-93, jan./abr., 2006.

SMEATON, A. F., KEOGH, G., GURRIN, C., McDONALD, K, SODRING, T. Analysis of papers from twenty-five years of SIGIR conferences: what have we been doing for the last quarter of a century? SIGIR Forum, Vol. 37, No. 1. (2003), pp. 49-53

SOUZA, Q., QUANDT, C., Metodologia de análise de redes sociais. In. Duarte, F., Quandt, C., Souza, Q. O tempo das redes. Perspectiva. 2008. 264p.

TARGINO, M. G. Orientador ou tutor é autor? Inf. Inf., Londrina, v. 15, n. esp. p. 144-155, 2010.

TOFFOLI, G. A., FERREIRA, S. M. S. P. Mapeamento da produção científica de pesquisadores brasileiros de Ciências da Comunicação: período de 2000 a 2009. Psicologia USP, São Paulo, v.1, n.22, 2011.

VAN DE SOMPEL, H., LAGOZE, C. The Santa Fe Convention of the Open Archives Initiative. D-Lib Magazine, vol. 6, no. 2, February, 2000.

VANZ, S. A. S., STUMPF, I. R. C. Colaboração científica: revisão teórico-conceitual. Perspectivas em Ciência da Informação, v. 15, n.2, p.42-55, maio/ago. 2010.

VASCONCELLOS, M. J. E. Pensamento Sistêmico: o novo paradigma da ciência. Papirus. $8^{\mathrm{a}}$ Edição. 2009. 268p.

VASSALO DE LOPES, M. I. O campo da Comunicação: sua constituição, desafios e dilemas. Revista Famecos. Porto Alegre. no 30. agosto 2006. 
VASSÃO, C. A., Metadesign: ferramentas, estratégias e ética para a complexidade. Editora Blucher. $1^{\text {a }}$ Ed. 2010. 132p.

VENEGEROLES, R., MURAD, S., VICENTE, R., A teia do conhecimento: modo de usar. In. Bibliotecas Digitais/Bibliotecas Virtuais. Revista USP. Dezembro/janeiro/fevereiro 2008-2009- p. 28-37.

WAGNER, C. S., LEYDESDORFF, L. Mapping global science using international coauthorships: a comparison of 1990 and 2000. In Proceedings of ninth international conference on scientometrics and informetrics, Beijing. 2003.

WAGNER, C., LEYDESDORFF, L. Network structure, sel-organization and the growth of international collaboration in science. Research Policy, Volume 34, Issue 10, December 2005, Pages 1608-1618

WARD, J., Unqualified Dublin Core usage in OAI-PMH data providers. OCLC Systems and Services: International Digital Libraries Perspectives. Vol. 20. no. 1. 2004. p. 40-47.

WASSERMAN, S., FAUST, K. Social network analysis: methods and applications. Structural Analysis in the Social Sciences Series. Cambridge University Press. 1994. 857p.

WATTS, D., Six degrees: the science of a connected age. Norton. 2003. 368p.

WATTS, D. The new science of networks. Annu. Rev. Sociol. 2004. 30:243-70.

WATZLAWICK, P., BEAVIN, J. H., JACKSON, D. D., Pragmática da comunicação humana. Cultrix. 1973. 266p.

WEBER, M. H., BENTZ, I., HOHLFELDT, A., Introdução. In. Tensões e objetos da pesquisa em comunicação. WEBER, M. H., BENTZ, I., HOHLFELDT, A. (orgs.). Editora Sulina. 2002. 293p.

WEITZEL, S. R. Fluxo da comunicação científica. In. Poblacion, D. A., Witter, G.,Silva, J. 
F. M. (org.). Comunicação e produção científica: contexto, indicadores,avaliação. Angellara, São Paulo, 2006, pag. 82 - 114. 428p.

WELLMAN, B. Network analysis: some basic principles. Sociological Theory, Vol. 1. 1983, pp. 155-200.

WITTEN, I. H., BAINBRIDGE, D., NICHOLS, D. M. How to build a digital library. Morgan Kauffmann Publishers. 2nd edition. 2010. 656p.

WITTER, G. P., Produção científica. Campinas, SP: Editora Átomo, 1997. 181p.

WUCHTY, S., JONES, B. F., UZZI, B., The increasing dominance of teams in production of knowledge. Science Magazine. p. 1/10.1126. April. 2007.

ZHOU, P., Su, X., LEYDESDORFF, L. A comparative study on communication structures of Chinese journals in the social sciences. Journal of the American Society for Information Science and Technology Volume 61, Issue 7, pages 1360-1376, July 2010 